\title{
The Impact of Product Positioning Strategy, Manufacturing Strategy and their co-alignment on Firm's Performance
}

\author{
By \\ Irfan Butt \\ B.A. (The College of Wooster, Ohio, USA) \\ MBA (Thunderbird School of Global Management, Arizona, USA)
}

A thesis submitted to the Faculty of Graduate Studies and Research in Partial fulfillment of the requirements for the degree of

Doctor of Philosophy in Management

Sprott School of Business

Carleton University

Ottawa, Canada

@ Copyright Irfan Butt 2009 
Library and Archives Canada

\section{Published Heritage} Branch

395 Wellington Street Ottawa ON K1A ON4 Canada
Bibliotheqque et

Archives Canada

Direction du

Patrimoine de l'édition

395 , rue Wellington

Ottawa ON K1A ON4

Canada
Your file Votre référence

ISBN: 978-0-494-63869-9

Our file Notre référence

ISBN: 978-0-494-63869-9
NOTICE:

The author has granted a nonexclusive license allowing Library and Archives Canada to reproduce, publish, archive, preserve, conserve, communicate to the public by telecommunication or on the Internet, loan, distribute and sell theses worldwide, for commercial or noncommercial purposes, in microform, paper, electronic and/or any other formats.

The author retains copyright ownership and moral rights in this thesis. Neither the thesis nor substantial extracts from it may be printed or otherwise reproduced without the author's permission.

\begin{abstract}
AVIS:
L'auteur a accordé une licence non exclusive permettant à la Bibliothèque et Archives Canada de reproduire, publier, archiver, sauvegarder, conserver, transmettre au public par télécommunication ou par l'Internet, prêter, distribuer et vendre des thèses partout dans le monde, à des fins commerciales ou autres, sur support microforme, papier, électronique et/ou autres formats.
\end{abstract}

L'auteur conserve la propriété du droit d'auteur et des droits moraux qui protège cette thèse. $\mathrm{Ni}$ la thèse ni des extraits substantiels de celle-ci ne doivent être imprimés ou autrement reproduits sans son autorisation.
In compliance with the Canadian Privacy Act some supporting forms may have been removed from this thesis.

While these forms may be included in the document page count, their removal does not represent any loss of content from the thesis.
Conformément à la loi canadienne sur la protection de la vie privée, quelques formulaires secondaires ont été enlevés de cette thèse.

Bien que ces formulaires aient inclus dans la pagination, il n'y aura aucun contenu manquant. 


\section{Abstract}

Both product positioning and manufacturing strategies are business level strategies developed by the marketing and operations management departments of firms. Influenced by resource-based and market-based views, both positioning and manufacturing strategies have dimensions which at times are identical, such as quality, cost/price, and innovation. Both strategies are postulated to have a significant impact on organizational performance.

The objective of this study is to understand how manufacturing firms in Canada develop these strategies and what is their impact on bottom line; i.e., what are the factors which influence the development of these strategies; how these strategies individually impact firm's performance and what is the impact of co-alignment of two strategies on a firm's performance. The findings of the empirical study are based on the data collected from 194 manufacturing firms in Canada.

The study was virtually divided into three parts. First, the influence of certain factors on the development of positioning strategies and, in turn, the impact of positioning strategies on a firm's performance was examined. Second, a number of factors impacting development of manufacturing strategies were investigated, along with relationship of manufacturing strategy with organizational performance. Third, the co-alignment of positioning and manufacturing strategy was determined using profile deviation technique. The adherence to ideal profile is taken as co-alignment for this study.

It was found that the development of positioning strategy is influenced more by customer orientation than competitor orientation. Marketing capability plays an important role in 
the development of positioning strategy. Focus on brand and company image leads to higher customer satisfaction, more loyalty and better financial performance.

The final evidence regarding preference of resource orientation over market orientation is inconclusive in this study as both of them influence only one manufacturing strategy each. Our study confirms the conventional wisdom that each manufacturing strategy is backed by the corresponding manufacturing capability. However, it reinforces the notion that certain manufacturing capabilities, such as delivery, are integral to the operations and survival of the firm. Cost, delivery and flexibility capabilities lead to improved financial performance, while quality impacts customer satisfaction and loyalty.

This is the first study which empirically demonstrates that co-alignment of manufacturing and marketing can be examined by operationalizing it as the lack of correspondence between the profile of the top performing strategic configuration and rest of the strategic configurations. 


\section{Acknowledgement}

A long arduous journey which took seven years has finally reached this stage! My visibly grey hair, shinning black at the time of joining the $\mathrm{PhD}$ program, testifies to my struggles. This journey was saddled with moments of bleak sadness as well as times of sheer joy. I endured the irreplaceable loss of both of my parents in the beginning of the program but also witnessed the blissful birth of my two younger children.

I thank God Almighty who gave me the ability, strength and courage to persist through all these years. There are a number of people who made it possible for me to reach this stage. I am deeply indebted to my supervisors, Prof. Uma Kumar and Prof. Vinod Kumar, who guided, directed, and encouraged me at every step, from conceptualization to conclusion of this study. Their concern and compassion for their students is unmatched and heart warming. I offer my sincere thanks to both of them. I would also like to thank Dr. Alan Cai for his guidance and support.

I would like to thank a number of friends, fellow students and colleagues who shared good times and experiences with me and provided wonderful company. There is a long list of friends but I would mention Bhasker Mukerji and Shavin Malhotra, in particular. I also thank Mahmud A. Shareef and V. Vedmani for their support in completing this thesis.

I would like to thank all my professors at Sprott who sowed the seeds of critical thinking and reflection in me. I received excellent support from Janice Walker, Anne Irvin, Pam Norris, Greg Schmidt, Melissa Doric and other administrative staff at Sprott School of Business. My employer since July 2007, Lahore University of Management Sciences, has 
supported me tremendously in finishing off this thesis by giving me plenty of time off and a reduced course load. Thank you Dean Shaukat Brah. I would like to thank Ruth Latta and John Malloch who provided editorial help in this work.

One person who perhaps suffered more hardship than anybody else during my $\mathrm{PhD}$ program is my beloved wife, Alia. In addition to taking care of the household affairs while I was busy with my studies, she has done a fabulous job of raising our four lovely children. I am truly thankful to her for her unconditional support and unwavering commitment. My four children - Danish, Noor, Umair and Faatimah had to frequently put up with my unplanned long days at the university. Thank you so much for your sacrifice, patience and love.

I dedicate this work to people I adore the most - my parents, my wife and my children. 


\section{Table of Contents}

ABSTRACT.

ACKNOWLEDGEMENT III

LIST OF TABLES IX

LIST OF FIGURES. $\mathbf{X I}$

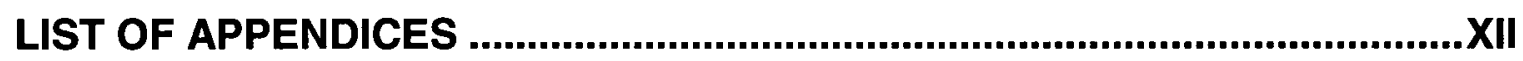

CHAPTER 1: INTRODUCTION................................................................. 1

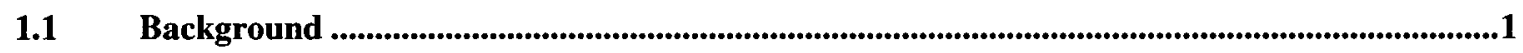

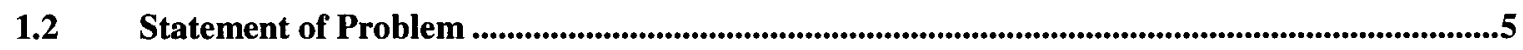

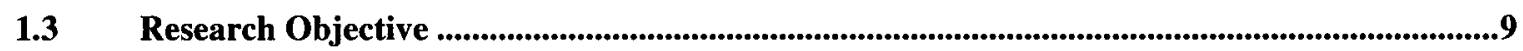

1.4 Organization of the Remaining Chapters ............................................................................................10

CHAPTER 2: MANUFACTURING STRATEGY ........................................... 12

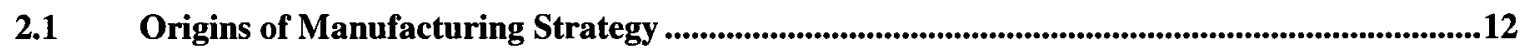

$2.2 \quad$ Manufacturing Strategy Defined ............................................................................................................13

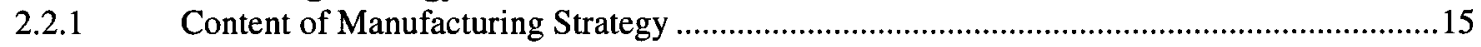

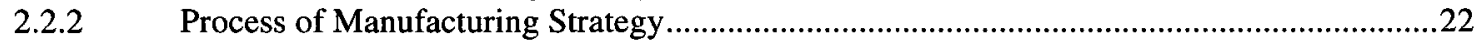

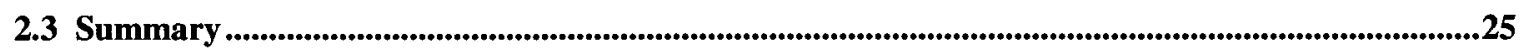

CHAPTER 3: POSITIONING STRATEGY .................................................... 26

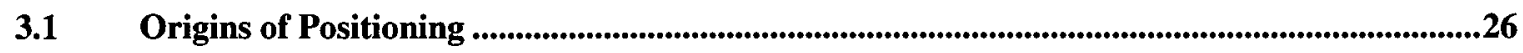

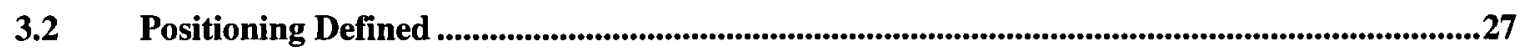

3.3 Positioning and Other related Concepts .................................................................................................29

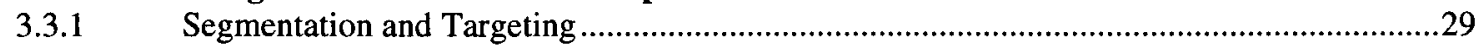

3.3.2 Competitive Advantage and Differentiation...........................................................................30

3.4 Positioning Strategy .......................................................................................................................31

3.4.1 Positioning Typology, Positioning Strategy and Positioning Dimension ...............................31

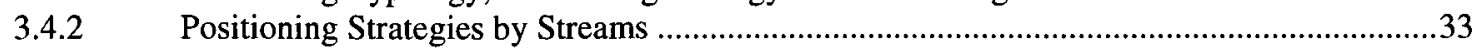

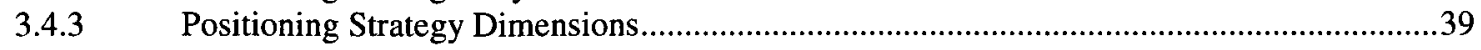

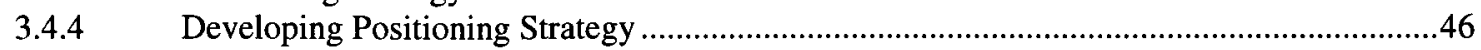


CHAPTER 4: ALIGNING POSITIONING AND MANUFACTURING

STRATEGIES............................................................................................. 50

4.1 Marketing Strategy ….........................................................................................................................................50

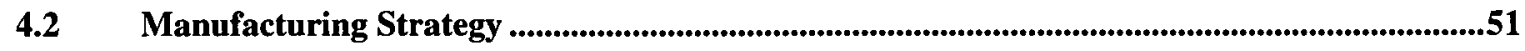

4.3 Aligning Manufacturing Strategy with Marketing Strategy ............................................................53

4.4 Aligning Manufacturing Strategy with Positioning Strategy ..................................................57

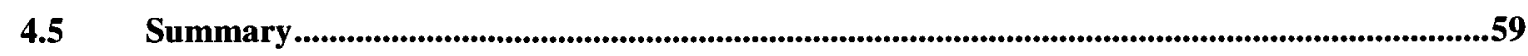

CHAPTER 5: THEORETICAL BACKGROUND ...........................................60

5.1 Determinants of Positioning and Manufacturing Strategies ........................................................60

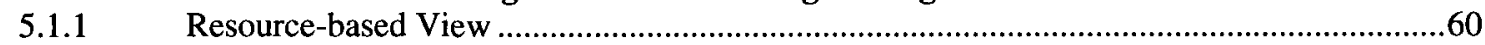

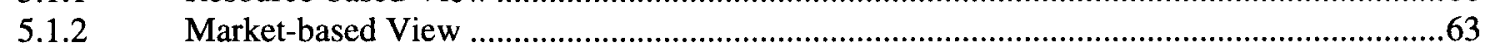

5.1.3 Integration of Resource Based and Market Based Views.....................................................64

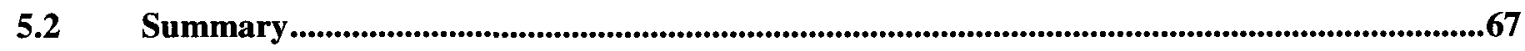

CHAPTER 6: CONCEPTUAL FRAMEWORK ............................................68

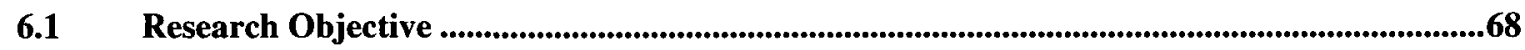

$6.2 \quad$ Conceptual Framework ..................................................................................................................69

$6.3 \quad$ Hypotheses .............................................................................................................................................69

6.4 Identification and Specification of Variables........................................................................72

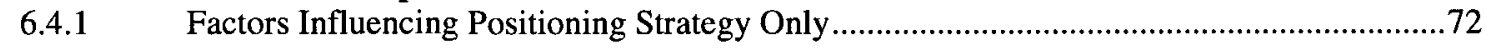

6.4.2 Factors Influencing Manufacturing Strategy Only …........................................................

6.4.3 Factors Influencing both Positioning and Manufacturing Strategies .....................................77

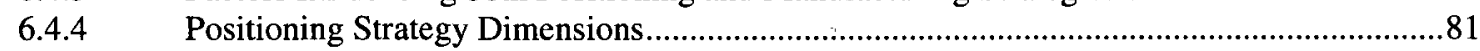

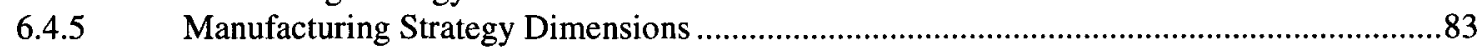

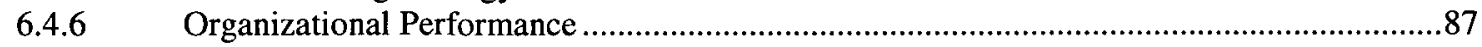

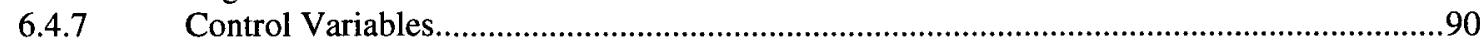

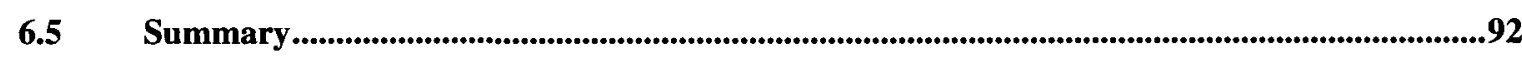

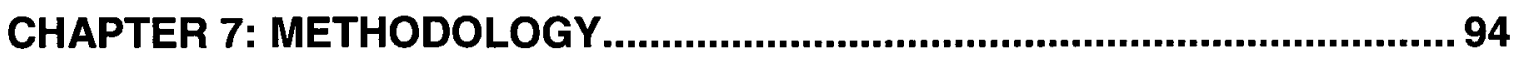

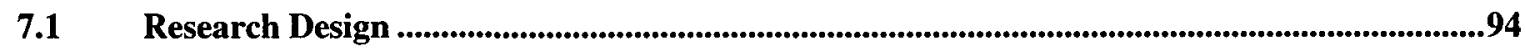

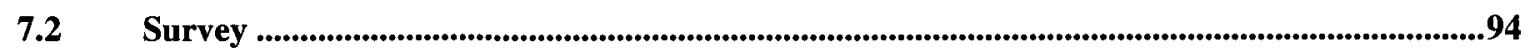

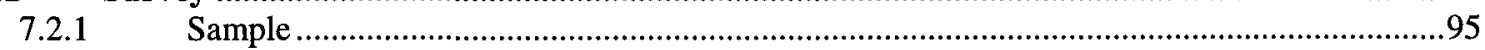

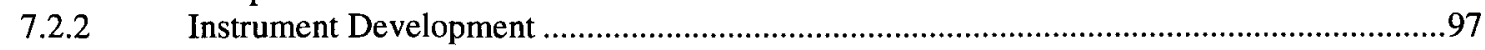

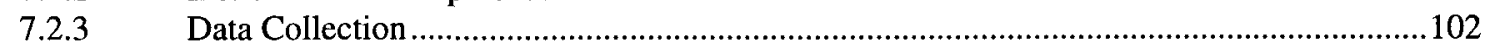

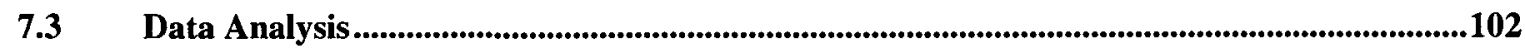




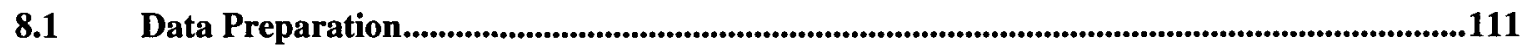

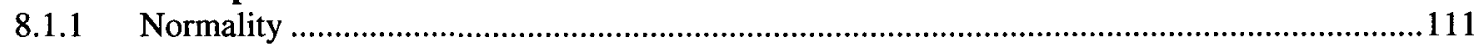

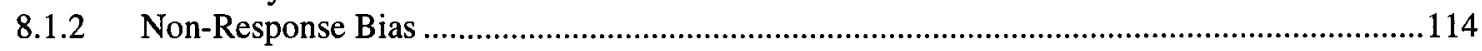

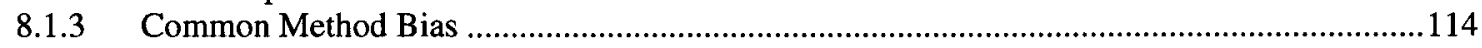

$8.2 \quad$ Principal Component Analysis.....................................................................................................115

8.2.1 Influencing Factors - Positioning Strategy (Independent variables) .....................................117

8.2.2 Influencing Factors - Manufacturing Strategy (Independent variables) ....................................120

8.2.3 Organizational Performance (Dependent variables) .................................................................123

8.2.4 Positioning Strategy Dimensions (Mediating variables) .........................................................124

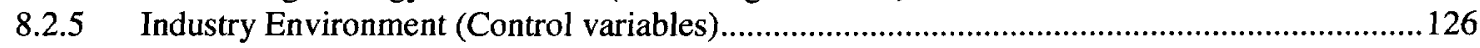

8.2.6 Summary of Principal Component Analysis .......................................................................... 127

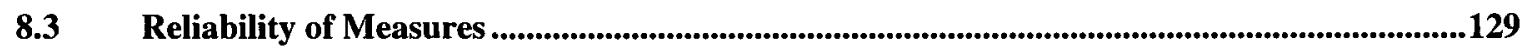

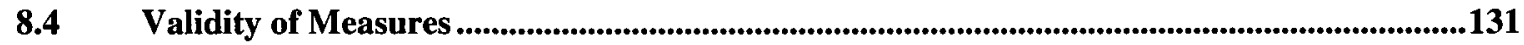

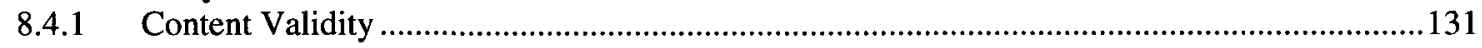

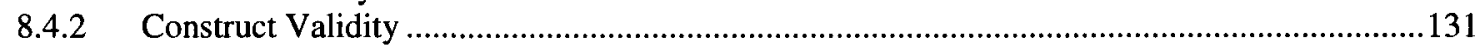

8.5 Revised Conceptual Model ......................................................................................................134

$8.6 \quad$ Revised Hypotheses.............................................................................................................................135

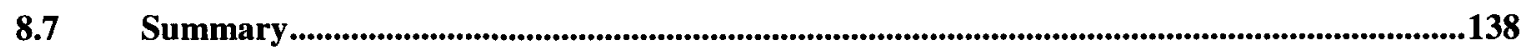

CHAPTER 9: DATA ANALYSIS .................................................................. 139

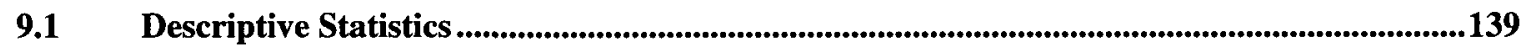

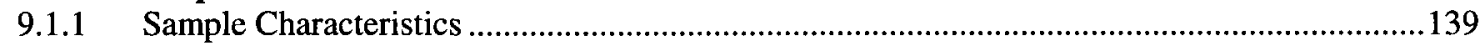

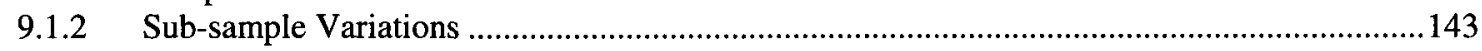

9.2 Correlation and Regression Analysis .......................................................................................145

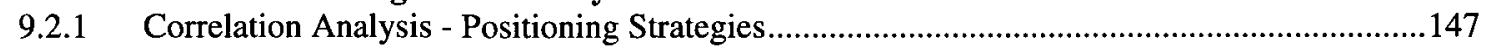

9.2.2 Regression Analysis - Positioning Strategies ........................................................................151

9.2.3 Correlation Analysis - Manufacturing Strategies ...................................................................160

9.2.4 Regression Analysis - Manufacturing Strategies....................................................................164

$9.3 \quad$ Co-alignment (Fit) Analysis - Profile deviation ...................................................................172

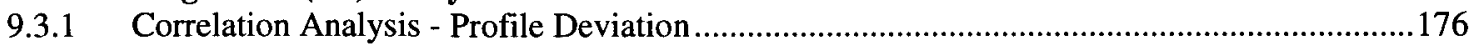

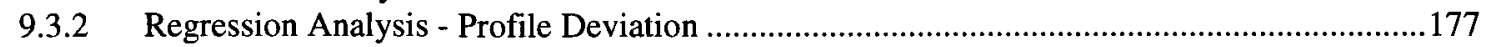

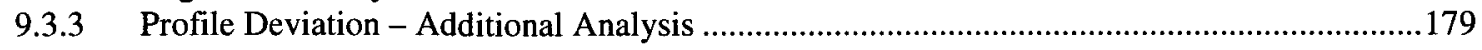

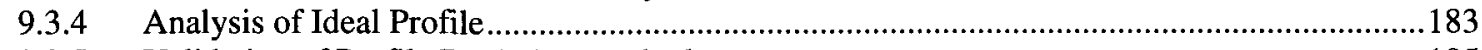

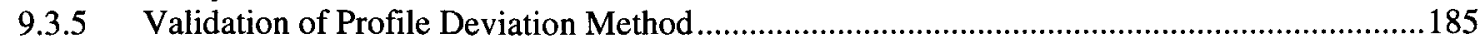

$9.4 \quad$ Assumptions of Regression Analysis .........................................................................................188

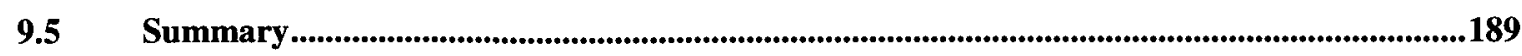

CHAPTER 10: DISCUSSION.......................................................................... 191 
10.1 Positioning Strategies....................................................................................................................192

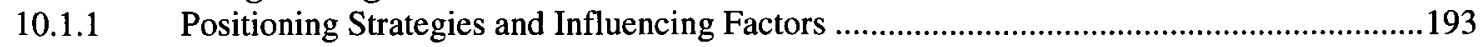

10.1.2 Positioning Strategies and Organizational Performance....................................................202

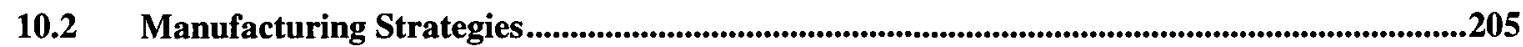

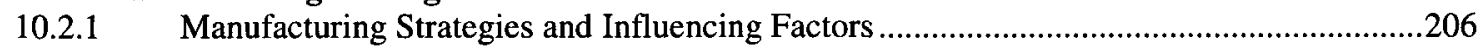

10.2.2 Manufacturing Strategies and Organizational Performance …...........................................212

10.3 Co-alignment of manufacturing and positioning strategies ................................................213

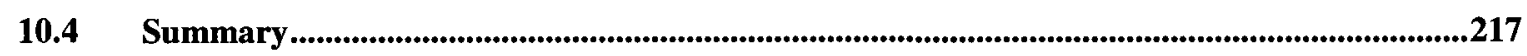

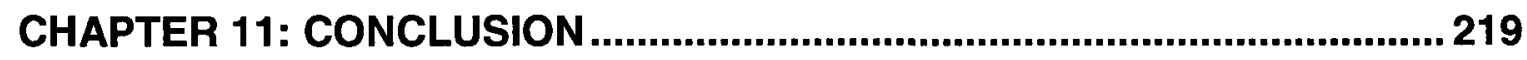

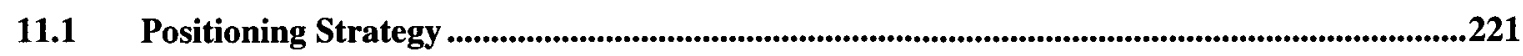

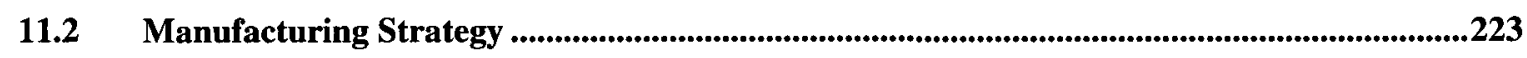

11.3 Co-alignment of Positioning and Manufacturing Strategy …...............................................225

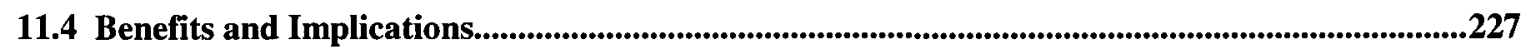

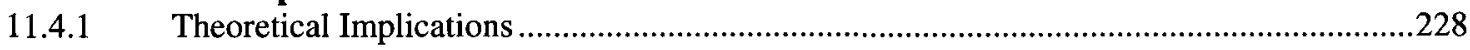

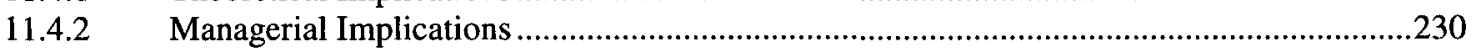

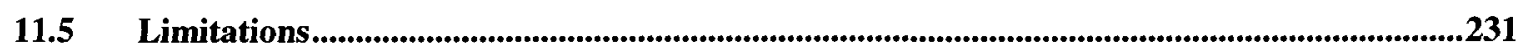

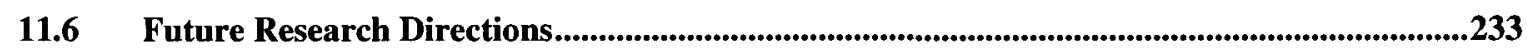

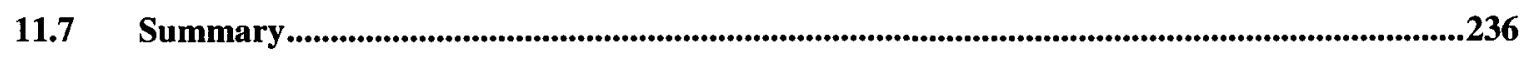

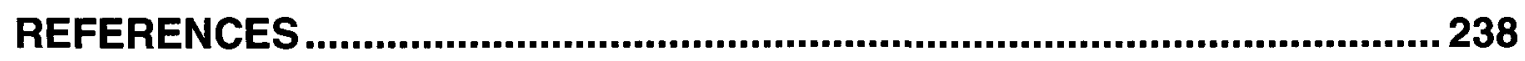




\section{List of Tables}

TABLE 1: MANUfaCturing STRATEgy DeFinitions

TABLE 2: COMPARISON OF STRATEGIC DECISION CATEGORIES

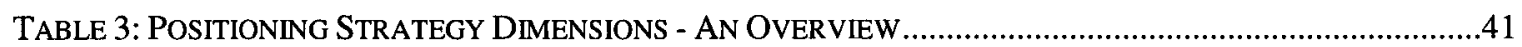

TABLE 4: POSITIONING STRATEGY DIMENSIONS - A CONTENT ANALYSIS ……...................................................4

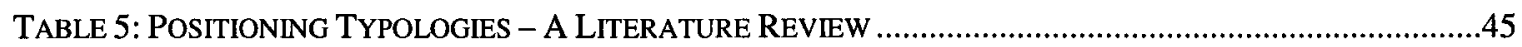

TABLE 6: KEY DECISION AREAS OF MANUFACTURING AND MARKETING ..................................................55

TABLE 7: MANUFACTURING AND MARKETING INTEGRATION RESEARCH ..............................................56

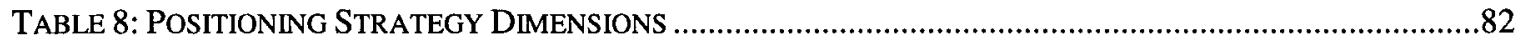

TABLE 9: MANUfACTURING STRATEGY DIMENSIONS - LITERATURE REVIEW 1 .............................................83

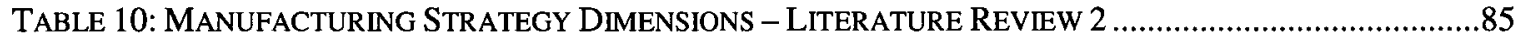

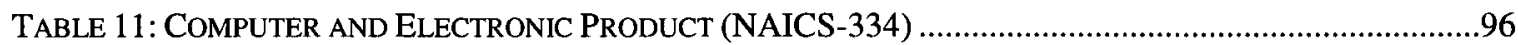

TABLE 12: ELECTRICAL EQUIPMENT, APPLIANCE AND COMPONENT (NAICS-335) …...................................96

TABLE 13: MEASURES-FACTORS INFLUENCING POSITIONING STRATEGY …...................................................98

TABLE 14: MEASURES-FACTORS INFLUENCING MANUFACTURING STRATEGY ….......................................99

TABLE 15: MEASURES-FACTORS INFLUENCING MANUFACTURING \& POSITIONING STRATEGY .....................99

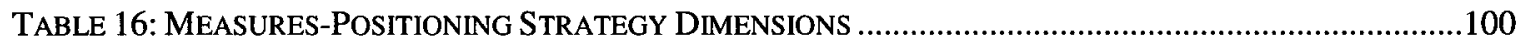

TABLE 17: MEASURES-MANUFACTURING STRATEGY DIMENSIONS ..........................................................100

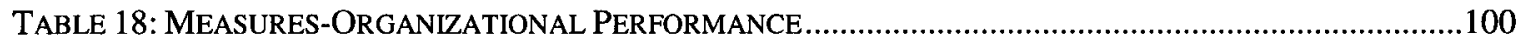

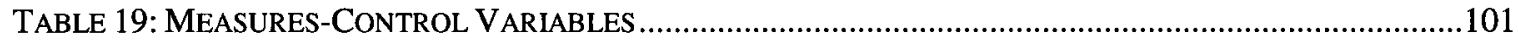

TABLE 20: REFERENCES FOR OPERATIONAL MEASURES OF VARIABLES ..............................................101

TABLE 21: ALTERNATIVE PERSPECTIVES OF THE CONCEPT OF FIT IN STRATEGY RESEARCH ........................104

TABLE 22: A COMPARISON OF REDUCTIONISTIC AND HOLISTIC PERSPECTIVES OF COALIGNMENT ..............105

TABLE 23: EMPIRICAL STUDIES WITH FIT CONCEPTUALIZATION …..........................................................107

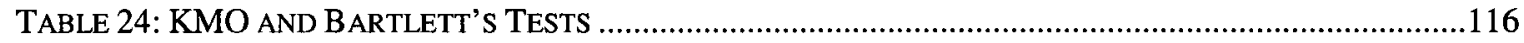

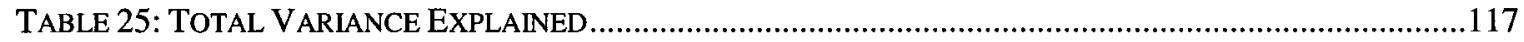

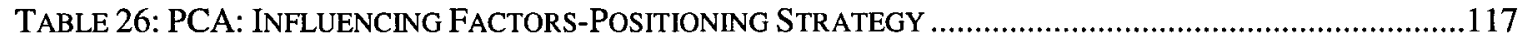

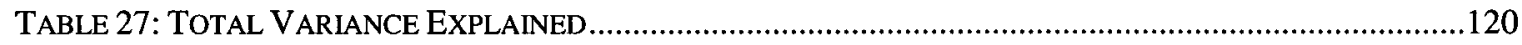

TABLE 28: PCA-INFLUENCING FACTORS-MANUFACTURING STRATEGY ..............................................120

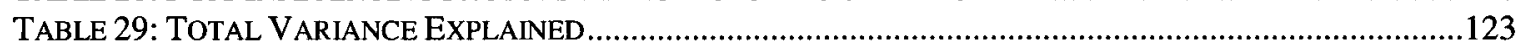

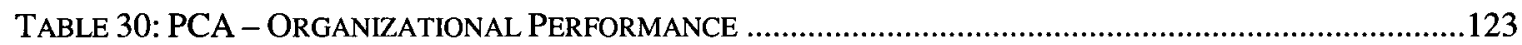

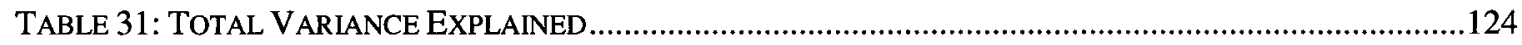

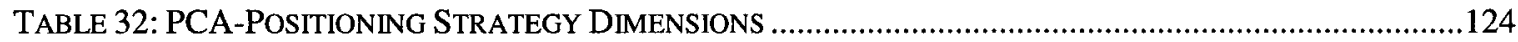

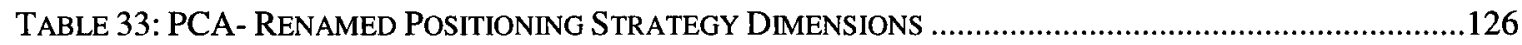

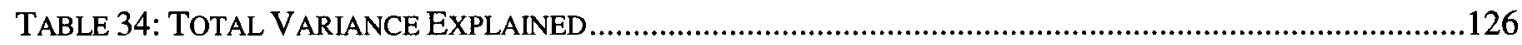

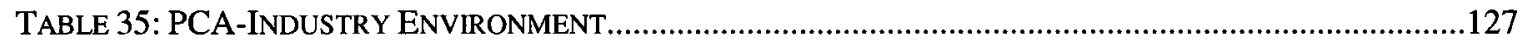

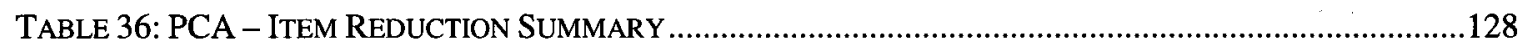

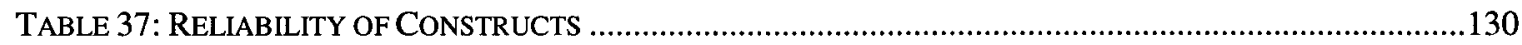

TABLE 38: CORRELATION MATRIX OF INFLUENCING FACTORS - POSITIONING STRATEGY ...........................133

TABLE 39: CORRELATION MATRIX OF INFLUENCING FACTORS - MANUFACTURING STRATEGY ..................133

TABLE 40: CORRELATION MATRIX OF POSITIONING STRATEGY DIMENSIONS ...........................................134

TABLE 41: CORRELATION MATRIX OF MANUFACTURING STRATEGY DIMENSIONS.....................................134

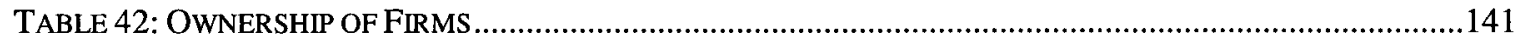

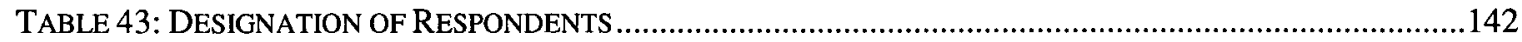

TABLE 44: SIGNIFICANT DIFFERENCES BETWEEN SMALL FIRMS AND MEDIUM \& LARGE FIRMS .....................143

TABLE 45: SIGNIFICANT DIFFERENCES BETWEEN CANADIAN AND FOREIGN FIRMS ......................................144

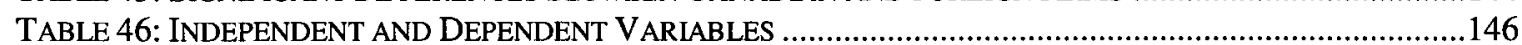

TABLE 47: CORRELATION-INFLUENCING FACTORS AND POSITIONING STRATEGY DIMENSIONS.....................148

TABle 48: Correlation- Positioning STRATEgy Dimensions and ORganizational Performance.150

TABLE 49: REGRESSION EQUATIONS-POSITIONING STRATEGY AND INFLUENCING FACTORS .......................152

TABLE 50: REGRESSION RESULTS - POSITIONING STRATEGY AND INFLUENCING FACTORS ..........................153

TABLE 51: REGRESSION EQUATIONS-POSITIONING STRATEGY AND ORGANIZATIONAL PERFORMANCE .....157

TABLE 52: REGRESSION RESULTS-POSITIONING STRATEGY AND ORGANIZATIONAL PERFORMANCE............158 
TABLE 53: FindiNGS OF POSITIONING STRATEGY HYPOTHESES

TABLE 54: CORRELATION- INFLUENCING FACTORS AND MANUFACTURING STRATEGY DIMENSIONS ...

TABLE 55: CORRELATION- MANUFACTURING STRATEGY DIMENSIONS AND ORGANIZATIONAL

PERFORMANCE

TABLE 56: REGRESSION EQUATIONS-MANUFACTURING STRATEGY AND INFLUENCING FACTORS ..............164

TABLE 57: REGRESSION RESULTS - MANUFACTURING STRATEGY AND INFLUENCING FACTORS..................166

TABLE 58: REgRESSION EQUATIONS-MANUFACTURING STRATEGY AND ORGANIZATIONAL PERFORMANCE

TABLE 59: REGRESSION RESULTS-MANUFACTURING STRATEGY AND ORGANIZATIONAL PERFORMANCE.. 170

TABLE 60: FINDINGS OF MANUFACTURING STRATEGY HYPOTHESES .172

TABLE 61: EMPIRICAL STUDIES WITH PROFILE DEVIATION CONCEPTUALIZATION

TABLE 62: Co-ALIGNMENT OF POSITIONING STRATEGY AND MANUFACTURING STRATEGY ……..................177

TABLE 63: REGRESSION EQUATIONS-CO-ALIGNMENT OF POSITIONING STRATEGY AND MANUFACTURING

STRATEGY

TABLE 64: REGRESSION RESULTS-CO-ALIGNMENT OF POSITIONING STRATEGY AND MANUFACTURING

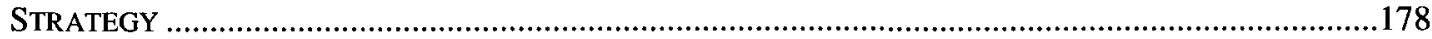

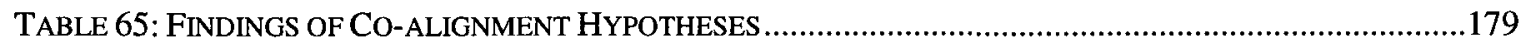

TABLE 66: Co-ALIGNMENT OF POSITIONING STRATEGY AND MANUFACTURING STRATEGY - SECOND IDEAL PROFILE

TABLE 67: REgRESSION RESULTS- CO-ALIGNMENT OF POSITIONING STRATEGY AND MANUFACTURING

STRATEGY (SECOND IDEAL PROFILE)

TABLE 68: CO-ALIGNMENT OF POSITIONING STRATEGY AND MANUFACTURING STRATEGY - RANDOM PROFILE

TABLE 69: REgRESSION RESULTS-CO-ALIGNMENT OF POSITIONING STRATEGY AND MANUFACTURING

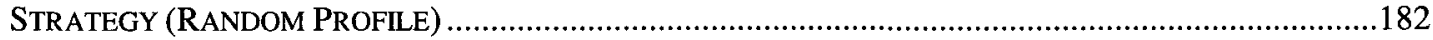

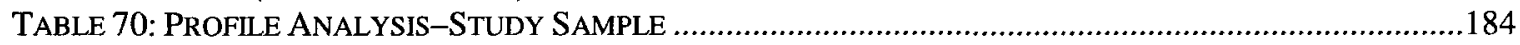

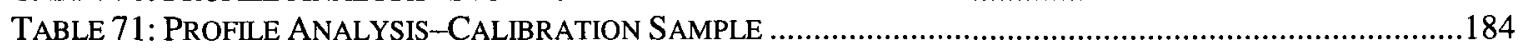

TABLE 72: REgRESSION RESUlTS-VALIDATION OF PROFILE DEVIATION, DEVIATION FROM POSITIONING

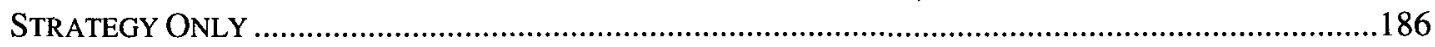

TABLE 73: REGRESSION RESULTS- VALIDATION OF PROFILE DEVIATION, DEVIATION FROM

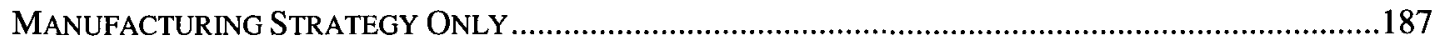

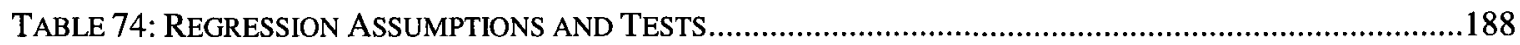

TABLE 75: FINDINGS OF TESTS TO CHECK REGRESSION ASSUMPTIONS ......................................................188 


\section{List of Figures}

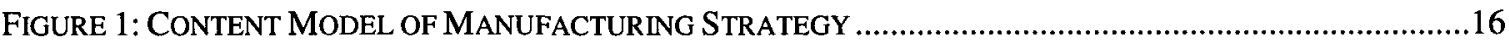

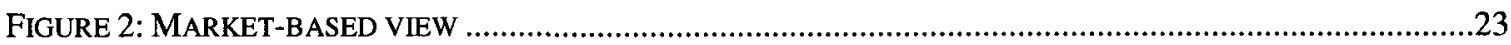

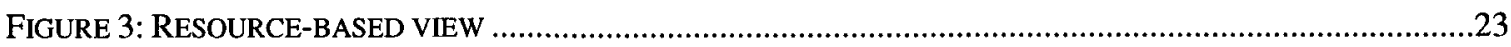

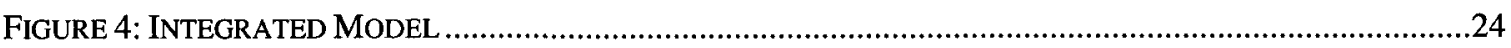

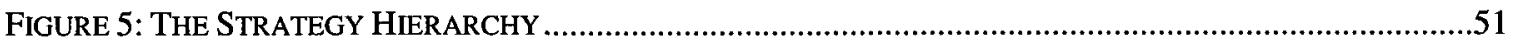

FIGURE 6: LINKING BUSINESS STRATEGY TO MANUFACTURING STRATEGY ............................................52

FIGURE 7: MARKETING OPERATIONS INTEGRATION FRAMEWORK WITHIN A FIRM ……...............................54

FIGURE 8: CO-ALIGNMENT OF MANUFACTURING AND POSITIONING STRATEGIES......................................58

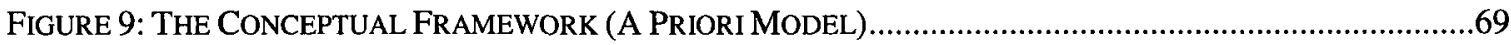

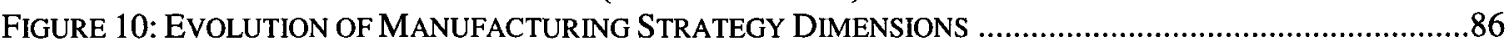

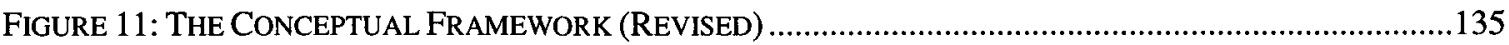

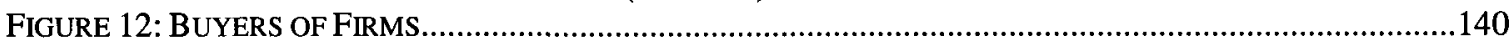

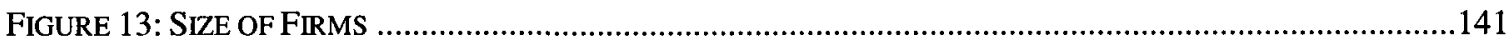

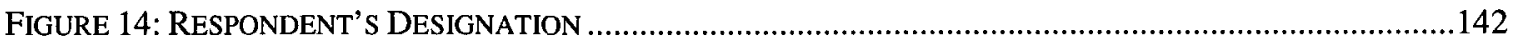

FIGURE 15: A SNAPSHOT OF CONCEPTUAL FRAMEWORK .......................................................................146

FIGURE 16: POSITIONING STRATEGY FRAMEWORK …….....................................................................147

FIGURE 17: MANUFACTURING STRATEGY FRAMEWORK ……..................................................................161

FIGURE 18: CO-ALIGNMENT OF POSITIONING AND MANUFACTURING STRATEGY …..................................176 


\section{List of Appendices}

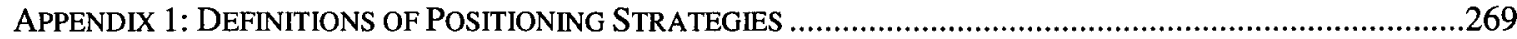

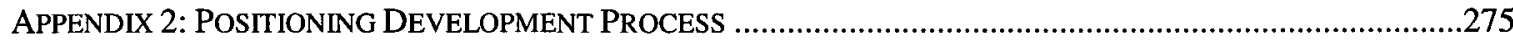

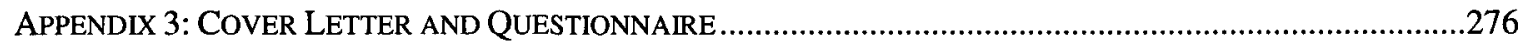

APPENDIX 4: CONVERGENT VALIDITY-CORRELATION MATRIX OF CONSTRUCTS …..................................285

APPENDIX 5: SIGNIFICANT DIFFERENCES BETWEEN SMALL AND LARGE \& MEDIUM FIRMS ..........................28

APPENDIX 6: SIGNIFICANT DIFFERENCES BETWEEN CANADIAN AND FOREIGN FIRMS ................................292

APPENDIX 7: CALCULATION OF PROFILE DEVIATION FOR CO-ALIGNMENT.............................................295 


\section{Chapter 1: Introduction}

This chapter sets the context by initially starting with the concepts of corporate and business level strategies while later introducing the concepts of positioning and manufacturing strategies. It pinpoints the similarities and differences between the two before presenting the statement of problem. The research objectives are presented at the end.

\subsection{Background}

"Strategy" has been defined as the "determination of the basic long-term goals and objectives of an enterprise and the adoption of courses of action and the allocation of resources necessary for carrying out these goals" (Dioguardi, 1997). Strategy is considered a mechanism through which activities of diverse functional departments marketing, production, research and development $(\mathrm{R} \& \mathrm{D})$, procurement and finance etc. are integrated (Porter, 1991).

Strategy, when applied by a firm, is called corporate strategy. The major focus of corporate strategy is determination of the businesses a firm should be involved in and allocation of resources to those businesses. Corporate strategy entails decision-making at the highest level of the organization (Varadarajan and Clark, 1994).

A business level strategy, on the other hand, focuses on "how a business unit or division chooses to compete in an industry" and maintains competitive advantage (Greenley, 1984). Porter (1980, 1985) and Miles and Snow (1978) have been credited with proposing well-received business-level strategies. The term "business strategy" has been 
used interchangeably with "competitive strategy", "market strategy", "product-market strategy", and "business unit strategy" (Varadarajan and Clark, 1994). The term competitive strategy is also used frequently in manufacturing strategy literature to depict competitive priorities, the integral component of manufacturing strategies.

Positioning, considered as one of the fundamental components of strategy and management, is a well-established concept in literature (Kotler, 1999; Hooley, Broderick, and Möller, 1998). Positioning is considered to be one of the most important elements of marketing strategy since it has a direct effect on the tactical decisions undertaken by the company to influence and serve the customers (Hooley et al., 2001).

Positioning is defined as "the act of designing the company's offerings (products and services), so that they occupy a meaningful and distinct competitive position in the target customers' minds" (Kotler, 1998). Positioning strategy is defined as the choice of target segments and the selection of differential advantage(s) used by a firm to compete in the market (Doyle, 1994; Hooley and Saunders, 1993; Jobber, 1998). The differential advantage used by the firm to compete is called the dimension of positioning strategy. The firms normally compete on one or more dimensions such as innovation, quality, value, service, etc.

It is very common to find statements in the literature highlighting the importance of positioning. Dovel (1990) states that, "Positioning should not be just a part of your strategy but the backbone of your business plan." Huber and Holbrook (1979) state that, "product positioning decisions have become central to a firm's competitive strategy." Hibbert (1995) calls it a vital tool to combat competitive pressures in the market place. 
Porter (1996) cautions that companies who opt for operational efficiency instead of focusing on positioning strategies may not be able to achieve long-term growth. The importance of positioning is echoed by other authors as well (e.g. Blankson and Kalafatis, 2004; Clement and Grotemeyer, 1990; Devlin, Ennew, and Mirza, 1995) who note that the concept of positioning has become essential to a firm's success.

Proposed as a theoretical concept in literature, positioning is primarily an applied process practised by firms. Its importance as a strategic tool is expected to rise in future due to accelerating national and international competition in virtually all economic sectors (Augustine, Long, and Pantzallis, 1992).

Manufacturing strategy, a concept introduced in the literature by Skinner (1969), refers to the competencies that a firm develops around its operations to achieve competitive advantage. Strongly integrated with a firm's business strategy, manufacturing strategy is considered to be an important component of overall corporate strategy (Anderson et al., 1989).

Hayes and Wheelwright (1984) define manufacturing strategy as "a consistent pattern of decision-making in the manufacturing function linked to the business strategy." Swamidass and Newell (1987) describe manufacturing strategy as "a tool for effective use of manufacturing strengths as a competitive weapon for achievement of business and corporate goals."

It has been emphasized that a firm should develop manufacturing strategy (or operations strategy) within the broader context of organizational level strategy. The manufacturing strategy dimensions are generally classified as quality, cost, delivery and flexibility 
(Skinner, 1978; Sweeney, 1994). The manufacturing strategy is expected to align the company's capabilities and resources with its competitive strategy. The choice of specific strategy dimensions is influenced by the customer demands and competitors (Pun, 2004). The companies which develop and implement manufacturing strategy are known to have significantly higher return on sales (Miltenburg, 2008).

It is argued in the literature that manufacturing strategies are based either on marketrequirements or formulated on the basis of manufacturing resources. Cagliano et al. (2005) in an empirical study found that some firms concentrate on market-relevant aspects whereas others focus on their manufacturing competences such as unique practices or proprietary equipment. Firms competing in highly competitive environments tend to follow market-based strategy while organizations operating in low competitive intensity environments predominantly follow resource-based strategy (Thun, 2008).

One can argue that there are similarities and linkages between positioning and manufacturing strategies. For example, both positioning and manufacturing strategies have dimensions, which in some cases are almost identical, such as price, quality, and innovation. Also, both positioning and manufacturing strategies consider resource-based view and market-based view for the development of respective strategies. An appropriate manufacturing strategy provides competitive advantages to the firm. The market positions are based on the concept of differentiation from competitors which is driven by the competitive advantages of the firm. In a nutshell, the concept of competitive advantage links manufacturing and positioning strategies. Theoretically, the manufacturing strategy aids the development of competitive advantages which form the underlying basis on which the positions are created. 
However, there are also a number of fundamental differences between positioning and manufacturing strategies. At a theoretical and practical level, they belong to separate domains. Positioning strategy is considered the heart of marketing strategy, whereas manufacturing strategy strictly belongs to operations management. Normally, positioning and manufacturing strategies are developed independently of each other by a firm's marketing and operations management departments. Manufacturing strategy is increasingly considered in the literature as a resource-based viewpoint, although marketperspective is secondarily considered as well. Positioning strategy, on the other hand, is primarily based on market-perspective, although resources are needed to create and defend market positions.

\subsection{Statement of Problem}

Both positioning and manufacturing strategies, driven by overall corporate strategy, are business level strategies, developed by different departments within the same organization. For a manufacturing firm to operate effectively and profitably, it needs to craft both strategies with considerable thought and systematic analysis, taking into consideration all the factors that influence the development of the respective strategies. The understanding of factors that affect the development of manufacturing and positioning strategies can significantly aid the process of strategy development.

However, there is a dearth of studies in both operations and marketing domains which comprehensively examine the factors influencing the development of each strategy. For instance, Dangayach and Deshmukh (2001b) conducted an extensive review of 260 articles on manufacturing strategy and found less than 10 percent of the literature on the 
topic of manufacturing strategy development process. Of the studies on the topic of process, even fewer consider a comprehensive set of factors since this area has not been studied in detail. Individual studies have examined the constructs of market orientation, resource orientation, innovation and environmental dynamism but no more than two constructs have been empirically investigated by any study. The construct of manufacturing capability is not at all considered as an antecedent for manufacturing strategy.

Though positioning has been studied extensively from the perspective of the consumer, there are only a handful of studies which look at positioning from the firm's perspective. There are only a few empirical studies which study the positioning development process of the firm, and these do not delve into the details of factors taken into consideration by the firms while developing positioning strategies. With reference to Resource Based View, Hooley, Broderick, and Möller (1998) state that the positioning alternatives available to firms are limited by their resources and capabilities. However, there are only two studies (Gura u, 2004; Hooley and Greenly, 2005) which study the impact of a firm's assets and capabilities on its positioning strategies. Influencing factors such as customer and competitor orientation have not been deliberated in the literature with the exception of Gura u (2004) who accounts for competitive conditions.

Thus, there is a significant gap in both operations management and positioning literature in term of understanding and empirically testing the complete spectrum of factors which influence the development of respective strategies. 
Dangayach and Dangayach (2001b) identified performance measurement of manufacturing strategy as one of the areas of future research after reviewing 260 studies on manufacturing strategy. They proposed the use of multidimensional measures to encapsulate organizational performance. A number of studies have empirically tested the impact of manufacturing strategy on a firm's performance after the publication of their paper. However, the majority of those studies look only at the operations dimensions of manufacturing performance (For example, Kathuria and Porth, 2003; Meybodi, 2006; Schroeder, Bates, and Junttila, 2002).

Though various authors suggest there that there is a positive relationship between a company's performance and clearly defined positioning strategies, the empirical evidence to support this proposition is very limited (Brooksbank 1994; Devlin, Ennew and Mirza, 1995; Porter, 1996). An empirical study conducted by McAlexander and Becker (1993) found that positioning strategy correlated significantly with financial performance. However, that study was limited in its scope, focusing on health care professionals, (privately practising dentists) in the state of Oregon, USA. Lately, Kale, and Arditi (2002) studied the impact of positioning strategies in the United States construction industry upon performance indicators - growth in contracts, awards, profitability, and overall performance.

Thus, the impact of positioning and manufacturing strategy on financial and non-financial aspects of a firm's performance is another under-researched area in the literature.

The manufacturing strategy, primarily developed on the basis of the firm's capabilities and resources, ought to take into consideration market requirements and competitive 
intensity. The positioning strategy, on the other hand, is always in relation to the competitor and from the perspective of market (customers), and ought to be based on the firm's sustainable competitive advantages provided by its resources and capabilities. Just as an appropriate manufacturing strategy is necessary to align the firm's competitive strategy with its skills and resources, a clearly defined positioning strategy is integral to present and communicate the firm's competitive advantages from the perspective of customers in relation to the competitors. At a practical level, the respective operations and marketing departments develop these strategies independent of each other.

Positioning strategy is a fundamental component of marketing strategy and there are a number of studies in the literature which explore the link between manufacturing and marketing strategy. The concept of positioning, with its focus on identifying a target set of customers, then presenting a product based on dimensions considered relevant and important by customers, enables the firm to compete effectively in today's fiercely competitive market. However, an effective positioning strategy, based on sustainable competitive advantages, is strongly influenced by manufacturing strategy, amongst other things. The positioning strategy must be based on the competitive advantage of a firm. The role of manufacturing in establishing competitive advantage for a firm is well established now. However, it is marketing which takes that competitive advantage and converts it into positioning strategy.

The operations management literature clearly states that marketing strategy and manufacturing strategy must be aligned to maximize the firm's performance (Calantone, Dröge, and Vickery, 2002; Malhotra and Sharma, 2002; Prabhaker, 2001; Caron and Ernest, 1991). Positioning strategy has been linked with both manufacturing and 
marketing strategy in the literature (Berry, Hill, and Klompmaker, 1999). However, there is not a single empirical study in operations or marketing literature which has explored the concept of co-alignment of manufacturing and positioning strategies, though it has been casually mentioned in the operations management research.

Researchers (e.g., Hauser, Tellis, and Griffin, 2005) have noted a need for crossdisciplinary research, particularly in the areas of marketing and strategic management (Paladino, 2007). Surprisingly, despite 40 years of research in the areas of positioning and manufacturing, the literature is devoid of the studies which have empirically researched these concepts within the same framework. There is only one study in the literature which presents a conceptual framework depicting linkages of positioning strategy with manufacturing strategy (Berry, Hill, and Klompmaker, 1999). The proposed thesis, therefore, breaks new ground in examining manufacturing and positioning strategies and empirically testing the co-alignment of positioning and manufacturing strategies, thus contributing significantly to both operations and marketing literatures.

\subsection{Research Objective}

The broad overall objective of this research is to examine the interplay of product positioning and manufacturing strategies of manufacturing firms in Canada. This research endeavors to answer the following specific questions:

A) What factors are taken into consideration by firms while choosing positioning strategy dimension/s? 
B) What factors are taken into consideration by firms while choosing manufacturing strategy dimension/s?

C) What is the impact of a firm's positioning strategy on its performance?

D) What is the impact of a firm's manufacturing strategy on its performance?

E) What is the impact of co-alignment of a firm's manufacturing and positioning strategies on its performance?

\subsection{Organization of the Remaining Chapters}

This study is divided into eleven chapters. The present chapter provides an introduction to the research. The literature review is divided into four chapters. Chapter Two provides a review of manufacturing strategies, mainly focusing on the content and process. Chapter Three presents a review on various aspects of positioning - the concept of positioning, various facets of product, service and generic positioning strategy, taxonomy and typology of positioning strategy dimensions and how positioning strategy is developed. Chapter Four brings together studies which deliberate co-alignment of manufacturing and marketing strategies with reference to positioning strategy. The theoretical underpinnings of the research model from manufacturing and positioning strategy perspectives are discussed in Chapter Five with a discussion on market-based and resource-based views. Chapter Six delves into the details of research questions, a priori conceptual framework and hypotheses. The identification and specification of constructs is discussed in detail. The methodological details of sampling, data collection and data analysis are provided in Chapter Seven. Chapter Eight provides details about 
data cleaning and Principal Component Analysis (PCA). The revised conceptual framework based on the findings of PCA and revised hypotheses are also presented. The findings of correlation, regression and profile deviation analysis are reported in Chapter Nine. Chapter Ten discusses the findings in the light of the literature and provides plausible rationale for some of the findings which are not in line with the literature. The conclusion, implication, limitations and future research directions are discussed in Chapter Eleven. 


\section{Chapter 2: Manufacturing Strategy}

This chapter introduces manufacturing strategy by providing historical background and various definitions of manufacturing strategy proposed in the literature. The literature discusses two aspects of manufacturing strategy: content and process. The studies on content mainly deal with the topic of competitive priorities and decisions which support these priorities: structural and infrastructural. There are a few studies which discuss the issue of developing the manufacturing strategy.

\subsection{Origins of Manufacturing Strategy}

In the 1960s it was believed that the declining productivity of US industry and loss of markets to the Japanese and Europeans was linked to the top management's lack of interest in the manufacturing function (Anderson, Cleveland, and Schroeder, 1989). Skinner, a professor at Harvard Business School, noticed that the manufacturing plants were unable to perform properly; he posited that the prime reason was that the manufacturing plants were run by technical people, industrial engineers and computer experts, who had no role to play in the corporate strategy (Amoako-Gyampah, 2003). $\mathrm{He}$ stated that "top executives tend to avoid involvement in manufacturing policy making, manufacturing managers are ignorant of corporate strategy, and a function that could be a valuable.....tool of corporate strategy becomes a liability instead" (Anderson, Cleveland, and Schroeder, 1989). He argued that the manufacturing function should be strategized at the corporate level rather than the operational level (Amoako-Gyampah, 2003). 
Skinner (1969) introduced the concept of manufacturing strategy in his seminal and famous Harvard Business Review article titled, "Manufacturing - missing link in corporate strategy". A steady stream of research, mainly conceptual in nature, followed Skinner's article. The large amount of research has intensified with increasing sophistication in last two decades. A number of studies in the literature have tested Skinner's arguments and refined their conceptualization (e.g., Dangayach and Deshmukh, 2001a; Gupta and Somers, 1996; Swamidass and Newell, 1987; Ward and Durray, 2000).

\subsection{Manufacturing Strategy Defined}

Manufacturing strategy is defined as "the competencies that a firm develops around the operations function (Amoako-Gyampah, 2003, p 577). These competencies are meant to achieve competitive advantage (Anderson et al., 1989). Skinner (1969) defined manufacturing strategy as the "set of manufacturing system design aspects managers (must) decide on" (Cagliano, Acur, and Boer, 2005).

Hayes and Wheelwright (1984) define manufacturing strategy as "a consistent pattern of decision-making in the manufacturing function linked to the business strategy." Swamidass and Newell (1987) describe manufacturing strategy as "a tool for effective use of manufacturing strengths as a competitive weapon for achievement of business and corporate goals."

Cox and Blackstone (1998) consider manufacturing strategy as "a collective pattern of decisions that acts upon the formulation and deployment of manufacturing resources. To be most effective, the manufacturing strategy should act in support of overall strategic directions of the business and provide for competitive advantages." 
Platts et al. (1998, p. 517) develop a working definition: “a pattern of decisions, both structural and infrastructural, which determine the capability of a manufacturing system and specify how it will operate, in order to meet a set of manufacturing objectives which are consistent with the overall business objectives." A brief overview of definitions of the manufacturing strategy proposed in literature is given below:

Table 1: Manufacturing Strategy Definitions

\begin{tabular}{|c|c|}
\hline Skinner, 1969 & $\begin{array}{l}\text { Exploiting certain properties of the manufacturing function as a } \\
\text { competitive weapon }\end{array}$ \\
\hline $\begin{array}{l}\text { Hayes \& } \\
\text { Wheelwright, } \\
1985\end{array}$ & $\begin{array}{l}\text { A sequence of decisions that over time, enables a business unit to achieve } \\
\text { a desired manufacturing structure, infrastructure and set of specific } \\
\text { capabilities }\end{array}$ \\
\hline $\begin{array}{l}\text { Fine \& Hax, } \\
1985\end{array}$ & $\begin{array}{l}\text { It is a critical part of the firm's corporate and business strategies, } \\
\text { comprising a set of well coordinated objectives and action programs } \\
\text { aimed at securing a long-term sustainable advantage over competitors }\end{array}$ \\
\hline $\begin{array}{l}\text { Swamidass \& } \\
\text { Newell, } 1987\end{array}$ & $\begin{array}{l}\text { The effective use of manufacturing strengths as a competitive weapon for } \\
\text { the achievement of business and corporate goals }\end{array}$ \\
\hline $\begin{array}{l}\text { McGrath \& } \\
\text { Bequillard, } \\
1989\end{array}$ & $\begin{array}{l}\text { The overall plan as to how the company should manufacture products on a } \\
\text { world wide basis to satisfy customer demand }\end{array}$ \\
\hline $\begin{array}{l}\text { Swink \& Way, } \\
1995\end{array}$ & $\begin{array}{l}\text { Decisions and plans affecting resources and policies directly related to } \\
\text { sourcing, production, and delivery of tangible products }\end{array}$ \\
\hline $\begin{array}{l}\text { Berry et al., } \\
1995\end{array}$ & $\begin{array}{l}\text { The choice of firm's investment in processes and infrastructure that } \\
\text { enables it to make and supply its products to chosen markets }\end{array}$ \\
\hline $\begin{array}{l}\text { Cox and } \\
\text { Blackstone, } \\
1998\end{array}$ & $\begin{array}{l}\text { A collective pattern of decisions that acts upon the formulation and } \\
\text { deployment of manufacturing resources. To be most effective, the } \\
\text { manufacturing strategy should act in support of the overall strategic } \\
\text { directions of the business and provide for competitive advantage }\end{array}$ \\
\hline Brown, 1999 & $\begin{array}{l}\text { A driving force for continual improvements in competitive } \\
\text { requirements/priorities and enable the firm to satisfy a wide variety of } \\
\text { requirements. }\end{array}$ \\
\hline $\begin{array}{l}\text { Ward \& Duray, } \\
2000\end{array}$ & Manufacturing-oriented dimensions that win orders \\
\hline $\begin{array}{l}\text { Cagliano et al., } \\
2005\end{array}$ & $\begin{array}{l}\text { The configuration of strategic priorities the manufacturing system does or } \\
\text { will pursue }\end{array}$ \\
\hline $\begin{array}{l}\text { Miltenburg, } \\
2008\end{array}$ & A plan for moving a company from where it is to where it wants to be \\
\hline
\end{tabular}

Adapted from Dangayach and Deshmukh (2001b) 
It has been emphasized that firms should develop manufacturing strategy (or operations strategy) within the broader context of organizational level strategy. The manufacturing strategy is expected to align a company's capabilities and resources with its competitive strategy. The manufacturing strategy dimensions are generally classified as quality, cost, delivery and flexibility (Skinner, 1978; Sweeney, 1994). The choice of specific strategy dimensions is influenced by the customer demands and competitors (Pun, 2004). The companies which develop and implement manufacturing strategy are known to have significantly higher return on sales, the ratio of profit before tax to sales (Miltenburg, 2008).

There has been a steady stream of research in this area focusing mainly on two aspects of manufacturing strategy: content and process (Dangayach and Deshmukh, 2001b). The content literature focuses mainly on the significance of the manufacturing function for improving product competitiveness through setting and accomplishing long-term goals in terms of cost, quality, flexibility, delivery, reliability and innovation etc. These long-term goals are also called the dimensions of manufacturing strategy. The bulk of manufacturing strategy literature is focused on the content aspects. The process of manufacturing strategy addresses the method used to develop and implement the manufacturing strategy (Hurreeram, 2007). A brief overview of content and process is presented below:

\subsubsection{Content of Manufacturing Strategy}

Contents are the specific decisions and actions of manufacturing strategy (O'Regan and Ghobadian, 2002). Content comprise of two components: competitive priority 
dimensions based on corporate and business unit goals and long-term decision areas important to manufacturing function (Hallgren and Olhager, 2006). Leong, Snyder, and Ward (1990) depict the manufacturing strategy in the following framework that they call the "content model" of manufacturing strategy.

Figure 1: Content Model of Manufacturing Strategy

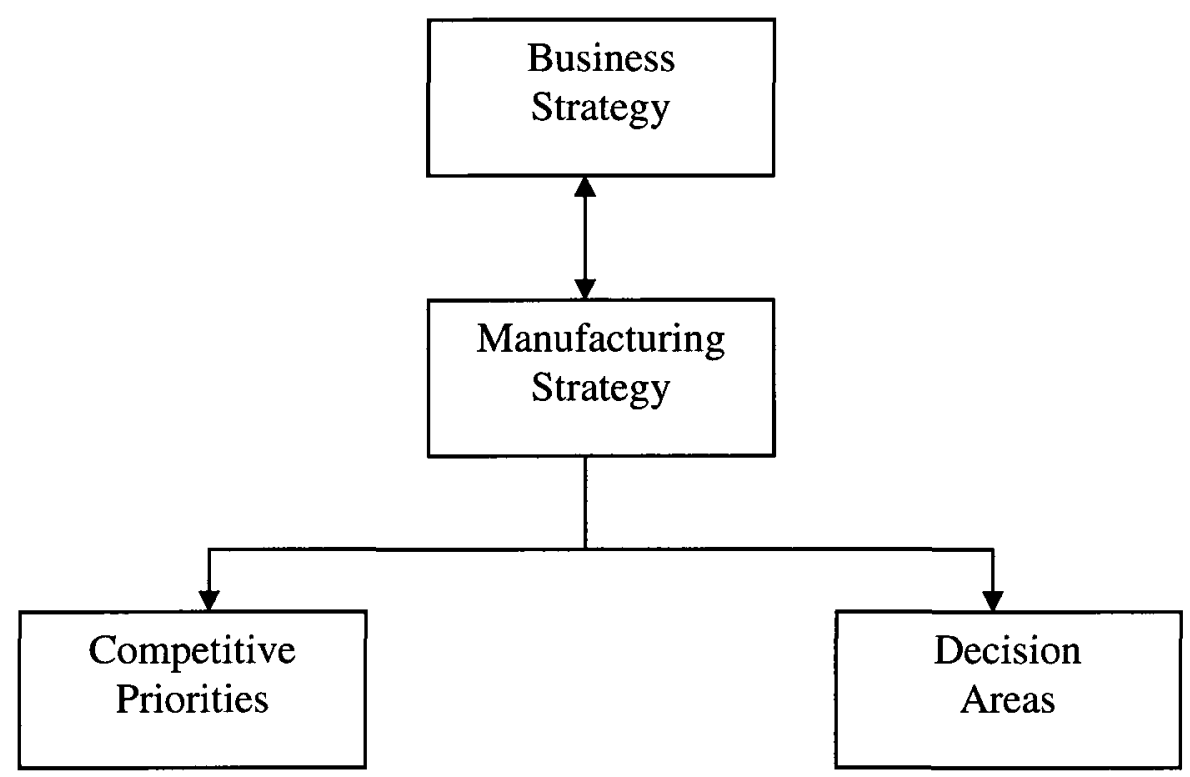

Source: Leong, Snyder, and Ward (1990)

According to the above framework, manufacturing strategy is driven from business strategy and comprises of two aspects, competitive priorities and decision areas, also called content of manufacturing strategy.

\subsubsection{Competitive Priorities}

Competitive priorities of manufacturing strategy, also referred to as competitive strategy in the literature, are defined as the dimensions on which the firm competes in the marketplace (Hayes and Wheelwright, 1984). Avella, Fernandez, and Vazquez (1998) 
call them manufacturing priorities and define them as "characteristics of the products on which production should be based to be able to provide the company with competitive advantages" (p. 3114). The terms "manufacturing priority", "competitive priorities" and "manufacturing strategy dimensions" are used interchangeably in the literature (Swamidass and Newell, 1987).

There has been a considerable discussion in the literature on this subject. Wheelwright (1978) classified the competitive priorities into four categories: price, flexibility, quality and dependability. Avella, Fernandez and Vazquez (1998) consider flexibility, quality, delivery and cost to be the main manufacturing priorities, based on their literature review.

Hays and Schmenner (1978) suggested five dimensions: price, quality, dependability, product flexibility, and volume flexibility. Leong, Snyder, and Ward (1990), after conducting a comprehensive review of literature, stated that the five most important competitive priorities are: quality, delivery, cost, flexibility, and innovativeness. Hill (1993) divided the priorities into two categories: order winner and order qualifiers. Order winner priorities help to win the order and comprise price, delivery, quality, product design and variety. Order-qualifiers must be met by the company just to stay in the market. Krajewski and Ritzman (1996) identified four priorities: cost, quality, time and flexibility. Boyer and Pagell (2000) state that there seems to be a general consensus about the key competitive priorities which form the content of marketing strategy. The key competitive priorities are cost, quality, flexibility and delivery. Pun (2005) concludes that competitive priorities generally comprise quality, cost, delivery, flexibility, and innovation. 
There are two perspectives on identification of appropriate competitive priorities: market orientation comprises of market requirements while manufacturing orientation stresses manufacturing capabilities (Hallgren and Olhager, 2006). Swink and Hegarty (1998) found that the defining of competitive priorities could depend on the perspective used. A manufacturing-based internal perspective might consider cost, product conformance and lead time to be important. A customer-based external perspective might consider price, product performance and delivery speed to be important. Though these two set of priorities are related, there could be a difference between manufacturing outcomes and product attributes in the marketplace. Since most of the manufacturing operations are not in touch with the customers, it is important for them to be able to define priorities in terms of customers' expectations (Swink and Hegarty, 1998).

Trade-off versus Sand-cone Model: Skinner $(1969,1974)$ argued that a firm's manufacturing strategy should identify the competitive priorities by reflecting the realities of competitive environment and support the corporate strategy. In subsequent studies Hayes and Wheelwright (1984) and Hill (1985) further refined Skinner's standpoint.

There are two schools of thought in manufacturing strategy literature on how a firm should choose its competitive priorities or manufacturing strategy dimensions. The "trade-offs" school of thought, which initially garnered support (Filippini et al., 1995; Hayes and Wheelwright, 1984) argues that there are trade-offs in picking one dimension over another; therefore, firms need to focus on the dimension in line with their business strategy. The idea of trade-offs, proposed by Skinner (1969), is based on the premise that companies need to focus on certain aspects of their manufacturing to produce products 
which can satisfy a set of customers since it is not possible for a firm to do everything and please everyone. Therefore, companies need to choose amongst the dimensions of quality, cost, flexibility and dependability (Sarmiento et al., 2007). The "sand-cone model" (Ferdows and De Meyer, 1990; Noble, 1995), also called "cumulative capability model" (Avella, Fernandez, and Vazquez, 1998) has received more support lately (Flynn et al., 1999) and suggests that a firm can decide to employ multiple competitive priorities following a certain sequence. (Brown, Squire, Blackmon, 2007).

Buffa (1984) argued that it was difficult for a company to focus on all of the dimensions simultaneously. Instead, a company could assign different level of importance to each priority (Wheelwright, 1984). Some researchers, though, (Kathuria, 1997; Noble, 1995) noticed that a number of manufacturers are able to emphasize and consequently perform better on many, if not all, of the dimensions of competitive priorities (Kazan, Özer, and Çetin, 2006).

Limitations with Competitive Priorities: Swink and Hegarty (1998) point to a very significant limitation in the current conceptualization of the competitive priorities: they do not distinguish between manufacturing capabilities and manufacturing outcomes. The most frequently cited manufacturing priorities - cost, quality, dependability and flexibility - are referred to in the literature both as capabilities and outcomes, means and end. It is necessary to clearly distinguish between customer wants, manufacturing outcomes, and manufacturing capabilities. Customers do not purchase a firm's capabilities of flexibility or dependability. Instead they want products, with certain characteristics and attributes. Swink and Hegarty (1998) propose a conceptual framework 
in which manufacturing outcomes (priorities) are influenced by manufacturing capabilities, while manufacturing priorities lead to product differentiation dimensions.

\subsubsection{Decision Areas}

Decisions related to manufacturing and operations issues are called structural and infrastructural decisions (Hallgren and Olhager, 2006; Hill, 1987). Skinner (1969) identified the choice areas in manufacturing strategy as plant and equipment, production planning and control, labour and staffing, product design and engineering, and organization and management (Cagliano, Acur, and Boer, 2005). Hayes and Wheelwright (1984) were the first to propose that decisions in manufacturing-related issues could be grouped into two categories: structural and infrastructural. Since then, numerous authors have contributed to the development and establishment of the set of decision categories, and associated policy areas normally used (Hallgren and Olhager, 2006).

A snapshot of structural and infrastructural decisions, form various studies, is given below in Table 2:

Table 2: Comparison of Strategic Decision Categories

\begin{tabular}{|l|l|l|l|}
\hline Author & Year & Structural & Infrastructural \\
\hline Skinner & 1974 & $\begin{array}{l}\text { - Plant and equipment } \\
\end{array}$ & $\begin{array}{l}\text { - Production planning and control } \\
\text { - Organization and management } \\
\text { - Labour and staffing } \\
\text { - Product design/engineering }\end{array}$ \\
\hline $\begin{array}{l}\text { Hayes and } \\
\text { Wheelwright }\end{array}$ & 1984 & $\begin{array}{l}\text { - Capacity } \\
\text { - Facilities } \\
\text { - Technology } \\
\text { - Vertical integration }\end{array}$ & $\begin{array}{l}\text { - Quality } \\
\text { - Organization }\end{array}$ \\
\hline
\end{tabular}




\begin{tabular}{|c|c|c|c|}
\hline & & & $\begin{array}{l}\text { - New product development } \\
\text { - Performance measurement } \\
\text { systems }\end{array}$ \\
\hline Buffa & 1984 & 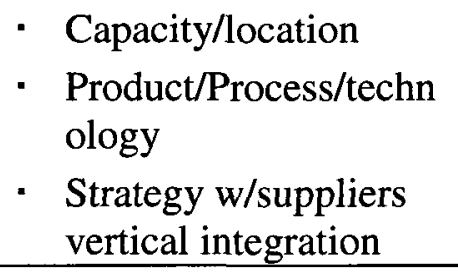 & $\begin{array}{l}\text { Strategic implications of } \\
\text { operating decisions } \\
\text { - Workforce and job design } \\
\text { - Position of production system }\end{array}$ \\
\hline $\begin{array}{l}\text { Fine and } \\
\text { Hax }\end{array}$ & 1985 & $\begin{array}{l}\cdot \text { Capacity } \\
\text { - Facilities } \\
\text { - Processes and } \\
\text { technologies } \\
\end{array}$ & $\begin{array}{ll}\text { - } & \text { Product quality } \\
\text { - } & \text { Human resources } \\
\text { - } & \text { Scope of new products }\end{array}$ \\
\hline $\begin{array}{l}\text { Hallgren and } \\
\text { Olhager }\end{array}$ & 2006 & $\begin{array}{l}\text { - Process technology } \\
\text { - Facilities } \\
\text { - Capacity } \\
\text { - } \text { Vertical integration }\end{array}$ & $\begin{array}{l}\text { - } \text { Organization } \\
\text { - } \text { Manufacturing planning \& } \\
\text { control } \\
\text { - } \text { Quality } \\
\text { - } \\
\text { New product introduction } \\
\end{array}$ \\
\hline $\begin{array}{l}\text { Ward, } \\
\text { McCreery } \\
\text { and Anand }\end{array}$ & 2007 & $\begin{array}{ll}\text { - } & \text { Capacity } \\
\text { - } & \text { Sourcing \& vertical } \\
\text { integration } \\
\text { - } \text { Facilities } \\
\text { - Information \& process } \\
\text { technology }\end{array}$ & $\begin{array}{ll}\text { - } & \text { Resource allocation and capital } \\
\text { budgeting systems } \\
\text { - } \\
\text { - } \text { Human resource systems } \\
\text { - } \text { Work planning \& control systems } \\
\text { - } & \text { Measurement \& reward systems } \\
\text { - } & \text { Product \& process development } \\
\text { systems organization }\end{array}$ \\
\hline
\end{tabular}

Adapted from Leong, Snyder, and Ward (1990)

Structural decisions are strategic in nature, whereas infrastructural are tactical. Structural decisions are further sub-classified into capacity, facility \& location, technology/structure, and vertical integration (Kazan, Özer, and Çetin, 2006). Infrastructural decisions include planning and control systems, quality, work force, organization etc. (Hayes and Wheelwright, 1984; Kathuria, 2000; Ward et al., 1990). Hayes and Wheelwright (1984) and Hill (2000) stressed that structural and infrastructural investment decisions link operations and business strategy (Ward, McCreery, and Anand, 2007). 


\subsubsection{Process of Manufacturing Strategy}

"Process" relates to the development and implementation of strategic plan (O'Regan and Ghobadian, 2002) or "how these decisions and actions come about" (Pun, 2005). Skinner (1969) and Hill (1985) emphasized the importance of the process of manufacturing strategy formation and implementation. Skinner (1969) suggests the top-down approach where manufacturing task is based on the business strategy. Dangayach and Deshmukh (2001b) conducted an extensive review of the manufacturing strategy literature, a total of 260 articles from 31 refereed international journals and conferences, and divided the entire literature into content and process-related issues. They concluded that processrelated articles accounted for less than 10 percent of the literature, indicating that research on manufacturing strategy formulation is limited.

There are two opposing views with respect to the development of manufacturing strategy. The market-based view, which takes an external perspective, regards manufacturing strategy as a derivative of business strategy and emphasizes the consideration of market requirements at the manufacturing level (Thun, 2008). Figure 2 presents a depiction of market-based view: 


\section{Figure 2: Market-based view}

\section{market requirements}

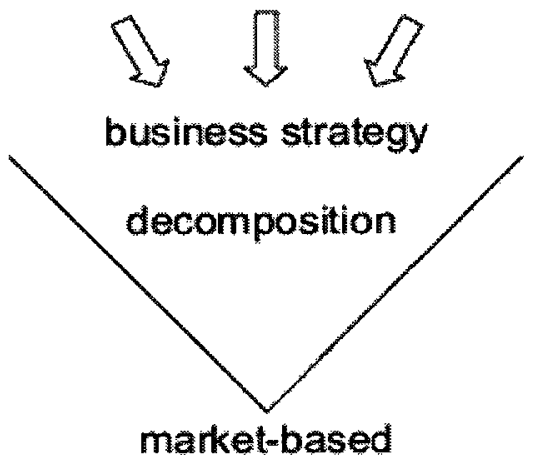

Source: Thun (2008) manufacturing strategy

The resource-based view, on the other hand, takes an internal perspective and considers a firm's internal assets, resources and capabilities to be the main determinant of the manufacturing strategy (Thun, 2008). Figure 3 presents a depiction of resource-based view:

Figure 3: Resource-based view

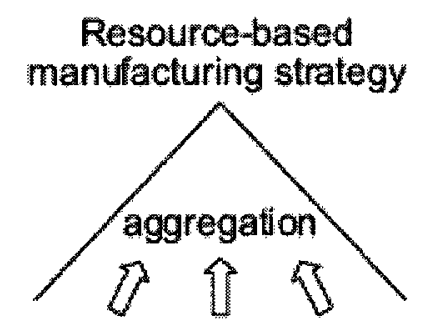

Source: Thun (2008) strategic manufacturing resources

Thun (2008) questions the rationale of following either one of the two approaches. He suggests that today's highly competitive markets require an integration of both approaches since either approach followed in isolation will have its weaknesses. To strengthen his argument, he quotes Slack and Lewis (2002) who also stressed "reconciliation of market requirements with operations resources". Thun (2008) proposes 
an integrated manufacturing strategy model which incorporates both market-based and resource-based views.

To test the model he conducted an empirical study by taking data from the international "High-Performance Manufacturing" project, a cooperation of research groups from the USA, Japan, Germany, Sweden, Finland, South Korea, Italy, and Austria. He concluded that some companies clearly follow either a market-based or a resource-based approach while other firms try to integrate both approaches. He also found that a number of firms do not have a clearly defined manufacturing strategy. The integrated model proposed by Thun (2008) is given below:

\section{Figure 4: Integrated Model}

market requirements

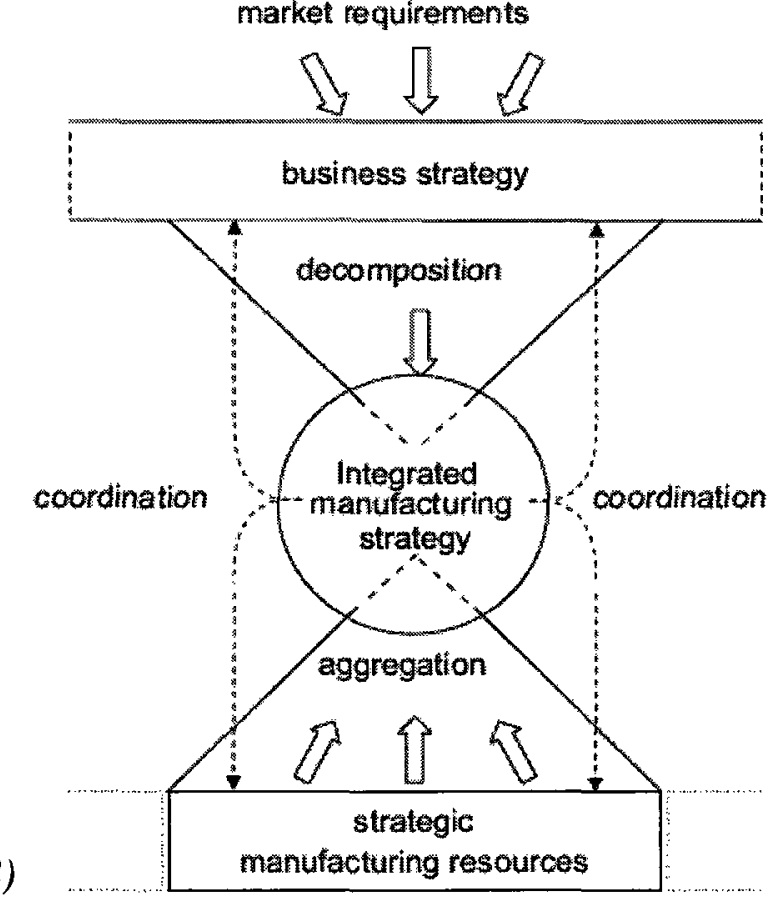




\subsection{Summary}

The concept of manufacturing strategy, introduced by Skinner (1969), is normally divided into two aspects - content and process. The content comprises formulating competitive priorities (also called manufacturing strategy dimensions) and making structural and infrastructural decisions to support the competitive priorities. The process normally entails following a market-based or a resource-based view of strategy development, although an integrated perspective is also proposed in the literature. There are two approaches proposed in the literature for the selection of appropriate manufacturing strategy dimensions. The market-based or external-looking approach favours taking market (customer) requirements and competitor actions into consideration. The resource-based or internal-looking approach stresses building and concentrating on internal resources and capabilities without much regard for external factors. 


\section{Chapter 3: Positioning Strategy}

This chapter provides an overview of what positioning is and how it is linked to other concepts of marketing such as segmentation, targeting, competitive advantage and differentiation. Various definitions of positioning presented in the literature are discussed to develop an understanding of how the concept has evolved. The literature on product and service positioning is also discussed to provide a comprehensive account of the concept. The difference between positioning strategy and dimension is highlighted and positioning development process is discussed.

\subsection{Origins of Positioning}

The origins of positioning go back to firm's communication or advertising strategy. It is postulated that the buyer's mind, with a limited capability to retain information, contains "slots" or "positions" for each competitive product, ranked by sales volume. New products, with communication, fight to outperform the leader to take over the top slot, or the position relative to top slot, or settle for a lower slot, or significantly differentiate the product to create a new slot. The earlier concept of positioning conceived its application only within firm's promotion and communication strategy, as a vehicle to influence the consumer's mind. The current concept of positioning considers it as an essential component of marketing strategy, not just communication strategy. It is argued that the impact of positioning is now extended into all the elements of the marketing strategy rather than just communication strategy (Ganesh and Oakenfull, 1999; Crawford, 1985). Ries and Trout (1981) are credited with bringing this concept into mainstream though it was discussed much earlier in marketing literature. 


\subsection{Positioning Defined}

"There is a consensus in the literature that...there has been no single universally accepted definition of the concept of positioning" (Blankson and Kalafatis, 1999a, p. 109). Lack of appreciation of the positioning concept is sometimes tied to the absence of an allencompassing definition of positioning and the difficulties faced by practitioners in implementing the positioning process. Aaker and Shansby (1982) were among the first to point out that, "positioning means different things to different people". Rigger (1995) blames lack of definition as the main factor behind practitioners' and academic researchers' inability to clearly operationalise the concept.

Alpert and Gatty (1969) define product positioning as "studying the ways in which consumer differ as well as how consumer perceptions of various brands differ" (p. 65). Comparing the 1970s, the 'age of positioning', with the 1950s, when nobody had heard the term, McIntyre (1975) calls positioning an outward approach of looking at consumers' perceptions of the products which takes into account not only the strengths and weakness of a firm's own brands but also that of competitors'.

Houston and Hanieski (1976) call positioning a promotional strategy which highlights certain dimensions of a particular brand as opposed to other brands within the same class. The dimensions could be intangible or physical product characteristics. The objective of positioning, they contend, is to find a "niche" for the brand.

Lautman (1993) defines positioning as a "preferred and unique niche in a customer's mind" (p. 12). He breaks down positioning into three components - attributes, benefits and claims. The first step in developing positioning is to identify a product or service's 
"intrinsic" attributes. The ingredients are the attributes at the most basic level, followed by characteristics and features, which define a product. The attributes are normally very large in number, and frequently, research is used to identify the most important, valued, and meaningful attributes from the customer's perspective. The attributes, however, must carry underlying benefits. The benefits come in three forms: functional, physical, and psychological. The benefits and attributes are communicated through claims. Claims or promises provide the reason for purchase or unique selling proposition.

Gwin and Gwin (2003) consider value to be a central element of effective positioning. Aaker (1998) calls value an outcome of differentiation strategy, which must be communicated to the customer. Differentiation is achieved through identification of attributes that deliver the benefits desired by the customer. However, a cost advantage could spur the firm to offer value by charging a lower price.

Kalafatis, Tsogas, and Blankson (2000) call most differences in definitions "superficial". They seem to agree with Arnott's (1992) definition, “...positioning is the deliberate, proactive, iterative process of defining, modifying and monitoring consumer perceptions of a marketable object..." (p. 417).

A number of authors (Jobber, 1998; Doyle, 1994; Hooley and Saunders, 1993) define positioning as the choice of target market segments and the creation of differential advantage that enables a firm to compete effectively.

Pike and Ryan (2004) rightly point out that "positioning is underpinned by the philosophy of understanding and meeting unique consumer needs" (p. 333). Positioning acts like glue which links the corporate internal analysis to external environmental 
analysis as well as to customer needs and wants. This is the foundation of strategic management which aims to match internal resources with external opportunities.

It is evident from the above definitions that the concept of positioning was considered to have a narrow application in the beginning when some authors considered it a component of promotional strategy. The concept was also deemed applicable only to products rather than whole organizations. Ries and Trout (1981) were the first to highlight the importance of positioning an organization as a whole rather than only its product and services. Doyle (1983) expanded the concept of positioning by stating it as the choice of target market and selection of differential advantage, thereby automatically making segmentation a prerequisite to positioning.

Various definitions of positioning compiled from the literature are given in Appendix 1.

\subsection{Positioning and Other related Concepts}

As is evident from the discussion on positioning definitions in the preceding section, the concept of positioning is not a stand-alone concept. It either encompasses a number of concepts or somehow has linkages with them. The concepts deemed linked to positioning are discussed below:

\subsubsection{Segmentation and Targeting}

The task of dividing the total market, which is often too large to be served efficiently, into smaller segments that share common characteristics, is called "segmentation" (Kotler, 1987). The underlying philosophy behind this concept is to match the products and services of the firms to the specific needs of the segments rather than coming up with one 
proposition for the entire market (Lovelock, 1986). Segmentation is at the heart of the positioning. There can be no positioning without the focus provided by the segmentation. Ries and Trout (1986) vehemently support this notion while discussing positioning. They state, "In the communication jungle out there, the only hope to score big is to be selective, to concentrate on narrow targets, to practice segmentation."

However, the necessary condition of focus as a prerequisite for effective positioning does not mean that an organization cannot serve more than one segment. Rather, an organization may choose to serve multiple segments, employing separate positioning strategies for each targeted segment. The market segments that a firm chooses to serve are called "target markets" and the task of choosing segments is called "targeting" (Dibb and Simkin, 1993). Therefore, targeting is the essence of positioning. Gwin and Gwin (2003) consider targeting to be one of the core concepts of positioning. Van Doren and Spielman (1989) consider segmentation and niching to be important components of positioning. Segmentation, targeting, and positioning are considered components of one sequence where an activity starting with segmentation ends with the practice of positioning (Gwin and Gwin, 2003).

\subsubsection{Competitive Advantage and Differentiation}

A competitive advantage is defined as "something unique or special a firm does or possesses that gives it an edge over competitors" (Belch and Belch, 1993). Thus, the competitive advantage of a firm enables it to distinguish itself and its offering from the rest of the offerings. Brooksbank (1994) suggests that competitive advantage must be sustainable, offering something of value to the customer. Based on a company's strengths 
and "distinctive competencies", it should be difficult for competitors to copy. In order to compete successfully in the marketplace, an organization must offer a product or service that is different from that of the competitors. The identification of this difference, termed "competitive advantage", has also been called "positioning" in the literature (Lovelock, 1991). The competing organizations are perceived to be different on the basis of certain dimensions.

Kotler and Andreasen (1991) describe the relationship between positioning and competitive advantage by stating that "positioning involves establishing a competitive advantage for the organization that differentiates it from others...... and then communicating that advantage clearly to target customers" (p. 12).

"Differentiation" is defined as "the act of designing a set of meaningful differences to distinguish the company's offering from competitors' offerings" (Kotler and Turner, 1998). It then follows that differentiation is based on the advantage a company possesses over its competitors; i.e., competitive advantage. Positioning involves establishing and communicating an organization's competitive advantage based on differentiation of the market. Tull and Kahle (1989) consider differentiation to be an important component of positioning.

\subsection{Positioning Strategy}

\subsubsection{Positioning Typology, Positioning Strategy and Positioning Dimension}

One comes across three terms in the positioning literature - positioning typology, positioning strategy and positioning dimension, which have been assigned varying 
meanings by different authors, but at times might have been used interchangeably. It is, therefore, important to discuss and define them for the purpose of this research. "Positioning strategy" is the most frequently used term in the literature whereas "typology" is the least frequently used one.

Typology is a classification scheme, the process of setting up and selecting categories to organize and analyze data. Blankson and Kalafatis (2004) define positioning typology as "the theoretical foundation underpinning a grouping of factors that reflect or describe positioning strategies". A firm can employ a single strategy or collection of strategies which are mutually inclusive rather than being the indicators of different types of positions. So a set of strategies proposed by a researcher would be called a typology.

Positioning strategy has been used to mean different things in the literature. On the one hand it is defined in a broader terms such as the choice of target market segments and the creation of differential advantage that enables a firm to compete effectively (Doyle, 1994; Hooley and Saunders, 1993; Jobber, 1998). On the other hand, the elements of how a firm competes in the market i.e., the differential advantages are also designated as the positioning strategy.

Kotler (1998) states that an effective positioning strategy distinguishes a product in the customer's mind from competitive offerings. There are numerous ways for firms to compete in the market, distinguish their offering from the competitors' and establish a position in the minds of the consumers. Some authors (Aaker and Shansby, 1982; Kotler and Andreasen, 1991; Lovelock and Weinberg, 1984) call them "a combination of features perceived to be desirable by the target market" while others call them 
“attributes" (Berry, 1982; Gwin and Gwin, 2003; Lautman, 1993), "benefits" (Lautman, 1993) "needs and wants" (DiMingo, 1988), "memorable characteristics" (Dibb and Simkin, 1993), and "dimensions" (Houston and Hanieski, 1976; Zineldin, 1996).

In agreement with various authors, "positioning strategy" for this study is defined as "the choice of target segments and the selection of differential advantage (s) used by firm to compete in the market." There are two facets of this definition - identification of the target market and development of differential advantages. The term "dimension", in this study, is used to mean tangible or intangible characteristics that differentiate one offering from another. What we call "dimension" here is mostly called "positioning strategy" in the literature (for examples see, Aaker and Shansby, 1982; Brooksbank, 1994; Gruca and Klemz, 2003; Percy, Rossiter, and Elliott, 2001; Sayman et al., 2002).

The term "dimension" has been used by a number of studies (for examples see, Berry, 1969; Blankson and Kalafatis, 1999a; Blankson and Kalafatis, 2004; Zineldin, 1996). The studies which use factor analysis sometimes call factors the "strategies" and underlying items the "dimensions", at times. For example, one of the positioning strategies proposed by Blankson and Kalafatis (2004) is "Attractive". The underlying factors or dimensions are "Aesthetics", "Cool", "Elegant" and "Attractive". Another strategy is "Brand Name" where underlying factors/dimensions are "The name of the offering", "Leaders in the market", "Extra features", and "Wide range".

\subsubsection{Positioning Strategies by Streams}

Based on the underlying themes, the studies proposing positioning strategies can be divided into four distinct streams - corporate, product, service, and generic (applicable to 
both product and service). The corporate level strategy of distinguishing the firm relative to competition in the marketplace, on certain dimensions, is called corporate positioning strategy. Theoretically, corporate positioning can be defined as the positioning of the whole organization as one entity, rather than (or in addition to) positioning individual products, services, or brands. Corporate positioning strategy is not within the scope of this research. Product, service and generic positioning strategies are, therefore, discussed in detail next.

\subsubsection{Product Positioning Strategy}

The very first paper on positioning strategies, written in 1969 by Alpert and Gatty, proposed positioning by behavioural lifestyle. Using a brand rating index survey, it collected data from 5,424 male respondents on eighty variables. Factor analysis was used to identify 25 male consumer segments. They were divided into two categories of beer consumers - heavy and light. The authors stated that this approach to developing a profile of the users for "product positioning" was based on consumer purchasing patterns and product use.

Most of the studies in this stream, written in the 1980s, proposed and tested positioning strategies for various industries ranging from automobiles and steel to adhesive and personal hygiene. A number of these authors emphasized attribute-based positioning; for example, softening point, viscosity, color stability and start colour etc. for adhesive (Doyle and Saunders, 1985), handling, horsepower, acceleration, gas mileage, safety, driving comfort, passenger comfort etc. for automobiles (Johansson and Thorelli, 1985), 
fragrance, effective deodorant, dryness, anti-perspirant, texture etc, for personal hygiene (Ganesh and Oakenfull, 1999).

Johansson and Thorelli (1985) define product positioning primarily in the context of "product design" where the task of the firm is to develop product attributes and functional characteristics as well as packaging, brand name and styling, in such a manner that the benefits generated from those attributes match the requirements of the target segment. In the end, it is the buyer's perception of benefit-generating attributes, rather than the actual attributes, which matters to the consumer.

A conceptual paper entitled, "Positioning your Product" by Aaker and Shansby (1982) is one of the most quoted papers in the positioning literature. These authors were the first to propose generic strategies to product positioning. They proposed six approaches to the positioning strategy: 1) attribute, 2) price-quality, 3) use or application, 4) product-user, 5) product class, and 6) the competitor. They strongly argued in favour of using sophisticated analysis as a basis for developing positioning strategy.

Baier and Gaul (1999) differentiate between positioning options, which they state are (perceptual) product attributes (e.g., cheapness, printing quality, or speediness of a laser printer) and design options, which they call underlying (physical) product characteristics (e.g., price, line width or number of pages per minute).

\subsubsection{Service Positioning Strategy}

The first study in this stream was published 18 years after the initial study on product positioning came out in 1969 . The number of studies in this stream is relatively small. It 
has been argued in the literature that positioning strategies for services might be different from product due to varying characteristics.

Shostack (1987) states that processes are to services as raw materials are to products. If products can be redesigned with a change in raw materials, then services can be designed and re-designed as well by changing the processes. The author argues that process can be "engineered" to develop strategic service positioning. Service organizations can change the positioning of their services by changing the way the service is structured. He proposes four ways (strategies) to categorize the processes - high complexity, low complexity, high divergence, and low divergence. Skaggs and Youndt (2004) also highlight the importance of service process for positioning of services. However, they cite lack of research on how service processes should be designed for effective positioning.

Service processes can be also differentiated by three mechanisms: customer coproduction, customer contact, and service customization. The focus on each of these processes varies from firm to firm. They represent the strategic element due to the difficulty in changing them in the short run (Skaggs and Youndt, 2004).

The characteristics of services outlined by Timmila and Vepsalainen (1995) are frequency and timeliness of transactions, uncertainty, degree of customization, information complexity and types of resources used. Considering the complexity and contingency of services, the authors categorize the service mix into four types, from simple to complex - mass transactions, standard contracts, customized delivery, and contingent relationship. In order to cater to each type of service mix, the authors 
recommend four service processes - fast routine processes, flexible integrated processes, focused processes and adaptive processes.

Blankson (2004) conducted an empirical research to study positioning strategies employed by retail stores in the United Kingdom. Based on consumer perceptions, six strategies were implemented by the retailers - Top of the range, Service, Reliability, Attractiveness, Brand Name, Value for Money and Selectivity.

\subsubsection{Generic Positioning Strategy}

The studies which propose positioning strategies, not relevant to only one specific stream but applicable to both products and services, can be classified as "generic" positioning strategies. For example, Crawford (1985) conducted very extensive research to study the actual positioning practices of firms selling products and services in consumer and industrial markets. Based on the literature he cites five options that are commonly used by the companies: positioning to an attribute (features, benefits), to a product category, to a particular use, to a particular user and against a particular competitor.

Alden, Steenkamp, and Batra (1999) conducted extensive research in seven Asian and Western countries - India, Thailand, Korea, Germany, Netherlands, France and the United States - to investigate the brand positioning strategies in advertising. A total of 1,267 national-brand television advertisements were coded as "national", "foreign" and "global", based on predefined criteria. Based on correspondence analysis, the "“Global Consumer Culture" positioning in advertisements was validated. The five indicators used to identify consumer culture positioning were: pronunciation of brand name, symbols used and/or spelling of visually displayed brand name, symbols used for brand logo, 
central themes, and appearance of salesperson. One could question the validity of these measures or the use of additional measures. Nonetheless, this study made a significant contribution to the field of positioning.

The synthesis of the literature reveals that generic positioning strategies could be broadly categorized into two types.

Attributes/Features Based: Attribute is normally defined as a construct through which objects or individuals can be distinguished. It is also defined as "characteristics inherent in or ascribed to something." One of the most frequently used positioning strategies is associating an offering with consumer perceptions of attributes considered relevant and important to that product/industry. Often a multi-attribute positioning is used since the objective is to present the offering as a "bundle of attributes" (Henthorne and Williams, 1995). Several positioning studies explore the relationship between product attributes, consumer perceptions and choice (Kaul and Rao, 1995). However, there are others who propose using "attitude" rather than "attribute" for positioning (Javalgi, Boney, and Gombeski, 1995).

The first step in developing a positioning strategy is to identify a product or service's "intrinsic" attributes. The attributes are normally very large in number, and frequently, research is used to identify the most important, valued, and meaningful attributes from the customer's perspective. The attributes, however, must carry underlying benefits. "Feature", a prominent aspect of product/service, a "characteristic", is used interchangeably with "attribute". Tangible or intangible, evident or hidden, it may not be clearly translated into benefits from the consumer's perspective, but is implied. 
Benefits Based: Krieger and Green (2002) state that attributes are expressed or inferred in terms of benefits. They claim that selection of "attractively priced consumer benefits" is key to successful positioning. The benefits should be valued by consumers, distinctive in some way, believable, deliverable, and sustainable. Crawford (1985) defines benefit as "some way in which a user gains from the product". He goes on to say that benefits are "more vague" and "interpretative" and may not necessarily be related to product features. A number of positioning strategies are based on specific benefits, direct or indirect, a product/service offers to the consumers.

\subsubsection{Positioning Strategy Dimensions}

Two approaches can be used to identify positioning strategy dimensions. First, the positioning literature is extensively reviewed to develop taxonomy of positioning dimensions proposed by various authors. Second, major positioning typologies proposed in the literature are used as a yardstick to compare with the findings of the first approach.

\subsubsection{Taxonomy of Positioning Dimensions}

Taxonomy is called the classification of the objects according to the genesis of things. The literature for taxonomy was searched in three stages. The Business Source Complete online database was initially used to search studies relevant to the topic. Once the online resource was fully exhausted, the references of all the major studies were used to identify the studies that were not captured by the online search. For the purpose of this taxonomy, only those studies that were published in academic journals are considered. In the third stage, twenty journals, each with four or more studies in positioning, were searched individually, with their issues starting from inception, to ensure a comprehensive search. 
A total of 214 studies were deemed relevant to the topic. The studies were then scanned to identify those proposing product, service and generic positioning strategy dimensions. A total of 41 studies were found relevant to product, service and generic positioning. All the bibliographic information along with positioning strategy dimensions for each study was entered into Microsoft Access database. The data was thoroughly edited for errors and exported to Microsoft Excel for summations and cross-tabulations.

There were a number of studies that had conducted factor analysis of underlying dimensions to come up with factors (strategies). Some of the studies used multiple measures (underlying items) to capture the same factor. For example, one study (Ford and Honeycutt, 1991) used four different indicators to measure personnel quality. Also, some studies used product or service-specific attributes as positioning dimensions. Since different authors could possibly give different names to the same factors, it was decided to consider only underlying dimensions rather than factors for the purpose of analysis. As mentioned earlier, for the sake of clarity it was decided to use the term "dimension" for the strategies as well. It was also more appropriate to use dimensions since comparing factors and dimensions within the same analysis would have been tantamount to comparing apples and oranges.

In order to ensure fair representation of the positioning dimensions, repetitive positioning dimensions or multiple attributes within the same study (especially applicable to studies using factor analysis) were coded as redundant so that they would not be counted twice within the same study. However, similar or identical dimensions were reported by multiple studies. The next logical step, therefore, was the cross tabulation of dimensions 
by the studies within each stream. The unique dimensions per stream after crosstabulation, given below in Table 3, were: product (41), service (40), and generic (40).

Table 3: Positioning Strategy Dimensions - An Overview

\begin{tabular}{|l|l|l|l|l|l|}
\hline Stream & $\begin{array}{l}\text { Total } \\
\text { Dimensions }\end{array}$ & Redundant & $\begin{array}{l}\text { Dimensions } \\
\text { without } \\
\text { Redundant }\end{array}$ & $\begin{array}{l}\text { Unique to } \\
\text { Stream } \\
\text { (After cross-tab) }\end{array}$ & $\begin{array}{l}\text { Number } \\
\text { of } \\
\text { Studies }\end{array}$ \\
\hline Product & 161 & 71 & 90 & 41 & 21 \\
\hline Service & 57 & 5 & 52 & 40 & 11 \\
\hline Generic & 98 & 46 & 52 & 40 & 9 \\
\hline
\end{tabular}

A considerable number of dimensions within each stream were proposed only once or twice leaving a small number of dimensions, with higher counts, to overwhelmingly represent the stream. For example, in the product stream, only 8 dimensions out of a total of 41 dimensions accounted for $50 \%$ of dimensions within that stream.

For the sake of further analysis, a number of dimensions were systematically removed using the following criteria: Any dimension proposed only once was eliminated from further analysis. Any dimension proposed more than once but was mentioned by less than $10 \%$ of studies within that stream was also eliminated from further analysis. Using the above criteria, the top dimensions for each stream are given in Table 4.

Table 4: Positioning Strategy Dimensions - A Content Analysis

\begin{tabular}{|l|l|l|l|l|l|}
\hline No. & Dimension & $\begin{array}{l}\text { Overall } \\
\text { Total }\end{array}$ & $\begin{array}{l}\text { Product } \\
\text { Total }\end{array}$ & $\begin{array}{l}\text { Service } \\
\text { Total }\end{array}$ & $\begin{array}{l}\text { Generic } \\
\text { Total }\end{array}$ \\
\hline 1 & Value/Price & 17 & 12 & 3 & 2 \\
\hline 2 & Attribute & 15 & 13 & 2 & \\
\hline 3 & Reliability & 12 & 7 & 3 & 2 \\
\hline 4 & Quality/Top of the range & 12 & 9 & & 3 \\
\hline 5 & Service & 9 & 3 & 4 & 2 \\
\hline 6 & Attractive & 7 & 3 & & 4 \\
\hline 7 & Range-Product & 3 & 3 & & \\
\hline 8 & Reputation & 3 & 3 & & \\
\hline
\end{tabular}




\begin{tabular}{|l|l|l|l|l|l|}
\hline 9 & Availability & 2 & 2 & & \\
\hline 10 & Benefit & 2 & 2 & & \\
\hline 11 & Country & 2 & & & 2 \\
\hline 12 & Customization & 2 & & 2 & \\
\hline 13 & Differentiation & 2 & 2 & & \\
\hline 14 & Experience & 2 & & & 2 \\
\hline 15 & Features & 2 & 2 & & \\
\hline 16 & Modern & 2 & & 2 & \\
\hline 17 & Performance & 2 & 2 & & \\
\hline 18 & Segment & 2 & & & 2 \\
\hline 19 & Social Class & 2 & & & 2 \\
\hline 20 & Technology & 2 & 2 & & \\
\hline 21 & Traditional & 2 & & 2 & \\
\hline 22 & User Type & 2 & & 2 & \\
\hline
\end{tabular}

Note: The total, given in descending order, represents the number of times each dimension has been proposed by a study.

One of the questions posed earlier was: how different are positioning strategies (or dimensions in this case) for products and services? From Table 4, one can see that the top four service positioning dimensions - service, reliability, and value - are among the top five dimensions of product positioning, though their ranking (i.e., the order of importance) is not the same. For tangibles (products), the physical "attribute" dimension, which can be judged relatively easily by the customer, is ranked number two after value. For intangibles (services), "service" is the top ranking dimension and it is not amongst the top four product dimensions. The other two dimensions - reliability and value - seem to be equally important to both products and services. However, there are four dimensions of services - customization, modern, traditional and user type - which do not fare in the product stream. By the same token, a number of dimensions - quality/top of the range, attractive, product range, reputation, availability, benefit, differentiation, features, performance, and technology - are only product specific. It can be stated that focus on different dimensions by product and service stream could justify the argument, 
discussed earlier, that products and services have different characteristics and would need different positioning strategies.

There are some marked differences between product and service positioning dimensions. The tangible aspect of products is evident through higher focus on "attribute" and "quality", though "value" and "reliability" dimensions are considered important in both products and services. Since it is easier to determine quality in products than in services, price differentiation is an important positioning dimension for products. Despite the importance of "service" in products, it does not emerge as one of the major dimensions for the product stream. The "quality" is almost non-existent from services (mentioned only once; not shown in the Table). This would make sense to authors who argue for different positioning strategies for services. It could be claimed that specific characteristics of services make it difficult to judge their quality. "Service" aspect, obviously, is the most important dimension of the services stream. However, one must exercise caution in arriving at any firm conclusions due to the relatively smaller number of studies and consequently fewer dimensions within the service stream.

Generic strategies share some dimensions with products and service streams. However a number of dimensions are, surprisingly, unique to this stream, though the dimensions of this stream should have been applicable to all others streams as well. Three dimensions service, value and reliability - seem to be common to product, services and generic streams. However, the two leading dimensions of the generic stream - attractive and quality/top of the range, are only used by product to some extent and are completely missing from the services stream. Also, a number of dimensions - country, segment and social class - are not mentioned by any other stream. Tracing the origins of these 
dimensions back to the studies and authors (Table not shown here) reveals that almost half of them are conceptual studies proposing generic strategies with obviously no underlying empirical basis.

\subsubsection{Typology of Positioning Strategies}

As mentioned earlier typology is a classification scheme, the process of setting up and selecting categories to organize and analyze data. Blankson and Kalafatis (2004) define positioning typology as "the theoretical foundation underpinning a grouping of factors that reflect or describe positioning strategies." A firm can employ a single strategy or collection of strategies which are mutually inclusive rather than being the indicators of different types of positions. So a set of strategies proposed by a researcher would be called a typology.

There are two typologies which are considered seminal - Aaker and Shansby (1982) and Crawford (1985). Both of these typologies have been referred by numerous articles. The two recent typologies - Blankson and Kalafatis (2004) and Hooley and Greenley (2005) have been proposed by teams of authors who have authored the highest and second highest number of studies in the area of positioning, 11 and 6 studies respectively, in an otherwise highly fragmented area of research. The topologies proposed by these two teams of authors have thus taken advantage of cumulative tradition. The typologies proposed by the four studies are given below in Table 5: 
Table 5: Positioning Typologies - A Literature Review

\begin{tabular}{|l|l|l|l|}
\hline $\begin{array}{l}\text { Aaker and Shansby } \\
(\mathbf{1 9 8 2})\end{array}$ & $\begin{array}{l}\text { Crawford } \\
\mathbf{( 1 9 8 5 )}\end{array}$ & $\begin{array}{l}\text { Blankson and } \\
\text { Kalafatis (2004) }\end{array}$ & $\begin{array}{l}\text { Hooley and } \\
\text { Greenley (2005) }\end{array}$ \\
\hline Attribute & Features & Top of the range & Price \\
\hline Price/Quality & Benefits & Service & Quality \\
\hline Use or Application & Surrogates & Value for money & Service \\
\hline Product/Service User & & Reliability & Innovation \\
\hline Produce/Service Use & & Country & Customization \\
\hline Competition & & Brand name & \\
\hline
\end{tabular}

Note: Aaker and Shansby (1982) and Hooley and Greenley (2005) topologies are conceptual

The first positioning typology, in a conceptual piece, was proposed by Aaker and Shansby (1982) in one of the most frequently referenced paper on positioning titled "Positioning your Product". The positioning strategies proposed by the authors are very generic and border on the domain of segmentation in some cases such as positioning by user, use and application.

Based on the content analysis of 350 brands, Crawford (1985) found three major categories - features, benefits, and surrogates. He found that $32 \%$ products were positioned on benefits, $19 \%$ on features and $23 \%$ on surrogates. He concluded that $26 \%$ products were not positioned at all. The surrogate category was described as the situation where the ad, instead of describing the feature/benefits, says something about the product and lets the consumers reach their own individual conclusions.

The positioning typology proposed by Blankson and Kalafatis (2004) is by far the most rigorous in terms of methodological procedures followed to develop the typology. An initial set of statements for products and services, in terms of their features, benefits, and attributes, was compiled from the focus groups of the consumers. A set of 140 statements 
was generated from six groups with a total of 36 individuals. After getting feedback from scale development experts from academia and industry, the initial inventory was reduced to 54 statements. In the next step, 109 mature individuals of 25 years and above completed a postal survey, comprised of 54 statements. The factor analysis resulted in satisfactory loading of 0.5 and above for 42 statements. A positioning typology of eight positioning strategies emerged from this analysis. Another round of surveys, with 357 completed questionnaires, was carried out to test and validate the initial positioning constructs. The proposed typology of positioning strategies based on eight factors is: top of the range, service, value for money, reliability, attractiveness, country-of-origin, the brand name, and selectivity. Three to five items supported each factor/strategy.

The positioning typology proposed and empirically tested by Hooley and Greenley (2005) was initially proposed by Hooley, Broderick, and Möller (1998) and is primarily conceptual in nature. However, in their well-known book on competitive positioning (Hooley, Saunders, and Piercy 2004) they elaborate that these generic positioning strategies are based on cost leadership and differentiation, the two main strategies for creating competitive advantage originally proposed by Porter (1980).

\subsubsection{Developing Positioning Strategy}

In order to develop a profound understanding of the concept of positioning, it is important to ascertain what steps or approaches are actually followed by the companies to develop positioning strategies. The positioning literature was thoroughly scanned and a total of 11 studies with positioning development processes were found in the literature. They were published over a period of 22 years, from 1982 to 2004 . The number of steps 
followed to develop, and in some cases implement, positioning strategy range from a minimum of three to a maximum of ten. No less than eight of those processes were conceptual so steps proposed by them have not been validated empirically. Three empirical studies, hardly sufficient to draw any significant conclusions, are discussed below:

Doyle and Saunders (1985) propose a seven step procedure called, "A Market Segmentation and Product Positioning Model" for industrial markets. The seven steps are: define objectives, determine market segments, evaluate segments, select target market, develop a positioning strategy, develop the marketing mix, and validate the strategy. The authors provide an application of the model by collecting customer and competitor data for a particular company. All seven steps were carried out, using cluster and factor analysis, to demonstrate how a company will implement this process.

Mühlbacher, Dreher, and Gabriel-Ritter (1994) also propose a model of positioning process for industrial markets called MIPS: Model for managing industrial positioning strategy. Their proposed process resembles that of Doyle and Saunders (1985) discussed earlier but adds a few useful steps. They emphasize determining the "key success factors and their importance for each segment". Key success factors could be the attributes/dimensions a buyer considers important while making a purchase. This essential element, focusing on identifying customers' wants, is not deliberated by Doyle and Saunders (1985). An important aspect of internal analysis, to clearly identify differential advantage, considered by Mühlbacher, Dreher, and Gabriel-Ritter (1994), has not been mentioned by Doyle and Saunders (1985). A case study with a small number of respondents was then conducted to demonstrate the application of the model. 
Vardis and Vasa-Sideris (2000) also conducted a case study where consumer inputs were used to develop a positioning strategy for a bank. A tracking study was then carried out to check the advertising recall of the promotion campaign based on that positioning. The advertising agency formed a group of 12 people from the company and advertising agency who worked together to develop positioning statements which were further refined by the agency and turned into creative advertising concepts to be tested by customers through focus groups.

All the studies in the literature proposing positioning development steps are listed in Appendix 2. A careful review of the Appendix 2 reveals that there are at least six steps, which have been proposed by at least four studies. Those steps are as follows:

1. Select a Segment/Targeting

2. Determine competitors' positions

3. Analyze/Understand Customers

4. Select/Develop positioning strategy

5. Develop a Marketing Mix

6. Monitor/validate position

Some of the steps given above could overlap and are open to different interpretations as well. For example, determining competitors' positions could involve first identifying and then analyzing the competitors, given as a separate step by some researchers. The above six steps, nonetheless, capture the essence of positioning development process. 


\subsection{Summary}

The objective of this chapter was to give the reader a thorough understanding of the concept of positioning. The broad overview of a number of positioning definitions gives one a snapshot of how the definition, and consequently the concept of positioning, have evolved and expanded over time. There is sufficient evidence in the literature to claim that positioning is primarily a strategic issue, though in the past some scholars confined it to a promotional strategy. Segmentation and targeting are the prerequisites for positioning since there can be no positioning unless a specific set of customers is identified first. Positioning is primarily based on the differential advantage of the firm which comes from sustainable competitive advantages.

The terms "dimension" and "positioning strategy" are used interchangeably in the literature causing lot of confusion at time. Positioning strategy for this study is defined as "the choice of target segments and the selection of differential advantage (s) used by firm to compete in the market." The term "dimension", in this study, is used to mean tangible or intangible characteristics that differentiate one offering from another or provide the differential advantage.

Taxonomy of positioning strategy dimensions was developed from the literature using content analysis approach. The four major typologies of positioning strategies proposed in the literature were also discussed. The positioning development process comprising of various steps taken by companies to arrive at the positioning decision was synthesized from the literature. 


\section{Chapter 4: Aligning Positioning and Manufacturing Strategies}

This chapter commences with a brief overview of marketing and manufacturing strategies in order to highlight the differences between the two, and presents literature, primarily conceptual, on the integration of marketing and manufacturing strategies. A conceptual framework proposed in the literature which links positioning strategy to manufacturing strategy is also discussed.

\subsection{Marketing Strategy}

"Marketing strategy" has been synonymously used with "strategic marketing" in the literature (Hooley, Beracs, and Kolos, 1993). Varadarajan and Clark (1994) define it as "configuration and allocation of resources across the marketing mix variables in a particular product market." It is based on analysis of consumers, competitors and other environmental forces. Other strategic inputs - financial, Research and Development (R\&D), and human resources etc. - are combined to develop an integrated business strategy. Since the marketing philosophy envisages marketing to act as a guiding force for the entire organization, marketing strategy should be an integral component of business strategy (Wind and Robertson, 1983).

In terms of hierarchy, marketing strategy is a part of business-level strategy, which in turn is driven from corporate strategy (Greenley, 1984). Morgan, McGuinness and Thorpe (2000) agree that a corporate, business, and functional strategy hierarchy is a useful way of looking at three main levels of management. 
Figure 5, given below, provides a graphical depiction of the relationship amongst various types of strategies.

\section{Figure 5: The Strategy Hierarchy}

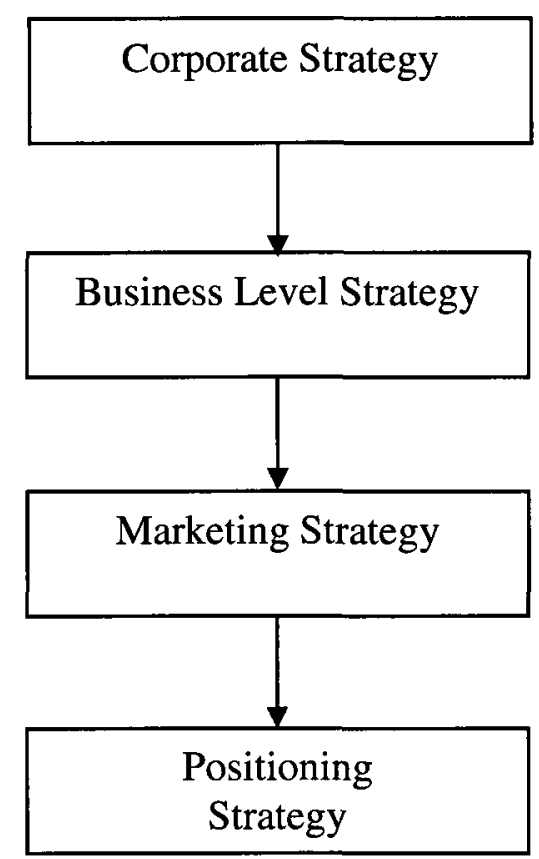

\subsection{Manufacturing Strategy}

Manufacturing strategy refers to the competencies that a firm develops around its operations to achieve competitive advantage. In line with Skinner's initial arguments, Thun (2008) stresses that "manufacturing strategy must be regarded as a derivative of business strategy decomposing market requirements on the manufacturing level" ( $p$ 372). Attempts have been made in the literature to link Porter's generic competitive strategies to manufacturing strategies. For example, Kotha and Orne (1989) propose a framework of generic manufacturing strategies based on the works of Porter $(1980,1985)$ and Hayes and Wheelwright (1985). 
In one of the first studies to provide insights into the interplay between manufacturing strategy and business strategy, Anderson and Schroeder (1991) empirically analyze the process of manufacturing strategy. Similarly, Bates et al. (1995) investigate the relationship between manufacturing strategy and organizational culture and emphasize the link between manufacturing strategy and business strategy.

It has been asserted in the literature that manufacturing and business strategies should be linked (Corbett and Van Wassengove, 1993; Garvin 1993; Schendel and Hofer, 1979). Kim and Arnold (1996) graphically depict the linkage of manufacturing strategy with business strategy and its subsequent impact on business performance, given below in Figure 6:

Figure 6: Linking Business Strategy to Manufacturing Strategy

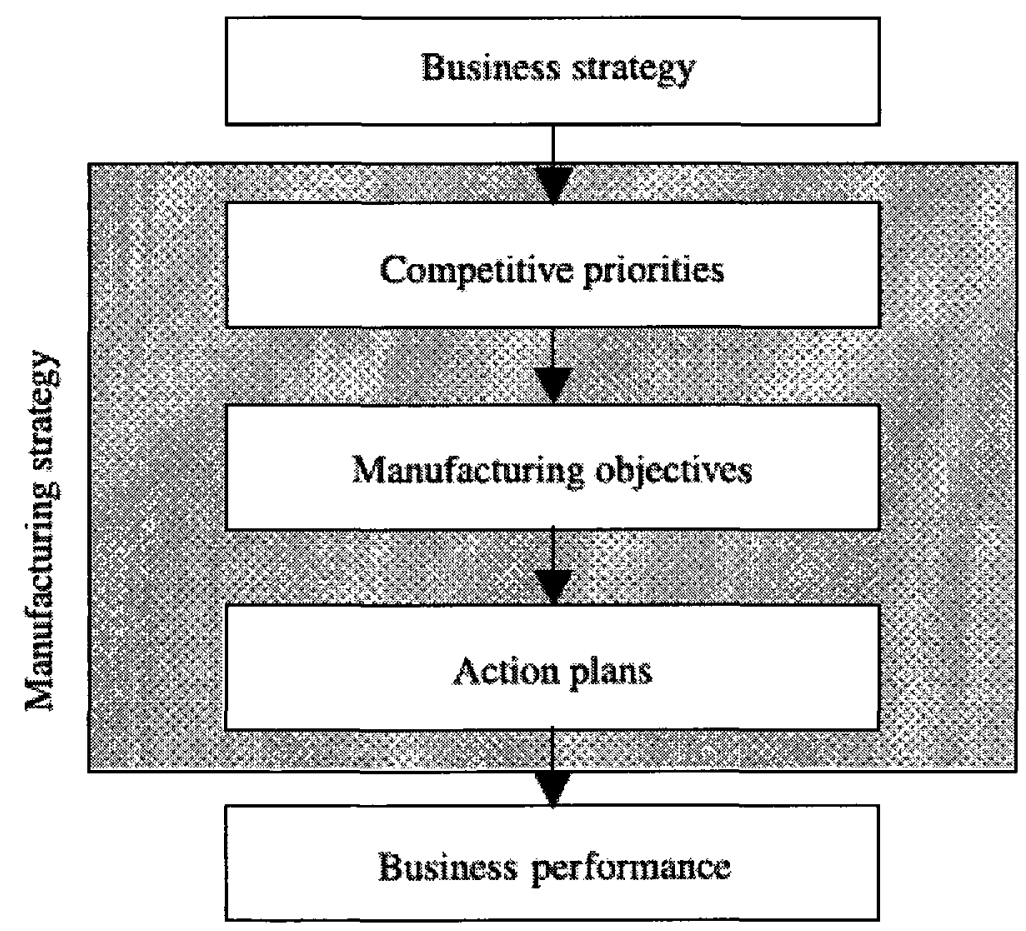

Source: Kim and Arnold (1996) 


\subsection{Aligning Manufacturing Strategy with Marketing Strategy}

The alignment of manufacturing strategy with other functional strategies, specifically marketing, has received special attention, since marketing strategy is explicitly formed after conducting customer and competitor analysis, while manufacturing strategy implicitly considers customers and competitor's perspective. Manufacturing strategy is connected to business strategy through market requirements (Hill, 1985). Market requirement or identification of customer's needs and wants is the foundation of marketing strategy. Thus, manufacturing and marketing strategies are inadvertently linked through their focus on understanding market requirements.

A number of studies have emphasized the alignment of manufacturing resources and capabilities with the requirements of the market in the manufacturing strategy development process. It relates to the internal marketing and corporate assets and external customer and competitor positions. Various methods have been proposed in the literature to achieve harmony between manufacturing and marketing strategies (e.g. Berry et al., 1999; Hill, 2000; Joseph, 1999; Mills et al., 2002; Platts and Gregory, 1990; Ray, 2005).

Platts and Gregory (1990) propose a conceptual model for manufacturing strategy development and propose that manufacturing objectives should be based on market audit - to determine customers' needs and wants, market size and potential - and competitor audit, to assess competitors' performance against the same criteria. Pun (2005) empirically tested the model which prescribes that manufacturing strategy is directly 
influenced by corporate strengths, marketing strengths, technology strengths, and operations strengths.

The consistency in operations and marketing strategies also leads to positive effects on the performance (Deane et al., 1991; Swamidass and Newell, 1987). However, to date, a concrete relationship between the dimensions of manufacturing strategy and marketing strategy has yet to emerge. Malhotra and Sharma (2002) propose a model of marketing and manufacturing operations integration in Figure 7:

Figure 7: Marketing operations integration framework within a firm

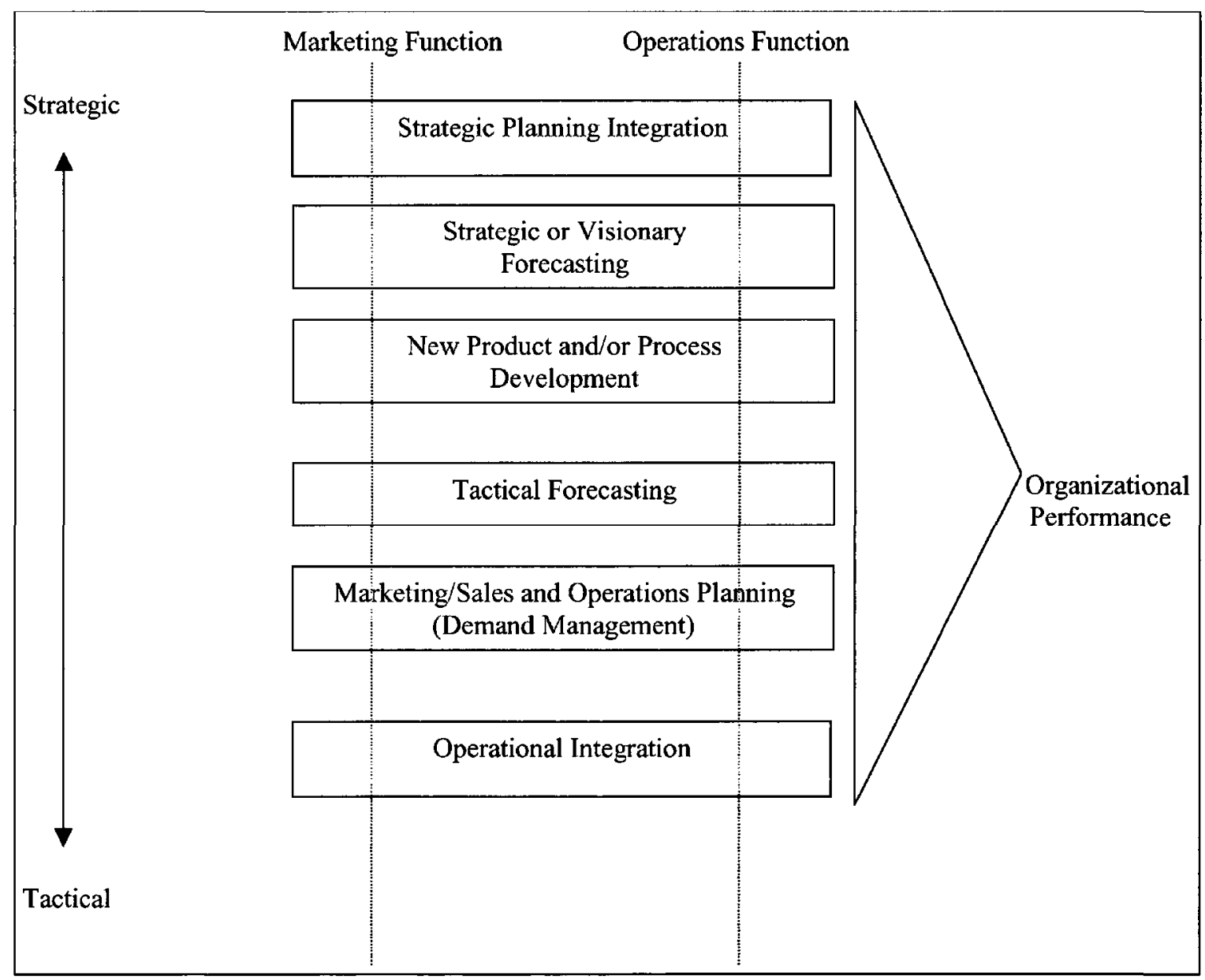

Source: Malhotra and Sharma (2002) 
The above framework shows that opportunities for marketing-manufacturing integration exist in key decision-making areas within a firm. The integration can be made both at the tactical and strategic levels.

Kelly and Flores (2002) also reiterate the integration of manufacturing and marketing/sales areas in various functions such as product development, process development, marketing/sales planning, and manufacturing planning decisions. They contend that integration of manufacturing and marketing decisions with strategic alignment of the firm's business strategy and external environment has not received much attention in the literature. They summarize below the key functional decision areas between marketing and manufacturing:

Table 6: Key decision areas of Manufacturing and Marketing

\begin{tabular}{|l|c|c|}
\hline \multirow{2}{*}{ Decision area } & \multicolumn{2}{|c|}{ Functional domain } \\
\cline { 2 - 4 } $\begin{array}{l}\text { Process and product } \\
\text { development }\end{array}$ & $\begin{array}{l}\text { Manufacturing } \\
\text { - } \begin{array}{l}\text { Determining changes } \\
\text { to existing production } \\
\text { process capabilities }\end{array}\end{array}$ & $\begin{array}{l}\text { Marketing/sales } \\
\text { product design } \\
\text { specifications }\end{array}$ \\
\hline $\begin{array}{l}\text { Development of new } \\
\text { production processes } \\
\text { capabilities }\end{array}$ & $\begin{array}{l}\text { Developing new product } \\
\text { design specifications }\end{array}$ \\
$\begin{array}{l}\text { Manufacturing and } \\
\text { planning }\end{array}$ & $\begin{array}{l}\text { Determining long-term } \\
\text { capacity requirements } \\
\text { (resource planning) }\end{array}$ & $\begin{array}{l}\text { Developing long-range } \\
\text { demand forecast }\end{array}$ \\
\hline $\begin{array}{l}\text { Developing long-term } \\
\text { production plans } \\
\text { (production planning) }\end{array}$ & $\begin{array}{l}\text { Developing sales plans } \\
\text { prodermining the timing of }\end{array}$ \\
\hline
\end{tabular}

Source: Kelly and Flores (2002) 
Kelly and Flores (2002) present an overview of research conducted on the integration of manufacturing and marketing strategies.

Table 7: Manufacturing and Marketing Integration Research

\begin{tabular}{|c|c|c|c|}
\hline \multirow[b]{2}{*}{ Decision areas } & \multicolumn{3}{|c|}{ Type of research } \\
\hline & Conceptual & Analytical & Empirical \\
\hline $\begin{array}{l}\text { Process and } \\
\text { product } \\
\text { development }\end{array}$ & $\begin{array}{ll}\text { - } & \text { Blois (1980) } \\
\text { - } & \text { Fizsimmons } \text { et al. } \\
\text { (1991) } \\
\text { - } \text { Hayes and } \\
\text { Wheelwright (1979) } \\
\text { - Hill (1988) } \\
\text { - Konijnendijk (1994) } \\
\text { - Nemetz and Fry } \\
\text { (1988) } \\
\text { - Shapiro (1977) } \\
\text { - Stalk and Hout (1990) } \\
\text { - Utterback and } \\
\text { Abernathy (1975) } \\
\text { Whelwright and Clark } \\
\text { (1992) } \\
\text { Wheelwright and } \\
\text { Hayes (1985) }\end{array}$ & - $\underset{\text { (1992) }}{\text { Kim et al. }}$ & $\cdot$ \\
\hline $\begin{array}{l}\text { Manufacturing } \\
\& \\
\text { marketing/sales } \\
\text { planning }\end{array}$ & $\begin{array}{ll}\text { - } & \text { Spencer and Cox } \\
& (1994) \\
\text { - } & \text { Konijnendijk (1994) } \\
\text { - } & \text { Palmatier and Shull } \\
& (1989) \\
\text { - } & \text { Powers et al. (1989) } \\
\text { - } & \text { Shapiro (1977) } \\
\text { - Shapiro et al. (1992) } \\
\text { - } \quad \text { Vollmann et al. (1997) }\end{array}$ & $\begin{array}{l}\text { Crittenden } \\
\text { (1992) } \\
\text { - Damon and } \\
\text { Schramm } \\
(1972) \\
\text { - Leitch (1974) }\end{array}$ & $\begin{array}{l}\text { Van Dierdonck } \\
\text { and Miller } \\
(1980)\end{array}$ \\
\hline
\end{tabular}

Source: Kelly and Flores (2002) 
It is evident from the above Table that manufacturing-marketing integration research has been limited to conceptual pieces and no significant attempt has been made to empirically test the underlying assumptions of conceptual propositions.

\subsection{Aligning Manufacturing Strategy with Positioning Strategy}

Marketing strategy is a relatively broad concept which deals with allocating marketing resources across marketing mix variables - product, price, promotion and place. Within marketing strategy, positioning is the concept and activity which is focused on understanding the requirements of a particular target segment and coordinating all the other aspects of marketing mix - product, price, promotion and place, in such a way that enables a product or service to occupy a preferred and unique niche in a customer's mind vis-à-vis that of competitors. Thus, positioning is focused on understanding needs of the market and a manufacturing strategy based on understanding market requirements ought to be aligned with it.

Berry, Hill, and Klompmaker (1999) were the first to recognize that there is a linkage between manufacturing strategy and positioning strategy. They state that positioning decisions made by the marketing people do not take into consideration what role manufacturing will play in supporting the positioning strategy of the firm. By the same token, manufacturing decisions do not reflect an insightful understanding of customer requirements and specifically what dimensions will be used by the marketing to position the product. They claim that the lack of connection between marketing and manufacturing functions leads to underachievement of strategic objectives. The authors call this disconnect "lack of alignment". They propose a conceptual framework, given in 
Figure 8 , for linking manufacturing and positioning strategies and elaborate upon it with an example of a company.

Figure 8: Co-alignment of Manufacturing and Positioning Strategies

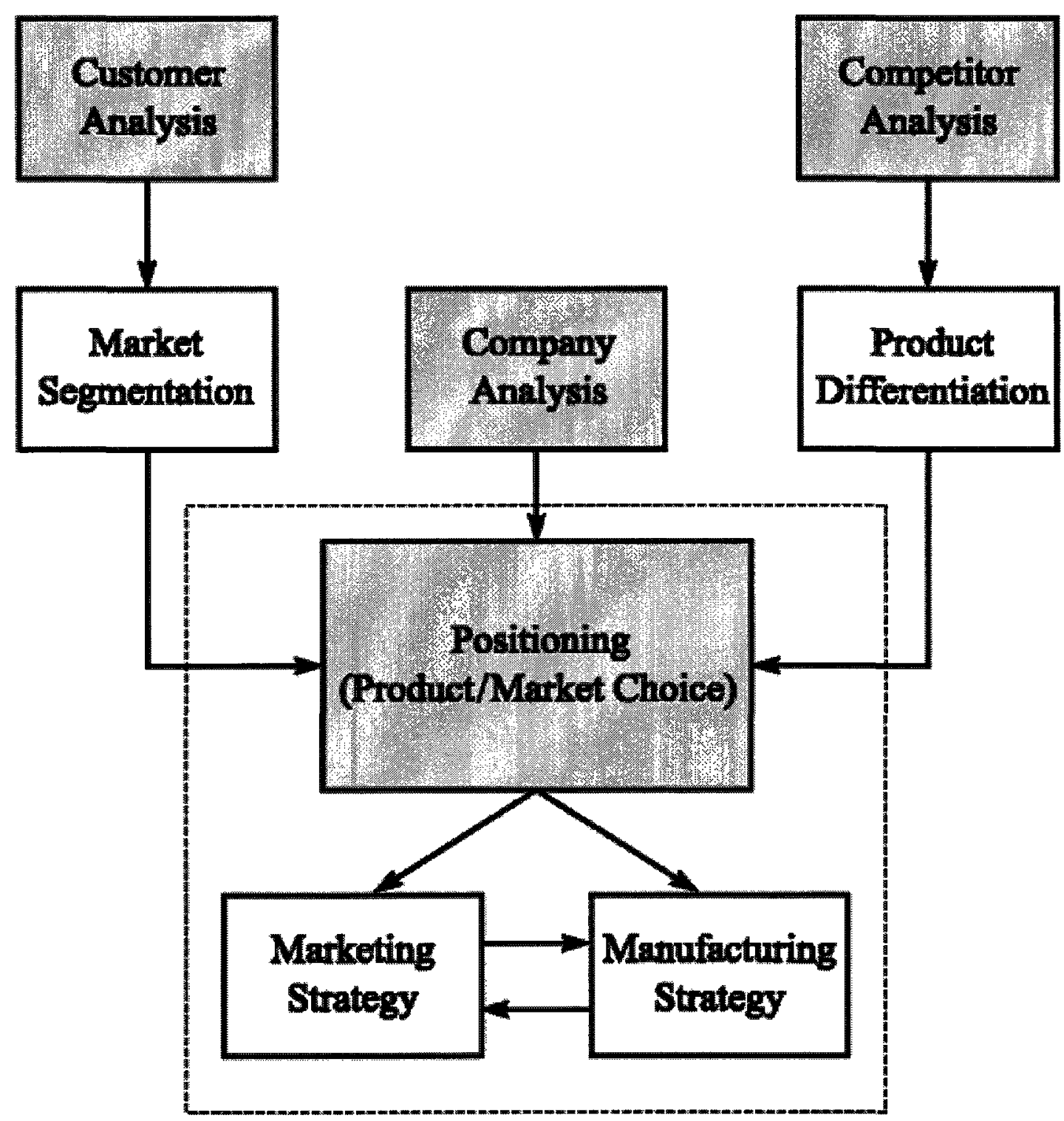

Source: Berry, Hill, and Klompmaker (1999) 
Nonetheless, the co-alignment of positioning and manufacturing strategies has not been discussed conceptually and/or validated empirically in the literature since publication of the above study ten years ago.

\subsection{Summary}

The co-alignment of manufacturing and marketing strategy has been deliberated considerably in the literature since both of them are considered to be business level strategies which are driven from corporate strategy. Also, both manufacturing and marketing strategies are theoretically developed after understanding market (customer) requirements. However, most of the work in this domain is conceptual.

Positioning strategy, a subset of marketing strategy, is focused on understanding the needs of a particular segment of the market and then coordinating all other activities of the marketing mix in such a way that a customer clearly comprehends the differential advantage a product offers relative to the competitors. Manufacturing and positioning strategies ought to be aligned since the product developed by the manufacturing facility is the one positioned by the marketing department. However, with the exception of one conceptual study, the literature is devoid of research on this topic. 


\section{Chapter 5: Theoretical Background}

This chapter provides an overview of the theoretical underpinnings as to how positioning and manufacturing strategies are developed. Resource-based and market-based views are two underlying perspectives used for developing both manufacturing and positioning strategies.

\subsection{Determinants of Positioning and Manufacturing Strategies}

The underlying theory which supports the development of manufacturing strategy is the resource-based view (RBV) though market orientation has also been purported to influence manufacturing strategy. Positioning strategy, on the other hand, is primarily developed on the premise of market orientation though $\mathrm{RBV}$ is also used as a viable rationale. A brief discussion of both the perspectives is presented next.

\section{$\underline{5.1 .1 \quad \text { Resource-based View }}$}

Resource Based View (RBV) advocates using the company's internal resources, competencies, and capabilities as essential determinants of strategy. This paradigm argues that differences in the firm's performance can be traced back to heterogeneous assets and capabilities owned by the company.

RBV assumes that each firm has unique resources and capabilities (Wernerfelt, 1984) and the growth of the firm is subject to the efficient use of the resources and deployment of capabilities. The RBV states that the firm's resources and capabilities determine its competitive advantage and firms that enjoy superior capabilities relative to their 
competitors have significant advantage over competitors (Peteraf, 1993; Russo and Fouts, 1997; Schendel, 1994).

Resources are productive assets that are owned by the firm, whereas "capability" is the ability of the firm to efficiently exploit these resources, to manufacture products or develop services to achieve business objectives (Amit and Shoemaker, 1993). Grant (1991) categorized resources into tangible, intangible and human resources. The tangible resources are financial capital, equipment, and manufacturing plant etc., while the intangible resources are the firm's reputation, brand image and the perceived quality of its products. The intellectual capital or human resources are the skills and knowledge of its employees, and other knowledge-oriented assets (Juga, 1999).

The capabilities are normally tacit, inimitable and non-transferable, and are firm-specific. They are developed over a period of time through the interplay of the firm's resources (Amit and Shoemaker, 1993). Day (1994) has defined capability as "complex bundles of skills and accumulated knowledge, exercised through organizational processes that enable firms to coordinate activities and make use of their assets." Amit and Schoemaker (1993) consider capabilities as the ability of the firm to employ resources in productive activity to achieve certain objectives. Some researchers suggest that a firm's strategy should be based on its capabilities and should not be dependent upon external environment since there is an incessant change in technology, customer needs and preferences (Chien, 2005). A firm will put together different resources to produce capabilities specific to that firm and potentially difficult to imitate (Amit and Shoemaker, 1993). 
The resource-based view of manufacturing strategy is manifested by Hayes and Wheelwright (1984) who state that manufacturing strategy leads to the creation of a set of specific capabilities. Bates et al. (2001) emphasize the role of resources in building manufacturing capability which, aligned with business strategy, serve as a source of competitive advantage. Cagilano et al. (2005) discriminate between four different types of manufacturing strategies: market-based, product-based, capability-based, and pricebased. They conclude that capability or resource-based manufacturing strategy is the "rising star", while market-based manufacturing strategy is lagging. Schroeder et al. (2002) empirically investigate the influence of resource-based view on manufacturing strategy. They posit that competitive advantage in manufacturing is achieved through proprietary processes and equipment, which are driven by external and internal learning.

Within strategic management literature, positioning represents the "classical view of strategy formulation", and is well documented in the literature. Strategic management literature gives a useful account of how positions are created to begin with. Positioning primarily rests on identifying differential advantage which culminates from competitive advantage of the firm created by the RBV of the firm. It suggests that a strategy needs to be based on the firm's resources and capabilities if it is to generate any long-term sustainable competitive advantage. In fact, changes in the external environment can only be responded to by adhering to the long term strategy of relying on internal resources (Hooley, Broderick, and Möller, 1998). It follows, therefore, that the positioning strategy of the firm should be based on internal strengths and weaknesses rather that external market factors. 


\section{$\underline{\text { 5.1.2 } \quad \text { Market-based View }}$}

Manufacturing strategy based on market-orientation focuses on external factors. Performance and competitive behaviour are determined by market structure. The external environment, comprising of economic, technological, political, environmental and social issues, is relevant but the real emphasis is on the industry. A company's success is strongly influenced by the competitive forces, measured by Porter's (1980) five forces model. According to this perspective, business environment should be monitored frequently and customers' needs and preferences should be taken into consideration to develop dynamic capabilities (López, 2005).

The market-based positioning strategy represents an outside-in perspective. The leading proponents of the market-based view are Miles and Snow (1978) and Porter (1985). Miles and Snow (1978) propose four competitive strategies - Defenders, Prospectors, Analyzer, and Reactors. The choice of an appropriate strategy depends on the underlying environmental factors. The Prospector strategy is recommended to be more suitable for unstable, rapidly changing environments caused by new technology and/or changing customer preferences. The Defender strategy is considered to be more appropriate for firms operating in mature and stable industries. The Analyzer strategy is deemed more suitable for emerging industries, whereas the Reactor does not correspond to a welldefined set of external circumstances (Oosthuizen, 2002). Porter (1985) proposed the two generic strategies, Low Cost and Differentiation, as a way to achieve competitive advantage. The strategy type propositions, postulated by Miles and Snow (1978) and Porter (1980) propose that management decisions about strategy are guided by the 
industry context, with considerable freedom of movement in charting the course of the firm.

Sustainable competitive advantage, it is argued, ought not to be based solely on the firm's assets and capabilities as advocated by the RBV of the firm which assumes that resources and capabilities are created through company history and are the results of learning processes and longer-term accumulation of assets which can not be changed in the short run (Hooley, Broderick, and Möller, 1998). A competitive advantage could only be sustained as long as customers consider it as an advantage. Any changes in customers' perceptions due to changing tastes and preferences or competitive moves could nullify an existing advantage.

\subsubsection{Integration of Resource Based and Market Based Views}

Though the recent literature suggests that the resource-based view is more likely to prevail for the development of manufacturing strategy, the issue of integration of resource and market-based views has also been deliberated, especially within the context of alignment of manufacturing and marketing strategies. Since marketing strategy subscribes to the fundamental tenets of market-based views, the alignment leads to the convergence of market and resource-based views. As manufacturing strategy is based on the premise of creating alignment between market opportunities and manufacturing capabilities (Hallgren and Olhager, 2006), a number of studies have emphasized the alignment of manufacturing resources and capabilities with the requirements of the market in the manufacturing strategy development process. In line with Skinner's initial arguments, Thun (2008) stresses that "manufacturing strategy must be regarded as a 
derivative of business strategy decomposing market requirements on the manufacturing level" (p. 372).

Pun (2005) empirically tested the model which prescribes that manufacturing strategy is directly influenced by corporate strengths, marketing strengths, technology strengths, and operations strengths. Slack and Lewis (2002) also emphasize the integration of resource and market-based views.

Thun (2008) posits the question of whether a manufacturing strategy should be based either on resource or market orientation or whether it could simultaneously incorporate both perspectives in a single manufacturing strategy. He calls such an approach "integrated manufacturing strategy".

While positioning strategy is primarily based on the market-based view - analysis of customers, competitors and external environment - the role of resources in providing sustainable competitive advantage to create and defend positions can not be ignored in the development of positioning strategies. Therefore, integration of resource-based and market-based perspectives is also alluded to in positioning literature.

While the market-based view is useful in describing industry-level competitive interactions of firms, its relevance and application to competitive positioning analysis at the firm level is inadequate. It does not address what characteristics a firm needs to achieve or defend a market position. The market-oriented strategy development approach does not take into consideration the firm's internal strengths and weaknesses (Teece et al., 1997). This is a significant weakness, since it has been argued that the success of a firm is influenced more by the firm's assets than the industry characteristics in which the firm 
operates. The RBV, however, explains firm-level competitive phenomena and has been acclaimed as a significant strategy paradigm (Morgan, Strong, and McGuinness, 2003).

Hooley, Broderick and Moller (1998) acknowledge that, conceptually, these two views fall on the opposite spectrum of a continuum, with market orientation emphasizing the need to consider external factors and the resource-based view stressing the need to focus on internal, organizational resources and assets. Positioning decisions, they argue, require alignment between external market requirements and internal capabilities and resources. Juga (1999) also recommends aligning positional advantages and process-based elements of the strategy to extract maximum competitive superiority.

By integrating the resource-based view (internally focused) with market positioning (externally focused), the firm's positioning strategy is linked with its resources and capabilities (Morgan, Strong, and McGuinness, 2003). This effectively fills the missing holes in positioning literature which advocates building a positioning strategy on longterm sustainable competitive advantage but does not elaborate on how competitive advantage would be sustained.

It is, therefore, concluded that competitive positions are created by matching the needs of the target customers with sustainable competitive advantages, achieved through a firm's resources and capabilities. The sustainability of such positions will depend on how effectively a firm guards and upgrades those resources before the competition catches up (Hooley et al., 2001). The manufacturing strategy, thus, plays an important role. 


\subsection{Summary}

The objective of this chapter was to give the reader a thorough understanding of the theoretical underpinnings of manufacturing and positioning strategies. Resource-based and market-based views have been proposed to explain how these strategies are developed. Manufacturing strategy literature consider the resource-based view to be the defining paradigm for manufacturing strategy development while positioning strategy is primarily developed based on market-views.

However, none of the perspectives independently provides sufficient rationale for the development of manufacturing and positioning strategies. It is, therefore, proposed that the integration of these approaches provides a better explanation of how these strategies are developed. 


\section{Chapter 6: Conceptual Framework}

This chapter presents the conceptual framework and hypotheses based on the study's objective and research questions. There is a detailed description of study variables. These variables primarily arise from the synthesis of literature on manufacturing strategy and positioning strategy underpinned by resource based and market-based views of the firm.

\subsection{Research Objective}

The objective of this research is to examine how manufacturing firms based in Canada develop and deploy positioning and manufacturing strategies. The research also examines the impact of each strategy and their co-alignment on firm's performance. The research endeavors to answer the following questions:

A) What factors are taken into consideration by the firms while choosing positioning strategy dimension/s?

B) What factors are taken into consideration by the firms while choosing manufacturing strategy dimension/s?

C) What is the impact of firm's positioning strategy on its performance?

D) What is the impact of firm's manufacturing strategy on its performance?

E) What is the impact of co-alignment of firm's manufacturing and positioning strategies on its performance? 


\subsection{Conceptual Framework}

A priori conceptual framework, developed after the extensive review and synthesis of literature, is given below. A detailed discussion of variables follows in the succeeding sections.

\section{Figure 9: The Conceptual Framework (A Priori Model)}

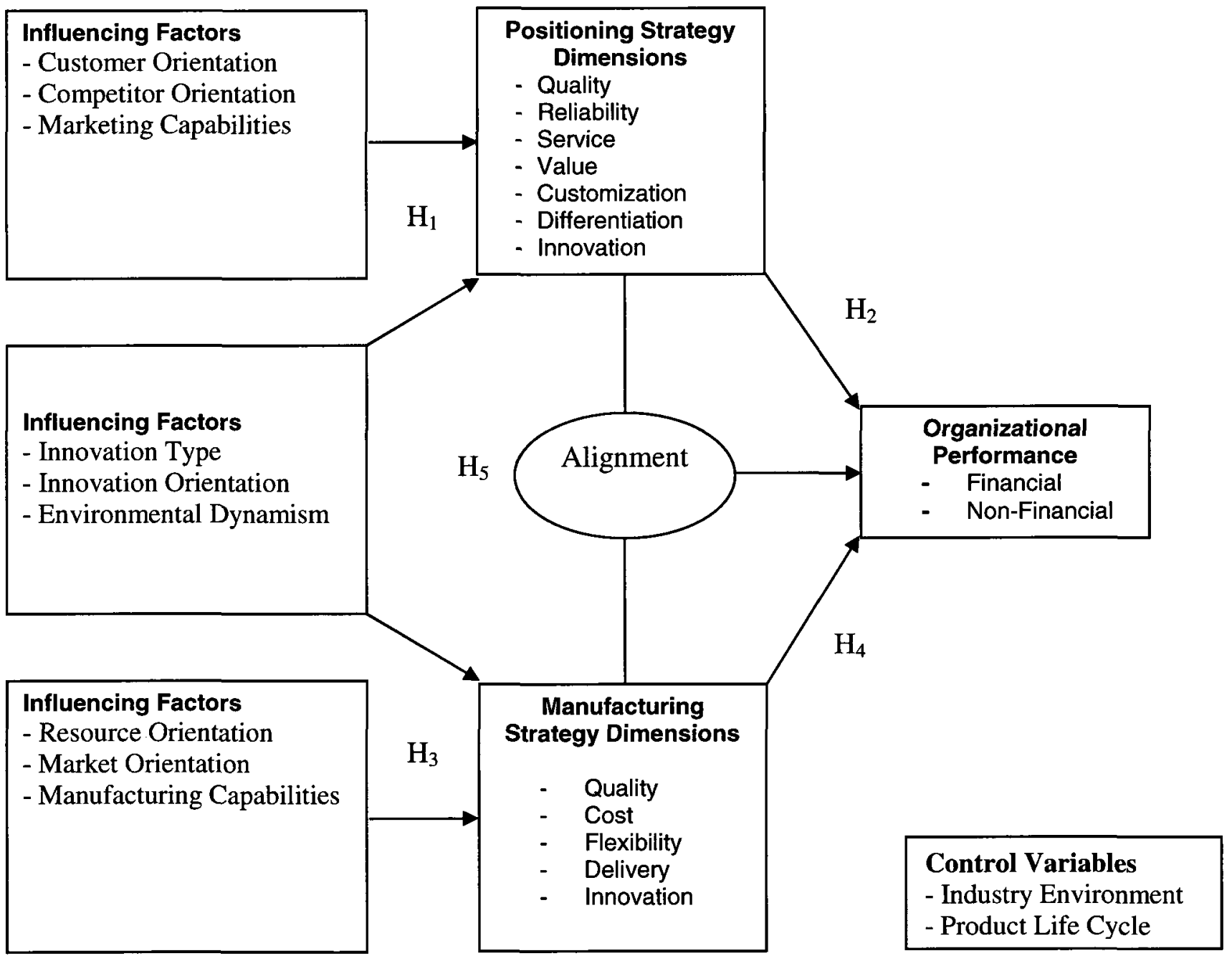

The above research questions depicted in the conceptual framework lead to the following hypotheses: 
$\mathrm{H}_{1 \mathrm{a}}$ : Customer orientation will have an impact on quality, reliability, service, value, customization, differentiation and innovation dimension of positioning strategy.

$\mathrm{H}_{1 \mathrm{~b}}$ : Competitor orientation will have an impact on of quality, reliability, service, value, customization, differentiation and innovation dimension of positioning strategy.

$\mathrm{H}_{1 \mathrm{c}}$ : Marketing capabilities will have an impact on quality, reliability, service, value, customization, differentiation and innovation dimension of positioning strategy.

$\mathrm{H}_{1 \mathrm{~d}}$ : Innovation type will have an impact on quality, reliability, service, value, customization, differentiation and innovation dimension of positioning strategy.

$\mathrm{H}_{1 \mathrm{e}}$ : Innovation orientation will have an impact on quality, reliability, service, value, customization, differentiation and innovation dimension of positioning strategy.

$\mathrm{H}_{1 \mathrm{f}}$ : Environmental dynamism will have an impact on quality, reliability, service, value, customization, and differentiation and innovation dimension of positioning strategy.

Positioning Strategy and Organizational Performance

$\mathrm{H}_{2 \mathrm{a}}$ : Positioning strategy will have a positive effect on firm's financial performance.

$\mathrm{H}_{2 b}$ : Positioning strategy will have a positive effect on firm's non-financial performance. 
Impact of Influencing Factors on Manufacturing Strategy

$\mathrm{H}_{3 \mathrm{a}}$ : Resource orientation will have an impact on quality, cost, flexibility, delivery, and innovation dimension of manufacturing strategy.

$\mathrm{H}_{3 \mathrm{~b}}$ : Market orientation will have an impact on quality, cost, flexibility, delivery, and innovation dimension of manufacturing strategy.

$\mathrm{H}_{3 \mathrm{c}}$ : Manufacturing capabilities will have an impact on quality, cost, flexibility, delivery, and innovation dimension of manufacturing strategy.

$\mathrm{H}_{3 \mathrm{~d}}$ : Innovation type will have an impact on quality, cost, flexibility, delivery, and innovation dimension of manufacturing strategy.

$\mathrm{H}_{3 \mathrm{e}}$ : Innovation orientation will have an impact on quality, cost, flexibility, delivery, and innovation dimension of manufacturing strategy.

$\mathrm{H}_{3 \mathrm{f}}$ : Environmental Dynamism will have an impact on quality, cost, flexibility, delivery, and innovation dimension of manufacturing strategy.

Manufacturing Strategy and Organizational Performance

$\mathrm{H}_{4 \mathrm{a}}$ : Manufacturing strategy will have a positive effect on firm's financial performance.

$\mathrm{H}_{4 \mathrm{~b}}$ : Manufacturing strategy will have a positive effect on firm's non-financial performance. 


\section{Co-alignment of Manufacturing and Positioning Strategies}

$\mathrm{H}_{5}$ : Lack of co-alignment of positioning and manufacturing strategy will have a negative impact on organizational performance.

\subsection{Identification and Specification of Variables}

There are seven set of variables in the conceptual framework -1) factors influencing positioning strategy only, 2) factors influencing manufacturing strategy only, 3) factors influencing both positioning and manufacturing strategies, 4) positioning strategy dimensions, 5) manufacturing strategy dimensions, 6) organizational performance, and 7) control variables. A detailed discussion on each follows.

\subsubsection{Factors Influencing Positioning Strategy Only}

\subsubsection{Customer Orientation}

Customer focus is the defining premise of marketing discipline (Levitt, 1960) and the key component of market orientation (Deshpandé and Farley, 1998). In marketing discipline there is a stream of research which highlights the benefits of customer orientation (Danneels, 2003). Customer orientation is also deemed to have a positive impact on business performance (Zhu and Nakata, 2007). It is stated that keeping a close contact with customers “...leads to a better understanding of customers' needs, closer tailoring of products and services, higher customer satisfaction, easier forecasting of demand, and closer relationships" (Danneels, 2003). 
There are a number of ways to attain positioning; however, consumer needs form the basis of positioning. Pike and Ryan (2004) point out that, “...positioning is underpinned by the philosophy of understanding and meeting unique consumer needs." Understanding and analyzing customer needs is an integral component of positioning development process. The choice of positioning strategy dimensions would, therefore, be influenced by customer orientation.

\subsubsection{Competitor Orientation}

Customer and competitor orientation are the vital components of the well-known construct of market orientation introduced by Kohli and Jaworski (1990). Schouten and McAlexander (1989) state that "the success of a positioning strategy lies in the firm's ability to differentiate itself in a positive way along one or more important dimensions from its competitors in the mind of customer" (p.69). DiMingo (1988) echoes the same sentiment by saying, "true positioning is the process of distinguishing a company or product from competitors" (p.34).

Since a position is always relative to that of competitors, analysis of competitors ought to be a fundamental step of the positioning process. By defining its competition and clearly stating its positioning, a firm is able to protect itself from the competitive pressures of other firms (Porter, 1985). Greenley (1984) states that positioning is influenced by the nature of the competitors within each segment. Competitor orientation, thus, is absolutely necessary for the development of positioning strategies. 


\subsubsection{Marketing Capabilities}

Considered as an important source of competitive advantage, marketing capability is defined as the "integrative processes designed to apply collective knowledge, skills, and resources of the firm to market needs of the business, enabling the business to add value to its goods and services, adapt to market conditions, take advantage of market opportunities and meet competitive threats" (Ussahawanitchakit, 2007, p. 53).

A number of studies in the recent years have highlighted the role of marketing capabilities in achieving competitive advantage. The origins of marketing capabilities stem from the resource-based view of the firm (Grant, 1991; Wernerfelt, 1984) and the capability-based view of the firm (Grant, 1996; Teece et al., 1997). It is stated that unique, inimitable, and distinctive marketing capabilities and resources lead to the development of competitive advantage (Hooley et al., 2005; Vorhies et al., 1999)

The marketing capability enables firms to identify customers' needs and build relationships with them, differentiate products and services from competitors, and manage relationships with suppliers and other strategic partners. It also assists firms in achieving better targeting and positioning relative to competitors (Ussahawanitchakit, 2007). Since positioning is based on the firm's sustainable competitive advantages and marketing capability enables the firms to achieve competitive advantage, it can be stated that marketing capability will have an impact on the chosen positioning strategy. 


\subsubsection{Factors Influencing Manufacturing Strategy Only}

\subsubsection{Resource Orientation}

The resource-based view of the firm stresses that its performance is driven by its resources. The objective of the firm is to develop and deploy a bundle of resources which are difficult for the competitors to imitate (Paladino, 2007). Bates et al. (2001) highlight the significance of developing manufacturing resources and capabilities by stating that the "manufacturing process is a result of a firm's long-term commitment to build manufacturing capabilities and resources."

The resource-based view posits that the success of the firm is influenced more by its strategic resources, assets, and capabilities than by its market position based on external factors (Wernerfelt, 1984). The resources are considered strategic if they help in attaining and maintaining market positions. Resources are the assets accessed, controlled, and owned by the firm. Resources could be tangible, such as production capacity and staff, and intangible, such as image and corporate culture. The firm's resources limit and constrain its range of capabilities - the activities the firm undertakes to support its strategy (Größler, 2007).

It has been found in the literature that firms developing manufacturing strategies use resource orientation as their primary and preferred paradigm (Cagilano et al., 2005). Thus, resource orientation is posited to influence the manufacturing strategy in this study. 


\subsubsection{Market Orientation}

Market orientation is defined as "the organizational culture that most effectively and efficiently creates the necessary behaviours for the creation of superior value for buyers and thus, continuous superior performance for the business" (Narver and Slater, 1990, p.21). Market orientation aims to keep the firm close to its competitors. The focus of resource orientation is internal while market orientation is external (Paladino, 2007).

Manufacturing strategy based on market-orientation focuses on external factors. Performance and competitive behaviour are determined by market structure. The external environment comprising of economic, technological, political, environmental and social issues is relevant but the real emphasis is on the industry. A company's success is strongly influenced by the competitive forces, measured by Porter's (1980) five forces model (Größler, 2007).

Though the literature points to the increasing use of resource orientation influencing the manufacturing strategy, market orientation is still considered vital, since knowledge of customer requirements and competitors' actions is necessary to compete effectively in today's highly competitive environment where customers are exposed to numerous product choices. It is posited, therefore, that market orientation will also have an impact on the development of manufacturing strategy.

\subsubsection{Manufacturing Capability}

The manufacturing strategy literature borrowed the term 'capabilities' from business strategy literature focused on resource-based view of the firm (Corbett and Claridge, 
2002). Manufacturing capability is defined as "the ability of a production system to compete on basic dimensions such as cost, flexibility and time" (Sarmientom et al., 2007, p. 368). Bates et al. (2001) emphasize the role of resources in building manufacturing capability which, aligned with business strategy, serves as a source of competitive advantage.

Zahra and Nelsen (2002) divide manufacturing capability into two components: the human component and the technological component. The human component includes knowledge, skills and creativity of the manufacturing personnel. The technological component is determined by the existing internal technological processes and the system used for manufacturing. Strong manufacturing capability also gives the firm flexibility to respond swiftly to the changes in business environment by making adjustments in the internal processes and systems. White (1996) conducted a meta-analysis of manufacturing capability studies and found a positive relationship between business performance and firm's capabilities.

Since the dimensions of manufacturing strategy - cost, quality, flexibility, dependability, and so on, are firmly dependent on capabilities of the firm, it is posited that manufacturing capability will have a direct impact on manufacturing strategy.

\subsubsection{Factors Influencing both Positioning and Manufacturing Strategies}

\subsubsection{Innovation Orientation and Type}

Innovation is defined as "the search for and the discovery, development, improvement, adoption, and commercialization of new processes, products, organizational structures 
and procedures" (Dosi, 1988, p. 1122). Yamina et al. (1997) state that rapid pace of technological change is mounting competitive challenges to the firms. $\mathrm{Li}$ and Simerly (2002) call innovation the "heart of firm success in today's competitive environment." It is considered to be a strong tool in combating competition and creating sustainable competitive advantage (Porter, 1990).

A number of authors have stated that, in the face of rising competition, investments in innovation are likely to give firms competitive advantage in global and international markets (Brown and Eisenhardt, 1995; Conner, 1991). Akman and Yilmaz (2008) consider innovation as a vital success factor in a highly competitive, global economy. Qian, Qi, and Yu-cheng (2008) also emphasize that an increasingly competitive world and highly demanding customers make it imperative for firms to develop strategies based on innovation. Innovation seems to have a significant impact on a firm's productivity and on the overall performance of the organization (Yamina et al., 1997).

The classic management literature clearly acknowledges the role of technology in supporting competitive strategies of the firm (Andrews, 1971; Ansoff, 1965). The fit between a firm's competitive strategy and its general technology has been stressed in the literature (Frohman, 1985; Porter, 1985). In fact, the Japanese have been credited for their success in incorporating appropriate technologies in integrated manufacturing strategies (Buffa, 1984). The links between competitive strategies and innovation have been well understood by mangers and researchers (Kantrow, 1980). However, the exact nature of the relationship between the two has not been established due to a dynamic environment (Rosenberg, 1982). 
Innovation, for the purpose of this study, is limited to technological innovation. An innovation orientation is a characteristic of the corporate culture and is normally considered as a component of a broader innovation culture. For this study it is defined as "openness to new types of technologies, the ability to search for these technologies proactively, being able to recognize them early on, and reacting to them appropriately, as well as an attempt to use these technologies purposefully for innovation to develop technologically first-class products that are superior to those of the competitors" (Herrmann, Gassmann, and Eisert, 2007).

Degree of innovation is determined by the type of innovation. Innovation could be radical (some times called disruptive and discontinuous) or incremental. Radical innovation is defined as "the commercialization of products and technologies that have strong impact on 1) the markets, in terms of offering wholly new benefits, and 2) the firm, in terms of its ability to create new businesses" (O'Connor and Ayers, 2005, p. 24). It is stated that different types of innovation have different effects on the product portfolios and need different types of resources and capabilities within the firm (Hurmelinna-Laukkanen, Sainio, and Jauhiainen, 2008). Radical innovations provide major competitive advantages to firms. Companies which launch products with radical innovation are market driven and redefine customer expectations (Sebastiao, 2005).

The tendency of a firm to use innovation as a manufacturing and positioning strategy, therefore, would be determined by the innovation orientation of the firm as well as the type of innovation it is most likely to introduce. 


\subsubsection{Environmental Dynamism}

Cravens (1975) states that environmental forces beyond a firm's control have an impact on its marketing strategy. Management decisions are guided by the overall corporate strategy. It is imperative for firms to continually monitor their environment for changes in buyer preferences, rapid environmental changes, and increased competition. Such changes could make the firm's current positioning outdated and/or offer new growth opportunities. Scanning of the environment provides an effective basis for linking corporate strategy to marketing strategy (Cravens, 1975).

The proponents of the resource-based view argue that an individual firm's competitiveness and performance within the same industry varies due to differences in internal competencies and capabilities (Flwler et al., 2000; Tyler, 2001). However, the impact of a firm's resources and competencies on its manufacturing strategy and performance is influenced by environmental factors such as environmental dynamism (Dess and Beard, 1984; McArthur and Nystrom, 1991). Organizational performance to some extent also depends on the fit of the strategy with the environment, according to contingency theory (Mintzberg, 1979).

Management decisions are guided by the marketing strategy positioning. It is imperative for firms to continually monitor their environment for changes in buyer preferences, rapid environmental changes, and increased competition. A number of authors (Aaker, 1992; Porter, 1991) state that the development of competitive positioning strategy requires thorough analysis of the internal and external environment so that the most attractive positions vis-à-vis competitors can be identified. Miles' and Snow's topologies (1978) 
and Porter's generic strategies (1985) both presume that the organization is positioned in a particular environment against specific competitors.

There is no consensus amongst the researchers as to the best way to conceptualize and measure external environment. However, environmental dynamism is one of the most frequently used measures of external environment. It is defined as the "rate of environmental change and unpredictability of that change" (Bierly and Daly, 2007, p. 498). This change can be caused by the entrance of new competitors, changes in customer preferences and variations in the firm's technological capabilities (Bierly and Daly, 2007).

Both manufacturing and positioning strategies are influenced by the external environment. It is, therefore, posited that environmental dynamism will have an impact on manufacturing as well as positioning strategies.

\subsubsection{Positioning Strategy Dimensions}

"Positioning strategy dimension" for this study is defined as features, benefits, attributes, any other characteristic or differentiating aspect offered by the firm to the customer. Two approaches were used in Chapter Three to identify positioning strategy dimensions. First, the positioning literature was extensively reviewed to develop taxonomy of product positioning dimensions, based on the content analysis. Second, major positioning typologies proposed in the literature were identified and compared with one another.

The findings of taxonomy, based on content analysis of positioning literature, revealed fourteen product positioning strategy dimensions. The dimensions mentioned by less than four studies (less than $15 \%$ of the studies) were eliminated for further consideration. This 
purging left the following four product positioning strategy dimensions which are most frequently used in the literature: Attribute, Quality/Top of the range Reliability, and Value/Price.

The positioning strategy dimensions of typologies are: Attribute, Benefits, Brand Name, Country, Customization, Features, Innovation, Price/Value, Quality/Top of the range, Reliability, and Service. A comparative summary of dimensions from taxonomy and typology is presented below in Table 8:

Table 8: Positioning Strategy Dimensions

\begin{tabular}{|l|c|c|l|}
\hline $\begin{array}{l}\text { Dimensions - } \\
\text { Literature Review }\end{array}$ & Typology & Taxonomy & $\begin{array}{l}\text { Name of dimensions } \\
\text { used in the study }\end{array}$ \\
\hline Attribute & $\mathrm{x}$ & $\mathrm{x}$ & Differentiation* \\
\hline Benefit & $\mathrm{x}$ & & Differentiation* \\
\hline Brand name & $\mathrm{x}$ & & Differentiation* \\
\hline Country & $\mathrm{x}$ & & Country \\
\hline Customization & $\mathrm{x}$ & & Customization \\
\hline Feature & $\mathrm{x}$ & & Differentiation* \\
\hline Innovation & $\mathrm{x}$ & & Innovation \\
\hline Quality/Top of the range & $\mathrm{x}$ & $\mathrm{x}$ & Quality \\
\hline Reliability & $\mathrm{x}$ & $\mathrm{x}$ & Reliability \\
\hline Service & $\mathrm{x}$ & & Service \\
\hline Value/Price & $\mathrm{x}$ & $\mathrm{x}$ & Value \\
\hline
\end{tabular}

* Attribute, benefit, band name, and features are considered components of differentiation dimension.

All the four positioning strategy dimensions identified on the basis of taxonomy (content analysis) and all the dimensions culled from positioning typologies are used for this research other than country. The country was not considered relevant since the study is focused only on manufacturers based in Canada. Four dimensions from typology attribute, feature, benefit and brand name - are labeled as "differentiation" dimension for the purpose of this study. However, indicators of the "differentiation" measure in the questionnaire will comprise of the four dimensions. Thus, the positioning strategy 
dimensions used for this research are: innovation, quality, reliability, service, customization, value, and differentiation.

\subsubsection{Manufacturing Strategy Dimensions}

Competitive priorities of manufacturing strategy, also called competitive strategy in the literature, are defined as the dimensions on which the firm competes in the marketplace (Hayes and Wheelwright, 1984). The terms "manufacturing priority", "competitive priorities" and "manufacturing strategy dimensions" are used interchangeably in the literature (Swamidass and Newell, 1987).

A number of studies in the literature propose manufacturing strategy dimensions. Fang and Wang (2006), however, conducted a systematic and an extensive review of the literature to develop taxonomy of manufacturing strategy dimensions from the literature. They reviewed thirty-seven studies over a period of twenty years. They found cost, quality, reliability and flexibility to be the most frequently used dimensions. The findings of their review are presented in Table 9:

Table 9: Manufacturing Strategy Dimensions - Literature Review 1

\begin{tabular}{|l|c|c|c|c|c|}
\hline Authors & Year & Cost & Quality & Reliability & Flexibility \\
\hline Underback \& Abernathy & 1975 & & & & $\mathrm{x}$ \\
\hline Skinner & 1978 & $\mathrm{x}$ & $\mathrm{x}$ & $\mathrm{x}$ & $\mathrm{x}$ \\
\hline Wheelwright & 1978 & $\mathrm{x}$ & $\mathrm{x}$ & $\mathrm{x}$ & $\mathrm{x}$ \\
\hline Buffa & 1980 & $\mathrm{x}$ & $\mathrm{x}$ & $\mathrm{x}$ & $\mathrm{x}$ \\
\hline Swamidass & 1980 & $\mathrm{x}$ & $\mathrm{x}$ & $\mathrm{x}$ & \\
\hline Wheelwright & 1981 & & $\mathrm{x}$ & & \\
\hline Wheelwright & 1984 & & $\mathrm{x}$ & & \\
\hline Fine \& Hax & 1985 & $\mathrm{x}$ & $\mathrm{x}$ & $\mathrm{x}$ & $\mathrm{x}$ \\
\hline Hill & 1985 & $\mathrm{x}$ & & $\mathrm{x}$ & $\mathrm{x}$ \\
\hline Richardson et al. & 1985 & $\mathrm{x}$ & $\mathrm{x}$ & $\mathrm{x}$ & $\mathrm{x}$ \\
\hline
\end{tabular}




\begin{tabular}{|l|c|c|c|c|c|}
\hline Ferdows et al. & 1986 & $\mathrm{x}$ & $\mathrm{x}$ & & $\mathrm{x}$ \\
\hline Schoeder et al. & 1986 & $\mathrm{x}$ & $\mathrm{x}$ & $\mathrm{x}$ & $\mathrm{x}$ \\
\hline Swamidass & 1986 & $\mathrm{x}$ & $\mathrm{x}$ & $\mathrm{x}$ & $\mathrm{x}$ \\
\hline De Meyer \& Ferdows & 1987 & & & & $\mathrm{x}$ \\
\hline Ferdows \& Lindberg & 1987 & & & & $\mathrm{x}$ \\
\hline Horte et al. & 1987 & & $\mathrm{x}$ & & \\
\hline Lindberg et al. & 1988 & & & $\mathrm{x}$ & \\
\hline Miller \& Roth & 1988 & $\mathrm{x}$ & $\mathrm{x}$ & $\mathrm{x}$ & $\mathrm{x}$ \\
\hline De Meyer et al. & 1989 & $\mathrm{x}$ & $\mathrm{x}$ & & \\
\hline Shroeder et al. & 1989 & & & & $\mathrm{x}$ \\
\hline Ferdows \& De Meyer & 1990 & $\mathrm{x}$ & $\mathrm{x}$ & $\mathrm{x}$ & \\
\hline Galbraith & 1990 & & & & $\mathrm{x}$ \\
\hline Lindberg & 1990 & & & & $\mathrm{x}$ \\
\hline Marucheck & 1990 & $\mathrm{x}$ & & & $\mathrm{x}$ \\
\hline Reitsperger \& Daneil & 1990 & & $\mathrm{x}$ & & \\
\hline Tunalv & 1990 & $\mathrm{x}$ & $\mathrm{x}$ & $\mathrm{x}$ & $\mathrm{x}$ \\
\hline De Meyer \& Ferdows & 1991 & $\mathrm{x}$ & $\mathrm{x}$ & & $\mathrm{x}$ \\
\hline Horte et al. & 1991 & & & & $\mathrm{x}$ \\
\hline Lindberg \& Trygg & 1991 & & & $\mathrm{x}$ & \\
\hline Hum \& Leow & 1992 & $\mathrm{x}$ & $\mathrm{x}$ & $\mathrm{x}$ & \\
\hline Tunalv & 1992 & $\mathrm{x}$ & $\mathrm{x}$ & $\mathrm{x}$ & $\mathrm{x}$ \\
\hline Corbeet \& Wassenhove & 1993 & $\mathrm{x}$ & $\mathrm{x}$ & $\mathrm{x}$ & \\
\hline Garvin & 1993 & & $\mathrm{x}$ & & $\mathrm{x}$ \\
\hline Fry et al. & 1994 & $\mathrm{x}$ & $\mathrm{x}$ & & \\
\hline Neely et al. & 1994 & $\mathrm{x}$ & $\mathrm{x}$ & $\mathrm{x}$ & \\
\hline Sweeney & 1994 & $\mathrm{x}$ & $\mathrm{x}$ & $\mathrm{x}$ & \\
\hline Williams et al. & 1995 & & $\mathrm{x}$ & $\mathrm{x}$ & \\
\hline
\end{tabular}

Source: Adapted from Fang and Wang (2006)

Since their analysis was limited to 1995, the most recent studies, starting from 1996 onward, were scanned to identify the manufacturing strategy dimensions currently being proposed in the literature. The findings are given in Table 10: 
Table 10: Manufacturing Strategy Dimensions - Literature Review 2

\begin{tabular}{|c|c|c|c|c|c|c|c|c|c|}
\hline Authors & Year & 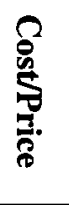 & 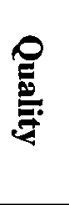 & 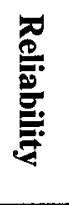 & 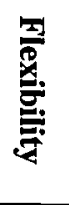 & 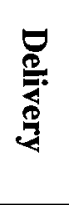 & 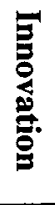 & Other-1 & Other-2 \\
\hline Kim \& Arnold & 1996 & $\mathrm{x}$ & $\mathrm{x}$ & & $x$ & $x$ & & & \\
\hline Krajewski \& Ritzman & 1996 & $\mathrm{x}$ & $\mathrm{x}$ & & $\mathrm{x}$ & & & Time & \\
\hline Avella et al. & 1998 & $\mathrm{x}$ & $\mathrm{x}$ & & $\mathrm{x}$ & $\mathrm{x}$ & & service & \\
\hline Joseph & 1999 & $\mathrm{x}$ & $\mathrm{x}$ & & $\mathrm{x}$ & & & dependability & speed \\
\hline Santos & 2000 & $\mathrm{x}$ & $\mathrm{x}$ & & & $x$ & $\mathrm{x}$ & & \\
\hline Boyer \& Pagell & 2000 & $\mathrm{x}$ & $x$ & & $\mathrm{x}$ & $\bar{x}$ & & & \\
\hline Ward \& Duray & 2000 & $\mathrm{x}$ & $\mathrm{x}$ & & $\mathrm{x}$ & $\mathrm{x}$ & & & \\
\hline Dangayach \& Deshmukh & 2001 & $\mathrm{x}$ & $\mathrm{x}$ & & $\mathrm{x}$ & $\mathrm{x}$ & $\mathrm{x}$ & & \\
\hline Devaraj et al. & 2001 & $\mathrm{x}$ & $\mathrm{x}$ & $\mathrm{x}$ & & $\mathrm{x}$ & & $\begin{array}{l}\text { product } \\
\text { range }\end{array}$ & \\
\hline Amoako-Gyampah & 2003 & $\mathrm{x}$ & $\mathrm{x}$ & & $\mathrm{x}$ & $\mathrm{x}$ & & & \\
\hline Demeter & 2003 & $\mathrm{x}$ & $\mathrm{x}$ & & $x$ & $\mathrm{x}$ & & & \\
\hline Brown \& Bessant & 2003 & & & & $\mathrm{x}$ & $x$ & $\mathrm{x}$ & & \\
\hline Dangayach \& Deshmukh & 2003 & $\mathrm{x}$ & $\mathrm{x}$ & & $\mathrm{x}$ & $\mathrm{x}$ & $\mathrm{x}$ & & \\
\hline Leung, Chan, \& Lee & 2003 & $\mathbf{x}$ & $\mathrm{x}$ & & $x$ & $\mathrm{x}$ & & \begin{tabular}{|l|}
$\begin{array}{l}\text { product } \\
\text { range }\end{array}$ \\
\end{tabular} & $\begin{array}{l}\text { new } \\
\text { product }\end{array}$ \\
\hline Pun & 2004 & $\mathrm{x}$ & $\mathrm{x}$ & & $x$ & & $\mathrm{x}$ & dependability & \\
\hline Devaraj et al. & 2004 & $\bar{x}$ & $\mathrm{x}$ & & $\mathrm{x}$ & $x$ & $\mathrm{x}$ & & \\
\hline Chan & 2005 & $\mathrm{x}$ & $\mathrm{x}$ & & $\mathrm{x}$ & $\mathrm{x}$ & & & \\
\hline $\begin{array}{l}\text { Osmanagić, Prester, \& } \\
\text { Podrug }\end{array}$ & 2005 & & $\mathrm{x}$ & & & $\mathrm{x}$ & $\mathrm{x}$ & service & \\
\hline Takala et al. & 2006 & $\mathrm{x}$ & $\mathrm{x}$ & & & & & dependability & speed \\
\hline Kazan, Özer, \& Cetin & 2006 & $\mathbf{x}$ & $\mathrm{x}$ & & $\mathrm{x}$ & $\mathrm{x}$ & & & \\
\hline Hallgren \& Olhager & 2006 & $\mathrm{x}$ & $\mathrm{x}$ & & $\mathrm{x}$ & $\mathrm{x}$ & & & \\
\hline Takala et al. & 2007 & $\mathrm{x}$ & $\mathrm{x}$ & & $x$ & & & $\begin{array}{l}\text { customer } \\
\text { focus }\end{array}$ & $\begin{array}{l}\text { know- } \\
\text { how }\end{array}$ \\
\hline Taps \& Steger-Jensen & 2007 & $\mathrm{x}$ & $\mathrm{x}$ & & $\mathrm{x}$ & $\mathrm{x}$ & & & \\
\hline Theodorou \& Florou & 2008 & $\mathrm{x}$ & $\mathrm{x}$ & & $x$ & & & dependability & efficiency \\
\hline $\begin{array}{l}\text { Amoako-Gyampah \& } \\
\text { Acquaah }\end{array}$ & 2008 & $\mathrm{x}$ & $\mathrm{x}$ & & $\mathrm{x}$ & $\mathbf{x}$ & & & \\
\hline
\end{tabular}

A comparison of Tables 9 and 10 makes it clear that three dimensions - cost, quality and flexibility - have the same significance in both tables. However, the dimension of reliability is almost non-existent in Table 10 while the dimension of delivery is not mentioned in Table 9. A review of literature unearthed that they are the same dimensions 
i.e. it is the reliability of the delivery. The dimension of innovation, however, does not appear in Table 9 and is found repeatedly in Table 10.

Prajogo et al. (2007) argue that quality is now taken as granted but the dimensions of flexibility, responsiveness and specifically innovation are "considered as order winners". They claim that innovation is the key factor in attaining outstanding manufacturing status and competing successfully in global markets. Osmanagić, Prester, and Podrug (2005) also highlight the importance of innovation in "meeting new consumer needs, offering wider range of products and services, and winning new markets."

Spring and Dalrymple (2000) argue that competitive criteria (manufacturing strategy dimensions) have evolved over time and that innovation is the most recent addition. They graphically depict the change in Figure 10:

\section{Figure 10: Evolution of Manufacturing Strategy Dimensions}

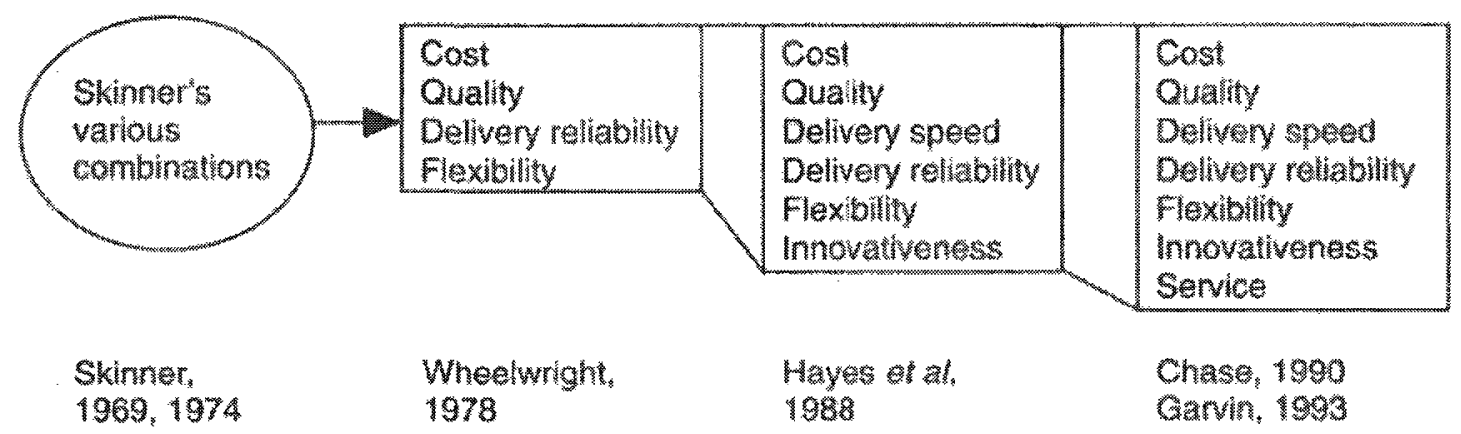

Source: Spring and Dalrymple (2000)

Therefore, based on the above discussion and synthesis of analysis, the manufacturing strategy dimensions to be used for this study are cost, quality, delivery, flexibility, and innovation. 


\subsubsection{Organizational Performance}

Organizational performance is a widely used construct and a number of studies in varying disciplines measure organizational performance for different objectives. There are two types of measures, objective and subjective, that are used in the literature to capture organizational performance. Objective measures are more tangible but are constrained to financial data only and thus are limited in scope. The standard measures of financial performance - revenue and profitability growth - are used by most of the studies. Subjective measures, on the other hand, are less concrete but provide a different and richer perspective about organizational effectiveness, especially in comparison to the competitors. The subjective measures, however, vary depending upon the precise objective of the study. It is recommended that researchers should consider multiple indicators of the performance to get a more comprehensive assessment of the performance (Allen et al., 2008). A brief overview of the literature in this area is given below.

Li et al. (2006) define organizational performance as "how well an organization achieves its market-oriented goals as well as its financial goals." They use seven indicators to measure a firm's performance: market share, return on investment, growth of market share, growth of sales, growth in return on investment, profit margin on sales, and overall competitive position.

Padma, Ganesh and Rajendran (2008), in a study of organizational performance of ISO 14000 certified Indian manufacturing firms, list a number of performance indicators such as customer satisfaction, employee morale, growth in exports, profitability, overall 
productivity, reduction in quality costs, overall financial performance, overall operational performance, savings in energy and environmentally desirable impact of product/ service.

Allen et al. (2008) use quality, productivity, market share, profitability, return on equity, and overall firm performance relative to competition. Customer satisfaction is considered as an indicator of a firm's operational as well as organizational performance. Profitability measures a firm's ability to generate earnings, the primary objective of any business (Padma, Ganesh, and Rajendran, 2008).

Macinati (2008) breaks down organizational performance into four areas: financial, operational, outcome subjective, and outcome objective. Financial performance is measured as net profit/loss, earnings before interest and taxes (EBIT), profit to revenue ratio and revenue growth over last three years. Since it is a study of the Italian National Health Service, the operational and outcome objectives were health care specific such as mortality rates, number of patients discharged etc. Nonetheless, patient satisfaction, market orientation, and reputation among stakeholders were subjective outcome performance measures.

Hult et al. (2007) conducted a three country study to identify the drivers of performance for globally focused organizations. They divided performance into two categories financial and marketing. Financial performance was measured by profitability, return on investment, cash flow. Marketing performance indicators were the rate of international market expansion and overall growth of international sales and customers. All the items were measured on a Likert-type scale ranging from "strongly disagree" (1) to "strongly agree" (7). 
Lenz (1981) conducted a review of antecedents of organizational performance. The author concluded that organization strategy, structure, industry type, and firm's competitive position in the industry etc. influence firm's performance. Gallagher, Brown and Brown (2008) propose that superior market culture leads to superior customer value which derives superior profitability. The market culture is proposed to have four components - customer insight, competitor awareness, collaborative approach, and criteria for decisions.

Neill and Rose (2006) study the impact of strategic complexity on market strategy and organizational performance. They define strategic complexity as the orientation of the organization towards its competitors, customers, products and macro-environment. They contend that the same dimensions are used for the purpose of strategic decision-making. The performance is measured from three perspectives - financial, efficiency, and customer. They emphasize the use of customer-based performance measures and propose that they should precede financial measures. The measures of organizational performance used in this study are based on financial and non-financial performance.

There are a number of studies, both in manufacturing and positioning literature, which link the respective strategies to organizational performance. As discussed earlier, the coalignment of manufacturing and marketing strategies is also purported to improve performance. Since positioning strategy is a component of marketing strategy, it is, therefore, posited that the co-alignment (fit) of manufacturing and positioning strategies would have a positive impact on financial and non-financial performance of the firm. The financial measures comprise profitability (overall and growth rate), ROI, sales growth 
and market share. Non-financial measures include customer satisfaction and customer loyalty.

\subsubsection{Control Variables}

The product life cycle and industry environment, measured by Porter's five forces model, are used as control variables in this study.

The product life cycle is one of the most widely accepted concepts in marketing. However, it has also been deemed useful for decision making in other functional areas of business such as finance, operations management, human resource management and research and development. It has been called one of the most important variables in determining strategy (Fowler and Thomas, 1993).

The concept of product life cycle has been used since 1970s to depict the changes in the product as it moves from design to obsolescence. The concept of product life cycle anticipates and specifies the strategic needs of products as they age in the marketplace. It allows the management to develop a strategy which corresponds to the changing requirements as the product moves from one stage of lifecycle to another. It has been found that firms adapt their strategies to suit the changes in environment and product life cycle is the significant part of the environment (Fowler and Thomas, 1993). Thus, the strategies developed for a particular stage of product life cycle might not be applicable in other stages.

There are four stages in product life cycle - introduction, growth, maturity and decline. The product life cycle should be considered by marketers while developing positioning 
strategies since the advertising and positioning strategies vary depending upon the stage the product is in. Product positioning requires adjustment with changing consumer preferences and maturing markets (Ganesh and Oakenfull, 1999). The product life cycle affects the positioning strategy since consumer preferences become refined with the passage of time (Kahn, Kalwani, and Morrison, 1988). Moon (2005) cautions that the strong influence of product life cycle on the determination of positioning strategies might result in competitors adopting similar positioning strategies during each of the life cycle stages. The manufacturing strategy would also be influenced by product life cycle since the focus on its dimensions - cost, quality, flexibility, delivery, and innovation - could vary depending upon the stage the product is in.

It has been posited in the literature that external environment - general as well as specific industrial, has an impact on manufacturing strategy as well as overall business strategy and profitability (Gebauer, 2008; Low and Cheng, 2006; Ward and Duray, 2000). The general environment may influence organizations but its relevance is not very clear. The specific environment is directly relevant to the organizations, including customers, suppliers, competitors, labour unions, government regulatory agencies, trade associations. The industry environment influences a firm's competitive actions, responses, and its performance. Grobler (2007) states that a company's success is strongly influenced by the competitive forces which emanate from the industry environment. The industrial environment has been operationalized as Porter's five forces model (Low and Cheng, 2006).

Porter (1980) proposed that the competitive environment is created by the interaction of five different forces acting on a business. The industry environment as depicted by 
Porter's (1980) five forces model comprises supplier power, buyer power, barriers to entry, threat of substitutes, and degree of rivalry among firms. The centerpiece of the model is the degree of rivalry among firms which is directly influenced by other four factors.

Since both product life cycle and industry environment could have an impact on firm's profitability and its business strategy, they are treated as control variables.

\subsection{Summary}

This chapter commences with research objectives, research questions, conceptual framework and hypotheses. The objective of the research is to discern the factors which influence the development of manufacturing and positioning strategies and examine the impact of each strategy on organizational performance. The co-alignment of positioning and manufacturing strategies and its impact on firm's performance will also be examined. By identifying the specific factors which are likely to influence manufacturing and positioning strategies, this chapter has explored the elements that lead to the selection of a particular dimension or set of dimensions for positioning and manufacturing strategies. The influencing factors, divided into three categories - factors influencing positioning strategy only, factors influencing manufacturing strategy only and factors influencing both manufacturing and positioning strategies - are described and discussed in detail. The specific dimensions of positioning strategy to be used in the research are identified on the basis of taxonomy and typology of positioning strategy dimensions discussed in Chapter Three. The major empirical typologies of positioning strategies from the literature are compared with the findings of the taxonomy to further refine the positioning strategy 
dimensions to be used in the study. Similarly, manufacturing strategy dimensions are identified on the basis of extensive review of operations management literature. 


\section{Chapter 7: Methodology}

This chapter provides details of the research design, sampling technique, sampling frame, survey instrument, data collection method and statistical analysis. The validated operational measures of variables culled from various studies in the literature are presented in a tabular form. There is also an extensive discussion on various approaches to the statistical calculation of fit.

\subsection{Research Design}

The design for this study is cross-sectional, ex-post facto, correlational research. The unit of analysis is a firm's major products/brands for positioning strategy and manufacturing unit associated with major products/brand for manufacturing strategy. Practically, the unit of analysis is the firm's strategic business unit (SBU). The data collection method is the self-administered structured questionnaire.

\subsection{Survey}

The self-administered mail method was selected, based on the process of elimination. The other two possible choices were telephone surveys and personal interviews. Telephone surveys are not considered efficient with long questionnaires (Stempel and Westley, 1981) and personal interviews were not feasible due to distances involved and number of responses needed. 


\subsubsection{Sample}

The data was collected from top decision makers from manufacturing companies in Canada. The two sub-sectors chosen in the manufacturing sector are:

\section{Computer and electronic product sub-sector (NAICS code 334)}

2. Electrical equipment, appliance and component sub-sector (NAICS Code 335).

The chosen industries were to meet two criteria to qualify for consideration in this study:

i) The products of the chosen firms could be differentiated on the basis of attributes, features, or benefits and ii) There are significant numbers of competitors which drive firms to promote their products and develop positioning strategy.

The industries in these two sub-sectors are characterized by their frequent introduction of new products (Rajotte, 2007), their rapid pace of technological innovation, and their emphasis on promotion and selling of their products (United States Department of Labor, 2009) and, consequently, are highly likely to develop positioning strategy. The presence of a large number of competitors is confirmed by database of hundreds of firms listed under NAICS-334 and NAICS-335.

The firms manufacturing computers, computer peripheral equipments, and various electronic products are the parts of the computer and electronic product manufacturing sub-sector. The complete list of industries in this sub-sector, with their NAICS code, is given below in Table 11: 
Table 11: Computer and Electronic Product (NAICS-334)

\begin{tabular}{|l|l|}
\hline NAICS Code & Industries \\
\hline 334110 & Computer and peripheral equipment manufacturing \\
\hline 334210 & Telephone apparatus manufacturing \\
\hline 334220 & $\begin{array}{l}\text { Radio and television broadcasting and wireless communications } \\
\text { equipment manufacturing }\end{array}$ \\
\hline 334290 & Other communication equipment manufacturing \\
\hline 334310 & Audio and video equipment manufacturing \\
\hline 334410 & Semiconductor and other electronic component manufacturing \\
\hline 334511 & Navigational and guidance instruments manufacturing \\
\hline 334512 & Measuring, medical and controlling devices manufacturing \\
\hline 334610 & Manufacturing and reproducing magnetic and optical media \\
\hline
\end{tabular}

The electrical equipment, appliance and component manufacturing sub-sector comprises of industries manufacturing household appliances, electrical equipment, electrical components etc. The complete list of industries with their NAICS code is given below in Table 12.

Table 12: Electrical equipment, Appliance and Component (NAICS-335)

\begin{tabular}{|l|l|}
\hline NAICS Code & Industries \\
\hline 335110 & Electric lamp bulb and parts manufacturing \\
\hline 335120 & Lighting fixture manufacturing \\
\hline 335210 & Small electric appliance manufacturing \\
\hline 335223 & Major kitchen appliance manufacturing \\
\hline 335229 & Other major appliance manufacturing \\
\hline 335311 & Power, distribution and specialty transformers manufacturing \\
\hline 335312 & Motor and generator manufacturing \\
\hline 335315 & $\begin{array}{l}\text { Switchgear and switchboard, and relay and industrial control apparatus } \\
\text { manufacturing }\end{array}$ \\
\hline 335910 & Battery manufacturing \\
\hline 335920 & Communication and energy wire and cable manufacturing \\
\hline 335930 & Wiring device manufacturing \\
\hline 335990 & Battery manufacturing \\
\hline
\end{tabular}

The collection of data from more than one industry may have confounding effects on the results of the study. However, it provides higher generalizabilty to the outcome of the 
study (Vokurka and O'Leary-Kelly, 2000) and could help to draw broad conclusions which might be relevant to other industries in the manufacturing sector.

The Scottsinfo database was used to obtain information about the firms. It provides complete postal addresses as well as names and designation of key managers and executives. The database is updated annually and is considered a very comprehensive source of information about Canadian manufacturers.

\subsubsection{Instrument Development}

The self-administered structured questionnaire was developed on the basis of conceptual framework grounded in market-based and resource-based views. The procedures carried out to develop measures influence the quality of inference in measurement. The paradigm provided by Churchill (1979) and later updated by Gerbing and Anderson (1988) for developing measures for constructs follows the generally accepted psychometric principles and ensures reliability and validity. Churchill (1979) argues that measurement problems could be reduced drastically by using multi-item measures. He suggests defining the construct domain and generating items using literature, experience surveys and qualitative research. An effort was made to follow that paradigm as closely as possible.

The first step commences with the specification of the domain construct using extensive literature search. The second step entails generation of sample of items with a focus on capturing each dimension of the constructs under study. The second step is based on extensive literature review as well as qualitative research in case of unavailability of reliability tested measures in the literature. 
Following this approach, an extensive review of literature in positioning and manufacturing strategy was conducted to develop a conceptual framework and to identify constructs and underlying measures.

The measures were identified on the basis of extensive literature review and the variables discussed in the preceding chapter. All the measures and indicators have been taken from the literature and are thus validated by the researchers. Tables 13-20 below provide a complete listing of all the variables, measures and indicators. The references of the studies from which the indicators are taken are also given.

Table 13: Measures-Factors Influencing Positioning Strategy

\begin{tabular}{|c|c|c|}
\hline Variable & Indicator & Ref. \\
\hline $\begin{array}{l}\text { Customer } \\
\text { Orientation }\end{array}$ & $\begin{array}{l}\text { - Commitment to serving the customer needs is closely monitored } \\
\text { - Objectives and strategies are driven by the creation of customer satisfaction } \\
\text { - Competitive strategies are based on understanding customer needs }\end{array}$ & 11 \\
\hline $\begin{array}{l}\text { Competitor } \\
\text { Orientation }\end{array}$ & $\begin{array}{l}\text { - Salespeople regularly share information within our business concerning } \\
\text { competitors' strategies } \\
\text { - Respond rapidly to competitive actions that threaten us } \\
\text { - Top management regularly discusses competitors' strengths and strategies }\end{array}$ & 1 \\
\hline $\begin{array}{l}\text { Marketing } \\
\text { Capabilities }\end{array}$ & $\begin{array}{l}\text { - Developing strong relationships with distributors } \\
\text { - Attracting and retaining the best distributors } \\
\text { - Providing high levels of service support to distributors } \\
\text { - Developing and executing advertising programs } \\
\text { - Managing brand image and processes } \\
\text { - Managing corporate image and reputation } \\
\text { - Gathering information about customers and competitors } \\
\text { - Using market research skills to develop effective marketing programs } \\
\text { - Tracking customer wants and needs } \\
\text { - Making full use of marketing research information } \\
\text { - Marketing planning skills } \\
\text { - Recognizing the requirements of the customers } \\
\text { - Understanding the factors influencing customers choice }\end{array}$ & $\begin{array}{l}12 \& \\
13\end{array}$ \\
\hline
\end{tabular}


Table 14: Measures-Factors Influencing Manufacturing Strategy

\begin{tabular}{|c|c|c|}
\hline Variable & Indicator & Ref. \\
\hline $\begin{array}{l}\text { Resource } \\
\text { Orientation }\end{array}$ & $\begin{array}{l}\text { Make-versus-buy decisions are made to sustain or strengthen manufacturing } \\
\text { competence } \\
\text { - Gain a competitive advantage from our unique practices } \\
\text { - Organizations should build and maintain core competencies and skills } \\
\text { - Practices are unique and cannot be easily copied by others }\end{array}$ & 8 \\
\hline $\begin{array}{l}\text { Market } \\
\text { Orientation } \\
\text { (Business } \\
\text { Strategy } \\
\text { Orientation)* }\end{array}$ & 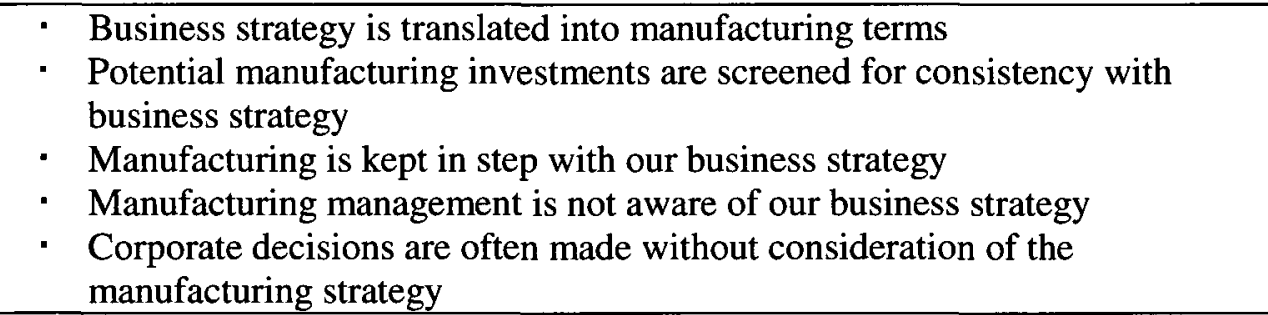 & 8 \\
\hline $\begin{array}{l}\text { Manufacturing } \\
\text { Capabilities }\end{array}$ & $\begin{array}{l}\text { Reducing production costs } \\
\text { - Reducing overall costs } \\
\text { - } \text { Reducing inventory levels } \\
\text { - Improving product support services } \\
\text { - Improving product performance } \\
\text { - Meeting product specification } \\
\text { - Improving product features } \\
\text { - Increasing variety of sizes } \\
\text { - Increasing variety of products } \\
\text { - } \text { Increasing delivery speed } \\
\text { - Increaining delivery due date } \\
\text { - Increasing production innovation } \\
\end{array}$ & $\begin{array}{l}16 \& \\
17\end{array}$ \\
\hline
\end{tabular}

* Note: Since the measures of market orientation relate more to business strategy than to customer and competitors (typically in marketing literature), the construct will be called business strategy orientation on wards to differentiate it from the constructs of customer and competitor orientation used in this study.

Table 15: Measures-Factors Influencing Manufacturing \& Positioning Strategy

\begin{tabular}{|l|l|c|}
\hline Variable & Indicator & Ref. \\
\hline $\begin{array}{l}\text { Innovation } \\
\text { Type }\end{array}$ & $\begin{array}{l}\text { - Introduce radical product innovations more frequently than competitors } \\
\text { years is significantly higher compared to the competition }\end{array}$ & 2 \\
\hline $\begin{array}{l}\text { Innovation } \\
\text { Orientation }\end{array}$ & $\begin{array}{l}\text { - } \text { Use innovative technologies in the new product development } \\
\text { - Proactive in the development and deployment of new technologies }\end{array}$ & 2 \\
\hline $\begin{array}{l}\text { Environmental } \\
\text { Dynamism }\end{array}$ & $\begin{array}{l}\text { - The rate at which products and services become outdated } \\
\text { - The rate of innovation of new products or services }\end{array}$ & 6 \\
& $\begin{array}{l}\text { The tate of innovation of new operating processes } \\
\end{array}$ & \\
\hline
\end{tabular}


Table 16: Measures-Positioning Strategy Dimensions

\begin{tabular}{|l|c|r|}
\hline Variable & Indicator & Ref. \\
\hline Quality & $\cdot$ High quality & \\
\hline Service & $\cdot$ Impressive service & \\
\hline Value & $\cdot$ Friendly & 1 \& 4 \\
& $\cdot$ Price relative to competitors & \\
\hline Differentiation & $\cdot$ Low price & 11 \& 16 \\
& $\cdot$ Product features & \\
& $\cdot$ Company image & \\
\hline Customization & $\cdot$ Brand image & \\
& $\cdot$ Cxtra effort to meet customer's requirements \\
\hline Innovation & $\cdot$ Product uniqueness & \\
\hline Reliability & $\cdot$ New technology & \\
\hline
\end{tabular}

Table 17: Measures-Manufacturing Strategy Dimensions

\begin{tabular}{|l|l|l|}
\hline Variable & Indicator & Ref. \\
\hline Flexibility & $\cdot$ Flexibility & \multirow{1}{*}{} \\
\hline Quality & $\cdot$ Quality & \\
\hline Delivery & $\cdot$ Delivery & \\
\hline Cost & $\cdot$ Cost & \\
\hline Innovation & $\cdot$ Innovation & \\
\hline
\end{tabular}

Table 18: Measures-Organizational Performance

\begin{tabular}{|c|c|c|}
\hline Variable & Indicator & Ref. \\
\hline $\begin{array}{l}\text { Financial } \\
\text { Performance }\end{array}$ & $\begin{array}{ll} & \text { Profit growth } \\
\text { - Overall profitability } \\
\text { - } \\
\text { - Seturn on investment } \\
\text { Sales growth } \\
\text { - } \text { Sarket Share } \\
\end{array}$ & $\begin{array}{l}5 \\
1 \\
17\end{array}$ \\
\hline $\begin{array}{l}\text { Non Financial } \\
\text { Performance }\end{array}$ & $\begin{array}{l}\text { Customer Satisfaction compared to competitors } \\
\text { - Customer Loyalty compared to competitors }\end{array}$ & 3 \\
\hline
\end{tabular}


Table 19: Measures-Control Variables

\begin{tabular}{|c|c|c|}
\hline Variable & Indicator & Ref. \\
\hline $\begin{array}{l}\text { Industry } \\
\text { Environment }\end{array}$ & $\begin{array}{l}\text { Competitive Rivalry } \\
\text { - Competition in our industry is cut-throat. } \\
\text { - There are many 'promotion wars' in our industry } \\
\text { - Price competition is a hallmark of our industry. } \\
\text { Buyer Power } \\
\text { - Our major customers are in a strong bargaining position with us. } \\
\text { - Our customers see little difference between our products and those of our } \\
\text { competitors. } \\
\text { - We pretty much have to comply with our customers' demands, even if they are } \\
\text { unreasonable. } \\
\text { Entry Barriers } \\
\text { - It is easy for new players to enter our industry. } \\
\text { - Potential entrants into our industry can expect strong retaliation from existing } \\
\text { players. } \\
\text { Threat of Substitutes } \\
\text { - Competitors outside our industry offer viable substitutes for our products. } \\
\text { - The prices we can charge for our products are constantly under pressure from } \\
\text { substitute products. } \\
\text { Supplier Power } \\
\text { - We have a large number of suppliers to choose from for our essential inputs } \\
\text { (e.g., raw materials). } \\
\text { - Our major suppliers have the strength to bargain with us effectively. } \\
\text { Our major suppliers or vendors have the power to dictate prices to us. }\end{array}$ & 1 \\
\hline $\begin{array}{l}\text { Product Life } \\
\text { Cycle }\end{array}$ & $\begin{array}{l}\text { Primary demand for the product is beginning to grow. } \\
\text { - Demand is growing rapidly. } \\
\text { - The products in the market are familiar to a majority of perspective customers. } \\
\text { - Products are viewed as commodities by a vast majority of customers. }\end{array}$ & 11 \\
\hline
\end{tabular}

Table 20: References for Operational Measures of Variables

1: Paladino (2007)

2: Herrmann et. al. (2007)

3: Hooley and Greenley (2005)

4: Li et. al. (2006)

5: Neill and Rose (2006)

6: Ward, McCreery and Anand (2007)

7: Blankson and Kalafatis (2004)

8: Thun (2008)

9: Wong and Ellis (2007)
10: Größler and Grübner (2006)

11: Theoharakis and Hooley (2008)

12: Vorhies and Morgan (2005)

13: Dutta et al. (1999)

14: Chan, Joseph W.K (2005)

15: Ward and Duray (2000)

16: Krajewski and Ritzman (2001)

17: Hill (1994) 


\subsubsection{Data Collection}

The data was collected with the use of surveys distributed by mail. The questionnaire, a copy of which is attached in the appendix, was sent to 2,500 companies along with a cover letter and a prepaid return envelope. The questionnaires were sent to the top executives and managers whenever possible. Since most of the questions primarily related to the strategy aspect of manufacturing and marketing, the senior managers were more likely to be the key informants.

The questionnaire was submitted to a panel of expert judges (one faculty member and one business executive) for review. The questionnaire was also pre-tested with five respondents. A number of adjustments were made to the wording of questions and certain measures deemed confusing by respondents were dropped from the questionnaire. The questionnaire was approved by Carleton University Research Ethics Committee before distribution.

A total of 206 questionnaires were received with a response rate of 8.24 percent. Upon return, all the questionnaires were assigned numerical codes and checked for completeness and clarity. A total of 194 questionnaires were deemed usable.

\subsection{Data Analysis}

SPSS statistical software was used to analyze the data. Means, standard deviations, percentages, and correlations were computed for descriptive analysis of the resulting data. Additionally, reliability estimates were determined using Cronbach's alpha. Principal component analysis (PCA) was conducted as an item reduction technique and to confirm the loading of indicators. 
Correlation analysis was conducted to ascertain the association between variables and hierarchical multiple regressions was used to test the relationship between the independent variables and the dependant variables while controlling for certain variables. It illustrates the extent to which the set of independent variables are able to predict the dependent variable.

Various terms, including "match", "alignment", "congruence", "complementary", "coalignment", and "consistency," have been used in the literature to signify "relationships between multidimensional phenomena" like business strategy and marketing organization. Many times, such terms are used interchangeably, though, in reality, each of these terms can have different meanings and underlying technical specifications (Vorhies and Morgan, 2003).

This study uses the term co-alignment but operationalizes it as "fit" since fit has been mostly been used in the literature with the connotations of correspondence based on statistical measures. The fit, in the literature, is defined in several ways depending upon conceptualization and testing of relationships between variables (Powell 1992). The choice of a statistical test for fit without understanding the validity of underlying assumptions can lead to serious errors in the research findings (Venkatraman and Prescott, 1990). Venkatraman (1989) has specified six different types of fit based on different conceptualizations and technical specifications. The details of six fit types are given in Table 21: 
Table 21: Alternative Perspectives of the Concept of Fit in Strategy Research

\begin{tabular}{|c|c|c|c|c|}
\hline $\begin{array}{l}\text { Key } \\
\text { Characteristics }\end{array}$ & \begin{tabular}{|l|} 
Underlying \\
conceptualizat \\
ion of fit
\end{tabular} & $\begin{array}{l}\text { Verbalization of } \\
\text { strategy proposition }\end{array}$ & $\begin{array}{l}\text { Number of } \\
\text { variables } \\
\text { in the } \\
\text { specificati } \\
\text { on of fit }\end{array}$ & $\begin{array}{l}\text { Analytical scheme } \\
\text { (s) for testing fit }\end{array}$ \\
\hline $\begin{array}{l}\text { 1) Fit as } \\
\text { Matching }\end{array}$ & Matching & $\begin{array}{l}\text { The match between } \\
\text { strategy and structures } \\
\text { enhances } \\
\text { administrative } \\
\text { efficiency }\end{array}$ & Two & $\begin{array}{l}\text { ANOVA } \\
\text { Deviation scores } \\
\text { Residual analysis }\end{array}$ \\
\hline $\begin{array}{l}\text { 2) Fit as Profile } \\
\text { Deviation }\end{array}$ & $\begin{array}{l}\text { Adherence to } \\
\text { a specified } \\
\text { profile }\end{array}$ & $\begin{array}{l}\text { The degree of } \\
\text { adherence to a } \\
\text { specified profile has } \\
\text { significant effect on } \\
\text { performance }\end{array}$ & Multiple & $\begin{array}{l}\text { The calculation of } \\
\text { deviation as a } \\
\text { Euclidean distance } \\
\text { in an n-dimensional } \\
\text { space } \\
\text { Multidimensional } \\
\text { Scaling }\end{array}$ \\
\hline $\begin{array}{l}\text { 3) Fit as } \\
\text { Gestalts }\end{array}$ & $\begin{array}{l}\text { Internal } \\
\text { congruence }\end{array}$ & $\begin{array}{l}\text { The nature of internal } \\
\text { congruence among a } \\
\text { set of strategic } \\
\text { variables differs across } \\
\text { "high" and "low" } \\
\text { performance businesses }\end{array}$ & Multiple & $\begin{array}{l}\text { Cluster analysis, } \\
\text { factor analysis }\end{array}$ \\
\hline $\begin{array}{l}\text { 4) Fit as } \\
\text { Moderation }\end{array}$ & Interaction & $\begin{array}{l}\text { The interactive effects } \\
\text { of strategy and } \\
\text { managerial } \\
\text { characteristics have } \\
\text { implications for } \\
\text { performance }\end{array}$ & Two & $\begin{array}{l}\text { Analysis of } \\
\text { variance, } \\
\text { moderated } \\
\text { regression analysis, } \\
\text { subgroup analysis }\end{array}$ \\
\hline $\begin{array}{l}\text { 5) Fit as } \\
\text { Mediation }\end{array}$ & Intervention & $\begin{array}{l}\text { Market share is a key } \\
\text { mediating variable } \\
\text { between strategy and } \\
\text { performance }\end{array}$ & $\begin{array}{l}\text { Two to } \\
\text { multiple }\end{array}$ & Path-analysis \\
\hline $\begin{array}{l}\text { 6) Fit as } \\
\text { Covariation }\end{array}$ & $\begin{array}{l}\text { Internal } \\
\text { consistency }\end{array}$ & $\begin{array}{l}\text { The degree of internal } \\
\text { consistency in resource } \\
\text { allocations has } \\
\text { significant effect on } \\
\text { performance }\end{array}$ & $\begin{array}{l}\text { Four to } \\
\text { multiple }\end{array}$ & $\begin{array}{l}\text { Second-order } \\
\text { confirmatory factor } \\
\text { analysis }\end{array}$ \\
\hline
\end{tabular}

Source: adapted from Venkatraman (1989) 
From the above Table, one can appreciate that the concept of fit is a rather complex phenomenon and requires a careful consideration of underlying assumptions and interplay of study variables to choose the appropriate operationalization of fit. Venkatraman (1989) insists upon choosing an appropriate perspective of fit within a given research context. When a situation involves fit between two concepts, moderation, mediation, and matching perspectives of fit could be considered. Fit as profile deviation and fit as gestalt could be used with multiple variables. However, he recommends using multiple perspectives for the sake of triangulation, which emphasizes using multiple methods to study a problem. Convergence of results across multiple perspective is an evidence of robustness; the reverse, however, is not true (Venkatraman, 1989). Another important issue is the distinction between reductionistic and holistic perspective of coalignment or fit presented in Table 22 .

Table 22: A Comparison of Reductionistic and Holistic Perspectives of Coalignment

\begin{tabular}{|l|l|l|}
\hline Characteristics & Reductionistic Perspective & Holistic Perspective \\
\hline $\begin{array}{l}\text { Dominant } \\
\text { approach to the } \\
\text { specification of } \\
\text { fit }\end{array}$ & $\begin{array}{l}\text { Fit between a characteristics of } \\
\text { environment and a few } \\
\text { characteristics of strategy }\end{array}$ & $\begin{array}{l}\text { A broader conceptualization of } \\
\text { coalignment between several } \\
\text { characteristics of strategy and } \\
\text { several characteristics of } \\
\text { environment }\end{array}$ \\
\hline Strengths & $\begin{array}{l}\text { Ability to isolate precisely specified } \\
\text { theoretical links }\end{array}$ & $\begin{array}{l}\text { Ability to retain the complex } \\
\text { interrelated nature of linkages }\end{array}$ \\
\hline Weaknesses & $\begin{array}{l}\text { Specification error due to invoking } \\
\text { ceteris paribus condition; inability to } \\
\text { isolate conflicting contingencies- } \\
\text { high likelihood of 'logical typing' } \\
\text { error due to disaggregation }\end{array}$ & $\begin{array}{l}\text { Complex nature of coalignment } \\
\text { makes it difficult to hypothesize } \\
\text { the nature of coalignment; } \\
\text { difficulty of generalizations }\end{array}$ \\
\hline $\begin{array}{l}\text { Common } \\
\text { analytical } \\
\text { methods }\end{array}$ & $\begin{array}{l}\text { Multiple regression analysis with } \\
\text { interaction terms; analysis of } \\
\text { variance; subgroup analysis }\end{array}$ & $\begin{array}{l}\text { Cluster analysis; pattern analysis } \\
\text { i.e. profile deviation), canonical } \\
\text { correlation analysis, second-order } \\
\text { factor analysis }\end{array}$ \\
\hline
\end{tabular}

Source: Adapted from Venkatraman and Prescott (1990) 
Within the context of strategy-environment co-alignment, Venkatraman and Prescott (1990) argue that it is important to maintain the holistic nature of co-alignment and question the rationale of bisecting the relationships into sets of bivariate interactions, a series of pairwise comparisons of two or more multidimensional constructs (Kabadayi, Eyuboglu, and Thomas, 2007).

There is a considerable discussion about fit in the configuration theory-based studies. A configurational approach, it is suggested, provides a more holistic view of co-alignment. Configuration is described as "common alignments among elements" (Miller, 1996, p. 507) and "multidimensional constellation(s) of the strategic and organizational characteristics of a business" (Vorhies and Morgan, 2003, p. 102). Configurations could also be called clusters which represent elements of "strategy, structure and environment" (Miller and Friesen, 1984).

Configurational theory stipulates "that the closer a firm matches an "ideal constellation," the better its outcomes" and profile deviation analysis is considered the most appropriate technique in this case (Hult, Boyer, and Ketchen Jr., 2007). Sabjerwal and Chan (2001) caution against using interacting or moderating perspectives of fit when multiple variables are involved. They also recommend the profile deviation approach on the basis of theoretical or empirical "configuration" to measure fit between two multivariate constructs.

Fit can be conceptualized as moderation or mediation when a small number of factors are under consideration with a specific criterion. However, with increase in the number of 
variables, the profile deviation is the most appropriate approach. Profile deviation is similar to a gestalt but it is criterion-specific (Mavondo and Hooley, 2006).

A number of studies in the literature have used profile deviation analysis to measure fit. For example Kabadayi, Eyuboglu, and Thomas (2007) study multiple channels fit with strategy and alignment; Hult, Boyer, and Ketchen Jr. (2007) inspect the relationship between quality, operational logistics strategy, and repurchase intentions; Kathuria and Porth (2003) examine strategy-managerial characteristics alignment and its impact on performance; Sabherwal and Chan (2001) investigate alignment between business and information systems strategies; Conrad, Brown, and Harmon (1997) inspect customer satisfaction and corporate culture; Marlin, Hoffman, and Lamont (1994) explore linkages between Porter's generic strategies, dynamic environments, and performance; and Venkatraman and Prescott (1990) test environment-strategy co-alignment and its impact on performance.

The literature on co-alignment and fit was thoroughly searched to identify empirical studies which had used Venkatraman's conceptualization of fit. The details of 14 studies published from 1990 to 2008 are given below in Table 23.

\section{Table 23: Empirical Studies with Fit Conceptualization}

\begin{tabular}{|c|c|l|l|l|}
\hline Ref. & Year & Co-alignment Variables & Criterion Variable & Fit Analysis \\
\hline 1 & 1990 & $\begin{array}{l}\text { Manufacturing, marketing and } \\
\text { administrative strategies }\end{array}$ & Performance & $\begin{array}{l}\text { Profile Deviation; } \\
\text { Interactionist; Covariation }\end{array}$ \\
\hline 2 & 1990 & External environment and Strategy & Performance & Profile Deviation \\
\hline 3 & 1992 & $\begin{array}{l}\text { Organizational differentiation and } \\
\text { integration }\end{array}$ & Performance & $\begin{array}{l}\text { Matching (Deviation Score } \\
\text { Analysis) }\end{array}$ \\
\hline 4 & 1994 & $\begin{array}{l}\text { External environment and business } \\
\text { strategy }\end{array}$ & Performance & Profile Deviation \\
\hline
\end{tabular}




\begin{tabular}{|c|c|l|l|l|}
\hline 5 & 1997 & Components of corporate culture & Customer Satisfaction & Profile Deviation \\
\hline 6 & 2001 & IS and business strategies & Performance & Profile Deviation \\
\hline 7 & 2001 & $\begin{array}{l}\text { External environment and business } \\
\text { strategy }\end{array}$ & Business Impact of IT & Canonical Correlation \\
\hline 8 & 2003 & $\begin{array}{l}\text { Managerial characteristics and } \\
\text { business strategy }\end{array}$ & Performance & Profile Deviation \\
\hline 9 & 2003 & $\begin{array}{l}\text { Marketing organization } \\
\text { characteristics and business strategy }\end{array}$ & Performance & Profile Deviation \\
\hline 10 & 2004 & $\begin{array}{l}\text { Manufacturing strategy and } \\
\text { manufacturing objectives }\end{array}$ & $\begin{array}{l}\text { Performance (plant } \\
\text { level) }\end{array}$ & Profile Deviation \\
\hline 11 & 2005 & Components of marketing capability & Performance & Profile Deviation \\
\hline 12 & 2007 & $\begin{array}{l}\text { External environment and business } \\
\text { strategy }\end{array}$ & Channel Performance & Profile Deviation \\
\hline 13 & 2007 & $\begin{array}{l}\text { Quality profile characteristics and } \\
\text { logistic strategy }\end{array}$ & $\begin{array}{l}\text { Customer Repurchase } \\
\text { Intentions }\end{array}$ & Profile Deviation \\
\hline 14 & 2008 & $\begin{array}{l}\text { External environment and business } \\
\text { strategy }\end{array}$ & None & Gestalts (Cluster Analysis) \\
\hline
\end{tabular}

Table 24: Authors of Empirical Studies with Fit Conceptualization

\begin{tabular}{|c|l|}
\hline Study Ref. & Authors \\
\hline 1 & Venkatraman, N. \\
\hline 2 & Venkatraman, N. and Prescott, John E. \\
\hline 3 & Powell; Thomas C. \\
\hline 4 & Marlin, Dan; Hoffman, James J. and Lamont, Bruce T. \\
\hline 5 & Conrad, Craig A.; Brown, Gene and Harmon, Harry A. \\
\hline 6 & Sabherwal; Rajiv and Chan, Yolande E. \\
\hline 7 & Luo, Yadong and Park, Seung Ho \\
\hline 8 & Kathuria, Ravi and Porth, Stephen J. \\
\hline 9 & Vorhies, Douglas W. and Morgan, Neil A. \\
\hline 10 & Devaraj, Sarv;Hollingworth, David G. and Schroeder, Roger G. \\
\hline 11 & Vorhies, Douglas W. and Morgan, Neil A. \\
\hline 12 & Kabadayi, Sertan; Eyuboglu, Nermin and Thomas, Gloria P. \\
\hline 13 & Hult, G. Tomas M.; Boyer, Kenneth K. and Ketchen Jr.; David J. \\
\hline 14 & Gebauer, Heiko \\
\hline
\end{tabular}


Almost eighty percent (11 out of 14$)$ studies have used profile deviation for fit analysis. The other methods, used no more than once each, are interactionist, covariation, matching and gestalts.

On the basis of the above discussion and overwhelming evidence from the literature (Table 23) it was decided to use profile deviation technique to measure fit. The major arguments in favour of using profile deviation are summarized as follows: 1) both the constructs, manufacturing strategy and positioning strategy, are multivariate, and bivariate perspective of fit is not recommended in the literature. 2) a holistic perspective employing configurations-based profile deviation is favoured over a reductionistic perspective in the literature. Profile deviation fit is defined as "the degree of adherence to an externally specified profile" (Venkatraman, 1989, p. 433).

In this perspective the researcher specifies an ideal profile, normally top performer, and determines how adherence to such a profile impacts performance (Venkatraman, 1989). The misalignment is calculated as the lack of correspondence between the profile of the top performing strategic configuration and rest of the strategic configurations. The Euclidean distance measure is used for this purpose. The lack of correspondence indicated by the misalignment score is correlated with the performance measures. A negative correlation is expected between misalignment and performance, i.e., as the distance between the top performing strategic configuration increases, performance should decline (Kathuria and Porth, 2003). The adherence to ideal profile will be taken as co-alignment for this study. 


\subsection{Summary}

The design for this study is cross-sectional correlational research. The unit of analysis for positioning strategy is the firm's major products/brands. For manufacturing strategy it is the unit producing those major products/brands. The data for this research was collected using the self-administered mail survey method. The data was collected from two industrial sub-sectors: computer and electronic products (NAICS code 334) and electrical equipment, appliances and components (NAICS Code 335). Operational measures were collected from the literature and were already validated. Regression analysis will be used to test the relationship between independent and dependent variables. Fit as a profile deviation will be used to calculate the lack of co-alignment of positioning and manufacturing strategies. 


\section{Chapter 8: Data Preparation}

The objective of various tests and initial analysis reported in this chapter is to prepare the data for advanced analysis. Skewness and Kurtosis were examined to check for normality. Non-response bias, as well as common method bias, tests were also conducted. Principal component analysis (PCA) is done to reduce the number of items. Reliability and validity are ascertained and revised conceptual model, after PCA, is presented. The hypotheses, to be empirically tested, are also revised in light of the revised framework.

\subsection{Data Preparation}

The accuracy of research outcome is considerably dependent on the quality of data and sampling. The data was coded into SPSS, checked for data entry errors, and examined for the accuracy and validity of some of the key assumptions such as normality and absence of outliers.

\subsubsection{Normality}

The assumption of data normality should be met for inferential statistical analysis. Conducting analysis on non-normally distributed data set with a large number of outliers can lead to incorrect results that may not generalize well (Stevens, 1996; Tabachnick and Fidell, 1989). Therefore, the distribution of each variable was examined prior to the analysis.

Normality can be checked by looking at descriptives (skewness, kurtosis), graphs (histogram, stem and leaf, box plot) and through theory-based tests (Shapiro-Wilk and Kolmogorov-Smirnov tests). 


\subsubsection{Shapiro-Wilk and Kolmogorov-Smirnov tests}

The null hypothesis of normality was rejected for all items using both the Shapiro-Wilk and Kolmogorov-Smirnov tests. However, this is not a cause for alarm as we are dealing with data collected using the Likert Scale. Mendenhall et al. (1993), in the book "Statistics for Management and Economics", writes:

"It is important to note that the Student's $t$ and the corresponding tabulated critical values are based on the assumption that the sampled population possesses a normal probability distribution." He goes on to write:

"Fortunately, this point is of little consequence, as it can be shown that the distribution of the $t$ statistic possesses nearly the same shape as the theoretical $t$ distribution for populations that are nonnormal but possess a mound shaped probability distribution."

Two major reasons for lack of normality are the presence of outliers and the nature of variable itself. In some way this finding was not surprising given the nature of survey questions. It is not possible to have a perfectly normal distribution with a 5-point likert scale question (University of Northern Iowa, 2009). This is because the range of answers in likert scale is discrete, not continuous. So the least we require is that the distribution be mound shaped.

\subsubsection{Histograms, box-plots and stem and leaf diagrams}

The mound shape can be checked by looking at histograms, box-plots and stem and leaf diagrams of the data. The analysis of histograms revealed that the distributions are indeed mound shaped for each and every item. 


\subsubsection{Skewness, Kurtosis and Outliers}

To examine further we did skewness and kurtosis tests. Through histograms we know that most of the variables exhibit strong negative skewness, while a very few are positively skewed. Some are even close to normal, with only slight skewness and almost normal tails centered on the median.

We were interested in determining to what extent skewness and kurtosis were reinforced by outliers. Steven observed that regardless of the data distribution, the percentage of observations that are contained within three standard deviations of the mean must be at 89\%. Shiffler (1988) suggests in Stevens (1996) that the largest possible $\mathrm{z}$ value in a data set is bounded by $\sqrt{ }(\mathrm{n}-1) / \mathrm{n}$. With sample size of 194 , the $\mathrm{z}$ score should not exceed 13.86 . Data analysis indicated that no variable in this study contained more than $3.6 \%$ of outliers. None of them has Z score that exceeded $|6.8|$.

Another way to assess the impact of outliers is to see whether or not the values classified as outliers are causing a serious problem with the data. SPSS has the option of giving the "5\% Trimmed Mean", in which it removes the top and bottom 5 per cent of the cases and calculates a new mean value. This can be compared with the original mean value to see if the outliers are having a significant influence on it. When trimmed mean was calculated, it was found that none of the trimmed means differed significantly from the original means.

Osborne (2002) suggests utilizing data transformations with care and not without a strong and clear reason. Data transformations, he cautions, can alter the fundamental nature of the data, such as "changing the measurement scale from interval or ratio to ordinal, and 
creating curvilinear relationships, complicating interpretation." Therefore, on the basis of various analyses, the existing outliers were not deleted or transformed, and the data set was considered approximately normal.

\subsubsection{Non-Response Bias}

With a relatively low response rate, it is important to see if the non-response bias could have an impact on the results. Non-response bias exists if there is any difference between those who responded and those who did not respond.

Normally the late respondents, not very prompt in sending the questionnaires back, are considered akin to non-respondents. Armstrong and Overton (1977) compare the early respondents with late respondents, called exploration method, to determine the extent of non-response bias.

The questionnaires received from the respondents were sequentially numbered and entered in SPSS. The dataset was thus grouped into two sets - the first 50 responses and last 50 responses. The t-test performed to check the difference in all independent variables did not produce significantly different scores at 5 percent confidence level.

\subsubsection{Common Method Bias}

To check for common method variance, we used Harman's (1967) one-factor test. We factor-analyzed all the items representing influencing factors, manufacturing strategy and performance variables in SPSS with a principal component extraction method and varimax rotation to examine if one single factor would emerge and would account for most of the covariance in the variables (Verhoef and Leeflang, 2009). 
If a large majority of the variance is explained by the first factor it is an indication that common method bias may be an issue. Using a varimax rotation, the factors had variances explained ranging from $1.24 \%$ to $21.61 \%$. Thus, it is concluded that common method bias does not appear to be a problem in this study.

\subsection{Principal Component Analysis}

Since almost all of the measures used in the study were supported by theory and validated in the literature, it was, therefore, concluded that exploratory factor analysis (EFA) was not required. However, it was decided to conduct Principal Component Analysis (PCA) of multi-item scales since measures were not used in this type of setting in the past and item reduction could be achieved with PCA. PCA is an item reduction scheme that clusters together items sharing a common source of variance (Stevens, 1996).

The purpose of PCA is to reduce the dimensionality of the data set (Malhotra, 2007; Zwol, 2006; Turias et al., 2005; Bouzida et al., 2004; Hill et al., 2004). However, EFA is often preferred when the goal of the analysis is to detect structure.

The independent variables were divided into two categories:

1) Influencing factors - positioning strategy

2) Influencing factors - manufacturing strategy

Another three sets of variables comprising of dependent, mediating, and control, are given below:

3) Organizational Performance (dependent variable)

4) Positioning Strategy Dimensions (mediating variable)

5) Industry Environment (control variable) 
Manufacturing strategy dimensions were single items and thus PCA was not needed for them. Product life cycle was a nominal scale and thus also excluded from PCA.

Before analyzing the scales, it is recommended to examine the intercorrelation matrix of each scale to see if it is factorable (Kim and Mueller, 1978a; Tabachnick and Fidell, 1989). According to Tabachnick and Fidell (1989), a factorable matrix should include several sizeable correlations (i.e., correlations that exceed .30). Stevens (1996) suggested that the presence of potential common underlying constructs can also be confirmed by Bartlett's sphericity test which tests the null hypothesis that the variables in the correlation matrix are uncorrelated. Upon examination, all correlation matrices were found to have several sizeable correlations, and Kaiser-Meyer-Oklin (KMO) Measure of Sampling Adequacy \& Bartlett's tests of sphericity were all found to be significant. The details of tests are given below in Table 24 .

Table 24: KMO and Bartlett's Tests

\begin{tabular}{|c|l|c|c|c|c|}
\hline \multirow{2}{*}{ Group } & \multicolumn{1}{|c|}{ Group Details } & \multirow{2}{*}{ KMO } & \multicolumn{3}{|c|}{ Bartlett's tests of Sphericity } \\
\cline { 5 - 6 } & & & Chi-Square & Df & $\begin{array}{c}\text { Significance } \\
\text { Level }\end{array}$ \\
\hline 1 & $\begin{array}{l}\text { Influencing Factors - } \\
\text { positioning strategy }\end{array}$ & 0.821 & 2975.997 & 435 & 0.000 \\
\hline 2 & $\begin{array}{l}\text { Influencing Factors - manufacturing } \\
\text { strategy }\end{array}$ & 0.817 & 2152.105 & 378 & 0.000 \\
\hline 3 & Organizational Performance & 0.776 & 659.731 & 21 & 0.000 \\
\hline 4 & Positioning Strategy Dimensions & 0.787 & 1225.509 & 120 & 0.000 \\
\hline 5 & Industry Environment & 0.737 & 632.845 & 78 & 0.000 \\
\hline
\end{tabular}

To improve the interpretability of the results, many statistics experts (e.g., Kim and Mueller, 1978b; Rummel, 1970; Stevens, 1996; Tabachnick and Fidell, 1989) have suggested the use of an orthogonal (varimax) rotation, that makes the factors uncorrelated and clearly clusters items that have high loadings on one factor. Only factors with 
eigenvalues greater than one were retained in the analysis, following Stevens' suggestion and Keiser's criterion. We retained only those factors that have factor loadings above 0.50. ). The reliability of each construct was measured with Cronbach's Alpha.

\subsubsection{Influencing Factors - Positioning Strategy (Independent variables)}

All the variables influencing the positioning strategy were entered into SPSS to conduct PCA. The findings are given below in Table 25 and 26.

Table 25: Total Variance Explained

\begin{tabular}{|c|c|c|c|}
\hline & \multicolumn{3}{|c|}{ Rotation Sums of Square Loadings } \\
\hline Component & Total & \% of Variance & Cumulative Variance \% \\
\hline 1 & 4.461 & 15.384 & 15.384 \\
\hline 2 & 3.361 & 11.589 & 26.973 \\
\hline 3 & 2.777 & 9.576 & 36.550 \\
\hline 4 & 2.626 & 9.054 & 45.604 \\
\hline 5 & 2.527 & 8.715 & 54.319 \\
\hline 6 & 2.416 & 8.332 & 62.651 \\
\hline 7 & 2.164 & 7.460 & 70.111 \\
\hline
\end{tabular}

Table 26: PCA: Influencing Factors-Positioning Strategy

\begin{tabular}{|l|c|}
\hline Component/Indicators & Loading \\
\hline Innovation Orientation & \\
We often use innovative technologies in the new product development & 0.79 \\
We are very proactive in the development and deployment of new technologies & 0.86 \\
We always rank among the first to use a new technology for new product development & 0.86 \\
Our products always reflect state-of-the-art technology & 0.70 \\
We introduce radical product innovations into the market more frequently than our & 0.84 \\
competitors & \\
Our percentage of radical product innovations in the product range in the last 3 years is & 0.86 \\
significantly higher compared to the competition $\quad$ Cronbach's Alpha $=0.919$ & \\
\hline Marketing Capability - Communication & \\
Developing and executing advertising programs & 0.61 \\
Managing brand image & 0.61 \\
Managing corporate image and reputation & 0.52 \\
\hline Marketing Capability - Planning & \\
Making full use of marketing research information &
\end{tabular}




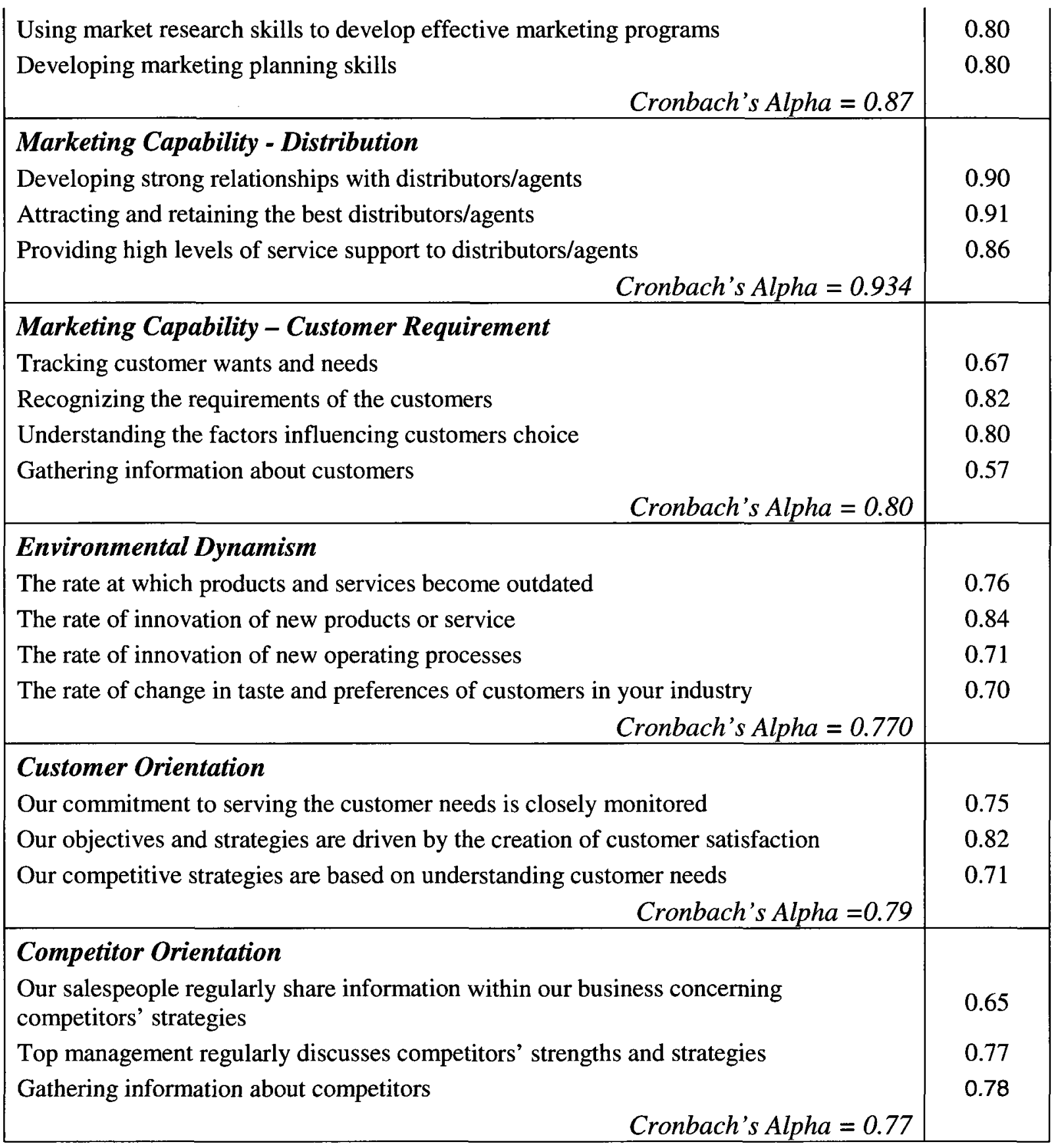

A total of seven components emerged after the analysis, accounting for $70 \%$ variance in the constructs, with eigenvalues of greater than 1 (Table 25).

The first component comprises innovation orientation and innovation type indicators. All the items loaded on the same component with high loadings and a very high Cronbach's 
Alpha of 0.919 . Both innovation orientation and innovation type indictors depict high technology aspects and thus are retained in the same component and named innovation orientation.

The original scale of marketing capability entered into the analysis had five dimensions market information management, marketing planning, distribution channel management, customer requirements, and marketing communication. Three indicators for marketing information loaded with three different components and were merged with those constructs as they appeared to represent those constructs. This leaves us with four dimensions of marketing capability - communication, planning, distribution, and customer requirement. Communication capability has relatively lower item loadings of 0.52 to 0.61 and Cronbach's Alpha of 0.664 . However, both the loading and Cronbach's Alpha meet the minimum threshold ( 0.50 for loading and .060 for Cronbach's Alpha) and thus component is retained. Planning, distribution, and customer requirement capabilities have high item loading and high Cronbach's Alpha, 0.87, 0.934, 0.80. The indicators for marketing communication and marketing planning loaded on the same component but are considered separate variables as supported by the literature.

Environmental dynamism was posited to influence the development of strategy positioning and manufacturing. All the items have high loading with high Cronbach's Alpha. One item from competitor orientation had a loading of less than 0.50 and was thus removed from the analysis. The remaining two items have high loading and Cronbach's Alpha. The constructs of customer and competitor orientation have three items each with high loadings as well as Cronbach's Alphas. 


\subsubsection{Influencing Factors - Manufacturing Strategy (Independent variables)}

All the variables influencing the manufacturing strategy were entered into SPSS to conduct PCA. The constructs of innovation orientation, innovation type and environmental dynamism were entered in previous analysis - factors influencing positioning strategy. However, these three factors are posited to influence the development of manufacturing strategy as well and thus were again entered in PCA for this analysis. The findings of PCA are given below in Table 27 and 28.

Table 27: Total Variance Explained

\begin{tabular}{|c|c|c|c|}
\hline & \multicolumn{3}{|c|}{ Rotation Sums of Square Loadings } \\
\hline Component & Total & \% of Variance & Cumulative Variance \% \\
\hline 1 & 4.941 & 14.972 & 14.972 \\
\hline 2 & 3.382 & 10.249 & 25.221 \\
\hline 3 & 3.074 & 9.316 & 34.538 \\
\hline 4 & 2.485 & 7.531 & 42.069 \\
\hline 5 & 2.314 & 7.012 & 49.081 \\
\hline 6 & 2.123 & 6.433 & 55.514 \\
\hline 7 & 1.935 & 5.863 & 61.377 \\
\hline 8 & 1.713 & 5.191 & 66.567 \\
\hline
\end{tabular}

Table 28: PCA-Influencing Factors-Manufacturing Strategy

\begin{tabular}{|l|c|}
\hline Component/Indicators & Loading \\
\hline Innovation Orientation & \\
\hline We often use innovative technologies in the new product development & 0.77 \\
We are very proactive in the development and deployment of new technologies & 0.83 \\
We always rank among the first to use a new technology for new product development & 0.88 \\
Our products always reflect state-of-the-art technology & 0.68 \\
We introduce radical product innovations into the market more frequently than our & 0.83 \\
competitors rars & 0.86 \\
Our percentage of radical product innovations in the product range in the last 3 years is & \\
\hline significantly higher compared to the competition $\quad$ Cronbach's Alpha $=0.919$ & \\
\hline
\end{tabular}




\begin{tabular}{|c|c|}
\hline Manufacturing Capability - Quality & \\
\hline Improving product support services & 0.58 \\
\hline Improving product performance & 0.87 \\
\hline Improving product reliability & 0.79 \\
\hline Improving product features & 0.64 \\
\hline Increasing design innovation & 0.63 \\
\hline Cronbach's Alpha $=0.819$ & \\
\hline Resource Orientation & \\
\hline We gain a competitive advantage from our unique practices & 0.60 \\
\hline We believe that organizations should build and maintain core competencies and skills & 0.61 \\
\hline Our practices are unique and cannot be easily copied by others & 0.60 \\
\hline Cronbach's Alpha $=0.651$ & \\
\hline Business Strategy Orientation & \\
\hline Our business strategy is translated into manufacturing terms & 0.75 \\
\hline $\begin{array}{l}\text { Potential manufacturing investments are screened for consistency with our business } \\
\text { strategy }\end{array}$ & 0.67 \\
\hline At our plant, manufacturing is kept in step with our business strategy & 0.69 \\
\hline Manufacturing management is not aware of our business strategy & 0.83 \\
\hline Corporate decisions are often made without consideration of the manufacturing strategy & 0.82 \\
\hline Cronbach's Alpha $=0.811$ & \\
\hline Environmental Dynamism & \\
\hline The rate at which products and services become outdated & 0.77 \\
\hline The rate of innovation of new products or service & 0.84 \\
\hline The rate of innovation of new operating processes & 0.71 \\
\hline The rate of change in taste and preferences of customers in your industry & 0.74 \\
\hline Cronbach's Alpha $=0.770$ & \\
\hline Manufacturing Capability - Cost & \\
\hline Reducing production costs & 0.87 \\
\hline Reducing overall costs & 0.85 \\
\hline Reducing inventory levels & 0.66 \\
\hline Cronbach's Alpha $=0.731$ & \\
\hline Manufacturing Capability - Flexibility & \\
\hline Increasing variety of sizes & 0.87 \\
\hline Increasing variety of products & 0.83 \\
\hline Cronbach's Alpha $=0.755$ & \\
\hline Manufacturing Capability - Delivery & \\
\hline Increasing delivery speed & 0.71 \\
\hline Maintaining delivery due date & 0.73 \\
\hline Cronbach's Alpha $=0.627$ & \\
\hline
\end{tabular}


A total of eight components emerged after the analysis, accounting for $67 \%$ variance in the constructs, with eigenvalues of greater than 1 (Table 27).

Just like the previous PCA (influencing factors of positioning strategy), the first component comprises innovation orientation and innovation type indicators. All the items loaded on the same component with high loadings and a very high Cronbach's Alpha of 0.919 .

The items for resource orientation and business strategy orientation loaded on the same construct. However, theoretically they are two distinct constructs, well defined in the literature. Therefore, it was decided to keep them as separate variables. All the items for business strategy and resource orientation have high loadings and Cronbach's Alphas. Only one item from resource orientation was removed due to loading of less than 0.50 .

Manufacturing capability was posited to have five dimensions - quality, cost, flexibility, delivery and innovation. One item each from resource orientation and innovation, quality capabilities were also removed for having less than 0.50 loadings. The sole remaining item from innovation capability loaded with quality capability. The remaining dimensions of manufacturing capability - quality, cost, flexibility, and delivery have high item loadings and reasonably good Cronbach's Alphas. Just like previous analysis, all the items for environmental dynamism were retained with high loadings and Cronbach's Alpha.

The items for innovation orientation and environmental dynamism have almost the same loading as when analyzed with positioning and manufacturing strategy influencing 
factors. Thus there is no change in the construct when applied within the domain of marketing or operations management domain.

\subsubsection{Organizational Performance (Dependent variables)}

Organizational performance has two dimensions, financial and non-financial. The findings of the PCA are given below:

Table 29: Total Variance Explained

\begin{tabular}{|c|c|c|c|}
\hline & \multicolumn{3}{|c|}{ Rotation Sums of Square Loadings } \\
\hline Component & Total & \% of Variance & Cumulative Variance \% \\
\hline 1 & 3.202 & 45.757 & 45.747 \\
\hline 2 & 1.670 & 23.859 & 69.607 \\
\hline
\end{tabular}

Table 30: PCA - Organizational Performance

\begin{tabular}{|c|c|}
\hline \multicolumn{2}{|l|}{ Component/Indicators } \\
\hline \multicolumn{2}{|l|}{ Performance - Financial } \\
\hline Market Share & 0.61 \\
\hline Sales Growth & 0.66 \\
\hline Return on investment & 0.89 \\
\hline Overall Profitability & 0.89 \\
\hline \multirow[t]{2}{*}{ Profit Growth } & 0.88 \\
\hline & \\
\hline \multirow{3}{*}{$\begin{array}{l}\text { Performance - Non Financial } \\
\text { Customer's satisfaction } \\
\text { Customer's loyalty }\end{array}$} & \\
\hline & 0.89 \\
\hline & 0.85 \\
\hline Cronbach's Alpha $=0.750$ & \\
\hline
\end{tabular}

As posited earlier, the two dimensions of organizational performance - financial and non financial - are loaded as two components, and together they explain almost $70 \%$ variation in the constructs (Table 29). All the items have high loadings and Cronbach's Alphas. 


\subsubsection{Positioning Strategy Dimensions (Mediating variables)}

There were seven positioning strategy dimensions culled from the literature - innovation, value, quality, service, customization, reliability, and differentiation, almost all of them with multiple items. However, some of the positioning strategy items used in this study were not validated in the literature. Therefore, PCA, in this case, is more like an exploratory factor analysis. The findings of the analysis are given below:

Table 31: Total Variance Explained

\begin{tabular}{|c|c|c|c|}
\hline & \multicolumn{3}{|c|}{ Rotation Sums of Square Loadings } \\
\hline Component & Total & \% of Variance & Cumulative Variance \% \\
\hline 1 & 2.252 & 14.074 & 14.074 \\
\hline 2 & 2.014 & 12.589 & 26.663 \\
\hline 3 & 1.706 & 10.664 & 37.327 \\
\hline 4 & 1.645 & 10.284 & 47.611 \\
\hline 5 & 1.594 & 9.960 & 57.570 \\
\hline 6 & 1.569 & 9.805 & 67.375 \\
\hline 7 & 1.224 & 7.650 & 75.026 \\
\hline 8 & 1.196 & 7.473 & 82.499 \\
\hline
\end{tabular}

Table 32: PCA-Positioning Strategy Dimensions

\begin{tabular}{|c|c|c|}
\hline \multicolumn{2}{|l|}{ Component/Indicators } & Loading \\
\hline \multicolumn{3}{|l|}{ Component 1 (Product Focus) } \\
\hline Product features & & 0.86 \\
\hline \multirow[t]{2}{*}{ Product benefits } & & 0.86 \\
\hline & Cronbach's Alpha $=0.88$ & \\
\hline \multicolumn{3}{|l|}{ Component 2(Quality) } \\
\hline High quality & & 0.71 \\
\hline High durability & & 0.80 \\
\hline High reliability & & 0.67 \\
\hline & Cronbach's Alpha $=0.74$ & \\
\hline
\end{tabular}




\begin{tabular}{|c|c|}
\hline $\begin{array}{l}\text { Component } 3 \text { (Price) } \\
\text { Low price } \\
\text { Price relative to competitors }\end{array}$ & $\begin{array}{l}0.89 \\
0.89\end{array}$ \\
\hline $\begin{array}{l}\text { Component } 4 \text { (Innovation) } \\
\text { Product uniqueness } \\
\text { New technology }\end{array}$ & $\begin{array}{l}0.78 \\
0.85\end{array}$ \\
\hline $\begin{array}{l}\text { Component } 5 \text { (Brand Focus) } \\
\text { Brand image } \\
\text { Company image }\end{array}$ & $\begin{array}{l}0.86 \\
0.79\end{array}$ \\
\hline $\begin{array}{l}\text { Component } 6 \text { (Customer Focus) } \\
\text { Extra effort to meet customer's requirements } \\
\text { Customizing product to meet customer's needs }\end{array}$ & $\begin{array}{l}0.62 \\
0.88\end{array}$ \\
\hline $\begin{array}{l}\text { Component } 7 \text { (Value) } \\
\text { Value to customer }\end{array}$ & 0.90 \\
\hline $\begin{array}{l}\text { Component } 8 \text { (Service) } \\
\text { Friendliness of staff }\end{array}$ & 0.94 \\
\hline
\end{tabular}

A total of eight components, with eigenvalues of greater than 1, explain 82 percent of variation in the constructs. The objective of PCA in this case was not only to reduce the number of dimensions but also to detect the underlying structure of the components since there are no validated measures for positioning strategies. The measures used in this study mainly come from the studies which have used them as indicators for competitive advantage. Only one item from service dimension did not load due to loading of less than 0.50. However, a number of items did not load on the intended dimensions. For example, quality loaded with reliability items, both differentiation and value split into two components each. However, the new components were strongly supported by theory and thus were retained and re-named. All the items have high loadings ranging from 0.62 to 
0.90. The Cronbach's Alphas are satisfactory to high. The components 7 and 8 , named value and service, are treated as single item constructs.

The components of positioning strategy were renamed as follows:

Table 33: PCA- Renamed Positioning Strategy Dimensions

\begin{tabular}{|l|l|}
\hline $\begin{array}{l}\text { Previous Construct } \\
\text { (Before PCA) }\end{array}$ & $\begin{array}{l}\text { Renamed Construct } \\
\text { (After PCA) }\end{array}$ \\
\hline $\begin{array}{l}\text { 1) Quality } \\
\text { 2) Reliability }\end{array}$ & 1) Quality \\
\hline 3) Service & 2) Service \\
\hline 4) Value & $\begin{array}{l}\text { 3) Value } \\
\text { 4) Price }\end{array}$ \\
\hline 5) Customization & 5) Customer Focus \\
\hline 6) Differentiation & $\begin{array}{l}\text { 6) Brand Focus } \\
\text { 7) Product Focus }\end{array}$ \\
\hline 7) Innovation & 8) Innovation \\
\hline
\end{tabular}

\subsubsection{Industry Environment (Control variables)}

The last group of variables, industry environment, is a control variable. It is based on Porter's five forces model which has five dimensions - competitive rivalry, buyer power, supplier power, entry barriers and threats of substitutes. The findings of the PCA are given below:

Table 34: Total Variance Explained

\begin{tabular}{|c|c|c|c|}
\hline & \multicolumn{3}{|c|}{ Rotation Sums of Square Loadings } \\
\hline Component & Total & \% of Variance & Cumulative Variance \% \\
\hline 1 & 1.994 & 28.483 & 28.434 \\
\hline 2 & 1.748 & 24.969 & 53.452 \\
\hline 3 & 1.501 & 21.443 & 74.869 \\
\hline
\end{tabular}


Table 35: PCA-Industry Environment

\begin{tabular}{|c|c|}
\hline Component/Indicators & Loading \\
\hline \multicolumn{2}{|l|}{ Rivalry } \\
\hline Competition in our industry is cut-throat. & 0.82 \\
\hline There are many "promotion wars" in our industry & 0.73 \\
\hline Price competition is a hallmark of our industry & 0.82 \\
\hline \multicolumn{2}{|l|}{ Cronbach's Alpha $=0.73$} \\
\hline \multirow{4}{*}{\multicolumn{2}{|c|}{$\begin{array}{l}\text { Supplier Power } \\
\text { Our major suppliers have the strength to bargain with us effectively } \\
\text { Our major suppliers or vendors have the power to dictate prices to us } \\
\qquad \text { Cronbach's Alpha =0.74 }\end{array}$}} \\
\hline & \\
\hline & \\
\hline & \\
\hline \multirow{4}{*}{$\begin{array}{l}\text { Substitute Products } \\
\text { Competitors outside our industry offer viable substitutes for our products } \\
\text { The prices of our products are always under pressure from substitute products } \\
\qquad \text { Cronbach's Alpha }=0.65\end{array}$} & \\
\hline & 0.92 \\
\hline & 0.70 \\
\hline & \\
\hline
\end{tabular}

One component, entry barriers, was completely eliminated, mainly due to cross-loading with other components which were theoretically not supported. Another component power of buyers - had reasonably high loadings (> .70) but Cronbach's Alpha of 0.378 and was thus removed from the analysis. The remaining components have high loadings as well as reasonably good values of Cronbach's Alpha.

\subsubsection{Summary of Principal Component Analysis}

PCA was conducted as a data reduction technique. Empirically reducing the number of variables into logical components provides reasonable power to detect significance while running regressions. Principal components, with little or no correlations among themselves, minimize the problem of multicollinerarity among the variables (Field, 2006). Principal component analysis was preferred over other factor analysis techniques as it is considered a psychometrically sound technique (Stevens, 1996). 
The Table below shows the total number of items before and after PCA:

Table 36: PCA - Item Reduction Summary

\begin{tabular}{|clcc|}
\hline \multirow{2}{*}{ Group } & \multicolumn{1}{c}{ Group Details } & $\begin{array}{c}\text { Items before } \\
\text { PCA }\end{array}$ & $\begin{array}{c}\text { Items after } \\
\text { PCA }\end{array}$ \\
\hline 1 & Influencing Factors - positioning strategy * & 30 & 29 \\
2 & Influencing Factors - manufacturing strategy * & 33 & 30 \\
3 & Organizational Performance & 7 & 7 \\
4 & Positioning Strategy Dimensions & 16 & 15 \\
5 & Industry Environment & 13 & 7 \\
\hline & TOTAL & 99 & 88 \\
\hline
\end{tabular}

* the items for innovation orientation and environmental dynamism were counted twice since they were part of influencing factors for both positioning and manufacturing strategy

Therefore, a total of 11 items were removed due to loadings less than 0.50 .

The factor loading ranged from 0.53 to 0.92 , which are comparable to figures obtained in many marketing studies (e.g., Edison and Geissler, 2003; Volckner and Sattler, 2006). In addition, the explained variance ranged from 0.68 to .82 which exceeds the 0.5 benchmark (Fornell and Larcker, 1981).

The resulting components formed scales that will be utilized in further analysis. It must be noted that for the purpose of scale development, weights of each initial item (i.e., its relative importance based on factor loadings) within a factor were not taken into account, and factor scores were computed as the summed average of the items loadings on each component.

Before conducing further analysis it is essential to establish the reliability and validity of the new measures. Any measurement instrument should be reliable and valid, and should 
measure what it is supposed to measure (Nunnally, 1978). The methods used to test reliability and validity are discussed in the following subsections.

\subsection{Reliability of Measures}

Testing internal consistency or reliability is essential in social science research as most studies involve latent variables. Internal consistency determines the degree to which the respondent's answer is consistent across the items of the same measure (Schwab, 1999).

There are several methods to assess the reliability of a measure. First of all, the use of scientifically well-grounded procedures of measure development entails a certain degree of reliability. When appropriate and relevant criteria for factor/component selection is applied (i.e., substantive meanings, factor loadings, and eigenvalues), factors/components can be considered reliable (Tabachnick and Fidell, 1989). Coefficient alpha is considered as the first test applied to all new measures (Nunnally, 1978). The coefficient determines the percentage of total variance which is caused by systematic or true variance in test scores.

The Table 37 lists the Cronbach's Alphas for all the multi-item constructs in the study. The Cronbach's Alpha values range from 0.60 to 0.93 , all exceeding the recommended level of 0.60 (Nunnally, 1967). Normally, coefficients of 0.7 or more are considered adequate (Nunnally 1978). However, Nunnally further states that adequate Cronbach's Alpha values for new scales can be taken as 0.60. Malhotra (2004) also considers Cronbach's Alpha greater than 0.6 to be adequate for reliability of construct. Anderson and Coughan (1987) suggest that a low alpha value is acceptable in marketing literature if 
scale is made-up of only two items. In fact, Kathuria and Porth (2003) used a multi-item scale with alpha as low as 0.36 .

\section{Table 37: Reliability of Constructs}

\begin{tabular}{|l|c|c|}
\hline Construct/Variable & Alpha & No. of Items \\
\hline Customer Orientation & 0.79 & 3 \\
\hline Competitor Orientation & 0.77 & 3 \\
\hline Marketing Capability - Distribution & 0.93 & 3 \\
\hline Marketing Capability - Marketing Communication & 0.66 & 3 \\
\hline Marketing Capability - Marketing Planning & 0.87 & 3 \\
\hline Marketing Capability - Customer Requirements & 0.80 & 4 \\
\hline Innovation Orientation & 0.92 & 6 \\
\hline Environmental Dynamism & 0.77 & 4 \\
\hline Resource Orientation & 0.65 & 3 \\
\hline Business Strategy Orientation & 0.81 & 5 \\
\hline Manufacturing Capability - Quality & 0.82 & 5 \\
\hline Manufacturing Capability - Cost & 0.73 & 3 \\
\hline Manufacturing Capability - Flexibility & 0.76 & 2 \\
\hline Manufacturing Capability - Delivery & 0.63 & 2 \\
\hline PS - Customer Focus & 0.60 & 2 \\
\hline PS - Product Focus & 0.88 & 2 \\
\hline PS - Brand Focus & 0.68 & 2 \\
\hline PS - Innovation & 0.75 & 2 \\
\hline PS - Quality & 0.74 & 3 \\
\hline PS - Price & 0.77 & 2 \\
\hline Firm Performance - Financial & 0.86 & 5 \\
\hline Firm Performance - Non-Financial & 0.75 & 2 \\
\hline Competitive Rivalry & 0.73 & 3 \\
\hline Supplier Power & 0.74 & 2 \\
\hline Threats of Substitutes & 0.65 & 2 \\
\hline & & \\
\hline & & 2 \\
\hline
\end{tabular}

However, high reliability only ensures that all the items of the scale "hang together" (Stevens, 1996, p.31) and consistently measure the same thing. Nonetheless, even perfectly reliable scales may not measure the right thing or be associated with other related variables (Cascio, 1991). Therefore, reliability is a necessary but insufficient condition adequacy of a measure. The measure must also be valid. 


\subsection{Validity of Measures}

A measurement instrument should meet at least two purposes - it should represent a specified universe of content and measure the subject matter (Nunnally, 1978). These purposes correspond to two types of validity - content and construct validity.

\subsubsection{Content Validity}

Content Validity is defined as the extent to which a measurement reflects the specific intended domain of content (Carmines and Zeller, 1991, p.20). The content validity of survey instruments can be ascertained by a review of the questionnaire by experts or potential respondents from the target population. The objective of the review is to assess the relevance of the items and remove any vagueness from questionnaire design. The content validity is a qualitative measure of validity and is normally not quantified with statistical methods. To attain content validity, a thorough and extensive literature review was conducted and the questionnaire was reviewed by two experts and pre-tested by five respondents.

\subsubsection{Construct Validity}

Construct validity is related to the ability of the measure to represent the concept being measured (Davis, 1996). For a construct to be validated, measures of variables in a theoretical framework should relate to each other in a predictable and a systematic way (Cronbach and Meehl, 1955). Thus, measures of constructs that are theoretically related to each other should statistically also be related. Similarly, measures of constructs that are theoretically unrelated to each other should statistically not be related. In line with this 
interpretation, construct validity is broken down into two sub-categories: convergent and discriminant (or divergent) validity. In this respect, it has been stated that researchers have to demonstrate evidence for both convergent and discriminant validity in order to establish construct validity (Trochim, 2002). Neither one alone is sufficient for establishing construct validity.

Convergent validity is established when correlations between different measures of the same theoretical construct are high and significantly different from zero. On the other hand, discriminant validity is recognized when correlations between measures of dissimilar constructs are low (i.e., close to zero) (House and Rizzo, 1972b). Therefore, a high correlation between the multiple measures of the same construct would prove that they reflect the same construct. On the other hand, the low correlations between different constructs of the same instrument would demonstrate that they represent distinct concepts not related to each other (Cascio, 1991).

To establish convergent validity, one must demonstrate that measures that should be related are related. Appendix 4 lists correlations between measures of each construct. There are total of 25 multi-item constructs. There are a total of five constructs with 7 inter-item correlations of less than 0.39 with the lowest inter-item correlation of 0.289 . The convergent validity is, therefore, established in this study.

To establish discriminant validity, one needs to demonstrate that measures that should not be related are in reality not related. In other words, discriminant validity represents the distinctiveness of constructs, and is measured by estimating the correlations between constructs (Edison and Geissler, 2003). Correlations are considered "excessively high" if 
greater than 0.85 (Kline, 2005, pg. 73). Tables 38 to 41 list the correlations between all constructs. In almost all cases, the correlations are acceptable, and suggest discriminant validity. The highest correlation is 0.548 , between two dimensions of marketing capability - communication and planning. However, it is well below the threshold of 0.85 prescribed by Kline (2005).

Table 38: Correlation Matrix of Influencing Factors - Positioning Strategy

\begin{tabular}{|c|c|c|c|c|c|c|c|c|}
\hline Construct & $\mathbf{1}$ & 2 & 3 & 4 & 5 & 6 & 7 & 8 \\
\hline 1 Customer Orientation & 1.000 & & & & & & & \\
\hline 2 Competitor Orientation & $.267^{* *}$ & 1.000 & & & & & & \\
\hline 3 Marketing Capability-distribution & $.232^{* *}$ & $.353^{* *}$ & 1.000 & & & & & \\
\hline $4 \begin{array}{l}\text { Marketing Capability- } \\
\text { communication }\end{array}$ & $.254^{* *}$ & $.293^{* *}$ & $.367^{* *}$ & 1.000 & & & & \\
\hline 5 Marketing Capability-planning & $.230^{* *}$ & $.492^{* *}$ & $.334^{* *}$ & $.548^{* *}$ & 1.000 & & & \\
\hline $6 \begin{array}{l}\text { Marketing Capability-customer } \\
\text { requirement }\end{array}$ & $.507^{* *}$ & $.331^{* *}$ & $.266^{* *}$ & $.380^{* *}$ & $.421^{* *}$ & 1.000 & & \\
\hline 7 Innovation Orientation & $.326^{* *}$ & $.262^{* *}$ & $.214^{* *}$ & $.383^{* *}$ & $.224^{* *}$ & $.342^{* *}$ & 1.000 & \\
\hline 8 Environmental dynamism & -.024 & $.165^{*}$ & -.035 & $.241^{* *}$ & $.201^{* *}$ & .009 & .099 & 1.000 \\
\hline
\end{tabular}

** Correlation is significant at the 0.01 level (2-tailed).

* Correlation is significant at the 0.05 level (2-tailed).

Table 39: Correlation Matrix of Influencing Factors - Manufacturing Strategy

\begin{tabular}{|c|c|c|c|c|c|c|c|c|}
\hline Construct & 1 & 2 & 3 & 4 & 5 & 6 & 7 & 8 \\
\hline 1 Resource Orientation & 1.000 & & & & & & & \\
\hline 2 Business Strategy Orientation & $.516^{* *}$ & 1.000 & & & & & & \\
\hline $\begin{array}{l}\text { Manufacturing Capability - } \\
\text { Quality }\end{array}$ & $.326^{* *}$ & $.356^{* *}$ & 1.000 & & & & & \\
\hline 4 Manufacturing Capability - Cost & $.155^{*}$ & $.279^{* *}$ & $.214^{* *}$ & 1.000 & & & & \\
\hline $\begin{array}{ll}\text { Manufacturing Capability - } \\
\text { Flexibility }\end{array}$ & $.197^{* *}$ & .123 & $.279^{* *}$ & .124 & 1.000 & & & \\
\hline $\begin{array}{l}\text { Manufacturing Capability - } \\
\text { Delivery }\end{array}$ & $.224^{* *}$ & $.295^{* *}$ & $.340^{* *}$ & $.325^{* *}$ & $.354^{* *}$ & 1.000 & & \\
\hline 7 Innovation Orientation & $.496^{* *}$ & $.329^{* *}$ & $.437^{* *}$ & .132 & $.196^{* *}$ & .084 & 1.000 & \\
\hline 8 Environmental dynamism & .017 & -.016 & .110 & .020 & .102 & -.035 & .099 & 1.000 \\
\hline
\end{tabular}

** Correlation is significant at the 0.01 level (2-tailed).

* Correlation is significant at the 0.05 level (2-tailed). 
Table 40: Correlation Matrix of Positioning Strategy Dimensions

\begin{tabular}{|l|c|c|c|c|c|c|c|c|}
\hline Construct & $\mathbf{1}$ & $\mathbf{2}$ & $\mathbf{3}$ & $\mathbf{4}$ & $\mathbf{5}$ & $\mathbf{6}$ & $\mathbf{7}$ & $\mathbf{8}$ \\
\hline $\mathbf{1}$ Customer Focus & $\mathbf{1}$ & & & & & & & \\
\hline $\mathbf{2}$ Product Focus & $.233^{* *}$ & 1.000 & & & & & & \\
\hline $\mathbf{3} \quad$ Brand Focus & $.289^{* *}$ & $.309^{* *}$ & 1.000 & & & & & \\
\hline $\mathbf{4}$ Innovation & $.297^{* *}$ & $.551^{* *}$ & $.401^{* *}$ & 1.000 & & & & \\
\hline $\mathbf{5}$ Quality & $.437^{* *}$ & $.496^{* *}$ & $.397^{* *}$ & $.390^{* *}$ & 1.000 & & & \\
\hline $\mathbf{6}$ Service & $.372^{* *}$ & $.167^{*}$ & $.245^{* *}$ & $.218^{* *}$ & $.211^{* *}$ & 1.000 & & \\
\hline $\mathbf{7}$ Price & $.254^{* *}$ & -.034 & -.049 & -.017 & -.028 & $.176^{*}$ & 1.000 & \\
\hline $\mathbf{8}$ Value & $.261^{* *}$ & $.341^{* *}$ & $.232^{* *}$ & $.256^{* *}$ & $.344^{* *}$ & $.246^{* *}$ & .111 & 1.000 \\
\hline
\end{tabular}

** Correlation is significant at the 0.01 level (2-tailed).

* Correlation is significant at the 0.05 level (2-tailed).

Table 41: Correlation Matrix of Manufacturing Strategy Dimensions

\begin{tabular}{|ll|l|l|l|l|l|}
\hline \multicolumn{1}{|c|}{ Construct } & \multicolumn{1}{c|}{$\mathbf{1}$} & \multicolumn{1}{c|}{$\mathbf{2}$} & $\mathbf{3}$ & $\mathbf{4}$ & $\mathbf{5}$ \\
\hline $\mathbf{1}$ Quality & 1.000 & & & & \\
\hline $\mathbf{2}$ Cost & $.160^{*}$ & 1.000 & & & \\
\hline $\mathbf{3}$ Flexibility & .115 & $.180^{*}$ & 1.000 & & \\
\hline $\mathbf{4}$ Delivery & $.320^{* *}$ & $.371^{* *}$ & $.325^{* *}$ & 1.000 & \\
\hline $\mathbf{5}$ Innovation & $.226^{* *}$ & .015 & .136 & $.213^{* *}$ & 1.000 \\
\hline
\end{tabular}

** Correlation is significant at the 0.01 level (2-tailed).

* Correlation is significant at the 0.05 level (2-tailed)

\subsection{Revised Conceptual Model}

Based on the findings of the PCA, the priori conceptual model was revised. The major difference in the revised and the priori conceptual model is the combining of constructs of innovation orientation and innovation type into one construct and renaming (along with respecification) of positioning strategy dimensions. 


\section{Figure 11: The Conceptual Framework (Revised)}

Influencing Factors
- Customer Orientation
- Competitor Orientation
- Marketing Capabilities
- Innovation Orientation
- Environmental Dynamism

\section{Control Variables}

- Industry Environment

- Product Life Cycle

Influencing Factors

- Resource Orientation

- Business Strategy Orient.

- Manufacturing Capabilities

- Innovation Orientation

- Environmental Dynamism

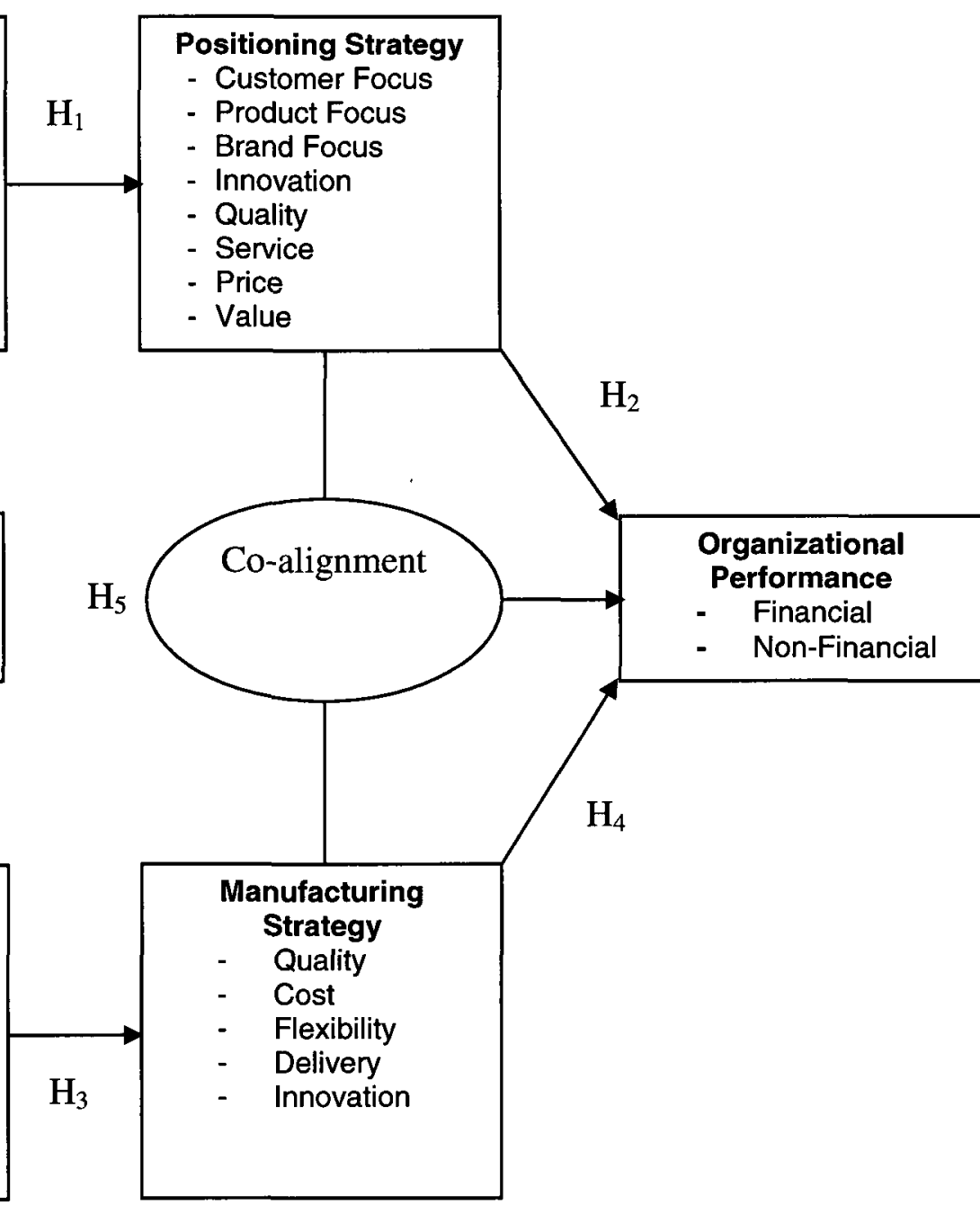

Accordingly, some of the hypotheses were also revised in line with the revised conceptual framework. The complete listing of hypotheses after revisions is given below:

\subsection{Revised Hypotheses}

The above research questions depicted in the conceptual framework lead to the following hypotheses: 
$\mathrm{H}_{1 \mathrm{a}}$ : Customer orientation will have an impact on customer focus, product focus, brand focus, innovation, quality, service, price and value positioning strategies.

$\mathrm{H}_{1 \mathrm{~b}}$ : Competitor orientation will have an impact on customer focus, product focus, brand focus, innovation, quality, service, price and value positioning strategies.

$\mathrm{H}_{1 \mathrm{c}}$ : $\quad$ Marketing capability will have an impact on customer focus, product focus, brand focus, innovation, quality, service, price and value positioning strategies.

$\mathrm{H}_{1 \mathrm{~d}}$ : Innovation orientation will have an impact on customer focus, product focus, brand focus, innovation, quality, service, price and value positioning strategies.

$\mathrm{H}_{1 \mathrm{e}}$ : Environmental dynamism will have an impact on customer focus, product focus, brand focus, innovation, quality, service, price and value positioning strategies.

\section{Positioning Strategy and Organizational Performance}

$\mathrm{H}_{2 \mathrm{a}}$ : Customer focus positioning strategy will have a positive effect on firm's financial and non-financial performance.

$\mathrm{H}_{2 b}$ : Product focus positioning strategy will have a positive effect on firm's financial and non-financial performance.

$\mathrm{H}_{2 \mathrm{c}}$ : Brand focus positioning strategy will have a positive effect on firm's financial and non-financial performance.

$\mathrm{H}_{2 \mathrm{~d}}$ : Innovation positioning strategy will have a positive effect on firm's financial and non-financial performance.

$\mathrm{H}_{2 \mathrm{e}}$ : Quality positioning strategy will have a positive effect on firm's financial and non-financial performance.

$\mathrm{H}_{2 f}$ : Service positioning strategy will have a positive effect on firm's financial and non-financial performance.

$\mathrm{H}_{2 \mathrm{~g}}$ : Price positioning strategy will have a positive effect on firm's financial and nonfinancial performance.

$\mathrm{H}_{2 \mathrm{~h}}$ : Value positioning strategy will have a positive effect on firm's financial and nonfinancial performance. 
$\mathrm{H}_{3 \mathrm{a}}$ : Resource orientation will have an impact on quality, cost, flexibility, delivery and innovation manufacturing strategy.

$\mathrm{H}_{3 \mathrm{~b}}$ : Business strategy orientation will have an impact on quality, cost, flexibility, delivery and innovation manufacturing strategy.

$\mathrm{H}_{3 \mathrm{c}}$ : Manufacturing capability will have an impact on quality, cost, flexibility, delivery and innovation manufacturing strategy.

$\mathrm{H}_{3 \mathrm{~d}}$ : Innovation orientation will have an impact on quality, cost, flexibility, delivery and innovation manufacturing strategy.

$\mathrm{H}_{3 \mathrm{e}}$ : Environmental dynamism will have an impact on quality, cost, flexibility, delivery and innovation manufacturing strategy.

\section{Manufacturing Strategy and Organizational Performance}

$\mathrm{H}_{4 \mathrm{a}}$ : Quality manufacturing strategy will have a positive effect on firm's financial and non-financial performance.

$\mathrm{H}_{4 \mathrm{~b}}$ : Cost manufacturing strategy will have a positive effect on firm's non-financial and non-financial performance.

$\mathrm{H}_{4 \mathrm{c}}$ : Flexibility manufacturing strategy will have a positive effect on firm's nonfinancial and non-financial performance.

$\mathrm{H}_{4 \mathrm{~d}}$ : Delivery manufacturing strategy will have a positive effect on firm's nonfinancial and non-financial performance.

$\mathrm{H}_{4 \mathrm{e}}$ : Innovation manufacturing strategy will have a positive effect on firm's financial and non-financial performance.

\section{Co-alignment of Manufacturing and Positioning Strategies and Organizational Performance}

$\mathrm{H}_{5}$ : Lack of co-alignment of manufacturing strategy and positioning strategy will have a negative effect on firm's financial performance and non-financial performance. 


\subsection{Summary}

The data was considered approximately normal after examining the skewness, kurtosis, histograms and QQ plots in addition to conducting various other tests. Non-response and common method bias do not seem to have any impact on the results.

Since measures used in the study were validated in the literature, PCA was used as a data reduction technique which resulted in removal of 11 items with loading of less than 0.5 . The factor loading ranged from 0.53 to 0.92 , comparable to figures obtained in many marketing studies. In addition, the explained variance ranged from 0.68 to .82 which exceeds the 0.5 benchmark.

The reliability of measures was assessed with Cronbach's Alpha which ranged from 0.60 to 0.93 , with most of them well above 0.70 . Both convergent and discriminant validity were established along with content validity. Since there was a change in some variables after PCA, the conceptual model was revised and the hypotheses were re-stated. 


\section{Chapter 9: Data Analysis}

The data analysis chapter commences with descriptives about sample characteristics in general to provide an indication of the size and nationality of firms and type of customers it serves. The differences between small and large and national versus foreign firms are also captured. Correlation analysis is used to test the association between variables. Hierarchical regression analysis is conducted to examine the impact of independent variables on dependent variables. An extensive profile deviation analysis with multiple sub-samples is conducted to test the impact of co-alignment of positioning and manufacturing strategy on firm's performance.

\subsection{Descriptive Statistics}

The survey was sent to the top echelons of the senior management (Chairman, CEO, President, Marketing Director) of the manufacturing companies from two sub-sectors in Canada. The survey collected data on various aspects of the firms - composition of their customers, number of employees, ownership of the company (Canadian or foreign) and designations of the respondents. As mentioned earlier, a total of 194 questionnaires were deemed usable.

\subsubsection{Sample Characteristics}

A large majority of the firms, 86 percent, sell their products to business firms; 14 percent sell to consumers and 20 percent to others such as government. The sum of three sectors is more than 100 percent since 34 firms sell to more than one sector and 3 firms sell to all three sectors. The comparison is given below in figure number 12 . 


\section{Figure 12: Buyers of Firms}

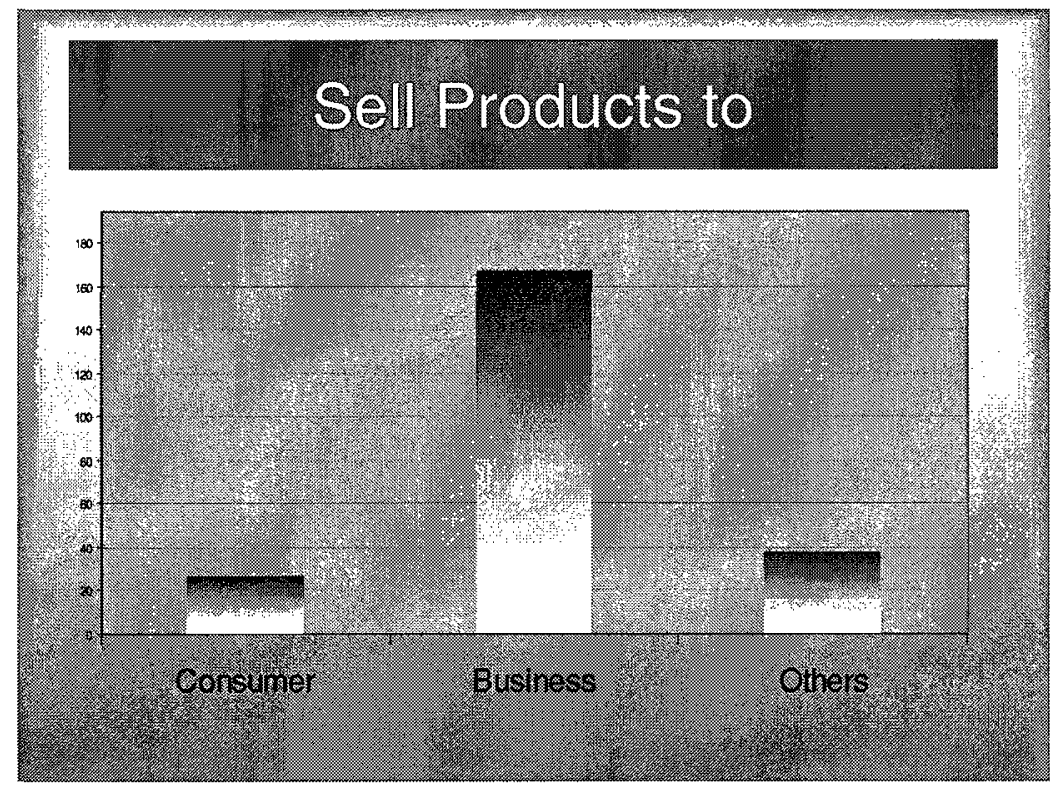

The respondents were also asked to indicate the size of the company, measured by number of employees in the firm. The sample included small as well as medium and large sized companies. However, the majority of the responses came from small sized companies. Out of 194 usable responses, 152 responses (78.4 percent) came from small companies, 33 responses (17 percent) from medium sized companies and only 9 responses (4.6 percent) from large companies (Figure 12).

Statistics Canada considers businesses having less than 100 employees as small size firms, 100 to 499 employees as medium-size firms and more than 500 employees as large-size firms. According to the 2004 Statistics Canada Report (Debus, 2005), 99.9 percent of the Canadian firms are small and medium size and only 0.1 percent are large. Our sample, thus, mirrors the makeup of the Canadian manufacturing landscape, to a large extent. 


\section{Figure 13: Size of Firms}

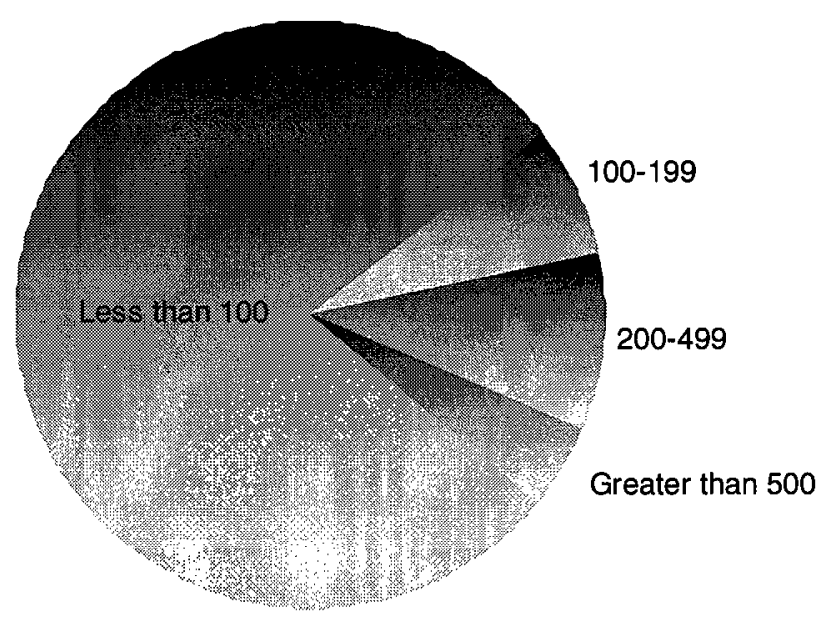

The ownership of the firms was also ascertained to see if there would be any difference between Canadian and foreign firms. As expected, 156 (80 percent) of the companies are Canadian owned while 38 ( 20 percent) are foreign owned. The US based companies dominate the foreign companies making up 10 percent of the sample. There are thirteen European companies ( 7 percent) and two (1 percent) from Asia. The details by country are given below in Table 42.

Table 42: Ownership of Firms

\begin{tabular}{|l|r|r|}
\hline Country & Number of Firms & Percent \\
\hline Canada & 156 & $80.4 \%$ \\
\hline US & 20 & $10.3 \%$ \\
\hline France & 3 & $1.5 \%$ \\
\hline Netherlands & 3 & $1.5 \%$ \\
\hline Germany & 2 & $1.0 \%$ \\
\hline Norway & 2 & $1.0 \%$ \\
\hline UK & 2 & $1.0 \%$ \\
\hline Switzerland & 1 & $0.5 \%$ \\
\hline India & 1 & $0.5 \%$ \\
\hline Japan & 1 & $0.5 \%$ \\
\hline Not Given & 3 & $1.5 \%$ \\
\hline
\end{tabular}


Since the respondents were intended to be top and senior managers of the companies, they were asked to state their designations to confirm the appropriateness of the sample. More than half (56 percent) of the questionnaires were completed by CEOs, presidents, and chairmen of the companies. Another 27 percent were completed by senior management such as VP, MD, Director, GM, and COO etc. A total of 17 percent were completed by managers and others such as controller, owner, partner etc. Thus, overwhelmingly, senior management responded to the questionnaire.

\section{Table 43: Designation of Respondents}

\begin{tabular}{|l|r|c|}
\hline Designation & Total & \\
\hline CEO/President/Chairman & 108 & $55.67 \%$ \\
\hline COO/CSO/CTO & 5 & $2.58 \%$ \\
\hline GM/Director & 24 & $12.37 \%$ \\
\hline Manager & 17 & $8.76 \%$ \\
\hline Others & 17 & $8.76 \%$ \\
\hline VP/MD & 23 & $11.86 \%$ \\
\hline
\end{tabular}

Figure 14: Respondent's Designation

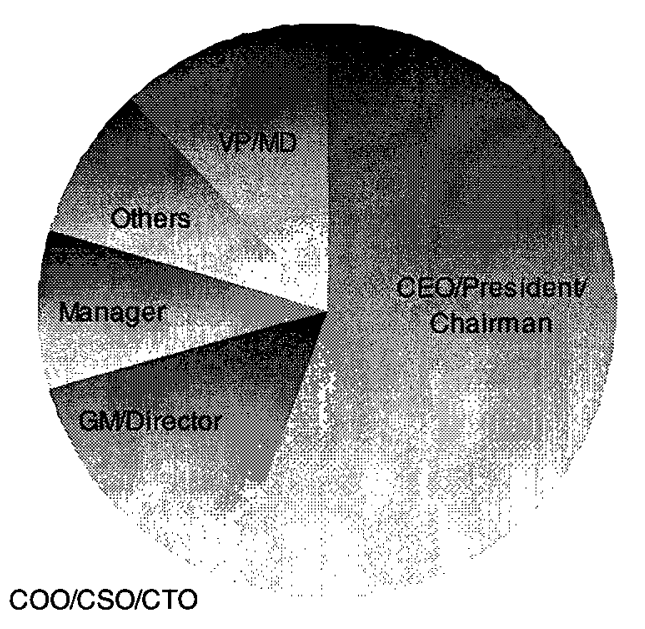




\subsubsection{Sub-sample Variations}

It was decided to further examine how differences in the size and nationality of the firms impacted their responses to various questions. The firms were divided into two size categories - small (less than 100 employees) and medium and large (100 and more employees). There are 152 small firms and 42 medium and large firms in the sample. The differences in means were calculated for all the variables with 2-tailed independent samples t-test. The complete details for all the variables are given in Appendix 5. The significant variables are given below in Table 44 .

Table 44: Significant differences between small firms and medium $\&$ large firms

\begin{tabular}{|l|c|c|c|}
\hline \multicolumn{1}{|c|}{ Variable } & $\begin{array}{c}\text { Mean (Small } \\
\text { Firms) }\end{array}$ & $\begin{array}{c}\text { Mean } \\
\text { (Medium \& } \\
\text { Large Firms) }\end{array}$ & $\begin{array}{c}\text { Mean Difference } \\
\text { (Small minus } \\
\text { Medium \& Large) }\end{array}$ \\
\hline Business strategy orientation & 4.0788 & 4.3333 & $-0.2546^{*}$ \\
\hline Positioning strategy - product focus & 4.1283 & 3.6071 & $0.5211^{* * *}$ \\
\hline Positioning strategy - innovation & 3.8322 & 3.3810 & $0.4513^{* * *}$ \\
\hline Manufacturing capability - cost & 3.8653 & 4.3252 & $-0.4599 * * *$ \\
\hline Manufacturing capability - flexibility & 3.1511 & 2.6429 & $0.5082 * *$ \\
\hline $\begin{array}{l}\text { Marketing capability - distribution } \\
\text { performance financial }\end{array}$ & 4.0516 & 3.5263 & $0.5252^{* * *}$ \\
\hline $\begin{array}{l}\text { p }<.10 \\
\text { p }<.05\end{array}$ & 3.0750 & 3.6571 & $-0.5821^{* * *}$ \\
$* * * \quad \mathrm{p}<.01$ & & & \\
\hline
\end{tabular}

The most significant difference is in terms of financial performance where large firms seem to have superior financial performance. Also, large firms have higher business strategy orientation. The smaller firms have a higher emphasis on product focus positioning strategy. In terms of manufacturing capability large firms put more emphasis 
on costs and have less flexibility in manufacturing capability. Also distribution marketing capability is emphasized more by small firms.

There are 156 ( 80 percent) Canadian owned firms and 35 (18 percent) non-Canadian firms in the sample. The rest did not specify nationality of the firm. Again, differences in means were calculated for all the variables with 2 -tailed independent samples $t$-test. The complete details for all the variables are given in Appendix 6. The significant variables are given below in Table 45 .

Table 45: Significant differences between Canadian and foreign firms

\begin{tabular}{|l|c|c|c|}
\hline \multicolumn{1}{|c|}{ Variable } & $\begin{array}{c}\text { Mean } \\
\text { (Canadian } \\
\text { Firms) }\end{array}$ & $\begin{array}{c}\text { Mean } \\
\text { (Foreign } \\
\text { Firms) }\end{array}$ & $\begin{array}{c}\text { Mean Difference } \\
\text { (Canadian minus } \\
\text { Foreign) }\end{array}$ \\
\hline Business strategy orientation & 4.087 & 4.329 & $-0.242^{*}$ \\
\hline Customer orientation & 4.420 & 4.246 & $0.174^{*}$ \\
\hline Positioning strategy - service & 3.923 & 3.500 & $0.423^{* *}$ \\
\hline Manufacturing capability - cost & 3.875 & 4.333 & $-0.458^{* * *}$ \\
\hline Manufacturing capability - flexibility & 3.158 & 2.614 & $0.544^{* * *}$ \\
\hline Marketing capability - distribution & 4.020 & 3.620 & $0.400^{*}$ \\
\hline Performance - financial & 3.108 & 3.584 & $-0.477^{* * *}$ \\
\hline
\end{tabular}

* $\quad \mathrm{p}<.10$

** $\mathrm{p}<.05$

$* * * \mathrm{p}<.01$

Foreign firms seem to have superior financial performance and higher market (business strategy) orientation. Canadian firms, on the other hand, have higher customer orientation. Canadian firms put higher emphasis on service positioning strategy as compared to foreign firms. In terms of manufacturing capability, foreign firms emphasize costs and have less flexibility in manufacturing capability. Also distribution marketing capability is emphasized more by Canadian firms. 


\subsection{Correlation and Regression Analysis}

Correlations analysis is the traditional way of checking simple association between two variables. The correlation coefficients measure the direction and strength of the hypothesized relationship between two variables, but they do not signify causality. This analysis is important in demonstrating which variables from influencing factors may be considered important enough to significantly impact development of positioning strategy.

Regression analysis was used to ascertain the nature of the relationship between independent and dependent variables and to investigate the causal effect of one variable upon another. In each multiple regression equation, the coefficient of determination $\left(\mathrm{R}^{2}\right)$ was examined to establish the proportion of variance in the DV that the IVs jointly accounted for. The F-statistic was used to determine the overall significance of the model (Lewis-Beck, 1980). Although higher values of $R^{2}$ are desirable, the researcher followed Allison's (1999) advice not to thoughtlessly reject models with smaller $\mathbf{R}^{2}$. Multivariate regression will help show which variables may significantly impact the development of positioning strategies by controlling for other variables.

In the following sections, first correlation analysis is conducted to show association between variables and, subsequently, regression analysis for the same variables is presented to demonstrate the nature of relationship.

Figure 15 below gives an overview of the conceptual model and relationships among variables. 
Figure 15: A Snapshot of Conceptual Framework

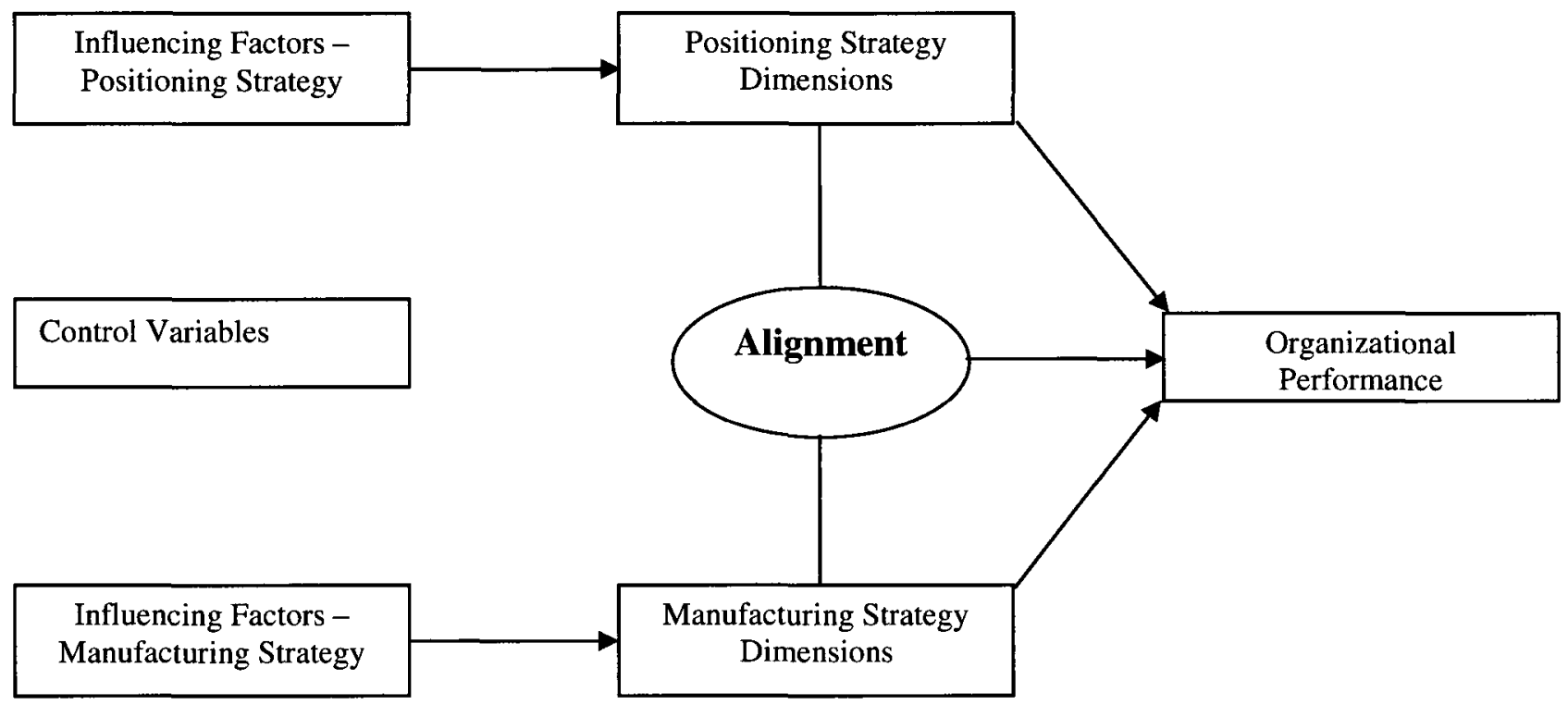

The overall conceptual framework was divided into three separate components for the sake of analysis and discussion. The details of three analyses are summed up in Table 46 below:

Table 46: Independent and Dependent Variables

\begin{tabular}{|l|l|l|l|}
\hline $\begin{array}{l}\text { Analysis } \\
\text { Group }\end{array}$ & Independent Variable & Dependent Variable & Hypotheses \\
\hline $\begin{array}{l}\text { Positioning } \\
\text { Strategies }\end{array}$ & $\begin{array}{l}\text { Influencing Factors - } \\
\text { Positioning Strategy }\end{array}$ & $\begin{array}{l}\text { Positioning Strategy } \\
\text { Dimensions }\end{array}$ & $\begin{array}{l}\mathrm{H}_{1 \mathrm{a}}, \mathrm{H}_{1 \mathrm{~b}}, \mathrm{H}_{\mathrm{lc}}, \mathrm{H}_{1 \mathrm{~d}}, \\
\mathrm{H}_{1 \mathrm{e}}\end{array}$ \\
\cline { 2 - 4 } & $\begin{array}{l}\text { Positioning Strategy } \\
\text { Dimensions }\end{array}$ & $\begin{array}{l}\text { Organizational } \\
\text { Performance }\end{array}$ & $\begin{array}{l}\mathrm{H}_{2 \mathrm{a}}, \mathrm{H}_{2 \mathrm{~b}}, \mathrm{H}_{2 \mathrm{c}}, \mathrm{H}_{2 \mathrm{~d}}, \\
\mathrm{H}_{2 \mathrm{e}}, \mathrm{H}_{2 \mathrm{f}}, \mathrm{H}_{2 \mathrm{~g}}, \mathrm{H}_{2 \mathrm{~h}}\end{array}$ \\
\hline \multirow{2}{*}{$\begin{array}{l}\text { Manufacturing } \\
\text { Strategies }\end{array}$} & $\begin{array}{l}\text { Influencing Factors - } \\
\text { Manufacturing Strategy }\end{array}$ & $\begin{array}{l}\text { Manufacturing } \\
\text { Strategy Dimensions }\end{array}$ & $\begin{array}{l}\mathrm{H}_{3 \mathrm{a}}, \mathrm{H}_{3 \mathrm{~b}}, \mathrm{H}_{3 \mathrm{c}}, \mathrm{H}_{3 \mathrm{~d}}, \\
\mathrm{H}_{3 \mathrm{e}}\end{array}$ \\
\cline { 2 - 4 } & $\begin{array}{l}\text { Manufacturing Strategy } \\
\text { Dimensions }\end{array}$ & $\begin{array}{l}\text { Organizational } \\
\text { Performance }\end{array}$ & $\begin{array}{l}\mathrm{H}_{4 \mathrm{a}}, \mathrm{H}_{4 \mathrm{~b}}, \mathrm{H}_{4 \mathrm{c}}, \mathrm{H}_{4 \mathrm{~d}}, \\
\mathrm{H}_{4 \mathrm{e}}\end{array}$ \\
\hline Co-alignment & $\begin{array}{l}\text { Co-alignment of } \\
\text { Positioning and } \\
\end{array}$ & $\begin{array}{l}\text { Organizational } \\
\text { Performance }\end{array}$ & $\mathrm{H}_{5}$ \\
\hline
\end{tabular}




\subsubsection{Correlation Analysis - Positioning Strategies}

This section deals with the examination of positioning strategy's relationship with influencing factors and organizational performance.

Figure 16 below depicts the nature of relationships where positioning strategy dimensions are impacted by a number of influencing factors - customer orientation, competitor orientation, marketing capabilities, innovation orientation and environmental dynamism, while organizational performance - financial and non-financial, is influenced by positioning strategy. Industry environment and product life cycle act as control variables.

\section{Figure 16: Positioning Strategy Framework}

Influencing Factors

- Customer Orientation

- Competitor Orientation

- Marketing Capabilities

- Innovation Orientation

- Environmental Dynamism
Positioning Strategy Dimensions

- Customer Focus

- Product Focus

- Brand Focus

- Quality

- Price

- Service

- Value

- Innovation

Control Variables

- Industry Environment

- Product Life Cycle

The findings of the correlation analysis are given below in Table 47: 
Table 47: Correlation-influencing Factors and Positioning Strategy Dimensions

\begin{tabular}{|l|l|l|l|l|l|l|l|l|}
\hline & $\begin{array}{l}\text { Customer } \\
\text { Focus }\end{array}$ & $\begin{array}{l}\text { Product } \\
\text { Focus }\end{array}$ & $\begin{array}{l}\text { Brand } \\
\text { Focus }\end{array}$ & Innovation & Quality & Service & Price & Value \\
\hline Customer orientation & $.267^{* *}$ & $.234^{* *}$ & $.237^{* *}$ & $.193^{* *}$ & $.375^{* *}$ & $.185^{* *}$ & -.038 & $.298^{* *}$ \\
\hline Competitor orientation & $.180^{*}$ & $.178^{*}$ & $.278^{* *}$ & .119 & .079 & .103 & $.222^{* *}$ & $.199^{* *}$ \\
\hline $\begin{array}{l}\text { Marketing Capability - } \\
\text { communication }\end{array}$ & $.246^{* *}$ & $.317^{* *}$ & $.611^{* *}$ & $.392^{* *}$ & $.277^{* *}$ & $.227^{* *}$ & .002 & $.263^{* *}$ \\
\hline $\begin{array}{l}\text { Marketing Capability - } \\
\text { planning }\end{array}$ & $.212^{* *}$ & $.291^{* *}$ & $.412^{* *}$ & $.359^{* *}$ & $.215^{* *}$ & .119 & .139 & $.222^{* *}$ \\
\hline $\begin{array}{l}\text { Marketing Capability - } \\
\text { distribution }\end{array}$ & .127 & $.297^{* *}$ & $.324^{* *}$ & $.191^{*}$ & $.244^{* *}$ & $.178^{*}$ & .085 & $.186^{*}$ \\
\hline $\begin{array}{l}\text { Marketing Capability - } \\
\text { Customer Requirement }\end{array}$ & $.307^{* *}$ & $.397^{* *}$ & $.311^{* *}$ & $.310^{* *}$ & $.412^{* *}$ & .118 & .083 & $.465^{* *}$ \\
\hline Innovation Orientation & $.212^{* *}$ & $.455^{* *}$ & $.335^{* *}$ & $.627^{* *}$ & $.270^{* *}$ & .107 & -.084 & $.218^{* *}$ \\
\hline $\begin{array}{l}\text { Environmental } \\
\text { Dynamism }\end{array}$ & $.147^{*}$ & .093 & $.145^{*}$ & $.245^{* *}$ & .051 & .059 & .065 & .052 \\
\hline
\end{tabular}

${ }^{*}$ Correlation is significant at the 0.05 level (2-tailed)

${ }^{\star *}$ Correlation is significant at the 0.01 level (2-tailed)

Customer Orientation: Since positioning strategy is developed from the perspective of customers, customer analysis and thus customer orientation are considered to be prerequisite for development of positioning strategy dimensions. From Table 47, it is evident that customer orientation has a positive and statistically significant association with all the dimensions of positioning strategy dimensions but price. The significant correlation coefficients range from a low of 0.185 for service to a high of 0.375 for quality.

Competitor Orientation: Positioning strategy is always developed relative to competitors. The analysis of competitors' positioning strategies and thorough understanding of how a firm's products positioning differs from competitors' is, thus, considered essential to the development of positioning strategy. Competitor orientation has a positive and statistically significant association with five out of eight positioning strategy dimensions - customer focus, product focus, brand focus, price, and value. The correlation coefficient is lowest for product focus (0.178) and highest for brand focus $(0.278)$. 
Marketing Capability: Four dimensions of marketing capability - communication, planning, distribution, and customer requirement - are assessed separately to capture the association between each dimension of marketing capability with positioning strategy dimensions.

Developing and executing advertising programs, managing brand as well as corporate image, is the domain of communication capability. Communication capability has positive and statistically significant correlations with all the dimensions of positioning strategy other than price. However, it has the strongest correlations with brand focus (0.611) and innovation (0.392).

Developing effective marketing programs using marketing research is the hallmark of marketing planning. Planning has positive and statistically significant correlations with all the dimensions of positioning strategy except price. It has the highest correlation with brand focus (.412) followed by innovation (.359).

Attracting and retaining the best distributors, providing them high level of support and building relationships with them is the distribution aspect of marketing capability. Distribution capability has a positive and statistically significant correlation with product focus, brand focus, innovation, quality, service and value. However, the correlation coefficient is highest for brand focus $(0.324)$ and product focus $(0.297)$ and the lowest for service (0.178) and value (0.186). It is not statistically significant for price and customer focus.

Gathering information about customers and tracking their needs and wants is the crux of understanding the customer requirement aspect of marketing capability. Customer 
requirement capability has a positive and statistically significant correlation with all the dimensions of positioning but price and service. It has the highest association with value (.465) followed by quality (.412).

Innovation Orientation: Innovation orientation and innovation type were posited to be two separate variables. However, their items loaded on one factor when principal component analysis was conducted. The two variables were then combined and the title innovation orientation was retained. Innovation orientation has positive and statistically significant correlation with all but two dimensions of positioning strategy - service and price. Understandably, it has the highest correlation (0.627) with innovation dimension of positioning strategy followed by product focus $(0.455)$ and brand focus $(0.335)$.

Environmental dynamism: Environmental dynamism was defined as the rate at which customer's tastes and preferences change, new products and services become outdated, and innovative products, services and processes are introduced. Environmental dynamism has a positive and statistically significant relationship with three dimensions of positioning strategy - innovation (0.245), customer focus $(0.147)$ and brand focus $(0.145)$.

The nature of association between positioning strategy dimensions and organizational performance was also analyzed. The findings of the correlation analysis are given below in Table 48.

Table 48: Correlation- Positioning Strategy Dimensions and Organizational Performance

\begin{tabular}{|l|c|c|c|c|c|c|c|c|}
\hline Variable & $\begin{array}{c}\text { Customer } \\
\text { Focus }\end{array}$ & $\begin{array}{c}\text { Product } \\
\text { Focus }\end{array}$ & $\begin{array}{c}\text { Brand } \\
\text { Focus }\end{array}$ & Innovation & \multicolumn{1}{|c|}{ Quality } & Service & Price & Value \\
\hline performance financial & $0.162^{* *}$ & 0.071 & $0.171^{* *}$ & 0.048 & 0.084 & 0.039 & -0.085 & $0.175^{* *}$ \\
\hline performance non-financial & $0.238^{*}$ & $0.160^{* *}$ & $0.349^{*}$ & $0.180^{* *}$ & $0.348^{*}$ & $0.207^{*}$ & -0.039 & $0.183^{* *}$ \\
\hline
\end{tabular}

${ }^{*}$ Correlation is significant at the 0.05 level (2-tailed)

** Correlation is significant at the 0.01 level (2-tailed) 
A positive relationship between a firm's performance and clearly defined positioning strategies has been suggested in the literature, though with little empirical evidence. This study sought to empirically test this relationship. Only three positioning strategy dimensions - value (0.175), brand focus $(0.171)$ and customer focus $(0.162)$ have positive and statistically significant relationships with a firm's financial performance. However, all positioning strategy dimensions other than price are positively and significantly correlated with the non-financial performance of the firm. The strongest correlation is with brand focus (0.349), followed by quality (0.348) and customer focus (0.238).

\subsubsection{Regression Analysis - Positioning Strategies}

Two sets of hierarchical regression analyses were performed using positioning strategies and organizational performance as the dependent variables. All regressions were controlled for industry environment and product life cycle. Three dimensions of Porter's industry competitiveness model - rivalry, threats of substitutes and power of supplier - are included in the study. The items for buyer power and barriers to entry did not load in PCA. Dummy variables were created for product life cycle, where 0 was coded for introduction, 1 for growth, 2 for maturity, and 3 for decline.

First Set: Positioning Strategy and Influencing Factors: In the first stage of the first set of analyses, the six control variables were entered into a regression model to separate their effects. In the second stage, eight independent variables were added to the model to separate their main effects. The regression equations used in each stage of the regression analyses are presented in Table 49: 
Table 49: Regression Equations-Positioning Strategy and Influencing Factors

\begin{tabular}{|l|l|l|}
\hline Stage & Purpose & Regression Equation \\
\hline 1 & $\begin{array}{l}\text { To test the main effects of } \\
\text { control variables }\end{array}$ & DV= $\alpha+$ PL1+PL2+PL3+IND1+IND2+IND3+ $\varepsilon$ \\
\hline 2 & $\begin{array}{l}\text { To test the main effects of } \\
\text { independent variables }\end{array}$ & $\begin{array}{l}\text { DV= } \alpha+\text { PL1+PL2+PL3+IND1+IND2+IND3+ } \\
\text { CUST_OR+ COMP_OR+ MKC_DS+ } \\
\text { MKC_CM+MKC_PL+ED+IN+ } \varepsilon\end{array}$ \\
\hline
\end{tabular}

$\mathrm{DV}=$ dependent variable

PL1 = Product Life Cycle dummy 1 (growth)

PL2 $=$ Product Life Cycle dummy 2 (maturity)

PS3 = Product Life Cycle dummy 3 (decline)

IND1 = Industrial Environment (Rivalry)

IND2 = Industrial Environment (Threat of substitute products)

IND3 = Industrial Environment (power of suppliers)

CUST_OR = Customer Orientation

COMP_OR $=$ Competitor Orientation

MKC_DS = Marketing Capability - Distribution

MKC_CM = Marketing Capability - Communication

MKC_PL = Marketing Capability - Planning

$\mathrm{ED}=$ Environmental Dynamism

IN = Innovation Orientation

$\alpha=$ the constant

$\varepsilon=$ the residual term

Table 50 below shows the results for 16 different multiple regressions, two for each dependent variable - one with control variables only and other with control and independent variables. 


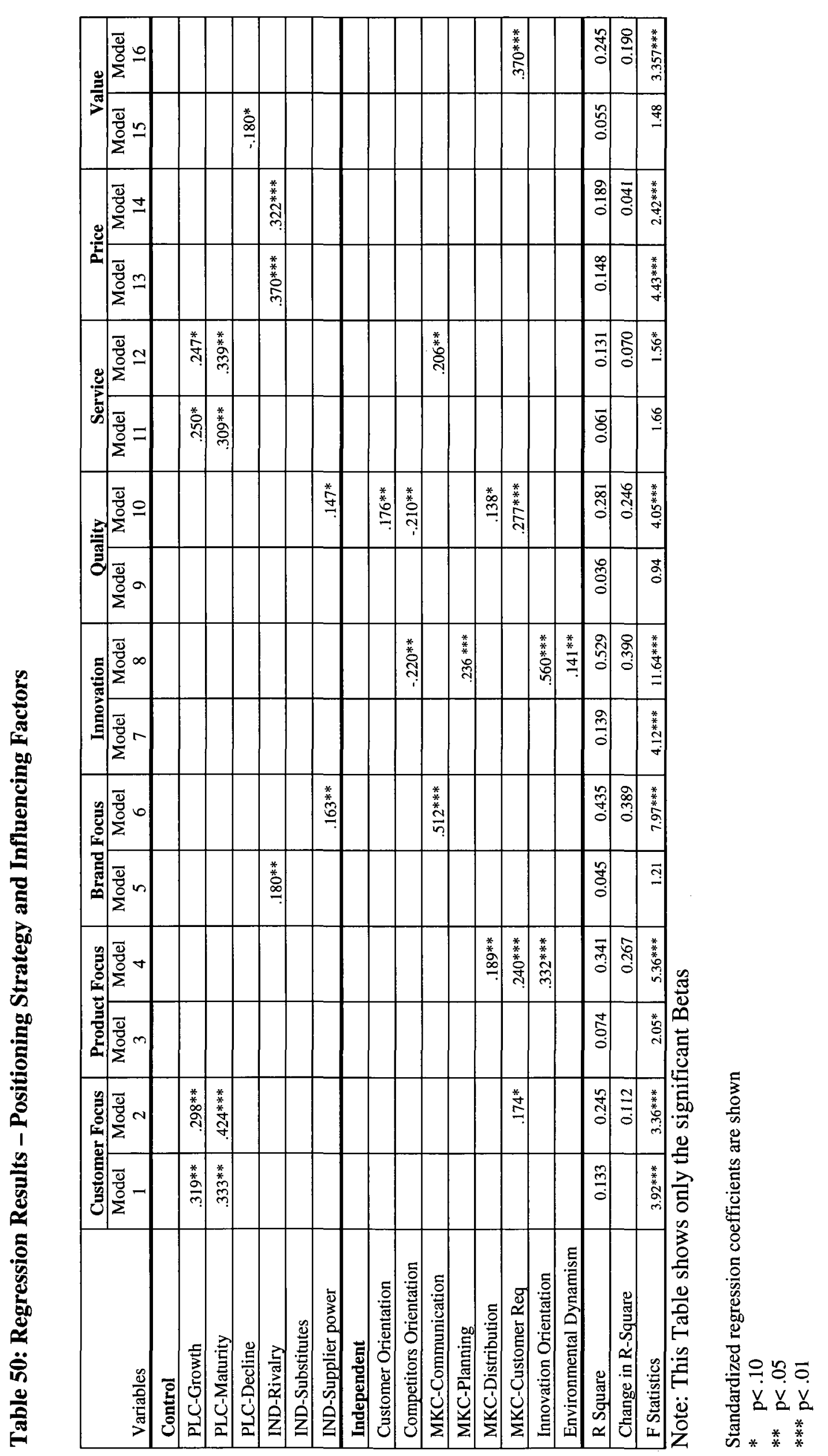


Table 50 displays the results of the hierarchical regression analyses. Models 1, 3, 5, 7, 9, 11,13 , and 15 involve the six control variables only. Models $2,4,6,8,10,12,14$, and 16 include all the control variables and eight independent variables.

As indicated by the F-statistic, all the eight models with both control and independent variables were a statistically significant and substantive predictor of positioning strategy dimensions with influencing factors. The $\mathrm{R}^{2}$ range from low of 0.131 (service) and 0.189 (price) to high of 0.529 (innovation) and 0.435 (brand focus).

The regression analyses highlight the importance of how various factors, independent variables (IV), influence different positioning strategy dimensions, dependent variables (DV), differently. There are a total of eight positioning strategy dimensions. However, most of the factors are predictors of only one or two strategy dimensions. Some of the major findings of regression analysis with respect to positioning strategy dimensions are as follows.

Two variables, customer orientation and competitor orientation, which had positive and statistically significant correlations with all the dimensions of positioning strategy other than price, are found to have a varying impact on different positioning strategy dimensions. Customer analysis, and thus customer orientation, is considered to be the most important factor a firm must consider in developing a positioning strategy. It positively impacts one out of eight positioning strategy dimensions - quality (.176). Competitor orientation is also considered one of the major aspects firms must consider while developing positioning strategy but in our study it affects two positioning strategy 
dimensions, innovation (-.220) and quality (-.210), but, interestingly, negatively to both of them. Thus hypotheses $1 \mathrm{a}$ and $1 \mathrm{~b}$ are partially supported.

Marketing capability is a significant predictor of positioning strategy dimensions. However, various aspects of marketing capability have different impacts on each dimension of positioning strategy. For instance, distribution capability is a predictor of product focus and quality, and planning capability is a predictor of innovation. Communication capability is a predictor of brand focus and service while customer requirement capability is the predictor of four positioning strategy dimensions - customer focus, product focus, quality and value. Hypothesis 1c is, thus, partially supported. Innovation orientation has a positively significant impact on product focus and innovation strategy while environmental dynamism impacts innovation strategy. Hypotheses 1d and 1e are also partially supported.

The control variable "product life cycle" significantly affects two positioning strategy dimensions - customer focus and service, in growth and maturity stage. The emphasis on customer focus and service as a positioning strategy increases in growth stage and become even higher in maturity stage. The control variable "industrial environment" impacts three positioning strategy dimensions - brand focus, quality and price. Rivalry in the industry positively impacts price positioning strategy while supplier power influences brand focus and quality positioning.

The interpretation of regression results from the perspective of positioning strategy would be as follows. Customer focus is positively influenced by customer requirement capability. Distribution and customer requirement capabilities, and innovation orientation 
are significant predictors of product focus. The significant predictor of brand focus is the communication aspect of marketing capability. Innovation as positioning strategy is negatively impacted by competitor orientation and positively influenced by planning capability, innovation orientation and environmental dynamism. Quality is negatively influenced by competitor orientation and positively by customer orientation, distribution and customer requirement marketing capabilities. Service is impacted by communication capability and value by customer requirement capability. Price is the only positioning strategy which is not influenced by any independent variable. There are only three positioning strategy dimensions which are impacted by more than two factors innovation and quality by four each and product focus by three; the rest are influenced by only one factor.

Some of the high regression coefficients $(B)$ include innovation orientation $(0.560)$ for innovation strategy, communication capability $(0.512)$ for brand focus, innovation orientation (.332) for product focus, and customer requirement capability for quality value (.370) and quality (.277).

Second Set: Positioning Strategy and Organizational Performance: In the first stage of the second set of analyses, the six control variables were entered into a regression model to separate their effects. In the second stage, eight independent variables were added to the model to separate their main effects. The regression equations used in each stage of the regression analyses are presented in Table 51: 
Table 51: Regression Equations-Positioning Strategy and Organizational Performance

\begin{tabular}{|c|c|c|}
\hline Stage & Purpose & Regression Equation \\
\hline 1 & $\begin{array}{l}\text { To test the main effects } \\
\text { of control variables }\end{array}$ & $\mathrm{DV}=\alpha+\mathrm{PL} 1+\mathrm{PL} 2+\mathrm{PL} 3+\mathrm{IND} 1+\mathrm{IND} 2+\mathrm{IND} 3+\varepsilon$ \\
\hline 2 & $\begin{array}{l}\text { To test the main effects } \\
\text { of independent variables }\end{array}$ & $\begin{array}{l}\mathrm{DV}=\alpha+ \\
\mathrm{PL} 1+\mathrm{PL} 2+\mathrm{PL} 3+\mathrm{IND} 1+\mathrm{IND} 2+\mathrm{IND} 3+\mathrm{PS} 1+\mathrm{PS} 2+\mathrm{PS} 3+ \\
\mathrm{PS} 4+\mathrm{PS} 5+\mathrm{PS} 6+\mathrm{PS} 7+\mathrm{PS} 8+\varepsilon\end{array}$ \\
\hline
\end{tabular}

DV $=$ dependent variable

PL1 $=$ Product Life Cycle dummy 1 (growth)

PL2 $=$ Product Life Cycle dummy 2 (maturity)

PS3 = Product Life Cycle dummy 3 (decline)

IND1 = Industrial Environment (Rivalry)

IND2 = Industrial Environment (Threat of substitute products)

IND3 = Industrial Environment (power of suppliers)

PS1 $=$ customer focus

PS2 $=$ product focus

PS3 = brand focus

PS4 = innovation

PS5 = quality

PS6 $=$ service

PS7 $=$ price

PS8 = value

$\alpha=$ the constant

$\varepsilon=$ the residual term

Table 52 below shows the results for four different multiple regressions, two for each dependent variable - one with control variables only and other with control and independent variables. 
Table 52: Regression Results-Positioning Strategy and Organizational Performance

\begin{tabular}{|c|c|c|c|c|}
\hline \multirow[b]{2}{*}{ Variables } & \multicolumn{2}{|c|}{ Performance Financial } & \multicolumn{2}{|c|}{ Performance NON-Financial } \\
\hline & Model 1 & Model 2 & Model 3 & Model 4 \\
\hline \multicolumn{5}{|l|}{ Control } \\
\hline \multicolumn{5}{|l|}{ PLC-Growth } \\
\hline \multicolumn{5}{|l|}{ PLC-Maturity } \\
\hline PLC-Decline & & & $-0.170^{*}$ & $-0.146^{*}$ \\
\hline \multicolumn{5}{|l|}{ IND-Rivalry } \\
\hline \multicolumn{5}{|l|}{ IND-Substitutes } \\
\hline \multicolumn{5}{|l|}{ IND-Supplier power } \\
\hline \multicolumn{5}{|l|}{ Independent } \\
\hline PS1 - customer focus & & $0.167^{*}$ & & \\
\hline \multicolumn{5}{|l|}{ PS2 - product focus } \\
\hline PS3 - brand focus & & $0.156^{*}$ & & $0.253 * * *$ \\
\hline \multicolumn{5}{|l|}{ PS4 - innovation } \\
\hline PS5 - quality & & & & $0.246^{* * * *}$ \\
\hline \multicolumn{5}{|l|}{ PS6 - service } \\
\hline \multicolumn{5}{|l|}{ PS7 - price } \\
\hline PS8 - value & & $0.158^{*}$ & & \\
\hline R Square & 0.042 & 0.123 & 0.058 & 0.236 \\
\hline Change in R-Square & & 0.08 & & 0.178 \\
\hline F Statistics & 1.231 & $1.596^{*}$ & 1.735 & $3.535 * * *$ \\
\hline
\end{tabular}

Note: This Table shows only the significant Betas

Standardized regression coefficients are shown

* $\mathrm{p}<.10$

** $\mathrm{p}<.05$

$* * * \mathrm{p}<.01$

Table 52 above displays the results of the hierarchical regression analyses. Model 1 and 3 involve the six control variables only, while Models 2 and 4 include all the control variables and eight independent variables.

As indicated by the F-statistic, both models with control and independent variables (Model 2 and 4) are statistically significant predictors of organizational performance with positioning strategy dimensions. The $\mathrm{R}^{2}$ for Model 2 is a modest 0.123 while for Model 4 is a reasonable 0.236 . 
There are total of eight positioning strategy dimensions in the analysis. However, only three - customer focus, brand focus, and value are significant predictors of financial performance. Brand focus and quality are significant predictors of non-financial performance. Brand focus is the only positioning strategy dimension which is the significant predictor of both financial and non-financial performance. Hypothesis $2 \mathrm{c}$ is thus fully supported while hypotheses $2 \mathrm{a}, 2 \mathrm{e}$ and $2 \mathrm{~h}$ are partially supported. Hypotheses $2 \mathrm{~b}, 2 \mathrm{~d}, 2 \mathrm{f}$, and $2 \mathrm{~g}$ are not supported. Only one control variable, product life cycle, influences organizational performance. Non-financial performance is negative in the declining stage.

Table 53 below provides a summary of findings of regression analysis for hypotheses posited earlier.

Table 53: Findings of Positioning Strategy Hypotheses

\begin{tabular}{|c|l|l|}
\hline \multicolumn{2}{|l|}{ Impact of Influencing Factors on Positioning Strategy } \\
\hline$H_{l a}$ & $\begin{array}{l}\text { Customer orientation will have an impact on customer focus, } \\
\text { product focus, brand focus, innovation, quality, service, price } \\
\text { and value positioning strategies. }\end{array}$ & $\begin{array}{l}\text { Partially } \\
\text { Supported }\end{array}$ \\
\hline$H_{l b}$ & $\begin{array}{l}\text { Competitor orientation will have an impact on customer } \\
\text { focus, product focus, brand focus, innovation, quality, } \\
\text { service, price and value positioning strategies. }\end{array}$ & $\begin{array}{l}\text { Partially } \\
\text { Supported }\end{array}$ \\
\hline$H_{l c}$ & $\begin{array}{l}\text { Marketing capability will have an impact on customer focus, } \\
\text { product focus, brand focus, innovation, quality, service, price } \\
\text { and value positioning strategies. }\end{array}$ & $\begin{array}{l}\text { Partially } \\
\text { Supported }\end{array}$ \\
\hline$H_{l d}$ & $\begin{array}{l}\text { Innovation orientation will have an impact on customer } \\
\text { focus, product focus, brand focus, innovation, quality, } \\
\text { service, price and value positioning strategies. }\end{array}$ & $\begin{array}{l}\text { Partially } \\
\text { Supported }\end{array}$ \\
\hline$H_{l e}$ & $\begin{array}{l}\text { Environmental dynamism will have an impact on customer } \\
\text { focus, product focus, brand focus, innovation, quality, } \\
\text { service, price and value positioning strategies. }\end{array}$ & $\begin{array}{l}\text { Partially } \\
\text { Supported }\end{array}$ \\
\hline
\end{tabular}




\begin{tabular}{|c|l|l|}
\hline \multicolumn{3}{|l}{ Positioning Strategy and Organizational Performance } \\
\hline$H_{2 a}$ & $\begin{array}{l}\text { Customer focus positioning strategy will have a positive } \\
\text { effect on firm's financial and non-financial performance. }\end{array}$ & $\begin{array}{l}\text { Partially } \\
\text { Supported }\end{array}$ \\
\hline$H_{2 b}$ & $\begin{array}{l}\text { Product focus positioning strategy will have a positive effect } \\
\text { on firm's financial and non-financial performance. }\end{array}$ & Not Supported \\
\hline$H_{2 c}$ & $\begin{array}{l}\text { Brand focus positioning strategy will have a positive effect } \\
\text { on firm's financial and non-financial performance. }\end{array}$ & Supported \\
\hline$H_{2 d}$ & $\begin{array}{l}\text { Innovation positioning strategy will have a positive effect on } \\
\text { firm's financial and non-financial performance. }\end{array}$ & Not Supported \\
\hline$H_{2 e}$ & $\begin{array}{l}\text { Quality positioning strategy will have a positive effect on } \\
\text { firm's financial and non-financial performance. }\end{array}$ & $\begin{array}{l}\text { Partially } \\
\text { Supported }\end{array}$ \\
\hline$H_{2 f}$ & $\begin{array}{l}\text { Service positioning strategy will have a positive effect on } \\
\text { firm's financial and non-financial performance. }\end{array}$ & Not Supported \\
\hline$H_{2 g}$ & $\begin{array}{l}\text { Price positioning strategy will have a positive effect on } \\
\text { firm's financial and non-financial performance. }\end{array}$ & Not Supported \\
\hline$H_{2 h}$ & $\begin{array}{l}\text { Value positioning strategy will have a positive effect on } \\
\text { firm's financial and non-financial performance. }\end{array}$ & $\begin{array}{l}\text { Partially } \\
\text { Supported }\end{array}$ \\
\hline
\end{tabular}

\subsubsection{Correlation Analysis - Manufacturing Strategies}

This section deals with the examination of the relationship of manufacturing strategy to influencing factors and organizational performance.

Figure 17 below depicts the nature of relationships where manufacturing strategy dimensions are impacted by a number of influencing factors - resource orientation, business strategy orientation, manufacturing capabilities, innovation orientation and environmental dynamism, while organizational performance - financial and non financial, is influenced by manufacturing strategy. Industry environment and product life cycle act as control variables. 


\section{Figure 17: Manufacturing Strategy Framework}

\begin{tabular}{l}
\hline Influencing Factors \\
- Resource Orientation \\
- Business Strategy Orientation \\
- Manufacturing Capabilities \\
- Innovation Orientation \\
- Environmental Dynamism \\
\end{tabular}
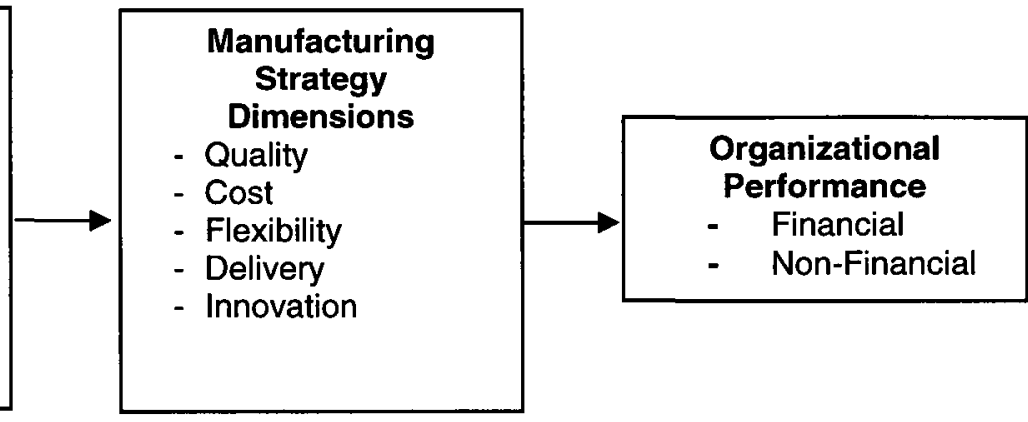

\section{Control Variables}

- Industry Environment

- Product Life Cycle

The findings of correlation analysis are given below in Table 54:

Table 54: Correlation- Influencing Factors and Manufacturing Strategy Dimensions

\begin{tabular}{|l|l|l|l|l|l|}
\hline Variables & Quality & Cost & Flexibility & Delivery & Innovation \\
\hline Resource Orientation & $.327^{* *}$ & .043 & $.193^{* *}$ & .138 & $.335^{* *}$ \\
\hline Business Strategy Orientation & $.316^{* *}$ & .111 & $.292^{* *}$ & $.194^{* *}$ & $.163^{*}$ \\
\hline $\begin{array}{l}\text { Manufacturing Capability - } \\
\text { quality }\end{array}$ & $.488^{* *}$ & .096 & $.158^{*}$ & $.214^{* *}$ & $.493^{* *}$ \\
\hline Manufacturing Capability - cost & $.249^{* *}$ & $.489^{* *}$ & $.274^{* *}$ & $.336^{* *}$ & .043 \\
\hline $\begin{array}{l}\text { Manufacturing Capability - } \\
\text { flexibility }\end{array}$ & $.234^{* *}$ & $.204^{* *}$ & $.203^{* *}$ & .139 & $.251^{* *}$ \\
\hline $\begin{array}{l}\text { Manufacturing Capability - } \\
\text { delivery }\end{array}$ & $.419^{* *}$ & $.325^{* *}$ & $.380^{* *}$ & $.617^{* *}$ & $.153^{*}$ \\
\hline Innovation orientation & $.204^{* *}$ & $.154^{*}$ & .114 & $.145^{*}$ & $.543^{* *}$ \\
\hline Environmental dynamism & -.012 & -.041 & .115 & .111 & $.280^{* *}$ \\
\hline
\end{tabular}

${ }^{*}$ Correlation is significant at the 0.05 level (2-tailed)

${ }^{* *}$ Correlation is significant at the 0.01 level (2-tailed)

Resource and Business Strategy Orientation: Resource orientation and business strategy

orientation are normally presented as two opposing views to the development of manufacturing strategies. There are some studies which support the integration of both 
orientations for the development of manufacturing strategy. From the above table it seems that manufacturing strategy is more strongly influenced by business strategy orientation than resource orientation since resource orientation has a positive and statistically significant correlation with only three manufacturing strategy dimensions quality, flexibility and innovation. Business strategy orientation, on the other hand, is positively and statistically significantly correlated with four dimensions of manufacturing strategy - quality, flexibility delivery and innovation.

Manufacturing Capability: The dimensions of manufacturing strategy are firmly dependent on capabilities of the firms. The four dimensions of manufacturing capability - quality, cost, flexibility, and delivery - are assessed separately to capture the association between each dimension of manufacturing capability with manufacturing strategy dimensions. Each dimension of manufacturing capability has a positive and statistically significant correlation with four of the five manufacturing strategy dimensions, except delivery, which has a positive association with all five manufacturing strategy dimensions.

Quality capability has the strongest correlation with quality strategy $(0.471)$, followed by innovation strategy (0.408). Cost capability has the highest correlation with cost strategy (0.489) followed by delivery strategy $(0.336)$. Flexibility capability is almost equally correlated with innovation strategy $(0.251)$ and quality strategy (0.234). Delivery capability has the highest correlation with delivery strategy $(0.617)$ followed by quality strategy (0.419).

Innovation Orientation: Innovation orientation has positive and statistically significant correlation with all but one dimension of manufacturing strategy - flexibility. 
Understandably, it has the highest (0.543) correlation with innovation dimension of manufacturing strategy followed by quality strategy $(0.204)$ and cost strategy $(0.154)$.

Environmental dynamism: Environmental dynamism was defined as the rate at which customers' tastes and preferences change, new products and services become outdated and innovative products, services and process are introduced. Environmental dynamism has a positive and statistically significant relationship with only one dimension of manufacturing strategy - innovation (0.280).

The nature of association between manufacturing strategy dimensions and organizational performance was also analyzed. The findings of the correlation analysis are given below in Table 55.

Table 55: Correlation- Manufacturing Strategy Dimensions and Organizational Performance

\begin{tabular}{|l|l|l|l|l|l|}
\hline Variable & Cost & Quality & Flexibility & Delivery & Innovation \\
\hline performance financial & $0.175^{* *}$ & 0.136 & $0.217^{* *}$ & $0.251^{* *}$ & 0.069 \\
\hline performance non-financial & 0.086 & $0.287^{* *}$ & 0.115 & $0.198^{*}$ & $0.177^{* *}$ \\
\hline
\end{tabular}

${ }^{*}$ Correlation is significant at the 0.05 level (2-tailed)

${ }^{\star \star}$ Correlation is significant at the 0.01 level (2-tailed)

A positive relationship between a firm's performance and clearly defined manufacturing strategies has been suggested in the literature. This study also sought to empirically test this relationship. Only three manufacturing strategy dimensions - cost $(0.175)$, flexibility (0.217) and delivery $(0.251)$ - have positive and statistically significant associations with a firm's financial performance. Similarly, only three manufacturing strategy dimensions are positively and significantly correlated with non-financial performance of the firm quality (0.287), delivery $(0.198)$ and innovation (0.177). Delivery is the only 
manufacturing strategy which has a positive and significant correlation with both financial and non-financial performance.

\subsubsection{Regression Analysis - Manufacturing Strategies}

Two sets of hierarchical regression analyses were performed using manufacturing strategies and organizational performance as the dependent variables. All regressions were controlled for industry environment and product life cycle. Three dimensions of Porter's industry competitiveness model - rivalry, threats of substitutes and power of supplier - are included in the study. The items for buyer power and barriers to entry did not load in PCA. Dummy variables were created for product life cycle, where 0 was coded for introduction, 1 for growth, 2 for maturity, and 3 for decline.

First Set: Manufacturing Strategy and Influencing Factors: In the first stage of the first set of analyses, the six control variables were entered into a regression model to separate their effects. In the second stage, eight independent variables were added to the model to separate their main effects. The regression equations used in each stage of the regression analyses are presented in Table 56:

Table 56: Regression Equations-Manufacturing Strategy and Influencing Factors

\begin{tabular}{|l|l|l|}
\hline Stage & Purpose & Regression Equation \\
\hline 1 & $\begin{array}{l}\text { To test the main effects } \\
\text { of control variables }\end{array}$ & DV= $\alpha+$ PL1+PL2+PL3+IND1+IND2+IND3+ $\varepsilon$ \\
\hline $\begin{array}{l}\text { To test the main effects } \\
\text { of independent variables }\end{array}$ & $\begin{array}{l}\text { DV= } \alpha+\text { PL1+PL2+PL3+IND1+IND2+IND3+RES_OR+ } \\
\text { MKT_OR+ MNC_QU+MNC_CS+ MNC_FL+ } \\
\text { MNC_IN+ED+IN+ } \varepsilon\end{array}$ \\
\hline
\end{tabular}

DV = dependent variable

PL1 = Product Life Cycle dummy 1 (growth)

PL2 = Product Life Cycle dummy 2 (maturity) 
PS3 = Product Life Cycle dummy 3 (decline)

IND1 = Industrial Environment (Rivalry)

IND2 = Industrial Environment (Threat of substitute products)

IND3 = Industrial Environment (power of suppliers)

RES_OR $=$ Resource Orientation

MKT_OR = Market Orientation

MNC_QU = Manufacturing Capability - Quality

MNC_CS = Manufacturing Capability - Cost

MNC_FL = Manufacturing Capability - Flexibility

MNC_IN = Manufacturing Capability - Innovation

$\mathrm{ED}=$ Environmental Dynamism

IN = Innovation Orientation

$\alpha=$ the constant

$\varepsilon=$ the residual term

Table 57 below shows the results for ten different multiple regressions, two for each of five dependent variables - one with control variables only and other with control and independent variables. 


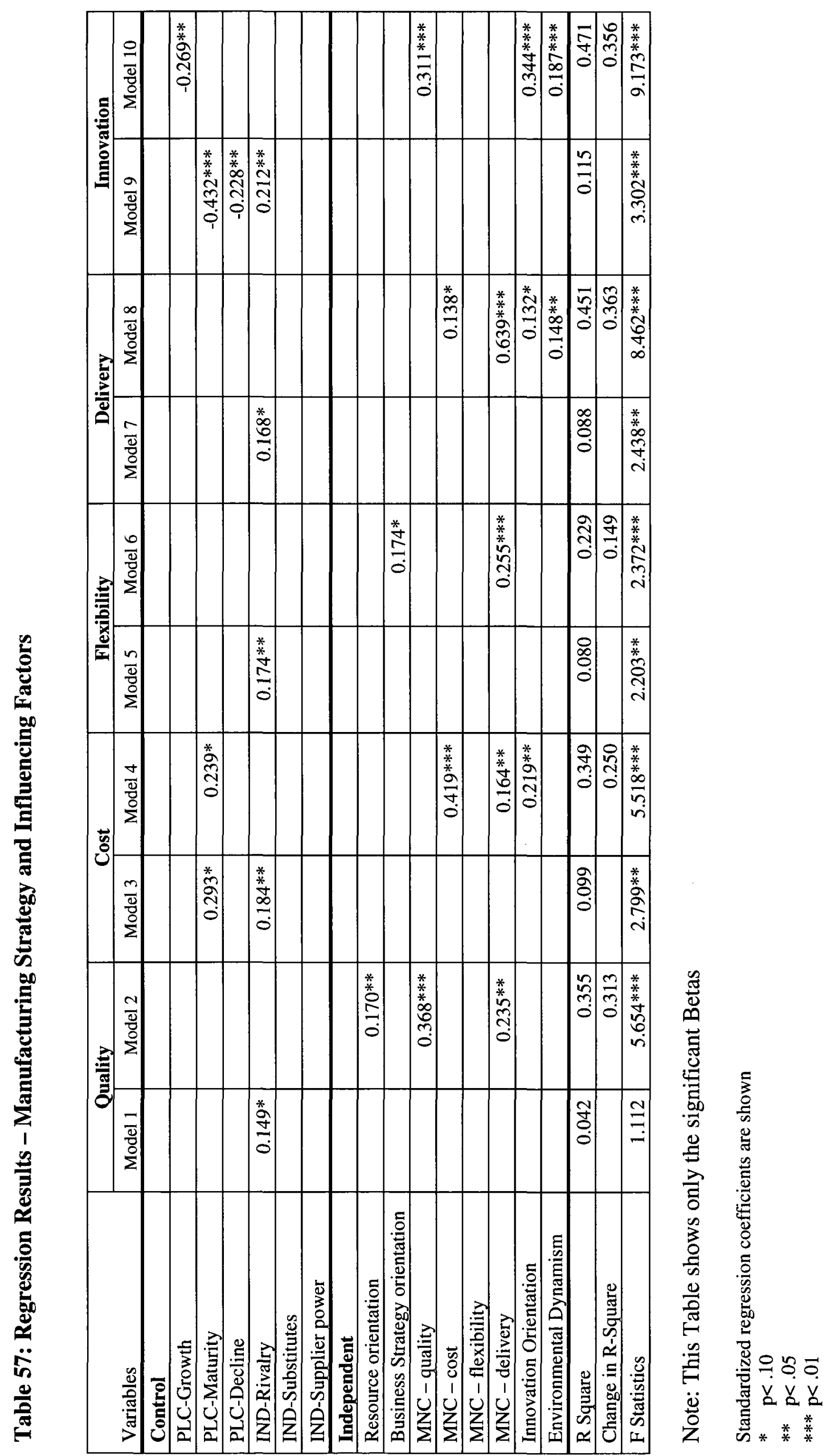


Table 57 above displays the results of the hierarchical regression analyses. Models 1, 3, 5, 7, and 9 involve the six control variables only. Models 2, 4, 6, 8, and 10 include all the control variables and eight independent variables.

As indicated by the F-statistic, all the five models with both control and independent variables were a statistically significant and substantive predictor of manufacturing strategy dimensions with influencing factors. The $\mathrm{R}^{2}$ range from a low of 0.229 (flexibility) and 0.349 (cost) to a high of 0.451 (delivery) and 0.471 (innovation).

The regression analyses underscore the significance of how various factors, independent variables (IV), influence different manufacturing strategy dimensions, dependent variables (DV), differently. There are five manufacturing strategy dimensions; however, most of the factors are predictor of only one or two strategy dimensions. Some of the major findings of regression analysis with respect to manufacturing strategy dimensions are as follows.

Resource orientation is a positive and significant predictor for quality while business strategy orientation was found to be statistically significant with flexibility manufacturing strategy. Hypothesis $3 \mathrm{a}$ and $3 \mathrm{~b}$ are thus partially supported.

Manufacturing capability is a significant predictor of manufacturing strategy dimensions. However, various aspects of manufacturing capability have different impact on each dimension of manufacturing strategy. For instance, quality capability is a predictor of quality and innovation strategies. Cost capability is a predictor of cost and delivery strategies. Delivery seems to be one of the essential manufacturing capabilities as it is a predictor of four out of five manufacturing strategies, with the exception of innovation 
strategy. Flexibility capability, though, does not seem to have any impact on manufacturing strategy. Thus hypothesis $3 \mathrm{c}$ is partially supported.

Innovation orientation appears to be an important factor since it has a positively significant impact on three manufacturing strategies - cost, delivery and innovation. Environmental dynamism, on the other hand, impacts delivery and innovation strategies. Hypotheses $3 \mathrm{~d}$ and $3 \mathrm{f}$ are also partially supported.

The control variable "product life cycle" impacts two manufacturing strategy dimensions - cost and innovation, in growth and maturity stages. The focus on cost strategy goes up in maturity stage while focus on innovation goes down in growth stage. The control variable "industrial environment" has three dimensions - rivalry, threat of substitute products and power of supplier. Threat of substitute products and supplier power do not influence any manufacturing strategy dimension. Rivalry, however, impacts all five manufacturing strategy dimensions when control variables are alone entered in the regression analysis. Nonetheless, rivalry is not a significant for any one of five manufacturing strategy dimensions once the independent variables are entered in the hierarchal regression analysis.

The interpretation of regression results from the perspective of manufacturing strategy would be as follows. Quality strategy is positively influenced by resource orientation, quality capability, and delivery capability. Cost strategy is positively influenced by cost and delivery capabilities and innovation orientation. Business strategy orientation and delivery capability influence flexibility strategy. Delivery strategy is positively influenced by cost and delivery capabilities as well as innovation orientation and 
environmental dynamism. Innovation capability is a positively influenced by innovation capability, environmental dynamism and innovation orientation.

Some of the high regression coefficients (ß) include delivery capability $(0.639)$ for delivery strategy, cost capability (0.419) for cost strategy, quality capability $(0.317)$ for quality strategy, and innovation orientation (.344) for innovation strategy.

Second Set: Manufacturing Strategy and Organizational Performance: Empirical studies examining the effects of manufacturing strategy on performance are not well represented in the literature (Dean and Snell, 1996). Adam and Swamidass (1989) conducted an extensive review of literature and concluded that lack of study amongst various variables, in particular, the impact of strategy on performance, is the "greatest weakness" of the field.

In the first stage of the second set of analyses, the six control variables were entered into a regression model to separate their effects. In the second stage, five independent variables were added to the model to separate their main effects. The regression equations used in each stage of the regression analyses are presented in Table 58:

Table 58: Regression Equations-Manufacturing Strategy and Organizational Performance

\begin{tabular}{|l|l|l|}
\hline Stage & Purpose & Regression Equation \\
\hline 1 & $\begin{array}{l}\text { To test the main effects } \\
\text { of control variables }\end{array}$ & DV= $\alpha+$ PL1+PL2+PL3+IND1+IND2+IND3+ $\varepsilon$ \\
\hline 2 & $\begin{array}{l}\text { To test the main effects } \\
\text { of independent variables }\end{array}$ & $\begin{array}{l}\text { DV= } \alpha+ \\
\text { PL1+PL2+PL3+IND1+IND2+IND3+MNS1+MNS2+ } \\
\text { MNS3+ MNS4+MNS5+ }\end{array}$ \\
\hline
\end{tabular}

$\mathrm{DV}=$ dependent variable

PL1 = Product Life Cycle dummy 1 (growth)

PL2 = Product Life Cycle dummy 2 (maturity) 
PS3 = Product Life Cycle dummy 3 (decline)

IND1 = Industrial Environment (Rivalry)

IND2 = Industrial Environment (Threat of substitute products)

IND3 = Industrial Environment (power of suppliers)

MNS1 = quality

MNS $2=$ cost

MNS 3 = flexibility

MNS $4=$ delivery

MNS 5 = innovation

$\alpha=$ the constant

$\varepsilon=$ the residual term

Table 59 below shows the results for four different multiple regressions, two for each dependent variable - one with control variables only and other with control and independent variables.

Table 59: Regression Results-Manufacturing Strategy and Organizational Performance

\begin{tabular}{|l|r|r|r|r|}
\hline \multirow{2}{*}{ Variables } & \multicolumn{3}{|c|}{ Performance Financial } & \multicolumn{2}{c|}{ Performance Non-Financial } \\
\cline { 2 - 5 } & Model 1 & Model 2 & Model3 & Model4 \\
\hline Control & & & & \\
\hline PLC-Growth & & & & \\
\hline PLC-Maturity & & & & \\
\hline PLC-Decline & & & $-0.170^{*}$ & \\
\hline Ind-Rivalry & & $-0.197^{* *}$ & & \\
\hline Ind-Substitutes & & & & \\
\hline Ind-Supplier power & & & & \\
\hline Independent & & & & \\
\hline MNS-Quality & & & & $0.224^{* * *}$ \\
\hline MNS-Cost & & $0.135^{*}$ & & \\
\hline MNS-Flexibility & & $0.178^{* *}$ & & \\
\hline MNS-Delivery & & $0.165^{*}$ & & \\
\hline MNS-Innovation & & & & \\
\hline R Square & 0.042 & 0.163 & 0.058 & \\
\hline Change in R-Square & & 0.121 & & 0.153 \\
\hline F Statistics & 1.231 & $2.883^{* * *}$ & 1.735 & $2.682^{* * *}$ \\
\hline
\end{tabular}

Note: This Table shows only the significant Betas

Standardized regression coefficients are shown

* $\mathrm{p}<.10$

$* * \quad \mathrm{p}<.05$

$* * * \mathrm{p}<.01$ 
Table 59 above displays the results of the hierarchical regression analyses. Models 1 and 3 involve the six control variables only, while models 2 and 4 include all the control variables and five independent variables.

As indicated by the F-statistic, both models with control and independent variables (Models 2 and 4) were a statistically significant predictor of organizational performance with manufacturing strategy dimensions. The $\mathrm{R}^{2}$ for Models 2 and 4 are reasonably good, 0.163 and 0.153 respectively.

There are total of five manufacturing strategy dimensions in the analysis; three of them cost, flexibility and delivery - are significant predictors of financial performance. Quality, however, is the only strategy which is a significant predictor of non-financial performance. Hypothesis $4 a, 4 b, 4 c$ and $4 d$ are, thus, partially supported. Hypothesis $4 \mathrm{e}$ is not supported.

The control variable "industrial rivalry" has a negative impact on financial performance. Only one control variable, "product life cycle," influences non-financial. Non-financial performance is negative in the decline stage when only control variables are entered. However, none of the control variables impacts non-financial performance once the independent variables are also entered in the regression analysis.

Table 60 below provides a summary of findings of regression analysis for hypotheses posited earlier. 
Table 60: Findings of Manufacturing Strategy Hypotheses

\begin{tabular}{|c|c|c|}
\hline \multicolumn{3}{|c|}{ Impact of Influencing Factors on Manufacturing Strategy } \\
\hline$H_{3 a}$ & $\begin{array}{l}\text { Resource orientation will have an impact on quality, cost, } \\
\text { flexibility, delivery and innovation manufacturing strategy. }\end{array}$ & $\begin{array}{l}\text { Partially } \\
\text { Supported }\end{array}$ \\
\hline$H_{3 b}$ & $\begin{array}{l}\text { Business strategy orientation will have an impact on quality, } \\
\text { cost, flexibility, delivery and innovation manufacturing } \\
\text { strategy. }\end{array}$ & $\begin{array}{l}\text { Partially } \\
\text { Supported }\end{array}$ \\
\hline$H_{3 c}$ & $\begin{array}{l}\text { Manufacturing capability will have an impact on quality, } \\
\text { cost, flexibility, delivery and innovation manufacturing } \\
\text { strategy. }\end{array}$ & $\begin{array}{l}\text { Partially } \\
\text { Supported }\end{array}$ \\
\hline$H_{3 d}$ & $\begin{array}{l}\text { Innovation orientation will have an impact on quality, cost, } \\
\text { flexibility, delivery and innovation manufacturing strategy. }\end{array}$ & $\begin{array}{l}\text { Partially } \\
\text { Supported }\end{array}$ \\
\hline$H_{3 e}$ & $\begin{array}{l}\text { Environmental dynamism will have an impact on quality, } \\
\text { cost, flexibility, delivery and innovation manufacturing } \\
\text { strategy. }\end{array}$ & $\begin{array}{l}\text { Partially } \\
\text { Supported }\end{array}$ \\
\hline \multicolumn{3}{|c|}{ Manufacturing Strategy and Organizational Performance } \\
\hline$H_{4 a}$ & $\begin{array}{l}\text { Quality manufacturing strategy will have a positive effect on } \\
\text { firm's financial and non-financial performance. }\end{array}$ & $\begin{array}{l}\text { Partially } \\
\text { Supported }\end{array}$ \\
\hline$H_{4 b}$ & $\begin{array}{l}\text { Cost manufacturing strategy will have a positive on firm's } \\
\text { non-financial and non-financial performance. }\end{array}$ & $\begin{array}{l}\text { Partially } \\
\text { Supported }\end{array}$ \\
\hline$H_{4 c}$ & $\begin{array}{l}\text { Flexibility manufacturing strategy will have a positive effect } \\
\text { on firm's non-financial and non-financial performance. }\end{array}$ & $\begin{array}{l}\text { Partially } \\
\text { Supported }\end{array}$ \\
\hline$H_{4 d}$ & $\begin{array}{l}\text { Delivery manufacturing strategy will have a positive effect } \\
\text { on firm's non-financial and non-financial performance. }\end{array}$ & $\begin{array}{l}\text { Partially } \\
\text { Supported }\end{array}$ \\
\hline$H_{4 e}$ & $\begin{array}{l}\text { Innovation manufacturing strategy will have a positive effect } \\
\text { on firm's financial and non-financial performance. }\end{array}$ & Not Supported \\
\hline
\end{tabular}

\subsection{Co-alignment (Fit) Analysis - Profile deviation}

This section deals with the co-alignment of positioning and manufacturing strategies and its impact on organizational performance. In general, it is a well accepted proposition in the literature that strategic co-alignment; that is, correspondence among a set of theoretically-related dimensions, significantly impacts performance. However, empirical evidence in this regard has been limited for two major reasons. First, there is the issue of 
the best way to define 'fit' or co-alignment, and second, the best way to operationalize it (Venkatraman, 1990).

The concept of alignment has numerous connotations in the literature. Venkatraman (1989) was the first to specify six different types of fit based on different conceptualizations and technical specifications. The details of six fit types were discussed in Chapter 7 (methodology). Given the rationale provided in Chapter 7 for using profile deviation and, in the face of overwhelming evidence confirming the use of this method by the majority of studies (Table 23), it was decided to use profile deviation analysis to operationalize fit analysis. Profile Deviation follows a three step process. In the first step, an ideal profile must be derived, either theoretically or empirically (Venkatraman, 1989). Since there was no theoretically ideal profile given in the literature, an empirically derived profile is used for this study. In empirical profiling, top-performing firms are identified and the characteristics deemed important in determining their superior performance are calibrated. Profile deviation studies usually select the $10 \%-15 \%$ top performing businesses in a data set to calibrate ideal profiles (Venkatraman and Prescott, 1990). A summary of how previous studies in the literature have used profile deviation is given below in Table 61: 
Table 61: Empirical Studies with Profile Deviation Conceptualization

\begin{tabular}{|c|c|c|c|c|c|c|c|c|c|}
\hline \multirow[b]{3}{*}{$\begin{array}{c}\text { Study } \\
\text { Ref. }\end{array}$} & \multicolumn{9}{|c|}{ Profile Deviation Studies Only } \\
\hline & \multicolumn{6}{|c|}{ Calibration Sample } & \multicolumn{3}{|c|}{ Analysis of Deviation } \\
\hline & Empirical & Theoretical & $\begin{array}{r}\text { Sample } \\
\text { size } \\
\end{array}$ & $\begin{array}{r}\text { Percent of } \\
\text { study sample }\end{array}$ & Multiple & Random & Regression & Correlation & Post Hoc \\
\hline 1 & Yes & No & 32 & 15 & Yes & Yes & No & Yes & No \\
\hline 2 & Yes & No & $\begin{array}{r}\text { Not } \\
\text { given }\end{array}$ & 10 & No & Yes & Yes & Yes & No \\
\hline 3 & & 5 & & & 2 & & 10 & & 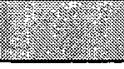 \\
\hline 4 & Yes & Yes & 17 & 10 & No & Yes & No & Yes & No \\
\hline 5 & Yes & No & $6 ; 12 ; 20$ & $10 ; 15 ; 20$ & No & No & No & Yes & No \\
\hline 6 & No & Yes & $\begin{array}{r}\text { Not } \\
\text { given }\end{array}$ & Not given & No & No & No & Yes & No \\
\hline 7 & & & & 28 & & 10. & & & \\
\hline 8 & Yes & No & 13 & 25 & No & No & No & Yes & No \\
\hline 9 & Yes & No & $5 ; 5 ; 5$ & Not used & No & Yes & Yes & No & No \\
\hline 10 & $\begin{array}{c}\text { Not } \\
\text { given }\end{array}$ & $\begin{array}{c}\text { Not } \\
\text { given }\end{array}$ & $\begin{array}{r}\text { Not } \\
\text { given }\end{array}$ & Not given & No & $\begin{array}{c}\text { Not } \\
\text { given }\end{array}$ & Yes & No & No \\
\hline 11 & Yes & No & 1 & Not used & Yes & Yes & Yes & No & No \\
\hline 12 & Yes & No & $6 ; 7 ; 8 ; 8$ & 10 & No & Yes & Yes & No & No \\
\hline 13 & Yes & No & $16-70$ & 10 & & Yes & Yes & No & No \\
\hline 14 & & 828 & & & & & 20 & & \\
\hline
\end{tabular}

\section{References for studies listed in Table 61}

\begin{tabular}{|c|l|c|}
\hline Study Ref. & \multicolumn{1}{|c|}{ Authors } & Year \\
\hline 1 & Venkatraman, N. & 1990 \\
\hline 2 & Venkatraman, N. and Prescott, John E. & 1990 \\
\hline 3 & Powell; Thomas C. & 1992 \\
\hline 4 & Marlin, Dan; Hoffman, James J. and Lamont, Bruce T. & 1994 \\
\hline 5 & Conrad, Craig A.; Brown, Gene and Harmon, Harry A. & 1997 \\
\hline 6 & Sabherwal; Rajiv and Chan, Yolande E. & 2001 \\
\hline 7 & Luo, Yadong and Park, Seung Ho & 2001 \\
\hline 8 & Kathuria, Ravi and Porth, Stephen J. & 2003 \\
\hline 9 & Vorhies, Douglas W. and Morgan, Neil A. & 2003 \\
\hline 10 & Devaraj, Sarv;Hollingworth, David G. and Schroeder, Roger G. & 2004 \\
\hline 11 & Vorhies, Douglas W. and Morgan, Neil A. & 2005 \\
\hline 12 & Kabadayi, Sertan; Eyuboglu, Nermin and Thomas, Gloria P. & 2007 \\
\hline 13 & Hult, G. Tomas M.; Boyer, Kenneth K. and Ketchen Jr.; David J. & 2007 \\
\hline 14 & Gebauer, Heiko & 2008 \\
\hline
\end{tabular}


One can make a number of observations about the application of profile deviation technique from the Table 61 . The studies are primarily using empirical calibration sample (a certain percentage of sample based on an empirical criteria; for example, performance) rather than a theoretical calibration sample, based on prior theory. The size of calibration sample ranges from 1 to 32 with a number of them in single digits. A large majority of the studies are using single, rather than multiple, calibration sample and do not corroborate findings with a random sample. Correlation and regression analyses are equally used to analyze deviation from the ideal profile. None of the studies have conducted post hoc analysis to determine the makeup of the ideal profile, if any.

In the current study, the ideal profile comprises $10 \%$ high performing firms. A cut-off point, where the performance dropped, was used to select a calibration sample of 21 firms. The mean scores of eight positioning strategy dimensions and five manufacturing strategy dimensions were then calculated for this ideal profile.

The second step entails determining the degree to which firms not included in the calibration sample, called "study sample" here, differ from ideal profile. This is done by using Euclidean distance formula (Venkatraman, 1990).

$$
\text { Dist }=\sqrt{\sum_{j}^{N}\left(X_{s j}-\bar{X}_{i j}\right)^{2}},
$$

where

$\mathrm{X}_{\mathrm{sj}}=$ the score for a firm in the study sample on the $\mathrm{jth}$ dimension,

$\overline{\mathrm{X}}_{\mathrm{ij}}=$ the mean for the ideal profile along the jth dimension, and

$j=$ the number of profile dimensions $(1,2, \ldots, 7)$. 
The third step involves studying the relationship between criterion variable, organizational performance in this case, and derived distance for firms in the study sample. For study hypotheses to be supported, the deviation from the ideal profile should be negatively and significantly related to organizational performance. Appendix 7 (page 295) provides complete details of how calculation for each step of profile deviation was carried out for this study.

\subsubsection{Correlation Analysis - Profile Deviation}

Figure 18 below depicts the nature of relationships where manufacturing strategy dimensions, positioning strategy dimension, and co-alignment of manufacturing and positioning strategy dimensions have an impact on organizational performance. Industry environment and product life cycle act as control variables.

Figure 18: Co-alignment of Positioning and Manufacturing Strategy

Control Variables

- Industry Environment

- Product Life Cycle

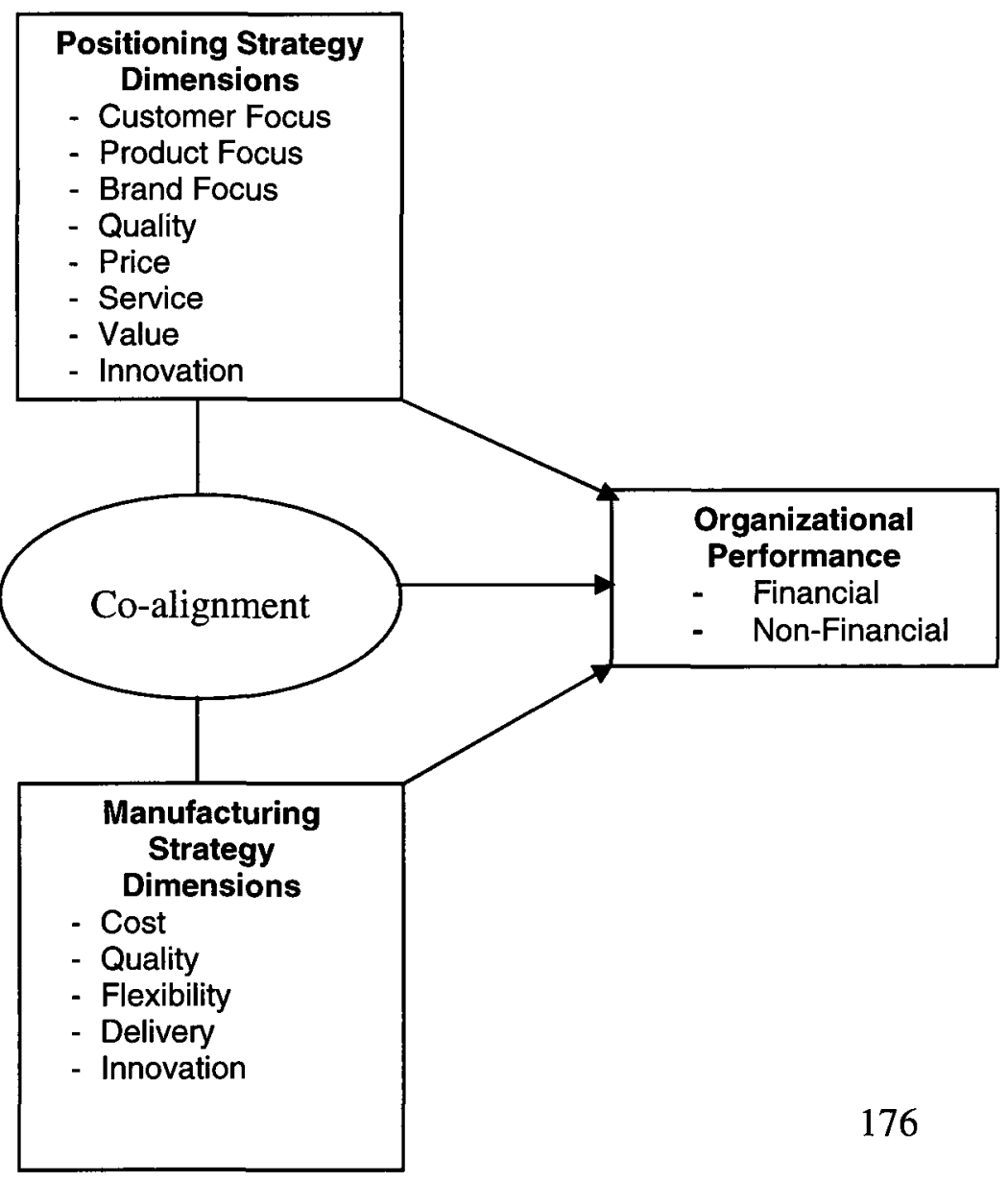


Correlation and regression were conducted to examine the relationship between organizational performances and distance from ideal profile. The findings of correlation analysis are given below:

\section{Table 62: Co-alignment of Positioning Strategy and Manufacturing Strategy}

\begin{tabular}{|l|r|}
\hline Variable & deviation from ideal profile \\
\hline performance non-financial & $-0.197^{*}$ \\
\hline performance financial & \\
\hline
\end{tabular}

It was posited that the deviation from the ideal profile should be negatively and significantly related to organizational performance. Both the indicators of organizational performance, financial and non-financial, have statistically significant negative correlations with deviation from ideal profile.

\subsubsection{Regression Analysis - Profile Deviation}

To further corroborate the above evidence, multiple regression analysis was also conducted. Two sets of hierarchical regression analyses were performed using organizational performance (financial and non-financial) as the dependent variable and deviation from ideal profile as the independent variable. All regressions were controlled for industry environment and product life cycle.

In the first stage of analysis, the six control variables were entered into a regression model to separate their effects. In the second stage, one independent variable was added to the model to separate its main effects. The regression equations used in each stage of the regression analyses are presented in Table 63: 
Table 63: Regression Equations-Co-alignment of Positioning Strategy and Manufacturing Strategy

\begin{tabular}{|l|l|l|}
\hline Stage & Purpose & Regression Equation \\
\hline 1 & $\begin{array}{l}\text { To test the main } \\
\text { effects of control } \\
\text { variables }\end{array}$ & DV= $\alpha+$ PL1+PL2+PL3+IND1+IND2+IND3+ $\varepsilon$ \\
\hline 2 & $\begin{array}{l}\text { To test the main } \\
\text { effects of independent } \\
\text { variable }\end{array}$ & DV= $\alpha+$ PL1+PL2+PL3+IND1+IND2+IND3+ DIS+ $\varepsilon$ \\
\hline
\end{tabular}

$\mathrm{DV}=$ dependent variable

PL1 $=$ Product Life Cycle dummy 1 (growth)

PL2 = Product Life Cycle dummy 2 (maturity)

PS3 = Product Life Cycle dummy 3 (decline)

IND1 = Industrial Environment (Rivalry)

IND2 = Industrial Environment (Threat of substitute products)

IND3 = Industrial Environment (power of suppliers)

DIS $=$ Distance from Ideal Profile

$\alpha=$ the constant

$\varepsilon=$ the residual term

Table 64 below shows the results for four different multiple regressions, two for each dependent variable - one with control variables only and the other with control and independent variables.

Table 64: Regression Results-Co-alignment of Positioning Strategy and Manufacturing Strategy

\begin{tabular}{|l|r|r|r|r|}
\hline \multirow{2}{*}{ Variables } & \multicolumn{3}{|c|}{ Performance Financial } & \multicolumn{2}{c|}{ Performance NON-Financial } \\
\cline { 2 - 5 } & Model 1 & Model 2 & \multicolumn{1}{c|}{ Model 3 } & Model 4 \\
\hline Control & & & & \\
\hline PLC-Growth & & & & \\
\hline PLC-Maturity & & & & \\
\hline PLC-Decline & & & & \\
\hline IND-Rivalry & & $-0.155^{*}$ & & \\
\hline IND-Substitutes & & & & \\
\hline IND-Supplier power & & & & \\
\hline Independent & & & & \\
\hline Deviation & & $-0.298^{* * *}$ & & $-0.160^{*}$ \\
\hline R Square & 0.042 & 0.12 & 0.058 & 0.081 \\
\hline Change in R-Square & & 0.078 & & 0.022 \\
\hline F Statistics & 1.106 & $2.921^{* * *}$ & & 1.56 \\
\hline
\end{tabular}


Note: This Table shows only the significant Betas

Standardized regression coefficients are shown

* $\mathrm{p}<.10$

$* * \mathrm{p}<.05$

$* * * \mathrm{p}<.01$

Table 64 above displays the results of the hierarchical regression analyses. Models 1 and 3 involve the six control variables only. Models 2 and 4 include all the control variables and one independent variable.

As indicated by the F-statistic, two models with both control and independent variables were a statistically significant and substantive predictor of organizational performance with lack of co-alignment. The $\mathrm{R}^{2}$ are relatively low at 0.120 and 0.081 . However, the regression coefficient $(\beta)$ in model 2 is quite reasonable at -0.298 .

Amongst the control variables, industrial rivalry has a negative impact on financial performance. Non-financial performance is negative in the decline stage when only control variables are entered. However, none of the control variables impact nonfinancial performance once the independent variable is also entered in the regression analysis. Hypothesis 5 is thus supported.

\section{Table 65: Findings of Co-alignment Hypotheses}

\begin{tabular}{|l|l|l|}
\hline$H_{5}$ & $\begin{array}{l}\text { Lack of co-alignment of manufacturing strategy and } \\
\text { positioning strategy will have a negative effect on firm's } \\
\text { financial performance and non-financial performance. }\end{array}$ & Supported \\
\hline
\end{tabular}

\subsubsection{Profile Deviation - Additional Analysis}

It was decided to conduct additional analyses with profile deviation to ensure that the results of fit analyses had high degree of credence. Two calibration samples were taken 
for this purpose. First, a second ideal profile was created from the top 15 percent of the performers and the second, a random sample of 20 respondents was taken to form a random profile calibration sample.

The mean scores of eight positioning strategy dimensions and five manufacturing strategy dimensions were then calculated for second ideal profile as well as the random calibration sample. The degree to which firms not included in the calibration sample, called "study sample" here, differed from the second ideal profile and random calibration sample was calculated using Euclidean distance formula.

For earlier profile deviation results to be corroborated, the deviation from the second ideal profile should also be negatively and significantly related to organizational performance, while the deviation from the random calibration sample should not be negatively and significantly related to organizational performance. The correlation and regression results of second ideal profile (15 percent) are given below:

Table 66: Co-alignment of Positioning Strategy and Manufacturing Strategy Second Ideal Profile

\begin{tabular}{|l|r|}
\hline \multirow{2}{*}{ Dependent Variable } & Independent Variable \\
\cline { 2 - 2 } & deviation from ideal profile \\
\hline performance non-financial & $-0.190^{* *}$ \\
\hline performance financial & $-0.246^{*}$ \\
\hline
\end{tabular}

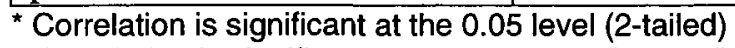

${ }^{\star \star}$ Correlation is significant at the 0.01 level (2-tailed)

Both the indicators of organizational performance, financial and non-financial, have statistically significant negative correlations with deviation from ideal profile. Table 67 given below presents the results of regression analysis conducted to determine the misalignment of positioning and manufacturing strategies based on second ideal profile. 
Table 67: Regression Results- Co-alignment of Positioning Strategy and Manufacturing Strategy (Second Ideal Profile)

\begin{tabular}{|l|c|c|c|c|}
\hline \multirow{2}{*}{ Variables } & \multicolumn{2}{|c|}{ Performance Financial } & \multicolumn{2}{c|}{ Performance NON-Financial } \\
\cline { 2 - 5 } Control & Model 1 & Model 2 & Model 3 & Model 4 \\
\hline PLC-Growth & & & & \\
\hline PLC-Maturity & & & & \\
\hline PLC-Decline & & & & \\
\hline IND-Rivalry & & $-0.165^{*}$ & & \\
\hline IND-Substitutes & & & & \\
\hline IND-Supplier power & & & & \\
\hline Independent & & & & \\
\hline Deviation & & $-0.298^{* * *}$ & & \\
\hline R Square & 0.042 & 0.114 & 0.058 & $0.150^{*}$ \\
\hline Change in R-Square & & & & 1.713 \\
\hline F Statistics & 1.048 & $2.613^{* * *}$ & & 1.477 \\
\hline
\end{tabular}

Note: This Table shows only the significant Betas

Standardized regression coefficients are shown

$* \quad \mathrm{p}<.10$

$* * \mathrm{p}<.05$

$* * * \mathrm{p}<.01$

Table 67 displays the results of the hierarchical regression analyses with the second ideal profile (top 15 percent performers). Models 1 and 3 involve the six control variables only. Models 2 and 4 include all the control variables and one independent variable.

As indicated by the F-statistic, the model with both control and independent variables is a statistically significant and substantive predictor of financial performance with lack of co-alignment. $\mathrm{R}^{2}$ is 0.114 , a slight decrease from $\mathrm{R}^{2}$ of 0.120 for first ideal profile (top 10 percent performers). However, the regression coefficient $(\beta)$ in Model 2 is exactly the same as it was for Model 2 with the first ideal profile, at -0.298 . Amongst the control variables, industrial rivalry has a negative impact on financial performance.

For non-financial performance, all the statistics parameters have deteriorated slightly with the second ideal profile. For example, $\mathrm{R}^{2}$ has come down from 0.081 (first ideal profile) to 0.078 . The significance level is 0.10 for the first ideal profile and 0.11 for the 
second ideal profile. Similarly, the regression coefficient at -0.150 for the second ideal profile is slightly less than regression coefficient for the first ideal profile $(-0.160)$.

The results, therefore, strongly corroborate the earlier findings that lack of co-alignment of positioning and manufacturing strategy will have a negative impact on the financial and non-financial performance of the firm.

A random profile calibration sample was also taken and analyzed to ensure that the findings of ideal profile were not merely by chance. The correlation and regression results of random profile calibration sample are given below:

Table 68: Co-alignment of Positioning Strategy and Manufacturing Strategy Random Profile

\begin{tabular}{|l|r|}
\hline \multirow{2}{*}{ Dependent Variable } & Independent Variable \\
\cline { 2 - 2 } & deviation from ideal profile \\
\hline performance non-financial & 0.003 \\
\hline performance financial & -0.112 \\
\hline
\end{tabular}

* Correlation is significant at the 0.05 level (2-tailed)

${ }^{* *}$ Correlation is significant at the 0.01 level (2-tailed)

Both the indicators of organizational performance, financial and non-financial, do not have statistically significant correlation with deviation from the ideal profile.

Table 69: Regression Results-Co-alignment of Positioning Strategy and Manufacturing Strategy (Random Profile)

\begin{tabular}{|c|c|c|c|c|}
\hline \multirow[b]{2}{*}{ Variables } & \multicolumn{2}{|c|}{ Performance Financial } & \multicolumn{2}{|c|}{ Performance NON-Financial } \\
\hline & Model 1 & Model 2 & Model 3 & Model 4 \\
\hline \multicolumn{5}{|l|}{ Control } \\
\hline \multicolumn{5}{|l|}{ PLC-Growth } \\
\hline \multicolumn{5}{|c|}{ PLC-Maturity } \\
\hline PLC-Declin & & & $-0.170^{*}$ & $-0.185^{*}$ \\
\hline \multicolumn{5}{|l|}{ IND-Rivalry } \\
\hline \multicolumn{5}{|c|}{ IND-Substitutes } \\
\hline \multicolumn{5}{|c|}{ IND-Supplier power } \\
\hline \multicolumn{5}{|c|}{ Independent } \\
\hline Deviation & & -0.094 & & 0.064 \\
\hline R Square & 0.042 & 0.050 & 0.058 & 0.062 \\
\hline \multicolumn{5}{|c|}{ Change in R-Square } \\
\hline F Statistics & 1.084 & 1.112 & 1.529 & 1.391 \\
\hline
\end{tabular}


Note: This Table shows only the significant Betas

Standardized regression coefficients are shown

* $\mathrm{p}<.10$

$* * \mathrm{p}<.05$

$* * * \mathrm{p}<.01$

Table 69 displays the results of the hierarchical regression analyses with random sample. Models 1 and 3 involve the six control variables only. Models 2 and 4 include all the control variables and one independent variable. As indicated by the F-statistic, none of the models is a statistically significant and substantive predictor of organizational performance with lack of co-alignment. The low $\mathrm{R}^{2}$ and insignificant coefficient for deviation term in the random profile regression provide additional confidence to our profile deviation results.

The results, therefore, strongly corroborate the earlier findings that lack of co-alignment of positioning and manufacturing strategy will have a negative impact on the financial and non-financial performance of the firm.

\subsubsection{Analysis of Ideal Profile}

Since there is no prior literature on the theoretical ideal profile with respect to coalignment of positioning and manufacturing strategies, for the empirical ideal profile, top $10 \%$ performers were used for this study. From the above analysis, we can conclude that deviation from the ideal profile leads to adverse impact on organizational performance both financial and non-financial. However, the difference between the type of strategies, manufacturing as well as positioning, adopted by the ideal profile versus the rest of the firms is still unclear. A correlation analysis was performed to assess association between 
manufacturing and positioning strategies of calibration and study sample to develop some insights. The details of the analysis are given below in Tables 70 and 71.

Table 70: Profile Analysis-Study Sample

\begin{tabular}{|l|l|l|l|l|l}
\hline \multirow{2}{*}{ Positioning Strategy } & \multicolumn{5}{|c}{ Manufacturing Strategy } \\
\cline { 2 - 6 } & Quality & Cost & Flexibility & Delivery & Innovation \\
\hline Customer Focus & $0.33^{*}$ & $0.20^{*}$ & $0.34^{*}$ & $0.33^{*}$ & $0.27^{*}$ \\
\hline Product Focus & $0.21^{*}$ & & & & $0.46^{*}$ \\
\hline Brand Focus & $0.32^{*}$ & & $0.25^{*}$ & $0.33^{*}$ & $0.42^{*}$ \\
\hline Innovation & $0.26^{*}$ & & & & $0.61^{*}$ \\
\hline Quality & $0.57^{*}$ & & $0.25^{*}$ & $0.21^{*}$ & $0.27^{*}$ \\
\hline Service & $0.19^{* *}$ & & $0.17^{* *}$ & & $0.28^{*}$ \\
\hline Price & & $0.42^{*}$ & & $0.26^{*}$ & \\
\hline Value & $0.39^{*}$ & $0.20^{*}$ & & $0.32^{*}$ & $0.32^{*}$ \\
\hline
\end{tabular}

* Correlation is significant at the 0.05 level (2-tailed)

${ }^{* *}$ Correlation is significant at the 0.01 level (2-tailed)

\section{Table 71: Profile Analysis-Calibration Sample}

\begin{tabular}{|l|l|l|l|l|l}
\hline & \multicolumn{5}{|c}{ Manufacturing Strategy } \\
\hline Positioning Strategy & Quality & Cost & Flexibility & Delivery & Innovation \\
\hline Customer Focus & & & & & \\
\hline Product Focus & $0.51^{* *}$ & & & & \\
\hline Brand Focus & & & & & $0.51^{* *}$ \\
\hline Innovation & & & & & $0.83^{* *}$ \\
\hline Quality & & & & & \\
\hline Service & & & & $0.51^{* *}$ & $0.54^{* *}$ \\
\hline Price & & & $0.50^{* *}$ & & \\
\hline Value & & & & & \\
\hline
\end{tabular}

* Correlation is significant at the 0.05 level (2-tailed)

${ }^{* *}$ Correlation is significant at the 0.01 level (2-tailed)

A quick overview of both the tables above reveals that firms in the study sample are indiscriminate when it comes to their emphasis on manufacturing and positioning strategy. The firms in the calibration sample, though, are much focused. There seems to be a clear pattern of co-alignment of manufacturing strategy dimension and 
corresponding positioning strategy dimensions. For example, the firms with product focus positioning strategy have corresponding emphasis on quality manufacturing strategy. The firms with brand focus positioning strategy are innovation-driven in manufacturing strategy. The firms with innovation positioning strategy pursue innovation as manufacturing strategy as well. Service positioning strategy corresponds with delivery and innovation manufacturing strategies. Price positioning strategy corresponds with flexibility manufacturing strategy.

\subsubsection{Validation of Profile Deviation Method}

In Profile Deviation method the researcher specifies an ideal profile, normally $10 \%$ of top performers, and determines how adherence to such a profile impacts performance. The misalignment or lack of co-alignment is calculated as the lack of correspondence between the profile of the top performing strategic configuration and rest of the strategic configurations.

In the first step, $10 \%-15 \%$ top performing businesses were identified and their characteristics deemed important (manufacturing strategy and positioning strategy) in determining their superior performance were calibrated. The second step entailed determining the degree to which firms not included in the calibration sample, called "study sample" here, differed from ideal profile. This was done using Euclidean distance formula. The third step involved studying the relationship between criterion variable, organizational performance in this case, and derived distance for firms in the study sample. The lack of correspondence indicated by the misalignment score was correlated with the performance measures. For study hypotheses to be supported, the deviation from 
the ideal profile was negatively and significantly related to organizational performance. The adherence to ideal profile was taken as co-alignment for this study.

The difference of firms from ideal profile (calibration sample) was calculated using Euclidean distance and incorporated both manufacturing strategy and positioning strategy measures. One valid question at this point would be how the results would have been different if the difference from ideal profile is based on manufacturing strategy only or positioning strategy only rather than a combination of the two (for the purpose of coalignment). If the deviation (based only on manufacturing or positioning strategy) is negatively correlated to performance then it casts doubts on the validity of our findings.

Two additional analyses were, thus, performed to verify the validity of our findings. The difference from ideal profile was calculated on the basis of manufacturing strategy only and positioning strategy only. The hierarchical regressions were conducted with deviation from manufacturing strategy and deviation from positioning strategy as independent variables. The findings are given below:

Table 72: Regression Results-Validation of Profile Deviation, deviation from Positioning Strategy Only

\begin{tabular}{|l|c|c|c|c|}
\hline \multirow{2}{*}{ Variables } & \multicolumn{2}{|c|}{ Performance Financial } & \multicolumn{2}{c|}{ Performance NON-Financial } \\
\cline { 2 - 5 } & Model 1 & Model 2 & Model 3 & Model 4 \\
\hline Control & & & & \\
\hline PLC-Growth & & & & \\
\hline PLC-Maturity & & & & \\
\hline PLC-Decline & & & & $-0.185^{*}$ \\
\hline IND-Rivalry & & & & \\
\hline IND-Substitutes & & & & \\
\hline IND-Supplier power & & & & \\
\hline Independent & & & & \\
\hline Deviation-PS & & & & \\
\hline R Square & 0.042 & 0.013 & & 0.213 \\
\hline F Statistics & 1.084 & 0.042 & 0.058 & 2.103 \\
\hline
\end{tabular}


Note: This Table shows only the significant Betas

Standardized regression coefficients are shown

* $\mathrm{p}<.10$

$* * \quad \mathrm{p}<.05$

$* * * p<.01$

Table 72 above displays the results of the hierarchical regression analyses for deviation from positioning strategy only. Models 1 and 3 involve the six control variables only. Models 2 and 4 include all the control variables and one independent variable.

As indicated by the F-statistic, model 2 with financial performance as dependent variable in not statistically significant. Model 4 with non-financial performance as dependent variable is statistically significant but deviation from ideal profile is positive instead of negative.

Table 73: Regression Results- Validation of Profile Deviation, deviation from Manufacturing Strategy Only

\begin{tabular}{|c|c|c|c|c|}
\hline \multirow[b]{2}{*}{ Variables } & \multicolumn{2}{|c|}{ Performance Financial } & \multicolumn{2}{|c|}{ Performance NON-Financial } \\
\hline & Model 1 & Model 2 & Model 3 & Model 4 \\
\hline \multicolumn{5}{|l|}{ Control } \\
\hline \multicolumn{5}{|l|}{ PLC-Growth } \\
\hline \multicolumn{5}{|l|}{ PLC-Maturity } \\
\hline PLC-Decline & & & $-0.170^{*}$ & $-0.191 *$ \\
\hline \multicolumn{5}{|l|}{ IND-Rivalry } \\
\hline \multicolumn{5}{|l|}{ IND-Substitutes } \\
\hline \multicolumn{5}{|c|}{ IND-Supplier power } \\
\hline \multicolumn{5}{|l|}{ Independent } \\
\hline Deviation-MS & & -0.004 & & 0.109 \\
\hline R Square & 0.042 & 0.042 & 0.058 & 0.069 \\
\hline F Statistics & 1.084 & 0.923 & 1.529 & 1.568 \\
\hline
\end{tabular}

Note: This Table shows only the significant Betas

Standardized regression coefficients are shown

* $\mathrm{p}<.10$

$* * \quad \mathrm{p}<.05$

$* * * \mathrm{p}<.01$

Table 73 above displays the results of the hierarchical regression analyses for deviation from manufacturing strategy only. Models 1 and 3 involve the six control variables only. 
Models 2 and 4 include all the control variables and one independent variable. As indicated by the F-statistic, none of the models is a statistically significant..

The above results further confirm the validity of co-alignment of positioning and manufacturing strategy findings using profile deviation method.

\subsection{Assumptions of Regression Analysis}

For regression tests to be valid, certain assumptions must be met. The details of regression assumptions and tests used to validate them are given below in Table 72:

Table 74: Regression Assumptions and Tests

\begin{tabular}{|l|l|}
\hline \multicolumn{1}{|c|}{ Regression Assumption } & \multicolumn{1}{c|}{ Tests Used } \\
\hline Heteroskedasticity & Breusch-Pagan/Cook-Weisberg Test \\
\hline Model Specification & Ramsey RESET Test for Omitted Variables \\
\hline Multicollinearity & Tolerance Levels/VIF \\
\hline Independence & Durbin-Watson Test \\
\hline Normality of Residuals & $\begin{array}{l}\text { Skewness, Kurtosis, Shapiro-Wilk Test, Kolmogrov- } \\
\text { Smirnov Test, Histograms, 5-pct Trimmed Mean } \\
\text { Comparison, QQ-Plot, Stem and Leaf diagram }\end{array}$ \\
\hline
\end{tabular}

The tests were conducted using STATA and SPSS software. The findings of the test for regression equations are given below in Table 73 .

Table 75: Findings of Tests to Check Regression Assumptions

\begin{tabular}{|c|c|c|c|c|c|}
\hline Regressions & $\begin{array}{l}\text { Heterosked } \\
\text { asticity }\end{array}$ & $\begin{array}{c}\text { Model } \\
\text { Specificatio } \\
n\end{array}$ & $\begin{array}{c}\text { Multicolli } \\
\text { nearity }\end{array}$ & $\begin{array}{l}\text { Normality of } \\
\text { Residuals }\end{array}$ & $\begin{array}{c}\text { Indepen } \\
\text { dence }\end{array}$ \\
\hline $\begin{array}{l}\text { Positioning strategy - customer } \\
\text { focus }\end{array}$ & $\mathrm{OK}^{*}$ & $\mathrm{OK}^{*}$ & OK & Acceptable & OK \\
\hline $\begin{array}{l}\text { Positioning strategy - product } \\
\text { focus }\end{array}$ & $\mathrm{x}$ & $\mathrm{OK}^{\star \star \star *}$ & OK & Acceptable & OK \\
\hline Positioning strategy - brand focus & $\mathrm{OK}^{\star \star \star \star}$ & $\mathrm{OK}^{\star * \star}$ & OK & Acceptable & OK \\
\hline Positioning strategy - innovation & $\mathrm{OK}^{*}$ & $\mathrm{OK}^{\star \star \star}$ & $\mathrm{OK}$ & Acceptable & OK \\
\hline Positioning strategy - quality & $x$ & $x$ & $\mathrm{OK}$ & Acceptable & OK \\
\hline Positioning strategy - service & $\mathrm{OK}^{\star \star}$ & $\mathrm{OK}^{\star \star *}$ & OK & Acceptable & OK \\
\hline Positioning strategy - price & $\mathrm{OK}^{\star * *}$ & $\mathrm{OK}^{\star \star \star}$ & OK & Acceptable & OK \\
\hline
\end{tabular}




\begin{tabular}{|c|c|c|c|c|c|}
\hline Positioning strategy - value & $\mathbf{x}$ & $\mathrm{OK}^{*}$ & OK & Acceptable & OK \\
\hline Manufacturing strategy -Quality & $x$ & $\mathbf{x}$ & OK & Acceptable & $\mathrm{OK}$ \\
\hline Manufacturing strategy-Cost & $\mathrm{OK}^{\star \star \star \star}$ & $\mathrm{OK}^{\star \star \star \star}$ & OK & Acceptable & OK \\
\hline Manufacturing strategy-Flexibility & $\mathrm{OK}^{\star \star \star}$ & $\mathrm{OK}^{\star \star \star \star}$ & OK & Acceptable & OK \\
\hline Manufacturing strategy-Delivery & $x$ & $\mathrm{OK}^{\star \star \star}$ & OK & Acceptable & OK \\
\hline Manufacturing strategy-Innovation & $\mathrm{OK}^{* * *}$ & $\mathrm{OK}^{\star \star \star}$ & OK & Acceptable & $\mathrm{OK}$ \\
\hline $\begin{array}{l}\text { Financial performance on } \\
\text { positioning strategy }\end{array}$ & $\mathrm{OK}^{\star * *}$ & $\mathrm{OK}^{\star \star \star \star}$ & OK & Acceptable & OK \\
\hline $\begin{array}{l}\text { Non-Financial performance on } \\
\text { positioning strategy }\end{array}$ & $\mathrm{OK}^{\star \star *}$ & $\mathrm{OK}^{\star \star \star}$ & OK & Acceptable & $\mathrm{OK}$ \\
\hline $\begin{array}{l}\text { Financial performance on } \\
\text { manufacturing strategy }\end{array}$ & $\mathrm{OK}^{\star \star \star \star}$ & $\mathrm{OK}^{\star \star \star}$ & OK & Acceptable & OK \\
\hline $\begin{array}{l}\text { Non-Financial performance on } \\
\text { manufacturing strategy }\end{array}$ & $\mathrm{OK}^{* \star \star}$ & $\mathrm{OK}^{\star \star \star \star}$ & OK & Acceptable & OK \\
\hline $\begin{array}{l}\text { Financial performance on } \\
\text { deviation }\end{array}$ & $O K^{* *}$ & $\mathrm{OK}^{\star \star \star \star}$ & OK & Acceptable & OK \\
\hline $\begin{array}{l}\text { Non-Financial performance on } \\
\text { deviation }\end{array}$ & $\mathrm{OK}^{\star \star \star \star}$ & $\mathrm{OK}^{\star \star \star}$ & OK & Acceptable & OK \\
\hline
\end{tabular}

Key for Heteroskedasiticy

$*$ = Homoskedasticity (Constant Variance) accepted at only 1 pct significance level, rejected at 5 and 10 pct

** $=$ Homoskedasticity (Constant Variance) accepted at 1 and 5 pct significance levels, rejected at 10

$* * *=$ Homoskedasticity (Constant Variance) accepted at all 3 levels of significance (1, 5 and 10 pct)

Key for Model Specification

* = Null hypothesis of "no omitted variables" accepted at only 1 pct significance level, rejected at 5 and $10 \mathrm{pct}$

** = Null hypothesis of "no omitted variables" accepted at 1 and 5 pct significance levels, rejected at 10

$* * *=$ Null hypothesis of "no omitted variables" accepted at all 3 levels of significance $(1,5$ and 10 pct)

\section{Note for Normality of Residuals}

Given that the data was of interval form (Likert Scale), the same criteria was used to assess normality of residuals as when checking for data normality (i.e. checking if the data was approximately and acceptably normal rather than going for normality in the strict technical sense) It is evident from the above table that there was no significant problem with any of the

regression assumptions.

\subsection{Summary}

This analysis is based on 194 usable questionnaires. A large majority (86 percent) of the firms sell their products to other business firms. Almost 95 percent of responses came from small and medium companies with less than 5 percent coming from large companies. Canadian-owned companies make up $80 \%$ of the sample, with 10 percent going to US and another 10 percent to the rest of the world. 
The analysis was divided into three major sections - 1) positioning strategies, influencing factors and firm's performance 2) manufacturing strategies, influencing factors and firm's performance 3) lack of co-alignment of positioning and manufacturing strategies. Customer orientation, marketing capability, innovation orientation and environmental dynamism had positive impact on certain dimensions of positioning strategy. Customer focus, brand focus, and quality positioning strategies had positive impact on organizational performance. Resource orientation, business strategy orientation, manufacturing capability, environmental dynamism and innovation orientation had a positive impact on certain dimensions of manufacturing strategy.

Most of the dimensions of manufacturing strategy - quality, cost, flexibility, and delivery - had significantly positive impact on organization performance. The innovation dimension was the only one not to have any impact on performance. The profile deviation analysis was conducted using three calibration samples -10 percent, 15 percent and a random sample to ascertain the impact of co-alignment of positioning and manufacturing strategy on organizational performance. It was firmly established that lack of co-alignment has a negative impact on the financial and non-financial performance of the firm. 


\section{Chapter 10: Discussion}

The data for this study was collected from senior executives and managers of 194 manufacturing firms based in Canada. Almost 80 percent of respondents are Canadianowned small firms mainly dealing with other business firms as their customers. There are some notable differences between Canadian firms compared to foreign firms, and between large firms compared to small firms.

The most significant difference is in terms of financial performance, where large and foreign firms seem to have superior financial performance. Also, both large and foreign firms have higher business strategy orientation. Canadian firms, on the other hand, have higher customer orientation. The smaller firms have a higher focus on product positioning strategy whereas Canadian firms put higher emphasis on service positioning strategy as compared to foreign firms. In terms of manufacturing capability, both large and foreign firms emphasize cost capability and have less focus on flexibility capability. Also, distribution marketing capability is emphasized more by small firms as well as by Canadian firms.

The objective of this study was to examine the manufacturing and positioning strategies of Canadian firms. The study investigates the factors which influence the development of respective strategies. It also examines the impact of each strategy and their co-alignment on firm's performance. The conceptual framework comprises three sub-frameworks positioning strategies, manufacturing strategies and co-alignment of the two. Accordingly, each sub-framework is discussed separately in this chapter. Since positioning strategies originate from marketing and manufacturing strategies belong to the operations 
management field, the relevant literature from each discipline is referred to, while interpreting the findings of analysis.

\subsection{Positioning Strategies}

Though research in positioning strategies dates back to 1960s, the major focus of studies in this area has been to identify and confirm a set of product or service attributes and firm's characteristics from the consumer's perspective on the basis of which products, services, and organizations are positioned. The concept of positioning has not been deliberated sufficiently in the business marketing literature i.e., from the perspective of the firms targeting other businesses rather than consumers. However, the relevance and importance of this concept to business marketing cannot be underscored. Kalafatis, Tsogas, and Blankson (2000) acknowledge that they were unable to identify empirically tested positioning strategies developed for the business market. Our study is the first of its kind to test such typology in a business market. The number of studies in the literature which can be used for comparison with the findings of our study are only a handful. Though there are a number of empirical studies within the business domain capturing business managers' perceptions of positioning in the industry, they do not study the positioning development process; that is, how companies actually go about developing and implementing a positioning strategy.

In fact, when Strategic Business Unit (SBU) is considered as a unit of analysis, to make direct reference to our study, no more than five articles were found in the positioning literature, and only some aspects of those studies can be compared to our research. Also, 
most of the factors influencing the development of positioning strategies, used in this study, have hardly been empirically tested in the positioning literature.

\subsubsection{Positioning Strategies and Influencing Factors}

Both customer and competitor orientations have been theoretically proposed to influence positioning strategy, though empirical studies in this area are scant. The correlation analysis indicates that all the dimensions of positioning strategy have statistically significant association with customer orientation other than price, while five out of eight positioning strategy dimensions have statistically significant association with competitor orientation. Customer orientation has the highest association with quality, followed by value, product and customer focus positioning. Competitor orientation has the highest association with brand and product focus, followed by value and service positioning. Overall, value and product focus positioning strategies seem to have high association with both competitor and customer orientation. However, when entered into regression analysis, competitor and customer orientation behaved very differently. Customer orientation has a statistically significant positive relationship with only one positioning strategy dimensions - quality. However, competitor orientation has statistically significant but negative relationships with only two dimensions - innovation and quality. So quality positioning is positively impacted by customer orientation and negatively by competitor orientation.

Customer and competitor orientation have been conceptually proposed to be the building blocks of positioning strategy development since positioning is always relative to competitors and requires thorough understanding of customer perceptions of product 
attributes and characteristics for a firm to be able to adequately position the product. The fact that competitor orientation is not positively significant, in regression analysis, for any of the positioning strategy dimensions could be taken as the inability of the respondent firms to consider competition while developing positioning strategies. This could be taken as a sign of weakness in the positioning strategy development process.

However, one of the major reasons for customer orientation being significant for only one, and not more, positioning strategy dimensions could also be attributed to the presence of another variable as influencing factor - customer requirement dimension of marketing capability. With its origins in resource based views, marketing capability enables the firms to achieve competitive advantage, the basis of formulating a positioning strategy. Marketing capability for this study was operationalized as distribution, communication, planning, and customer requirement.

Customer orientation and customer requirement marketing capability are somewhat similar (with inter construct correlation of .507) but two distinct constructs as evidenced through PCA. The inter-item correlations of two constructs range from 0.277 to .441 and a case could be made for merging the two constructs, but they are two separate constructs in the literature and thus not merged in this study. However, marketing requirement capability positively impacts four out of eight positioning strategy dimensions, providing support to the customer orientation construct. The findings for customer orientation, therefore, must be interpreted in the light of these results and the role of customer orientation in the development of positioning strategies should not be negated altogether. 
With the exception of Hooley and Greenley (2005), there is virtually no study in the positioning literature which has empirically tested constructs similar to competitor and customer orientation of the firms. Hooley and Greenley (2005) use the construct of market orientation, which by default contains some measures of both customer and competitor orientation. Using cluster analysis, they found market orientation to be high for firms focusing on service and innovation positioning with customized products and high technical quality. In correlation analysis we found low association with both innovation and service, high for quality and medium for customization (customer focus). Our regression analysis results do not corroborate with Hooley and Greenly (2005).

The difference in findings could possibly be attributed to two sources. First, the measurement scales used by both the studies are similar but not identical. Second, the sample in Hooley and Greenly (2005) was significantly different from the sample used in our study. They targeted chief marketing executives from various industries comprising manufacturing and services and from both consumer and business markets. Our sample is made up of mainly small manufacturers from the business market.

Price is the only positioning strategy not to have statistically significant association with any one of the marketing capabilities. All other positioning strategy dimensions have statistically significant association with almost all the dimensions of marketing capability. Overall, brand focus, innovation and product focus seem to have the strongest association with marketing capabilities while service has the weakest association. However, the picture becomes clearer in regression analysis where distribution capability affects product focus and quality, planning capability impacts innovation positioning, communication capability influences brand focus and service positioning and 
understanding customer requirement capability impacts the most, four out of eight positioning strategy dimensions - customer focus, product focus, quality and value.

Morgan, Strong and McGuinness (2003) published the first study which considered the role of marketing capabilities within the stream of positioning strategies. They conducted a mail survey of 149 marketing managers from various industries - manufacturing as well as services. The objective of their research was to see how firms pursing different strategies - prospector, defender, analyzer and reactor - differ in terms of their approach to product-market positioning. The marketing capabilities were operationalized as: building brand identification; innovation in marketing techniques and methods; strong influence over channels of distribution; developing and refining existing products; and extensive customer capabilities. It was found that the firms pursuing prospector strategies emphasize marketing capabilities significantly more than firms pursuing other types of strategies. Prospectors are likely to adopt a proactive approach to a competitive environment and tend to exploit and seek new opportunities. They are also likely to pioneer in product and market innovation. In terms of positioning strategy the findings reveal that prospectors also place emphasis on quality orientation, product scope and development and differentiation focus. Though Morgan, Strong and McGuinness (2003) do not directly study the impact of marketing capabilities on positioning strategy, it can be inferred from their study that marketing capability has a relationship with quality and product focus, in line with the findings of our study to a great extent. Two of the four marketing capability dimensions impact product focus and quality positioning in our study. 
Hooley and Greenley (2005) examine what marketing resources and capabilities are used by the firms implementing various competitive positioning strategies. They operationalized marketing capabilities into three dimensions - internal marketing support capabilities (financial, human resource, operations and marketing management), customer linking capabilities (understanding customer needs and building customer relationships and using information about market, customer and competitors), and organizational spanning activities (ability to launch new products, communicating across organization and setting good prices). They also list marketing assets, some of which have been characterized as marketing capabilities by others. The four marketing assets are: costumer-based, internal marketing supports, distribution-based and strategic alliance-based. They conducted a mail survey of 485 respondents in UK, mainly chief marketing executives. Using cluster analysis they found five groups of firms implementing a combination of positioning strategy dimensions with a particularly strong emphasis on one dimension.

Cluster One had the lowest emphasis on marketing capabilities. It had low scores on almost all dimensions of positioning strategies. The second cluster, with emphasis on service, was good at understanding customer needs and requirements. However, in our study the service positioning dimension was influenced only by communication aspect of marketing capability.

The third cluster comprises firms who are high on innovation. They make use of market information systems and distribution capabilities. In our study, marketing planning was significant for innovation positioning strategy. 
Firms that emphasize low price and rely on cost control assets for competitive advantage make up the fourth cluster. The fifth cluster comprises of large well-established firms who rely on their brand names and reputations to achieve their objectives. They seem to have low scores on all the marketing capability aspects. However, in our study, the firms who use brand image strategy rely heavily on the communication aspect of marketing capability.

Attia and Hooley (2007) conducted a mail survey of marketing managers from 94 pharmaceutical firms selling over-the-counter products in UK. The objective of their research was to examine the relationship between the competitive positions of the firms and their resources and capabilities to see if certain assets and capabilities were more important for certain competitive positions.

Capability was operationalized as: production and manufacturing expertise; new products development process; financial performance; understanding customer needs and developing relationships with them; relationship with supplier and distribution network; and setting prices to attract customers. Attia and Hooley (2007) explored only three positioning strategy dimensions - quality, price and innovation. Production and manufacturing capability was found to be significant with quality positioning while strong financial management capability was significant with price positioning. Two capabilities were found significant for innovation positioning - new product development process and the ability to launch customer-responsive new product development. Our study, however, did not operationalize those capabilities. Marketing planning capability had an impact on innovation positioning. 
A caution is in required in comparing the results of our research with the previous two studies since our study uses the term "marketing capabilities" and operationalizes it only within the context of marketing. Hooley and Greenley (2005) and Attia and Hooley (2007) use "capability" in a broad sense which includes both financial and production aspects. Therefore, those studies are not directly comparable to our findings. Nonetheless, these two studies are mentioned due to the dearth of studies on marketing capabilities within positioning literature.

Both innovation orientation and environmental dynamism have not been examined by any study within the context of positioning strategy. Innovation positioning is impacted by both innovation orientation and environmental dynamism. In fact, innovation orientation has the highest coefficient $(0.560)$ for innovation positioning, clearly demonstrating that firms which implement innovation positioning do so with a clear intent and purpose. The firms operating in an environment of high dynamism where consumers' tastes and preferences change frequently are also more likely to use innovation positioning. Innovation orientation also impacts firms who focus on product features and attributes to keep them competitive in the marketplace.

Another stream of research which can possibly be compared with the findings of our study is the manufacturing strategy configurations. Manufacturing strategy from that perspective is defined as the "the configuration of strategic priorities the manufacturing system does or will pursue" (Cagliano, Acur, and Boer, 2005, pg. 702). Manufacturing strategy in that context is similar to business strategy, also considered the basis of positioning strategy. Some of the strategies identified by configuration manufacturing strategies include low-cost, technology-driven and marketing intensive (Stobaugh and 
Telesio, 1983), caretaker, innovator and marketer (Miller and Roth, 1994), niche differentiators, broad differentiators, cost leader and lean competitors (Ward et al., 1996), designers, specialists, idlers, servers and mass customisers (Frohlich and Dixon, 2001). Each of these configurations has corresponding competitive priorities (called "manufacturing strategies" in this study). Cagliano, Acur, and Boer (2005) empirically tested four configuration strategies: product-based, capability-based, market-based and price-based. They used three longitudinal samples from the International Manufacturing Strategy Survey (IMSS) database for their analysis. They found price-based strategy to be on its way out. The firms pursuing price-based strategy moved to capability-based and product-based strategy over time. They concluded that firms are finding it difficult to compete based on price and are focusing on innovative and improved products to compete in the markets. They also found product-based strategy to be most widely spread and most stable.

A number of other studies have also found price strategy to be almost insignificant as a competitive strategy. For example, in a survey of 91 senior managers from USA, Meybodi (2006) found that price was not the primary element of competitive advantage. Similarly, Ward at el. (2007) conducted a survey of 101 manufacturing firms in USA and found evidence that firms pursuing price leadership without differentiating capabilities had an operational disadvantage over others and, in fact, were seriously hampered in their ability to build manufacturing capabilities.

On the a scale of 1 to 5 , with 1 being the least used and 5 being the most used, the price positioning strategy was rated as 2.88 by the respondents in our study. It comes out at the bottom when compared with the averages for other positioning strategies. This is the 
prime reason that price positioning strategy is not statistically significant with any influencing factor.

Control variables have been hardly employed by the studies in positioning literature with the exception of few studies (for example, Skaggs and Youndt, 2004; Kale and Arditi, 2002) which use firm size as control variable. Ours is the first study to incorporate control variables of product life cycle and industry's competitive environment into a positioning strategies model. Strategy-environment fit is a well-researched area in the literature and, according to contingency theory, organizational performance partly depends on this fit (Gebauer, 2008). We found a number of significant results with control variables. The emphasis on customer focus positioning strategy goes up in growth stage of product life cycle and is even higher in maturity stage. It is understandable, since firms find it difficult to customize products and make extra efforts to meet customers' requirements in the introduction stage when technology is not well-developed and the product is new, relatively expensive, and targeted to a small set of customers. Once the product moves up the ladder in product life cycle, the sales go up, costs go down, technology improves and it becomes easier to customize the product to meet customers' needs. Similarly, in the growth and maturity stages there is a higher focus on service positioning strategy. In the growth and maturity stages the competition intensifies and service is used as one of the factors to differentiate product from other firms.

With high industrial rivalry, cut-throat competition and promotion wars, the price positioning strategy becomes important as firms compete head-on. The firms using brand focus and quality positioning strategy seem to face high supplier power. 
In light of our analysis, the firms with product focus positioning strategy tend to develop strong relationships with distributors and provide a high level of service to them. The firms with service and brand focus have a strong emphasis on communication capability which entails developing and executing advertising programs to manage corporate and brand image. The firms with innovation positioning strategy rely on marketing planning. The firms with product focus positioning emphasize product features and characteristics. Such firms have innovation orientation, which, understandably, is needed to add new product features and attributes. Environmental dynamism, the rate at which products and services become outdated and customers' tastes and preferences change, forces the firms to implement innovation positioning strategy. Such firms also tend to be high on innovation orientation. Product focus, quality, and innovation positioning are the only three strategies which are impacted by a multiple factors.

\subsubsection{Positioning Strategies and Organizational Performance}

The impact of a firm's positioning strategies on its performance - financial and nonfinancial - was measured to see if any particular positioning strategy is likely to have a greater impact on organizational performance. The respondents were asked to divulge their perceptions of their firm's financial performance - market share, sales growth, ROI, and profitability. Questions about customer satisfaction and customer loyalty captured the non-financial aspects of performance. In our study only three positioning strategies customer focus, brand focus and value had statistically significant association with financial performance. The results of hierarchal regression mirrored the findings of correlation analysis. However, non-financial performance had significant association with all positioning strategy dimensions other than price. In hierarchal regression, though, only 
brand focus and quality positioning had an impact on non-financial performance. Therefore, brand focus is the only positioning strategy which positively impacts both financial and non-financial performance. There are four academic studies in recent literature which can be compared with our study and results.

Hooley, Lynch and Jobber (1992) conducted a study of 616 business firms in UK to examine generic marketing (positioning) strategies by market type, corporate attitudes and performance. Financial performance was measured by ROI, profit margin percentage, sales and market share. All the measures were self-reported. Two positioning strategies quality and price - were considered for the study. Different permutations of quality and price, with high and low, were compared with performance. The study found the best financial performance at high quality and same price, followed by higher quality/higher price. The performance was moderate to worst at same quality/same price. However, in our study, quality positioning impacted only non-financial performance and price positioning was not significant.

Kale and Arditi (2002) conducted a survey of construction companies in US to investigate the linkage of positioning strategies with organizational performance. Performance was measured by three indictors - growth in contract awards, profitability and overall performance. Using cluster analysis and ANCOVA, they found that firms with strong emphasis on cost, quality, schedule and innovation tended to have superior performance. We had two of those positioning dimensions - quality and innovation. Quality, in our study, impacted non-financial performance, while innovation, exhibiting positive association with non-financial performance in correlation analysis, was not significant in regression analysis. 
Hooley and Greenley (2005) examines the relationship between positioning strategies and organizational market performance. The performance was operationalized on four scales - sales volume, market share, customer satisfaction and customer loyalty. Using cluster analysis they formed five groups of firms implementing a combination of positioning strategy dimensions with a particularly strong emphasis on one dimension.

The first cluster, with low scores on almost all dimensions of positioning strategies, reported the weakest performance compared to competitors. The second cluster, with emphasis on service, and the third cluster with focus on innovation, performed around the sample average. Firms with emphasis on low price made up the fourth cluster and had overall weak performances. The fifth cluster, comprising of large well established firms that rely on their brand name and reputation to achieve their objectives, had the overall best financial performance but were lower than sample average on customer satisfaction and loyalty.

Their study points out that a clear positioning strategy based on innovation, customer relationship management and branding is more likely to lead to better performance than the positioning strategy of low price and unclear positioning strategy. This corroborates the findings of our study which showed customer and brand focus positioning strategies to be statistically significant with financial performance. The only other positioning to be statistically significant with financial performance in our study was value.

Blankson et al. (2008) investigated the relationship between positioning strategy dimensions and firm performance. The firm performance was operationalized as sales, profits, ROI, market share, company image, consumer perception and overall firm 
objectives. They conducted a survey of 118 executives and owners of SME businesses in mostly service sector. They found five positioning strategy dimensions - top of the range (quality), service, value for money, reliability and brand name - to have positive impact on performance. Three positioning strategy dimensions - attractiveness, country of origin and selectivity - did not have a positive relationship with firm performance. Our study corroborates their study as well, since brand focus and value also have statistically significant impact on performance, while brand focus and quality (top of the range and reliability) have significant impact on non-financial performance. However, in our study, service positioning was not statistically significant though it had positive association with non-financial performance. Our study, however, focused only on manufacturers while the majority of firms in Blankson et al. (2008) are from service sector.

In term of a firm's performance, the only significant control variable was product life cycle in the decline stage which had negative impact on non-financial performance.

\subsection{Manufacturing Strategies}

A number of studies in operations management literature have used the influencing factors as variables in varying combinations. However, this is the first study which has empirically tested a comprehensive set of variables which can influence the development of manufacturing strategy. This is also the first study to make a distinction between manufacturing strategy and manufacturing capability and to test them as separate variables in one study. In the past, the dimensions of manufacturing strategy - cost, quality, delivery and innovation - have been operationalized as strategy or capability and never empirically tested in the same study. We argue that a firm might have a number of 
manufacturing capabilities but may not necessarily choose to focus on them as its manufacturing strategy as well.

\subsubsection{Manufacturing Strategies and Influencing Factors}

Resource and market (business strategy) orientation have been posited to influence the development of manufacturing strategy. The debate in the literature, however, clearly favours resource orientation over market orientation as the main premise for the development of manufacturing strategy. We did not find this to be true in correlation analysis. Resource orientation had positive association with three manufacturing strategies - innovation, quality and flexibility - while business strategy orientation was positively associated with four - quality, flexibility, delivery and innovation strategy. However, when the variables were entered into regression analysis, only flexibility strategy was statistically significant with business strategy orientation, and quality strategy with resource orientation, thus rendering inconclusive findings in terms of dominance of one paradigm over another.

In the literature, resource and market orientation have empirically been tested mostly on variables other than manufacturing strategy, primarily in relation to a firm's performance. For example, Paiva, Roth and Fensterseifer (2008) conducted a study of 104 firms to examine the use of knowledge as a resource in the development of manufacturing strategy. It was found that cross-functional integration in manufacturing was positively related to resource orientation. Schroeder, Bates and Junttila (2002), in one of the first studies to test resource based theory in a manufacturing plant, categorize proprietary processes and equipment, internal learning and external learning as resources which 
influence manufacturing performance and found a positive relationship between resources and manufacturing performance. Thun (2008) is the first study to use both market-based and resource-based views as the factors that influence the manufacturing performance of firms. Using cluster analysis, they grouped the plants into high and lower performers. The market-based group showed better performance in terms of product mix and volume flexibility while the resource-based group showed high performance in inventory turnover and cycle time. It was also found that in a highly competitive environment, plants prefer a market-based or integrated strategy which incorporates both resource and market-based orientation.

Lin (2004) conducted a mail survey of 105 OEM Taiwanese firms to examine their use of network innovation agility as a firm strategy. Market orientation was found to significantly impact network innovation agility.

William et al. (1995) conducted a survey of 85 cotton fabric mills to examine the relationships among manufacturing strategy, business strategy, market orientation, technology orientation and firm performance. Their measures for market orientation were different from those we used in our study. None of the comparable measures for market orientation were significant, mostly in line with the findings of our study.

As mentioned earlier, the same measures (indicators) have been used in the literature to operationalize manufacturing capability and manufacturing strategy. The underlying assumption is that manufacturing capability and manufacturing strategy are synonymous; i.e., manufacturing capability translates into manufacturing strategy. Swink and Hegarty (1998) consider this assumption to be one of the major limitations in the 
conceptualization of manufacturing strategy dimensions. Taps and Steger-Jensen (2007) conducted a study of 34 international manufacturing joint ventures located in different developing regions to examine their choice of manufacturing strategy while sourcing production facilities to developing nations. It was found that manufacturing tasks, developed in terms of capabilities, focus more on operational efficiency than competitive priorities (manufacturing strategy). It is, therefore, possible for firms not to deploy a specific manufacturing capability as their strategy.

In correlation analysis we found each of four manufacturing capability dimensions - cost, quality, flexibility, and delivery - to be positively associated with at least four out of five manufacturing strategy dimensions. However, when we conducted hierarchal regression analysis, delivery was the only capability to impact four manufacturing strategy dimensions - quality, cost, flexibility and delivery. Quality capability impacts two strategy dimensions - quality and innovation - while cost also affects two dimensions cost and delivery. Flexibility capability, on the other hand, was not statistically significant with any manufacturing strategy dimension.

In line with the underlying assumptions of earlier studies, which consider manufacturing capability and manufacturing strategy to be one and the same, we found that cost capability impacts cost manufacturing strategy, quality capability affects quality strategy, and delivery capability has an impact on delivery strategy. However, a number of findings from our study defy the underlying assumptions about manufacturing capabilities. For example, flexibility capability does not affect flexibility strategy; quality capability is considered important for innovation as well; while cost capability is also significant for delivery strategy. Yet delivery capability is not only significant for 
delivery manufacturing strategy but it positively influences three other manufacturing strategies as well.

Nonetheless, to keep things in perspective it is important to acknowledge that in case a strategy is being influenced by more than one capability, the corresponding matching capability for each manufacturing strategy (i.e., cost capability for cost strategy) has the highest Beta coefficient in regression analysis and other capabilities influencing the same strategy have the lower Beta coefficients. Therefore, in general, the corresponding capability is the most important for that strategy but other capabilities might also influence that strategy.

The focus on delivery capability even when delivery is not the primary manufacturing strategy underscores that delivery capability is essential for the firms to stay in business. A number of studies in the literature highlight the strategic importance of delivery capability for firms. Hill (2000) claims that delivery capability is integral for a firm's survival, an essential element to keep suppliers satisfied. Kumar and Sharman (1992) argue that, amid intensifying competition, demanding customers will go somewhere else if firms do not deliver on time. A number of empirical studies have found that delivery is one of the top competitive priorities from the perspective of manufacturing firms (Scully and Fawcett, 1993; Tunalv, 1992; Horte et al., 1987). Taps and Steger-Jensen (2007) call delivery speed one of the most important manufacturing strategies based on literature review. Delivery speed was also rated the most important $(4.18 / 5.00)$ by the respondents in this study. 
We did not find any study in operations management literature which had used innovation orientation as a factor which can influence manufacturing strategy. Innovation orientation in this study impacts innovation and cost manufacturing strategies. The innovation orientation of firms with focus on cost strategy could be interpreted as the use of innovative means by firms to keep costs under control.

Environmental dynamism in this study was found to impact innovation strategy. There are a number of studies in the literature which examine the relationship between environmental dynamism and manufacturing strategy, though findings have been mixed. Ward et al. (1995) collected data from manufacturing firms in Singapore to investigate the relationship between business environment, operations strategy and performance. It was found that environmental dynamism leads to more emphasis on flexibility, delivery and quality.

Ward and Duray (2000) conducted a study of manufacturing firms in USA and did not find any impact of environmental dynamism on manufacturing strategy though it was found to influence differentiation business strategy which in turn affected quality, delivery and flexibility dimensions of manufacturing strategy. However, they used only four dimensions of manufacturing strategy - cost, quality, flexibility and delivery. They concluded that the impact of environmental dynamism is manifested through competitive strategy. Amoako-Gyampah (2003) conducted a study of manufacturing firms in Ghana to examine the relationship between selected business environmental factors and manufacturing strategy. Environmental dynamism did not have any significant impact on manufacturing strategy. 
The findings of our study do not corroborate with Ward et al. (1995), Swamidass and Newell (1987) and Van Dierdonck and Miller (1980), who found that environmental dynamism impacted a number of manufacturing strategy dimensions. However, none of the earlier studies have empirically tested innovation manufacturing strategy, which we examined in our study and found significant. Intuitively, it seems rational that innovation manufacturing strategy would be influenced by environmental dynamism since innovation could be an important component of manufacturing strategy in a dynamic environment, when changes in customer taste and preference are frequent and products become out-dated at a brisk pace. However, our findings are supported by Ward and Duray (2000) who found environmental dynamism does not affect cost, quality, flexibility and delivery manufacturing strategy.

Industry environment and product life cycle were used as control variables for this study. None of the studies in the past have explored the impact of product life cycle on manufacturing strategy. It was found that cost strategy is more important in the maturity stage than in the introduction and growth stages. From the theory of product life cycle we know that competition is very high in the maturity stage and profit margins are thin. The increased emphasis on cost thus suffices in this case. On the other hand, firms using innovation strategy reduce their emphasis on innovation in the growth stage. Innovation strategy, it seems, is extremely important in the introduction stage of the product life cycle. Industry environment did not have any impact on manufacturing strategy when independent variables were entered in the hierarchal regression. 


\subsubsection{Manufacturing Strategies and Organizational Performance}

There are a number of studies which have empirically tested the impact of manufacturing strategy on organizational performance. However, organizational performance, in the literature, has been operationalized as manufacturing (operational) as well as financial and non-financial performance. Our study measures only financial and non-financial performance. Cost, flexibility and delivery manufacturing strategies were found to positively impact financial performance whereas quality has a positive impact on nonfinancial performance, leading to higher customer satisfaction and loyalty.

Swamidass and Newell (1987) found that performance was positively related to flexibility strategy. Swink, Narasimhan and Kim (2005) found that high strategy integration along with cost efficiency and flexibility manufacturing capabilities lead to better market-based performance. Performance was operationalized as profitability, market share and growth in sales. The findings of our research corroborate both the studies.

Ward and Durray (2000) operationalized business performance as market share and sales growth and found quality strategy to influence performance. They found that cost, flexibility and delivery do not impact performance. They quote a number of studies in the literature (e.g., Buzzell and Gale, 1987; Flynn et al., 1995a; Williams et al., 1995) to highlight that, historically, quality is the one factor which predominantly impacts performance. However, quality in our study only influences non-financial performance.

Kazan, Ozer and Cetin (2006) examined the effect of manufacturing strategies on the financial performance of 102 firms in Turkey. In line with the findings of our study, 
cost/flexibility and quality were found to impact financial performance. The impact was higher for larger companies as compared to SMEs. Financial performance was measured as selling volume, profit, ROI, productivity, and profit margin ratio.

Amoako-Gyampah and Acquaah (2008) conducted a study of 192 firms in Ghana to investigate the relationship between manufacturing strategy, and competitive strategy and their impact on organizational performance. Firm performance was measured by market share and sales growth. They found a significant relationship between quality and firm performance. However, no significant relationship was found between delivery, cost, and flexibility and firm performance. They cite previous studies (Williams et al. 1995; Ward and Durray, 2000) which were also unable to find a sizable number of significant relationships between a firm's manufacturing strategy and its performance at strategic business unit level. They assert that firm performance is an outcome of contributions from various functional areas and that combining manufacturing with marketing and human resources might provide better results.

Thus, our results fully corroborate the findings of Swamidass and Newell (1987) and Swink, Narasimhan and Kim (2005) and, partially, the findings of Amoako-Gyampah and Acquaah (2008), Kazan, Ozer and Cetin (2006), and Ward and Durray (2000). Industrial rivalry, the control variable, not tested by previous studies, was found to have a negative impact on financial performance.

\subsection{Co-alignment of manufacturing and positioning strategies}

The discussion of coexistence of marketing and manufacturing started in the late 1970s (Shapiro, 1977) and continues until today. A number of studies have deliberated this 
issue, but mostly in conceptual pieces. It is argued that manufacturing strategy provides competitive advantage to firms while market positioning strategy is based on competitive advantage. Therefore, there is an intuitive link between manufacturing and positioning strategy. There is only one study in the literature which conceptually proposes this relationship.

The co-alignment of manufacturing and marketing has been emphasized in the literature and is posited to maximize firm's performance. The integration/alignment has traditionally been empirically tested by asking respondents questions about the extent of integration/alignment between two functions (Kelly and Flores, 2002; John, Young, and Miller, 1999). Venkatraman (1990) is the only study, to date, which uses a statistical method to test the concept of co-alignment of manufacturing and marketing, but more to demonstrate the application of a statistical method than to make a contribution to operations management literature. A number of studies in business strategy literature, though, have used statistical methods to compute co-alignment.

One of the major premises of this research is that an effective manufacturing strategy corresponds with the positioning strategy and that this co-alignment will have a positive impact on a firm's performance. However, following the empirical studies of coalignment in the literature, it is the lack of co-alignment or misalignment which is calculated and its impact on the performance is posited to be negative. Ours is one of the first studies to use profile deviation method to calculate lack of co-alignment or misalignment of manufacturing and marketing (positioning) strategies. It was posited that the lack of co-alignment of manufacturing and positioning strategies would have a negative impact on a firm's performance. The profile deviation entails selecting a 
theoretical or empirical ideal profile (a sub-sample comprising of $10-15 \%$ of top performers) which represents the firms who are considered to be the best, according to certain criteria, and are assumed to be implementing the co-alignment. In the absence of a theoretical profile, an empirical profile based on performance was taken. Two ideal profiles, comprising of 10 and 15 percent of the top performing firms were taken from the sample. The objective of taking two separate samples, instead of one, was to ensure that the findings were not by chance.

To calculate the deviation index from the ideal profile, the ideal profile's mean scores on positioning and manufacturing strategy were subtracted from each respondent's score on the identical strategy dimensions, for the rest of the sample. The resulting scores were entered into Euclidian distance formula. The deviation index was then regressed on financial and non-financial performance in addition to conducting correlation analysis.

Correlation analysis revealed a negative association between performance and deviation from the ideal profile for the sub-samples, 10 and 15 percent of top performers. Hierarchal regression confirmed that the findings of correlation analysis and deviation from ideal profile had a negative impact on both financial and non-financial performance, though beta coefficient was higher for financial performance, indicating that lack of coalignment has a worse impact on financial performance than on non-financial performance. The beta coefficient of minus -0.298 for financial performance was identical for 10 and 15 percent ideal profiles though it came down for non-financial performance from negative 0.160 (10 percent ideal profile) to negative 0.150 (15 percent ideal profile). The explanatory power of regression $\left(R^{2}\right)$ came down slightly from 0.12 to 
0.11 . The differences might not be highly significant but one can make the assertion that the farther one goes from the ideal profile, the higher the negative impact on performance.

To provide further credence to our findings, a random profile sample (not based on performance) of 10 percent of respondents was taken and the process of calculating deviation was repeated. The regression analysis provided beta coefficient of negative 0.09 for financial performance and positive 0.06 for non-financial performance. The regression, however, had a very small explanatory power of 0.05 and statistically was insignificant. A non-significant model of random profile, therefore, provides ample support to the validity of our profile deviation findings based on 10 and 15 percent of ideal profiles. There are no studies in the literature which can be compared with our findings.

There is no prior literature on co-alignment or correspondence between each manufacturing and positioning strategy. Therefore, an attempt was made to understand what differentiates top performers, whose positioning and manufacturing strategies are aligned, from low performers (rest of the sample), who are not implementing coalignment of respective strategies. A correlation analysis of positioning strategy dimensions with manufacturing strategy dimensions was conducted for both high and low performers. It was found that low performers generally tend to use multiple positioning and multiple manufacturing strategies. The high performers, on the other hand, were much focused, mostly choosing one manufacturing strategy for each positioning strategy dimension. This is a very critical finding for managerial implication. 
Most of the positioning-manufacturing strategy pairs can be logically supported by literature. However, there are some anomalies as well. The service positioning strategy makes perfect sense with delivery manufacturing strategy since delivery is one of the major components of the service. Nonetheless, the emphasis of service on innovation, at the same time, could be questioned by some but possibly be justified on the ground that a firm needs to be innovative to provide top notch service. The positioning-manufacturing co-alignment which stands out most and is the hardest to justify is that of price positioning and flexibility manufacturing strategy. Normally, one would expect the price positioning strategy to correspond with cost manufacturing strategy. Flexibility manufacturing strategy, on the other hand, could increase the cost of productions and operations resulting in higher prices.

However, all the previous studies on profile deviation (Table 61) determine the degree of co-alignment but do not delve into the process of analyzing the pattern of co-alignment. It is suggested in the literature that organizations like to attain co-alignment and strive towards this goal but might adopt different co-alignment patterns due to their unique strengths and weaknesses, resources and capabilities (Kearns and Sabherwal, 2006). Therefore, the findings of the above analysis on co-alignment pattern must be interpreted with caution.

\subsection{Summary}

Customer orientation is more likely to influence the development of positioning strategy as compared to competitor orientation. Distribution marketing capability influences product focus and quality positioning, communication capability has an impact on brand 
focus and service positioning while innovation positioning relies on planning capability. Firms with product focus also have high innovation orientation and firms with innovation positioning are impacted by environmental dynamism and innovation orientation. Customer-focused positioning strategy has a positive impact on financial performance while quality positioning has a positive impact on non-financial performance. Brand focus is the only positioning strategy to positively influence both financial and nonfinancial performance.

There is no conclusive evidence that either resource orientation or market (business strategy) orientation is more likely to influence the development of manufacturing strategy. Delivery is the most important manufacturing capability, followed by cost and quality. Cost, flexibility and delivery manufacturing strategies have a positive impact on financial performance while quality manufacturing strategy has a positive influence on non-financial performance.

The lack of co-alignment (fit) of positioning and manufacturing strategy was calculated with profile deviation analysis. The lack of co-alignment has a negative impact on both financial and non-financial performance. The results were corroborated with two calibration samples with 10 and 15 percent of top performers and a random calibration sample. 


\section{Chapter 11: Conclusion}

Product positioning and manufacturing strategies have been discussed sufficiently in the academic literature. However, both positioning and manufacturing strategies are business level strategies developed and implemented by marketing and operations management departments but driven by overall corporate strategy in general. There is a sizable stream of literature in marketing and operations management which argues that each of these strategies individually impacts organizational performance and that coordination and liaison between manufacturing and marketing leads to improved organizational performance. It is, therefore, important to understand the factors which influence the development of these strategies to the aid the process of strategy development. The literature on the process of development of these strategies, however, is very scant. It is also posited that there is a clear linkage between manufacturing and positioning strategies since manufacturing strategy seeks to provide competitive advantage to firms and positioning strategy is theoretically based on the competitive advantage. Thus one of the objectives of this research is to ascertain the impact of each strategy and their coalignment on a firm's performance.

The analysis is based on the mail survey of top executives of 194 manufacturing companies in Canada. The questionnaire sought executives' perceptions about their firms' market positioning strategies, manufacturing strategies, factors influencing the development of those strategies and financial and non-financial performance of their firms. The co-alignment of manufacturing and positioning strategy was calculated using a 
statistical method called profile deviation. An extensive literature review was conducted to identify a set of positioning and manufacturing strategies for empirical testing.

Almost 80 percent of responses came from small companies with less than 100 employees and only five percent from companies with more than 500 employees, in line with the makeup of the Canadian manufacturing landscape. Canadian-owned companies dominate the sample with 80 percent followed by USA at 10 percent. Almost 80 percent of the responses came from top management, including CEOs, presidents, and directors. The major customers of the responding firms are other businesses as indicated by 86 percent of respondents.

Medium and large firms seem to have superior financial performance. They also have higher market (business strategy) orientation and less emphasis on product focus positioning strategy, indicating the possibility that smaller firms might not have a fullfledged marketing department to spearhead marketing efforts. Also, medium and large firms focus more on costs and less on flexibility in manufacturing capability since added flexibility purportedly leads to higher costs. However, medium and larger firms are less likely to use innovation as a positioning strategy which could lead to higher costs in the short run. The smaller firms are thus more likely to use innovation positioning strategy.

Foreign firms have better financial performance and higher market (business strategy) orientation. Canadian firms, on the other hand, have a higher customer orientation and consequently are more focused on service as a positioning strategy. Canadian firms aim for higher flexibility in manufacturing capability and resultantly are less focused on cost capability. 
The study was virtually divided into three parts. First, the influence of certain factors on development of positioning strategies and, in turn, the impact of positioning strategies on the firm's performance was examined. Second, a number of factors impacting development of manufacturing strategies were investigated along with relationship of manufacturing strategy with organizational performance. Third, the co-alignment of positioning and manufacturing strategy was calculated using profile deviation technique and the impact of lack of co-alignment on a firm's performance was ascertained. Some of the key findings of the study for each part are as given below:

\subsection{Positioning Strategy}

We attempted to answer two broad questions related to positioning strategy: What factors are taken into consideration by the firms while choosing positioning strategy dimension/s? And what is the impact of firm's positioning strategy on its performance?

Customer and competitor orientation are theoretically considered to be the bedrock of positioning strategy. However, it was found that the development of positioning strategy is influenced more by customer orientation than competitor orientation, though the impact of customer orientation was not as strong as expected. These findings could also be attributed to the fact that a majority of the firms are small and may not have a system in place to develop a positioning strategy which formally and systematically conducts customer and competitor analysis. More research is needed to understand the impact of customer and competitor orientation on the adoption of a particular positioning strategy dimension 
Marketing capability plays an important role in the development of positioning strategy. One of the major findings of the study was the identification of certain marketing capability to support a specific positioning strategy. Understanding customer requirements appears to be the most important marketing capability which positively influences the positioning development process. It could be argued that customer orientation is prerequisite to understanding customer requirements so the importance of customer orientation to positioning development process is thus indirectly established.

There seem to be two different routes to enhanced organizational performance through positioning strategies. First, the firms equipped with customer knowledge emphasize quality but reap benefits only in the form of improved customer satisfaction and loyalty. Similarly, with a sound understanding of customer's requirements, firms customize products to meet customer needs which leads to improved financial performance. However, the second route, the focus on brand and company image leads to both higher customer satisfaction and loyalty and better financial performance. Incidentally, the major focus of such firms is not on understanding customer requirements but on communicating brand and company image through advertising.

Price positioning strategy, in line with the findings of other studies in the literature, is considered insignificant by the respondents since it does not lead to any competitive advantage. 


\subsection{Manufacturing Strategy}

Another objective of this study was to identify and validate the factors that are taken into consideration by firms while choosing manufacturing strategy dimensions and to examine the impact of a firm's manufacturing strategy on its performance.

There is a debate in the literature about the importance of resource versus market (business strategy) orientation for the development of manufacturing strategy, with literature lending more support to resource orientation. The final evidence regarding preference of resource orientation over market (business strategy) orientation is inconclusive in this study as both of them influence only one manufacturing strategy each. However, preliminary analysis indicates that market (business strategy) orientation is not on its way out, as suggested in the literature.

One of the highlights of this study, and a major contribution, is the empirical testing of manufacturing capability and manufacturing strategy as two distinct constructs, traditionally considered in the literature to be one and the same construct, despite the reservations expressed by some authors. The underlying assumption is that capabilities are developed once the manufacturing strategy dimensions have been decided upon (Größler and Grübner, 2006). So capabilities, in fact, represent the manufacturing strategy. Ours is the first study to take a different perspective on this aspect, by empirically trying to understand how various manufacturing capabilities impact different manufacturing strategy dimensions. Our findings confirm certain assumptions of the previous studies but also provide new insights, giving us a better understanding of relationship between capability and strategy. 
Our study confirms the conventional wisdom that each manufacturing strategy is backed by the corresponding manufacturing capability and thus could possibly be considered the reflection of each other. However, it reinforces the notion that certain manufacturing capabilities are integral to the operations and at times essential to the survival of the firm regardless of the distinct manufacturing strategy used by the firms. For example, delivery capability is considered essential by the firms though firm focus on quality, cost and flexibility as the major manufacturing strategy.

Environmental dynamism, one of the factors of external environment, has been used extensively in business strategy literature. However, its use in the operations management literature has been limited. In our study it was found to have a statistically significant impact on innovation strategy. Less empirical testing of environmental dynamism variable in operations management literature could be linked to the fact that innovation strategy is a relatively new variable in manufacturing strategy studies. Similarly, innovation orientation, statistically significant with innovation strategy, is almost nonexistent in the literature for the same reason.

The firms could be divided into three major groups in terms of organizational performance based on manufacturing strategy. First, the firms emphasizing quality strategy rely on resource orientation but it only leads to higher customer satisfaction and loyalty without having any impact on financial performance. Second, the firms which are influenced by market (business strategy) orientation focus on the flexibility aspect and tend to have superior financial performance. The third group of firms is influenced by innovation orientation, keep their costs in check and rely on either cost or delivery manufacturing strategy. Incidentally, the common thread amongst all the firms is the 
delivery capability which seems to be the essential component for improved organizational performance.

Two models - Product life cycle and Porter's five forces industry environment - have been conceptually proposed to be linked with positioning strategy and manufacturing process but had never been empirically tested in the literature, though both of these variables have been used in the marketing and management literature. Using them as control variables, this study was able to provide insights into their interaction with positioning and manufacturing strategy. The emphasis on a specific positioning strategy, it was found, is influenced by the stage of product life cycle and industry environment such and rivalry. Manufacturing strategy, in general, is not as much influenced by industry environment as it is by product life cycle.

\subsection{Co-alignment of Positioning and Manufacturing Strategy}

This thesis responds to the call by Weir et al. (2000) who state that there is an urgent need to develop integration between marketing and manufacturing at a strategic level. Co-alignment or integration of marketing and manufacturing has not been achieved in practice, they state, despite a number of publications on this topic. The integration mostly takes the form of functional co-ordination, models and frameworks which endeavor to link manufacturing to market such as just-in-time manufacturing and production planning. Also, the use of cross-functional teams in decision-making is considered an integration mechanism. This thesis strives to bridge the research gap identified by Weir et al. (2000) and empirically tests a framework, backed by theory, which links manufacturing and marketing at the strategic level. It also demonstrates how the application of this concept 
leads to enhanced organizational performance, thus making a significant contribution to the existing literature.

Hausman, Montgomery and Roth (2001) empirically demonstrate that business performance is improved when manufacturing and marketing work together in harmony for goal attainment. Venkataraman (1990) also empirically establishes that co-alignment of manufacturing and marketing leads to better performance.

However, it has been stated in the literature that a concrete relationship between marketing strategy and manufacturing strategy has not been established. Thus, there is evidence that co-alignment of manufacturing and marketing leads to improved organizational performance but it is not clearly demonstrated what mechanism leads to such performance other than suggestions to improve coordination between marketing and manufacturing in the areas of process \& product development and manufacturing \& marketing planning.

This is the first study which empirically demonstrates that alignment of manufacturing and marketing can be attained by achieving co-alignment of manufacturing and positioning strategy. It also provides evidence that lack of co-alignment would have a detrimental impact on a firm's performance. In this respect, profile deviation technique was used to calculate lack of co-alignment or fit. The adherence to ideal profile is taken as co-alignment for this study. Using correlation and regression analysis it was found that lack of co-alignment leads to negative impact on both financial and non-financial performance. The results were validated with two samples of top performers and a random sample. 
The correlation analysis of positioning and manufacturing strategies of top performers was conducted to elicit the pattern of co-alignment. An in-depth analysis of differences between top performers, who are assumed to have achieved co-alignment, and the rest of the sample (low performers) who are farther from co-alignment revealed that high performers mainly focus on one positioning and one (corresponding) manufacturing strategy at one point in time. The findings also favour the trade-off model of manufacturing strategy (as opposed to the sand-cone model) which states that firms employ multiple manufacturing strategies while giving preference to one over others.

However, the findings about pattern of co-alignment must be interpreted with caution since it is suggested that strategic co-alignment is an outcome of internal mechanism of interconnected elements of strategies and it is probable that different firms would reach that coalignment differently (Grover and Sabherwal, 2006).

\subsection{Benefits and Implications}

This research has a number of theoretical and practical implications for both operations and marketing disciplines. It contributes to the better understanding of the concept of positioning from the perspective of firm. The impact of positioning strategies on a firm's performance and the role of influencing factors on the deployment of specific positioning strategy dimensions have hardly been studied in the literature.

This research also contributes to the existing knowledge on manufacturing strategy. It moves the field forward by going beyond competitive strategy to positioning strategy and studies the co-alignment of manufacturing strategy and positioning strategy, thus helping 
the firms to understand how manufacturing strategy should be adjusted to align with the positioning strategy, which is ultimately how the products are viewed by the customers.

\subsubsection{Theoretical Implications}

This study contributes to the existing body of literature in several ways:

First, this study introduces a number of a new of constructs in the fields of positioning and manufacturing strategy. For example, innovation orientation has not been deliberated in positioning and manufacturing strategy literatures and the construct of environmental dynamism has not been considered in the field of positioning. This study empirically tests a number of constructs which have previously been conceptually proposed in the field of positioning, such as customer and competitor orientation. The construct of marketing capability, as defined by this study, is also new to the field of positioning. The control variables, product life cycle and industry environment, were never used by any study in the fields of manufacturing and positioning strategies.

Second, Swink and Hegarty (1998) point to a significant limitation in the conceptualization of competitive priorities (manufacturing strategy) that a distinction is not made between manufacturing capabilities and manufacturing outcomes (strategy). Theirs is the first study to conceptually introduce this concept. Ours is the first study to empirically test the concept of separate constructs for manufacturing strategy and manufacturing capability within the same model, thus opening the door for new debate and future research on the issue. 
Third, this study is also a first attempt to analyze the positioning development process of a firm using a comprehensive set of variables. No study thus far has attempted to simultaneously examine the interplay of influencing factors, positioning strategy dimensions and firm's performance. Therefore, this study will contribute significantly to the theoretical underpinnings of positioning strategy, and should stimulate future research in replicating those variables as well as identifying other variables not considered by this study.

Fourth, Tsogas, and Blankson (2000) acknowledge that they were unable to identify empirically tested positioning strategies developed for the business market. This study empirically tests a new typology of positioning strategies, different from what has been proposed in the literature. Also, this could be the first specific typology only for business firms.

Fifth, this study extends the argument posited by Anderson and Schroeder (1991) "that effective manufacturing strategy is inseparable from an effective process for the development of manufacturing strategy". Ours is one of the first studies which links the process (influencing factors) with content (manufacturing strategy).

Sixth, there are two schools of thought in manufacturing strategy literature on how a firm should choose its competitive priorities or manufacturing strategy dimensions. The idea of trade-offs proposed by Skinner (1969) is based on the premise that companies need to focus on certain aspects of their manufacturing to produce products which can satisfy a set of customers, since it is not possible for a firm to do everything and please everyone. Therefore, companies need to choose amongst the dimensions of quality, cost, flexibility 
and dependability (Sarmiento et al., 2007). The sand-cone model (Ferdows and De Meyer, 1990; Noble, 1995) suggests that a firm can decide to employ multiple competitive priorities following a certain sequence where one manufacturing dimension would be employed first rather than later. Whether a firm should follow a trade-off or sand-cone model could be addressed by aligning the manufacturing strategy with positioning strategy. This research, therefore, contributes significantly to the understanding of how positioning and manufacturing strategies should be aligned, what the interplay of impact on each strategy is, and what their combined affect on organizational performance is.

Seventh, this study contributes to the literature by expanding the understating of linkages between marketing and manufacturing. It bridges the two disciplines at the strategic level by introducing how co-alignment of positioning and manufacturing strategy can enhance a firm's performance.

\subsubsection{Managerial Implications}

This study offers at least four major managerial implications:

First, it provides evidence to manufacturing firms that certain positioning strategy and manufacturing strategy dimensions are likely to have a more positive impact on their financial and non-financial performance - a very useful finding for managers who can implement those strategies in their firms. This will reinforce the concepts of implementing positioning and manufacturing strategies. 
Second, identification of the factors considered by managers while developing positioning strategies and manufacturing strategies leads to better understanding of what specific factors must by considered by the firms to develop successful positioning and manufacturing strategies. It will thus provide practical guidance to companies who wish to implement such strategies for their firms.

Third, a new typology of positioning strategies, mainly for business firms, provides a practical avenue for managers to consider when developing positioning strategies.

Fourth, the falling trade barriers and a general move towards globalization are making the competitive landscape intense for manufacturing companies. Manufacturing firms from developing countries, in particular, have a cost advantage and are giving their competitors in the developed world run for their money. The coordination between marketing and manufacturing is posited to improve a firm's performance but how a firm can achieve such coordination at the strategic and tactical level has not been deliberated much in the literature. This study provides practical guidance to managers on how coalignment of manufacturing and positioning strategy leads to improved performance. Specifically, it demonstrates that high performers are very focused and normally pick one positioning and one corresponding manufacturing strategy at a time, rather than multiple positioning and manufacturing strategies.

\subsection{Limitations}

The data was collected from only two sub-sectors of the industry, purportedly limiting the generalizability of our findings. However, Boone and Whybark (1995) analyzed differences between two very different industries - small machine tool and textile - using 
an international database and concluded that differences in manufacturing practices between industries are much less than differences between countries due to environmental factors such as legal, cultural, and economic factors. Also, generalizability at this stage of the research process, with a newly developed conceptual framework, is not as vital an issue as it would be for well-developed theoretical models.

There is always a possibility of bias with self-reported data, since some people may respond without carefully thinking about the questions. Also, the opportunity to elaborate in case of confusion does not exist. To be accurate, the self-reported instruments rely on the truthfulness of the respondents. A respondent may misinterpret certain questions and hence may not provide the suitable response. However, such anomalies are minimized by making sure that respondents feel comfortable, knowing that they are anonymous and can not be identified. Also, the instructions for the correct method of responding diminish such likelihood. Respondents may also suffer from distractions while filling out the instruments, thereby affecting their ability to respond correctly, but the possibility of such errors was minimized by the use of simple wording.

Objective measures for organizational performance were not available. Measurement of manufacturing strategy based on a single-item scale could undermine the reliability of the study. However, there is a precedent for such measurement in the literature (Chan, 2005).

The survey was produced in only one of Canada's official languages - English. The mailing list included respondents from the province of Quebec as well. However, it was expected that response rate among francophones might be lower due to the potential difficulty of answering a survey published in English. Mail surveys typically generate 
lower response rates than other methods such as personal interviews. The response rate for mail surveys of business (industrial) markets is traditionally fairly low. The willingness of the respondents to participate in a mail survey, therefore, was realistically estimated.

There are also a number of limitations caused by the fact that some of the constructs were not empirically tested within the fields of positioning and manufacturing strategy. As mentioned earlier, there are hardly any empirical studies which deliberate the actual process followed by the companies while developing the positioning strategies. The lack of research on the development of positioning strategies may be a weak link in the current research. The constructs mainly taken from the positioning and operations management literatures have not been empirically tested within an integrative model. Though all the proposed constructs have been sufficiently justified with an extensive literature review, there is a possibility that more constructs could be added. Also, at times it was difficult to interpret the findings of this study since there is no prior empirical research available for comparison.

Like any other research, this study is not devoid of limitations. However, it also provides a significant number of benefits, discussed earlier.

\subsection{Future Research Directions}

This research might not have provided answers to all possible questions but it identifies, highlights, and brings forth a number of issues which provide opportunities for future research. 
Despite strong theoretical support for customer and competitor orientation for development of positioning strategy, they were not positively significant for most of the positioning strategy dimensions. Therefore, more research is required to further understand the positioning strategy development process, specifically the impact of customer and competitor orientation. Qualitative research, in particular, as a follow-up to quantitative research, would be useful in understanding the underlying reasons and motivations.

The majority of the firms - $80 \%$ - were small size firms. However, replication of the study to the large firms would extend the findings to a broader spectrum of firms. Also as compared to medium and large firms, smaller firms have low profitability, low focus on market orientation, higher use of product focus positioning strategy, less focus on costs capability and more focus on flexibility capability. Different results might be obtained if the study were replicated with large firms. Replicating the study would also confirm if the same set of variables are applicable to both types of firms.

A large majority ( 86 percent) of the firms in the sample sold their products only to businesses, not to consumers. This makes the study virtually a Business to Business (B2B) study. A sample of Business to Consumer firms and its comparison with B2B is another potential investigative area.

The notable differences between Canadian and foreign firms in terms of profitability, market and customer orientation and focus on different dimensions of positioning manufacturing strategy also necessitate the need to replicate this study with firms from different countries and with different national origins. In the literature, organizational 
culture is posited to have influenced manufacturing strategy. It follows that different national cultures and/or the globalization orientation of a firm might also affect the development of positioning and manufacturing strategies.

Single key informants were used as respondents in this study. Also single-item indicators were used to measure manufacturing strategy. Future studies could use multiple respondents in the firm and develop multi-item scales to measure manufacturing strategy. The new typology of positioning strategies advanced by this study needs to be refined with the addition of new measures. It should also be replicated in other industries and countries.

This is one of the first studies to use product life cycle and industry environment as control variables. Further research is needed to understand the role and influence of these control variables, in particular industry environment, upon manufacturing and positioning strategies.

Since this is the first study to use the constructs of manufacturing capability and manufacturing strategy within the same model, the nature of the relationship between the two constructs needs to be further explored with quantitative and qualitative research.

One set of relationships not tested by this study due to the scope of the project was the direct relationship between influencing factors and organizational performance. For example, the impact of customer, competitors, resource market, and innovation orientation on performance could be directly measured. Similarly, the impact of environmental dynamism on performance could bring new perspectives to the research. 
There is a possibility that interaction of two positioning or two manufacturing strategies would lead to higher organizational performance. For example, Kazan et al. (2006) had cost and flexibility load on one factor during factor analysis and it had a positive impact on the financial performance of the firm.

\subsection{Summary}

The chapter provides a summary of key findings and conclusions from this research. Most of the hypotheses posited in the beginning of this research are partially supported. However, one of the major hypotheses, that lack of co-alignment of positioning and manufacturing strategies leads to negative impact on financial and non-financial performance of the firm, was fully supported. The adherence to ideal profile is taken as co-alignment for this study.

Despite the best of conceptualization and research designs, research studies have some inherent limitations, mainly due to the constraints of time, money and, in some cases, lack of previous research. Due to its being a pioneer in its field, this research also has certain limitations related to research design.

Despite its limitations, this study provides significant benefits to both academics and practitioners. From a practical standpoint, the identification of relevant positioning strategy dimensions used by manufacturing companies, the factors considered by the companies while developing positioning and manufacturing strategies, and the development and empirical testing of a positioning framework used by the firms would be of immense use to managers, who are likely to use such strategies in future. The 
notion of co-alignment of positioning and manufacturing strategies would be useful to both marketing and operations management managers.

This study contributes to the existing body of literature in several ways: It introduces a number of a new of constructs in the fields of positioning and manufacturing strategy. It is the first study to empirically test the concept of separate constructs for manufacturing strategy and manufacturing capability within the same model. This study is also a first attempt to analyze the positioning development process of a firm using a comprehensive set of variables. This study empirically tests a new typology of positioning strategies, different from what has been proposed in the literature, the first specific typology only for business firms. It is one of the first studies which links the process (influencing factors) with content (manufacturing strategy). This research, therefore, contributes significantly to the understanding of how positioning and manufacturing strategies should be aligned, what the interplay of impact on each strategy is, and what their combined affect on organizational performance is. This study contributes to the literature by expanding the understating of linkages between marketing and manufacturing. It bridges the two disciplines at the strategic level by introducing how co-alignment of positioning and manufacturing strategy can enhance a firm's performance. 


\section{References}

Aaker, D. (1992), Strategic Market Management, as quoted in Chernatony, Leslie de, Kevin Daniels, and Gerry Johnson (1993), "Competitive positioning strategies mirroring sellers' and buyers' perceptions?", Journal of Strategic Marketing, 1, 229-248.

Aaker, David A. (1998), Strategic Marketing Management ( $5^{\text {th }}$ ed), New York, NY: John Wiley and Sons, Inc.

Aaker, David A. and J. Gary Shansby (1982), "Positioning Your Product", Business Horizons, 25 (3), 56-62.

Akman, Gülşen and Cengiz Yilmaz (2008), "Innovative Capability, Innovation Strategy and Market Orientation: An Empirical Analysis in Turkish Software Industry", International Journal of Innovation Management, 12 (1), 69-111.

Albers, S. (1979), "An Extended Algorithm for Optimal Product Positioning", European Journal of Operational Research, 3 (May), 222-231.

Alden, Dana L., Jan-Benedict E.M. Steenkamp, and Rajeev Batra (1999), "Brand Positioning Through Advertising in Asia, North America, and Europe: The Role of Global Consumer Culture", Journal of Marketing, 63, 75-87.

Allen, Richard S., Gail Dawson, Kathleen Wheatley, Charles S. White (2008), "Perceived diversity and organizational performance", Employee Relations, 2008, 30 (1), 20-33.

Allison, P.D. (1999), Multiple regression: A primer, Thousand Oaks, CA : Pine Forge Press.

Alpert, Lewis and Ronald Gatty (1969), "Product Positioning by Behavioral Life-styles", Journal of Marketing, 33 (2), 65-69.

Amit, R. and P.J.H. Shoemaker (1993), "Strategic assets and organizational rents", Strategic Management Journal, 14(1), 33-46.

Amoako-Gyampah, Kwasi (2003), "The relationships among selected business environment factors and manufacturing strategy: insights from an emerging economy", Omega, 31 (4), 287-301.

Amoako-Gyampah, Kwasi and Moses Acquaah (2008), "Manufacturing strategy, competitive strategy and firm performance: An empirical study in a developing economy environment", International Journal of Production Economics, 111 (2), 575-592. 
Amoako-Gyampah, Kwasi and Samuel S. Boye (2001), "Operations strategy in an emerging economy: the case of the Ghanaian manufacturing industry", Journal of Operations Management, 19 (1), 59-79.

Anderson, E. and A.T. Coughlan (1987), "International market entry and expansion via independent or integrated channels of distribution", Journal of Marketing, 51 (1), 71-82.

Anderson, John C., Gary Cleveland, and Roger G. Schroeder (1989), "Operations Strategy: A Literature Review”, Journal of Operations Management, 8 (2), 133158.

Andrews, K.R. (1971), “The Concept of a Corporate Strategy", Dow Jones-Irwin, Homewoood, IL.

Armstrong, J. Scott and Terry S. Overton (1977), "Estimating Nonresponse Bias in Mail Surveys", Journal of Marketing Research, 14 (3), 396-402.

Arnott, D. (1992), Bases of financial services positioning, as quoted in Kalafatis, Stavros P., Markos H. Tsogas, and Charles Blankson (2000), "Positioning strategies in business markets", Journal of Business and Industrial Marketing, 15 (6), 416437.

Arora, Raj (1982), "Consumer Involvement in Retail Store Positioning", Journal of the Academy of Marketing Science, 10 (1), 109-124.

Asnoff, H.I. (1965), Corporate Strategy, McGraw-Hill, New York.

Attia, Samaa T. and Graham Hooley (2007), "The role of resources in achieving target competitive positions", Journal of Strategic Marketing, 15 (2/3), 91-119.

Augustine, A.J., W.J. Long, and J. Pantzallis (1992), "Hospital positioning a strategic tool of the 1990s", Journal of Health Care Marketing, 12 (1), 15-23.

Avella, L., E. Fernandez, and C. J. Vazquez (1998), "Taxonomy of the manufacturing strategies of large Spanish industrial companies", International Journal of Production Research, 36 (11), 3113-3134.

Baier, Daniel and Wolfgang Gaul (1999), "Optimal product positioning based on paired comparison data", Journal of Econometrics, 89 (1/2), 365-392.

Baines, Tim, Gwyn Kay, Sola Adesola, and Martin Higson (2005), "Strategic positioning: an integrated decision process for manufacturers", International Journal of Operations \& Production Management, 25 (2), 180-201.

Bates, Albert D. (1976), “The Troubled Future of Retailing”, Business Horizons, 19 (4), 22-28. 
Bates, K., K. Blackmon, E.J. Flynn, and C. Voss (2001), Manufacturing strategy: Building capability for dynamic markets. In: Schroeder, R.G., Flynn, B.B. (Eds.), High Performance Manufacturing-Global Perspectives. Wiley, New York, pp. 59-72.

Bates, K.A., S.D. Amundson, R.G. Schroeder, and W.T. Morris (1995), "The crucial interrelationship between manufacturing strategy and organizational culture", Management Science, 41 (10), 1565-80.

Belch, G.E. and M.A. Belch (1993), Introduction to advertising and promotion: An integrated communications perspective ( $2^{\text {nd }}$ ed.), Boston: Richard D. Irwin, Inc.

Bennion Jr, Mark L. (1987), "Segmentation and Positioning in a Basic Industry", Industrial Marketing Management, 16 (1), 9-17.

Berry, Leonard L. (1969), "Retail Positioning Strategies for the 1980s", Business Horizons, 25 (6), 45-50.

Berry, Leonard L. (1982), "The Components of Department Store Image: A Theoretical and Empirical Analysis", Journal of Retailing, 45, 3-20.

Berry, W.L., T. Hill, and J.E. Klompmaker (1999), "Aligning marketing and manufacturing strategies with the market", International Journal of Production Research, 37 (16), 3599-3618.

Berry, William L., Terry J. Hill, and Jay E. Klompmaker (1995), "Customer-driven manufacturing", International Journal of Operations \& Production Management, 15 (3), 4-15.

Berthon, Pierre and Leyland Pitt (2001), "Positioning in Cyberspace: Evaluating Telecom Web Sites Using Correspondence Analysis", Information Resources Management Journal, 14 (1), 13-21.

Bierly, Paul E. and Paula S. Daly (2007) "Alternative Knowledge Strategies, Competitive Environment, and Organizational Performance in Small Manufacturing Firms", Entrepreneurship: Theory \& Practice, 31 (4), 493-516.

Bigné, J. Enrique and Natalia Vila López, (2002), "Competitive groups in the automobile industry: a compared supply-demand approach", Journal of Strategic Marketing, 10 (1), 21-45.

Blankson, Charles (2004)," Positioning strategies and incidence of congruence of two UK store card brands", Journal of Product and Brand Management, 13 (5), 315-328.

Blankson, Charles and Stavros P. Kalafatis (1999a), "Issues and challenges in the positioning of service brands: a review", Journal of Product and Brand Management, 8 (2), 106-118. 
Blankson, Charles and Stavros P. Kalafatis (1999b), "Issues of creative communication tactics and positioning strategies in the UK plastic card service industry", Journal of Marketing Communications, 5, 55-70.

Blankson, Charles and Stavros P. Kalafatis (2001), "The development of a consumer/customer-derived generic typology of positioning strategies", Journal of Marketing Theory \& Practice, Spring, 35-53.

Blankson, Charles and Stavros P. Kalafatis (2004), "The development and validation of a scale measuring consumer/customer-derived generic typology of positioning strategies", Journal of Marketing Management, 20, 5-43.

Blankson, Charles, Stavros P. Kalafatis, Julian Ming-Sung Cheng and Costas Hadjicharalambous (2008), "Impact of Positioning Strategies on Corporate Performance", Journal of Advertising Research, 48 (1), 106-122.

Blois, K.J. (1980), "The manufacturing/marketing orientation and its information needs", European Journal of Marketing, 14, 354-364.

Botha, Christel, John L. Crompton, and Seong-Seop Kim (1999), "Developing a Revised Competitive Position for Sun/Lost City, South Africa", Journal of Travel Research, 37, 341-352.

Bouzida, Y., F. Cuppens, N. Cuppens-Boulahia and S. Gombault (2004), " Efficient Intrusion Detection Using Principal Component Analysis ". 3ème Conférence sur la Sécurité et Architectures Réseaux (SAR), La Londe, France. June.

Boyer, K.K. and Pagell, M. (2000), "Measurement issues in empirical research: improving measures of operations strategy and advanced manufacturing technology", Journal of Operations Management, Vol. 18 No. 3, pp. 361-74.

Brooksbank, R. (1994), "The Anatomy of Marketing Positioning Strategy", Marketing Intelligence and Planning, 12 (4), 10-14.

Brown, S. (1999), "The role of manufacturing strategy in mass customization and agile manufacturing:, in Kanda et al. (Eds), International Conference POMS-99 (India) on Operations Management for Global Economy: Challenges and Prospects, Phoenix Publishing House, New Delhi, 35-50.

Brown, S. and K.M. Eisenhardt (1995), "Product development: past research, present findings and future directions", Academy of Management Review, 20 (2), 343379.

Brown, Steve and John Bessant (2003), "The manufacturing strategy-capabilities links in mass customization and agile manufacturing-an exploratory study", International Journal of Operations \& Production Management, 23 (7), 707730 . 
Brown, Steve, Brian Squire, and Kate Blackmon (2007), "The contribution of manufacturing strategy involvement and alignment to world-class manufacturing performance", International Journal of Operations \& Production Management, 27 (3), 282-302.

Buffa, Elwood S. (1980), "Research in Operations Management", Journal of Operations Management, 1-6.

Buffa, Elwood S. (1984), "Making American Manufacturing Competitive”, California Management Review, 26 (3), 29-46.

Buzzell, R.D. and B.T. Gale (1987), The PIMS principles, The Free Press, New York, NY.

Cagliano, R., N. Acur, and H. Boer (2005), "Patterns of change in manufacturing strategy configurations", International Journal of Operations \& Production Management, 25 (7), 701-718.

Calantone, Roger, Cornelia Dröge, and Shawnee Vickery (2002), "Investigating the manufacturing-marketing interface in new product development: does context affect the strength of relationships?" Journal of Operations Management, 20 (3), 273-287.

Carmines, E. G. And R.A. Zeller (1991), Reliability and validity assessment, Newbury Park: Sage Publications.

Casico, W.F. (1991), Applied psychology in personnel management $\left(4^{\text {th }}\right.$ ed), Englewood Cliffs, NJ: Prentice Hall.

Chien, S. H. (2005), "Taiwanese Firms' Foreign Direct Investment in China: Traditional Industries vs. Electronic Industries", The Journal of American Academy of Business, 6 (1).

Churchill, Gilbert A. (1979), "A Paradigm for Developing Better Measures of Marketing Constructs", Journal of Marketing Research, 16 (February), 64-73.

Clement, M. and H. Werner-Grotemeyer (1990), "The Iterative Positioning Process: An Internal Approach from the pharmaceutical Industry", Marketing and Research Today, June, 85-96.

Conner, K.R. (1991), "A Historical Comparison of Resource-Based Theory and Five Schools of Thought within Industrial Organization Economics: Do We Have a New Theory of the Firm?" Journal of Management, 17, 121-154.

Conrad, Craig A.; Brown, Gene; Harmon, Harry A. (1997), "Customer Satisfaction and Corporate Culture: A Profile Deviation Analysis of a Relationship Marketing Outcome", Psychology \& Marketing, 14 (7), 663-674. 
Corbeet, C and L. V. Wassenhove (1993), "Trade-Offs? What Trade Offs? Competence and Competitiveness in Manufacturing Strategy", California Management Review, 35 (4), 107-122.

Corbett, L.M. and G.S. Claridge (2002), "Key manufacturing capability elements and business performance", International Journal of Production Research, 40 (1), $109-31$.

Corstjens, Marcel and Peter Doyle (1989), "Evaluating Alternative Retail Repositioning Strategies", Marketing Science, 8 (2), 170-180.

Cox, J.F. III and J.H. Blackstone (1998), APICS Dictionary, $9^{\text {th }}$ ed., Falls Church, VA.

Crama, Yves and Pierre Hansen (1995), "Complexity of product positioning and ball intersection problems", Mathematics of Operations Research, 20 (4), 885-894.

Cravens, David W. (1975), "Marketing Strategy Positioning”, Business Horizons, December, 53-61.

Crawford, C.M. (1985), “A New Positioning Typology”, Journal of Product Innovation Management, 2(4), 243-253.

Crittenden, V.L. (1992), "Close the marketing/manufacturing gap", Sloan Management Review, 33, 41-52.

Cronbach, L.J. and P.E. Meehl (1955), "Construct validity in psychological tests", Psychological Bulletin, 52, 281-301.

Damon, W.W. and R. Schramm (1972), "A simultaneous decision model for production, marketing and finance", Management Science, 19, 161-172.

Dangayach, G. S. and S. G. Deshmukh (2001a), "Implementation of manufacturing strategy: a select study of Indian process companies", Production Planning \& Control, 12 (1), 89-105.

Dangayach, G. S. and S. G. Deshmukh (2001b), "Manufacturing strategy: Literature review and some issues", International Journal of Operations \& Production Management, 21 (7), 884-933.

Dangayach, G. S. and S. G. Deshmukh (2003), "Evidence of manufacturing strategies in Indian industry: a survey", International Journal of Production Economics, 83 (3), 279-98.

Daniel A. Sheinin (1998), "Positioning brand extensions: implications for beliefs and attitudes", Journal of Product \& Brand Management, 7 (2), 137-149.

Danneels, E. (2003), "Tight-loose coupling with customers: The enactment of customer orientation, Strategic Management Journal, 24 (2003), 559-576. 
Davies, Gary (1992), "Positioning, image and the marketing of multiple retailers", International Review of Retail, Distribution \& Consumer Research, 2 (1), 13-34.

Davis, D. (1996), Business research for decision making, Belmot, CA: Wadsworth Publishing Company.

Day, G.S. (1994), “The capabilities of market-driven organizations”, Journal of Marketing, 58 (4), 37-52.

De Meyer, A., and K. Ferdows (1991), "Quality Up, Technology Down: Manufacturing Improvement in Europe", International Journal of Technology Management: Special Publication on the Role of Technology in Corporate Policy, 156-153.

De Meyer, A., J. Nakane, J.G. Miller, K. Ferdows (1989), "Flexibility: the next competitive battle-the manufacturing futures survey", Strategic Management Journal, 10 (2), 135-144.

De Meyer, Arnoud and Kasra Ferdows (1987), "Managerial focal points in manufacturing strategy", International Journal of Production Research, 25 (11), 1551.

Deane, R.H., P.P. McDougall, and V.B. Gargeya (1991), "Manufacturing and marketing interdependence in the new venture firm: an empirical study", Journal of Operations Management, 10 (3), 329-343.

Debus, A. (2005), "Small Business Profile: An Overview of Canada's Small and Midsized Business Sector", Canadian Federation of Independent Business.

Demeter, Krisztina (2003), "Manufacturing strategy and competitiveness", International Journal of Production Economics, 81/82, 205.

Denton, Luther (1992), “Using Product Positioning Strategies to Establish National Images: An Exercise Using Current International Events in the Marketing Classroom", Journal of Marketing Education, 14 (1), 68-79.

Deshpandé, R. and J. U. Farley (1998), "Measuring market orientation: A generalization and synthesis", Journal of Market-Focused Management, 2 (3), 213-232.

Dess, G.G. and D.W. Beard (1984), "Dimensions of organizational task environments", Administrative Science Quarterly, 29, 52-73.

Devaraj, S., D.G. Hollingworth, and R. Schroeder (2001), "Generic manufacturing strategies: an empirical test of two configurational typologies", Journal of Operations Management, 19 (4), 427-52.

Devaraj, S., D.G. Hollingworth, and R. Schroeder (2004), "Generic manufacturing strategies and plant performance", Journal of Operations Management, 22 (3), 313-33. 
Devaraj, Sarv, David G.Hollingworth and Roger G. Schroeder (2004), "Generic manufacturing strategies and plant performance" Journal of Operations Management, 22 (3), 313-333.

Devlin, James F., Christine T. Ennew and Meera Mirza (1995), "Organizational positioning in retail financial services", Journal of Marketing Management, 11, 119-132.

Dibb, S. and L. Simkin (1993), "The strength of branding and positioning in services", International Journal of Service Industry Management, 4(1), 25-35.

Dillman, Don A. (1975), Mail and telephone surveys, New York, John Wiley and Sons.

Dillman, Don A. (2000), Mail and Internet Surveys: The Tailored Design Method, New York, John Wiley and Sons.

Dillon, William R., Teresa Domzal and Thomas J. Madden (1986), "Evaluating Alternative Product Positioning Strategies", Journal of Advertising Research, 26 (4), 29-36.

DiMingo, Edward (1988), “The fine art of positioning", Journal of Business Strategy, March/April, 34-38.

Dioguardi, Gianfranco (1997), "Ideas on Strategy in Ancient Philosophy", CEMS Business Review, 2, 131-135.

Dosi, G. (1988), "Sources, Procedures, and Microeconomic Effects of Innovation", Journal of Economic Literature, 26 (3), 1120-71.

Dovel, G.P. (1990), "Stake it out; Positioning Success, Step by Step", Business Marketing, July, 43-51, In Kalafatis, Stavros P., Markos H. Tsogas, and Charles Blankson (2000), "Positioning strategies in business markets", Journal of Business and Industrial Marketing, 15 (6), 416-437.

Doyle, Peter (1975), "Brand Positioning Using Multidimensional Scaling", European Journal of Marketing, 9 (1), 20-34.

Doyle, Peter (1983), Marketing Management, as quoted in Brooksbank, R. (1994), "The Anatomy of Marketing Positioning Strategy", Marketing Intelligence and Planning, 12 (4), 10-14.

Doyle, Peter (1994), Marketing Management and Strategy, as quoted in Percy, L., J. R. Rossiter and R. Elliott (2001), "Positioning Strategy", Strategic Advertising Management, 107-127.

Doyle, Peter and John Saunders (1985), Market Segmentation and Positioning in Specialized Industrial Markets", Journal of Marketing, 49 (2), 24-32. 
Dutta, S., O. Narasimhan, and S. Rajiv (2005), "Conceptualizing and Measuring Capabilities: Methodology and Empirical Application", Strategic Management Journal, 26 (3), 277-85.

Easingwood, Chris and Anthony Koustelos (2000), "Marketing High Technology: Preparation, Targeting, Positioning, Execution”, Business Horizons, 43 (3), 27 34.

Edison, Steve W. and Gary L Geissler (2003), "Measuring attitudes towards general technology: Antecedents, hypotheses and scale development", Journal of Targeting, Measurement \& Analysis for Marketing, 12 (2), 137-156.

Fang, Shih-Chieh and Jue-Fan Wang (2006), "Effects of Organizational Culture and Learning on Manufacturing Strategy Selection: An Empirical Study", International Journal of Management, 23 (3), 503-514.

Ferdows, K. and A. De Meyer (1990), "Lasting improvements in manufacturing performance: in search of a new theory", Journal of Operations Management, 9 (2), 168-184.

Ferdows, K. J., and P Lindberg (1987), "FMS as Indicator of the Strategic Role of Manufacturing", International Journal of Operations \& Production Management, 25(11) 1563-1571.

Ferdows, K., J.G. Miller, J. Nakane, and T.E. Vollmann (1986), "Evolving global manufacturing strategies: projections into the 1990s", International Journal of Operations \& Production Management, 6 (4), 6-16.

Ferdows, Kasra and Arnoud De Meyer (1990), "Lasting Improvements in Manufacturing Performance: In Search of a New Theory”, Journal of Operations Management, $9(2), 168-184$.

Filippini, R., C. Forza, and A. Vinelli (1995), "Compatibility and tradeoff between performance: a theory formulation and empirical evidence", paper presented at: Euroma, University of Twente, Enschede, 136-45.

Fine, C.H. and A.C. Hax (1985), "Manufacturing strategy: a methodology and an illustration", Interfaces, 15 (6), 28-32.

Fitzsimmons, J.A., P. Kouvelis,, and D.N. Mallick (1991), "Design strategy and its interface with manufacturing and marketing: a conceptual framework", Journal of Operations Management, 10, 398-415.

Flynn, B.B., R.G. Schroeder, and E.J. Flynn (1999), "World-class manufacturing: an investigation of Hayes and Wheelwright's foundation", Journal of Operations Management, 7, 249-69. 
Flynn, B.B., S. Sakakibara, and R. Schroeder (1995), "Relationship between JIT and TQM: practices and performance", Academy of Management Journal, 38 (5), 1325-1360.

Ford, John V. and Earl D. Honeycutt Jr. (1991), "Communication strategies for hospital positioning”, Journal of Hospital Marketing, 5 (2), 121-32.

Fornell, C. and D.F. Larcker (1981), Evaluating Structural Equation Models with Unobservable Variables and Measurement Error, Journal of Marketing Research, 18 (1), 39-50.

Fowler, Aubrey R. and Thomas, Joe (1993), "Functional Strategic Response to Progression through the Product Life Cycle: An Accomodation to Marketing Reality", American Business Review, June, 36-44.

Fowler, S.W., A.W. King, S.J. Marsh, and B. Victor (2000), "Beyond products: new strategic imperatives for developing competencies in dynamic environments", Journal of Engineering \& Technology Management, 17, 357-377.

Friedmann, R. and V. Parker Lessing (1987), "Psychological Meaning of Products and Product Positioning", Journal of Product Innovation Management, 4, 265-273.

Frohlich, M.T. and J.R. Dixon (2001), "A taxonomy of manufacturing strategy revisited", Journal of Operations Management, 19, 541-58.

Frohman, Alan L. (1985), "Putting Technology into Strategic Planning”, California Management Review, 27 (2), 48-59.

Fry, Timothy D., Daniel C. Steele, and Brooke A. Saladin (1994), “A Service-oriented Manufacturing Strategy", International Journal of Operations \& Production Management, 14 (10), 17-29.

Galbraith, C. S. (1990), “Transferring Core Manufacturing Technologies in High Technology Firms" California Management Review, 32 (4), 56-70.

Gallagher, Sean, Christopher Brown, Linden Brown (2008), "A strong market culture drives organizational performance and success", Employment Relations Today, 35 (1), 25-31.

Ganesh, Jaishankar and Gillian Oakenfull (1999), "International Product Positioning: An Illustration Using Perceptual Mapping Techniques", Journal of Global Marketing, 13 (2), 85-110

Garvin, D.A. (1993), "Manufacturing strategic planning", California Management Review, Summer, 85-106.

Gebauer, Heiko (2008), "Identifying service strategies in product manufacturing companies by exploring environment-strategy configurations", Industrial Marketing Management, 37 (3), 278-291. 
Gerbing, David W. and James C. Anderson (1988), "An Updated Paradigm for Scale Development Incorporating Unidimensionality and Its Assessment", Journal of Marketing Research, 25, 186-92.

Gershon, Howard J. (2003), "Strategic Positioning: Where Does Your Organization Stand?" Journal of Health Care Marketing, 48 (1), 12-14.

Grant, R.M (1991), "The resource-based theory of competitive advantage: Implications for strategy formulation", California Management Review, 33 (3), 114-135.

Grant, R.M. (1996), "Prospering in dynamically-competitive environments: Organizational capability as knowledge integration", Organization Science, 7 (4), 375-387.

Greenley, Gordon E. (1984), “An Understanding of Marketing Strategy”, European Journal of Marketing, 23 (8), 45-58.

Größler, Andreas and Grübner, André (2006), "An empirical model of the relationships between manufacturing capabilities", International Journal of Operations \& Production Management, 26 (5), 458-485

Größler, Andreas (2007), “A dynamic view on strategic resources and capabilities applied to an example from the manufacturing strategy literature", Journal of Manufacturing Technology Management, 18 (3), 250-266.

Gruca, Thomas S. and Bruce R. Klemz (2003), "Optimal new product positioning: A genetic algorithm approach", European Journal of Operational Research, 146 (3), 621-633.

Gupta, Y.P. and T.M. Somers (1996), "Business strategy, manufacturing flexibility, and organizational performance relationships: a path analysis approach", Production and Operations Management, 5 (3), 204-233.

Gurău, Călin (2004), "Positioning strategies in the value-added chain of the biopharmaceutical sector: the case of UK SMEs", Journal of Consumer Marketing, 21 (7), 476-485.

Gwin, Carol F. and Carl R. Gwin (2003), "Product Attributes Model: A Tool for Evaluating Brand Positioning", Journal of Marketing Theory and Practice, 11 (2), 30-42.

Hallgren, Mattias and Jan Olhager (2006), "Quantification in manufacturing strategy: A methodology and illustration", International Journal of Production Economics, 104 (1), 113-124.

Harman, H.H. (1967), Modern Factor Analysis, University of Chicago Press, Chicago, IL. 
Hassan, Salah S. and Stephen H. Craft (2005), "Linking global market segmentation decisions with strategic positioning options", Journal of Consumer Marketing, $22(2), 81-89$.

Hauser, John, Gerry Tellis, and Abbie Griffin (2005), "Research on Innovation: A Review and Agenda for Marketing Science. Special Report", Marketing Science Institute.

Hausman, Warren H., David B. Montgomer and Aleda V. Roth (2002), "Why should marketing and manufacturing work together? Some exploratory empirical results", Journal of Operations Management, 20, 241-257.

Hayes, R.H. and R.W. Schmenner (1978), "How should you organize manufacturing?", Harvard Business Review, 56 (1), 105-18.

Hayes, R.H. and S.C. Wheelwright (1979), "Link manufacturing process and product life cycles”, Harvard Business Review, 57 (1), 133-40.

Hayes, R.H. and S.C. Wheelwright (1984), "Restoring our Competitive Edge. Competing Through Manufacturing”, Wiley, New York, NY.

Hayes, R.H. and S.C. Wheelwright (1985), "Restoring Our Competitive Edge, Competing Through Manufacturing", John Wiley \& Sons, New York, NY, 3-24.

Hendon, Donald W. and Emelda L.Williams (1985), "Winning the Battle for Your Customer", Journal of Consumer Marketing, 2 (4), 65-75.

Henthorne, Tony L. and Alvin J. Williams (1995), "The gaming industry: The role of competitive analysis and market positioning", Economic Development Review, $13(4), 19-21$.

Herrmann, Andreas, Oliver Gassmann, Ulrich Eisert (2007), "An empirical study of the antecedents for radical product innovations and capabilities for transformation", Journal of Engineering \& Technology Management, 24 (/2), 92-120.

Hibbert, Sally Ann (1995), "The market positioning of British medical charities", European Journal of Marketing, 29 (10), 6-26.

Higgins, Lexis F. and Kimberly Weinstein (1997), "Winning market positioning strategies for long term care facilities", Health Marketing Quarterly, 15 (1), 3347.

Hill, Charles W.L. (1988), "Differentiation versus low cost or differentiation and low cost: a contingency framework", Academy of Management Review, 13 (3), 401-412.

Hill, Karen K., Lawrence O. Ticknor, Richard T. Okinaka, Michelle Asay, Heather Blair, Katherine A. Bliss, Mariam Laker, Paige E. Pardington, Amber P. Richardson, Melinda Tonks, Douglas J. Beecher, John D. Kemp, Anne-Brit Kolst $\varnothing$, Amy C. 
Lee Wong, Paul Keim, and Paul J. Jackson (2004), "Fluorescent Amplified Fragment Length Polymorphism Analysis of Bacillus anthracis, Bacillus cereus, and Bacillus thuringiensis Isolates", Applied and Environmental Microbiology, 70 (2), 1068-1080.

Hill, T. (1985), Manufacturing Strategy: The Strategic Management of the Manufacturing Function, Macmillan, London.

Hill, T. (1994), Developing a Manufacturing Strategy: Principles and Concepts. Manufacturing Strategy: Text and Cases. Chicago, IL: Richard D. Irwin.

Hill, T. (2000), Manufacturing Strategy-Text and Cases, second ed. Palgrave, Houndmills, Hampshire.

Hill, T.J. (1987), "Teaching manufacturing strategy", International Journal of Operations \& Production Management, 6 (3), 10-20.

Hill, T.J. (1993), "Manufacturing Strategy: The Strategic Management of the Manufacturing Function", 2nd ed., Macmillan, Basingstoke.

Hooley, Graham and John Saunders (1993), Competitive Positioning: The Key to Market Success, London: Prentice Hall.

Hooley, Graham J. and Gordon Greenley (2005), "The resource underpinnings of competitive positions", Journal of Strategic Marketing, 13, 93-116.

Hooley, Graham J., Gordon E. Greenley, John W. Cadogan and J. Fahy (2005), “The performance impact of marketing resources”, Journal of Business Research, 58, $18-27$

Hooley, Graham J., Amanda Broderick, and Kristian Möller (1998), "Competitive positioning and the resource-based view of the firm", Journal of Strategic Marketing, 6, 97-115.

Hooley, Graham J., Gordon Greenley, John Fahy, and John Cadogan (2001), "Marketfocused resources, competitive positioning and firm performance", Journal of Marketing Management, 17, 503-520.

Hooley, Graham J., James E. Lynch, and David Jobber (1992), "Generic marketing strategies", International Journal of Research in Marketing, 9, 75-89.

Hooley, Graham J., John A. Saunders, and Nigel F. Piercy (2004), Marketing strategy and competitive positioning, New York: Prentice Hall.

Hooley, Graham J., Jozsef Beracs, and Krisztina Kolos (1993), "Marketing Strategy Typologies in Hungary”, European Journal of Marketing, 27 (11), 80-101. 
Horte, S. A., S. Borjesson, and C. Tunalv (1991), "A Panel Study of Manufacturing Strategies in Sweden", International Journal of Operation \& Production Management, 11(3), 135-144.

Horte, S.A., P.Lindberg, C. Tunalv (1987), "Manufacturing strategies in Sweden", International Journal of Production Research, 25 (11), 15-73.

House, R.J. and J.R. Rizzo (1972a), "Role of conflict and ambiguity as critical variables in a model of organizational behavior", Organizational Behavior and Human Performance, 7, 467-505.

Houston, Franklin S. and John F. Hanieski (1976), "Pooled Marketing and Positioning", Journal of Advertising, 5 (1), 38-39.

Huber, Joel and Morris B. Holbrook (1979), "Using Attribute Ratings for Product Positioning: Some Distinctions among Compositional Approaches", Journal of Marketing Research, 16 (4), 507-516.

Hult, G. Tomas M, S. Tamer Cavusgil, Tunga Kiyak, Seyda Deligonul, Katarina Lagerström (2007), "What Drives Performance in Globally Focused Marketing Organizations? A Three-Country Study," Journal of International Marketing, $15(2), 58-85$.

Hult, G. Tomas M.; Boyer, Kenneth K.; Ketchen Jr., David J. (2007), “Quality, Operational Logistics Strategy, and Repurchase Intentions: A Profile Deviation Analysis", Journal of Business Logistics, 28 (2), 105-132.

Hum, S. and L. Leow (1992), "The Perception of the Strategic Role of Manufacturing amongst Operations Managers: An Empirical Study Based on a Newly Industrialized Economy", International Journal of Operations \& Production Management, 12 (11), 15-23.

Hurmelinna-Laukkanen, Pia; Liisa-Maija Sainio, and Tiina Jauhiainen (2008), "Appropriability regime for radical and incremental innovations", $R \& D$ Management, 38 (3), 278-289.

Hurreeram, Dinesh Kumar (2007), "Manufacturing strategy auditing for garment making companies", Benchmarking: An International Journal, 14 (3), 272-288.

Industry-Canada, Report (2006), "People and Excellence: The Heart of Successful Commercialization", in Report of the Expert Panel on Commercialization, Government of Canada, Ottawa: Industry Canada.

James E. Reinmuth and Javalgi, Rajshekhar G., Joseph W. Benoy, and William R. Gombeski (1995), "Positioning your service to target key buying influences: the case of referring physicians and hospitals", Journal of Services Marketing, 9 (5), $42-52$. 
Jobber, David (1998), Principles and Practice of Marketing, as quoted in Percy, Larry, John R. Rossiter and Richard Elliott (2001), "Positioning Strategy", Strategic Advertising Management, 107-127.

Johansson, Johny K. and Hans B. Thorelli (1985), "International product positioning", Journal of International Business Studies, 16 (3), 56-74.

John, Caron H. St. and Ernest H. Hall Jr. (1999), “The interdependency Between Marketing and Manufacturing", Industrial Marketing Management, 20 (3), 223229.

John, Caron H. St, Scott T. Young and Janis L. Miller (1999), "Coordinating Manufacturing and Marketing in International Firms", Journal of World Business, 34 (2), 109-127

John, George, Allen M. Weiss, and Shantanu Dutta (1999), "Marketing in TechnologyIntensive Markets: Toward a Conceptual Framework" Journal of Marketing, Special Issue, 63 (4), 78-91.

Joseph, A. T. (1999), "Formulation of Manufacturing Strategy", International Journal of Advanced Manufacturing Technologies, 15 (7), 522-535.

Juga, J. (1999), "Generic capabilities: Combining positional and resource-based views for strategic advantage", Journal of Strategic Marketing, 7, 3-18.

Kabadayi, Sertan; Eyuboglu, Nermin; Thomas, Gloria P. (2007), "The Performance Implications of Designing Multiple Channels to Fit with Strategy and Environment", Journal of Marketing, 71 (4), 195-211.

Kahn, Barbara E., Manohar U. Kalwani, and Donald G. Morrison (1988), "Niching Versus Change-of-Pace Brands: Using Purchase Frequencies and Penetration Rates to Infer Brand Positioning", Journal of Marketing Research, 25 (4), 384390.

Kalafatis, Stavros P., Markos H. Tsogas, and Charles Blankson (2000), "Positioning strategies in business markets", Journal of Business and Industrial Marketing, $15(6), 416-437$.

Kale, Serdar and David Arditi (2002), "Competitive Positioning in United States Construction Industry", Journal of Construction Engineering \& Management, $128(3), 238-247$.

Kantrow, Alan M. (1980), “The strategy-technology connection”, Harvard Business Review, 58 (4), 6-21.

Kathuria, R. (1997), "Lasting improvements in manufacturing performance: validation of the new theory', Proceedings of the 1997 Academy of Management Meetings, Boston, MA, August 8-13, 595. 
Kathuria, R. (2000), "Competitive priorities and managerial performance: a taxonomy of small manufacturers”, Journal of Operations Management, 18, 627-41.

Kathuria, Ravi and Stephen J. Porth (2003), "Strategy-managerial characteristics alignment and performance: A manufacturing perspective", International Journal of Operations and Production Management, 23 (3), 225-276.

Kauer, Robert T. and Eric Berkowitz (1997), "Positioning challenges in an evolving health care marketplace", Physician Executive, 23 (8), 46-51.

Kaul, A.and V.R. Rao (1995), "Research for product positioning and design decisions: An integrative review", International Journal of Research in Marketing, 12(4), 293-320.

Kazan, Halim, Gökhan Özer and Ayşe Tansel Çetin (2006), "The effect of manufacturing strategies on financial performance", Measuring Business Excellence, 10 (1)1426.

Kearns, Grover S. and Rajiv Sabherwal (2006), "Strategic Alignment Between Business and Information Technology: A Knowledge-Based View of Behaviors, Outcome, and Consequences", Journal of Management Information Systems, 23 (3), 129-162.

Keller, Kevin Lane (1999), "Brand Mantras: Rationale, Criteria and Examples", Journal of Marketing Management, 15 (1-3), 43-51.

Kelly, O'Leary- Scott W. and Benito E. Flores (2002), "The integration of manufacturing and marketing/sales decisions: impact on organizational performance", Journal of Operations Management, 20 (3), 221-240.

Kim, J.O. and C.W. Mueller (1978a), Introduction to factor analysis: What it is and how to do it, Beverly Hills, CA: Sage Publications, Inc.

Kim, J.O. and C.W. Mueller (1978b), Factor analysis: Statistical methods and practical issues, Beverly Hills, CA: Sage Publications, Inc.

Kim, J.S. and L.P. Ritzman, W.C. Benton, and D.L. Snyder (1992), "Linking product planning and process design", Decision Sciences, 23, 44-60.

Kim, J.S. and P. Arnold, (1996), "Operationalizing manufacturing strategy", International Journal of Operations \& Production Management, 16 (12), 45-73.

Kim, Samuel Seongseop, Yingzhi Guo, and Jerome Agrusa (2005), "Preference and Positioning Analyses of Overseas Destinations by Mainland Chinese Outbound Pleasure Tourists", Journal of Travel Research, 44 (2), 212-220.

Kline (2005), Principles and Practice of Structural Equation Modeling, The Guilford Press, New York. 
Kohli, A.K. and B.J. Jaworski (1990), "Market orientation: the construct, research propositions, and managerial implications", Journal of Marketing, 54(2), 1-18.

Konijnendijk, P.A. (1994), "Coordinating marketing and manufacturing in ETO companies", International Journal of Production Economics, 37 (1), 19-26.

Kotha, S. and D. Orne (1989), "Generic manufacturing strategies: a conceptual synthesis", Strategic Management Journal, 10 (3), 211-31.

Kotler, P. (1987), Marketing Management: Analysis, planning and control ( $5^{\text {th }}$ ed.), Englewood Cliffs, N.J: Prentice Hall, Inc.

Kotler, P. (1999), Marketing Management: Analysis, Planning, Implementation, and Control $\left(9^{\text {th }}\right.$ ed.), Prentice Hall College Division.

Kotler, P. and A. Andreasen (1991), Strategic Marketing for Nonprofit Organizations, as quoted in Hibbert, Sally Ann (1995), "The market positioning of British medical charities”, European Journal of Marketing, 29 (10), 6-26.

Kotler, P. and Ronald E. Turner (1998), "Marketing Management: Analysis, Planning, Implementation and Control", Prentice Hall Canada Inc., Scarborough, Ontario, Canada.

Krajewski, L.J. and L.P. Ritzman (1996), “Operations Management: Strategy and Analysis”, 4th ed., Addison-Wesley, Reading, MA.

Krieger, Abba M. and P.E. Green (2002), "A decision support model for selecting product/service benefit positioning", European Journal of Operational Research, 142 (1), 187-201.

Kumar, A. and G. Sharman (1992), "We love your product, but where is it?", The McKinsey Quarterly, 1, 24-44.

Lautman, Martin R. (1993), “The ABCs of positioning”, Marketing Research, 5(1), 12-18.

Lawton, Thomas C. (1999), "The Limits of Price Leadership: Needs-based Positioning Strategy and the Long-term Competitiveness of Europe's Low Fare Airlines", Long Range Planning, 32 (6), 573-586.

Lehmann, D.R. (1979), Market Research and Analysis. Irwin, Homewood, IL.

Leitch, R.A. (1974), "Marketing strategy and the optimal production schedule", Management Science, 21, 302-312.

Lenz, R. (1981), "Determinants' of Organizational Performance: an Interdisciplinary Review", Strategic Management Journal, 2 (2), 131-154. 
Leong, G.K., D. Snyder, and P. Ward (1990), "Research in the process and content of manufacturing strategy", Omega 18, 109-122.

Levitt, T. (1960), "Marketing myopia”, Harvard Business Review, 38, 45-56.

Lewis-Beck, M.S. (1980), Applied regression: An introduction, Beverly Hills, CA: Sage.

Li, Mingfang and Roy L. Simerly (2002), "Environmental Dynamism, Capital Structure and Innovation: An Empirical Test", International Journal of Organizational Analysis, 10 (2), 156-171.

Li, Suhong, Bhanu Ragu-Nathan, T.S. Ragu-Nathan and S. Subba Rao (2006), “The impact of supply chain management practices on competitive advantage and organizational performance”, Omega, 34 (2), 107-124.

Lin, B.W. (2004), "Original equipment manufacturers (OEM) manufacturing strategy for network innovation agility: the case of Taiwanese manufacturing networks", International Journal of Production Research, 42 (5), 943-957.

Lindberg, P. (1990), "Strategic Manufacturing Management: A Proactive Approach", International Journal of Production Management, 10 (2), 94-106.

Lindberg, Per and Lars Trygg (1991), "Manufacturing Strategy in the Value System", International Journal of Operations \& Production Management, 11 (3), 52-62.

Lindberg, Per, J. Linder and C. Tunälv (1988), "Strategic Decision in Manufacturing: On the Choice of Investments in Flexible Production Organization", International Journal of Production Research, 26 (10), 1695-1704.

López, Salvador Vivas (2005), "Competitive advantage and strategy formulation: The key role of dynamic capabilities", Management Decision, 43 (5), 661-69.

Lovelock, C.H. (1986), "Marketing of services", in Buell. V.P. (ed.), Handbook of modern marketing ( $2^{\text {nd }}$ eds.), New York: McGraw Hill Book Company, 36.136.10 .

Lovelock, C.H. and C.B. Weinberg (1984), Marketing for Public and Nonprofit Managers, as quoted in Hibbert, Sally Ann (1995), "The market positioning of British medical charities", European Journal of Marketing, 29 (10), 6-26.

Lovelock, Christopher (1991), Services Marketing, Englewood Cliffs, NJ: Prentice Hall.

Low, Wen-Shinn and Cheng, Soo May (2006), “A Comparison Study of Manufacturing Industry in Taiwan and China: Manager's Perceptions of Environment, Capability, Strategy and Performance", Asia Pacific Business Review, 12 (1), 19-38. 
Lowengart, Oded and Ehud Menipaz (2001), "On the marketing of nations and multinational corporations: a competitive positioning mapping", Management Decision, 39 (4), 302-314.

Lowry, James R. and B.D. Owens (2001), "Developing a Positioning Strategy for a University", Services Marketing Quarterly, 23 (2), 27-42.

Luo, Yadong and Seung Ho Park (2001), "Strategic Alignment and Performance of Market-Seeking MNCs in China", Strategic Management Journal, 22 (2), 141155.

Lury, Giles (2002), “Repositioning the art of positioning”, Brand Strategy, 157, 8.

Macinati, Manuela S (2008), "The relationship between quality management systems and organizational performance in the Italian National Health Service", Health Policy, 85 (2), 228-241.

Malhotra, Manoj K. and Subhash Sharma (2002), "Spanning the continuum between marketing and operations", Journal of Operations Management, 20 (3), 209-219.

Malhotra, N. (2004), Marketing Research, Englewood Cliffs, NJ, Pearson Education

Malhotra, Shavin (2007), Free Trade Zones: Characteristics and Tenant Behaviour, PhD Thesis, Sprott School of Business, Carleton University, Ottawa, Canada

Marken, G.A. (1997), "Market Positioning Needs New Look, New Emphasis", Public Relations Quarterly, 42 (3), 41-42.

Marlin, Dan; Hoffman, James J.; Lamont, Bruce T. (1994), Porter's Generic Strategies, Dynamic Environments, and Performance: A Profile Deviation Fit Perspective", International Journal of Organizational Analysis, 2 (2), 155-175.

Marucheck, A, R. Pannesi and C. Anderson (1990), "An Exploratory Study of the Manufacturing Strategy Process in Practice", Journal of Operations Management, 10 (1), 101-123.

Mavondo, Felix and Graham Hooley (2006), "Coaligning Business Orientation, Resources and Capabilities: Implications for Organisational Performance, Proceedings, Australia NewZealand Marketing Associaiton.

McAlexander, James H. and Boris W. Becker (1993), "Positioning health care services: yellow pages advertising and dental practice performance", Journal of Health Care Marketing, 13 (1), 54-57.

McArthur, Angeline W. and Paul C. Nystrom (1991), "Environmental Dynamism, Complexity, and Munificence as Moderators of Strategy-Performance Relationships", Journal of Business Research, 23 (4), 349-361. 
McGrath, M.E. and R.B. Bequillard (1989), "Integrated Manufacturing Strategies, Managing International Manufacturing", North Holland, New York, NY.

McIntyre, David R. (1975), "Multinational Positioning Strategy", Columbia Journal of World Business, 10 (3), 106-110.

Mendenhall, William,Miles, R.E. and C.C. Snow (1978), Organizational Strategy, structure, and process, as quoted in Oosthuizen, H. (2002), "Business strategy and marketing: the positioning versus resource-based dichotomy and the way forward", South African Journal of Business Management, 33 (3), 1-16.

Meybodi, Mohammad (2006), "Internal manufacturing strategy audit: the first step in integrated strategic benchmarking", Benchmarking: An International Journal, 13 (5), 580-595.

Miller, Danny (1996), "Configurations Revisited," Strategic Management Journal, 17 (7), 505-512.

Miller, Danny and Peter H. Friesen (1983), "Strategy-Making and Environment: The Third Link," Strategic Management Journal, 4 (3), 221-35.

Miller, J. and Roth, A. (1994), "A taxonomy of manufacturing strategies”, Management Science, 40, 285-304.

Mills, J., K. Platts, A. Neely, H. Richards, M. Bourne (2002), "Strategy and Performance: Creating a Winning Business Formula", Cambridge University Press, Cambridge.

Miltenburg, John (2008), "Setting manufacturing strategy for a factory-within-a-factory", International Journal of Production Economics, 113 (1), 307-323.

Mintzberg, Henry (1979), "Patterns in Strategy Formation", International Studies of Management \& Organization, 9 (3), 67-86.

Moon, Youngme (2005), "Break Free From the Product Life Cycle", Harvard Business Review, 83 (5), 86-94.

Morgan, Robert E., Carolyn A. Strong, and Tony McGuinness (2003), Product-market positioning and prospector strategy: An analysis of strategic patterns from the resource-based perspective", European Journal of Marketing, 37 (10), 14091439.

Morgan, Robert E., Tony McGuinness, and Eleri R. Thorpe (2000), "The contribution of marketing to business strategy formation: a perspective on business performance gains", Journal of Strategic Marketing, 8 (4), 341-362. 
Mühlbacher, Hans, Angelika Dreher, and Angelika Gabriel-Ritter (1994), "MIPSManaging Industrial Positioning Strategies", Industrial Marketing Management, 23 (4), 287-298.

Narus, James A. and James C. Anderson (1988), "Strengthen Distributor Performance through Channel Positioning", Sloan Management Review, 29 (2), 31-40.

Narver, John and Slater, Stanley F. (1990), "The Effect of a Market Orientation on Business Profitability", Journal of Marketing, 54(4), 20-35.

Neely, A., J. Mills, K. Platts, M. Gregory and H. Richards (1994), "Realizing Strategy through Measurement", International Journal of Operations \& Production Management, 14(3), 140-152.

Neill, Stern, Gregory M. Rose (2006), "The effect of strategic complexity on marketing strategy and organizational performance", Journal of Business Research, 59 (1), $1-10$.

Nemetz, Patricia L. and Louis W. Fry (1988), "Flexible Manufacturing Organizations: Implications for Strategy Formulation and Organization Design", Academy of Management Review, 13 (4), 627-639.

Noble, M.A. (1995), "Manufacturing strategy: testing the cumulative model in a multiple country context", Decision Sciences, 26 (5), 693-721.

Nunnally, J.C. (1978), Psychometric theory (2 ${ }^{\text {nd }}$ ed.), New York: McGraw-Hill, Inc.

Nunnally, Jum C (1967), Psychometric Theory, New York: Mc- Graw-Hill Book Company.

O'Regan, N. and A. Ghobadian (2002), "Effective strategic planning in small and medium-sized firms", Management Decision, 40 (7), 663-671.

O'Connor, Gina Colarelli and Alan D. Ayers (2005), "Building A Radical Innovation Competency", Research Technology Management, 48 (1), 23-31.

Oosthuizen, H. (2002), "Business strategy and marketing: the positioning versus resource-based dichotomy and the way forward", South African Journal of Business Management, 33 (3), 1-16.

Orth, Ulrich R. and Jarmila Tureckova (2002), "Positioning the destination product 'Southern Moravia"', Journal of Vacation Marketing, 8 (3), 247-262.

Osborne, Jason (2002), "Notes on the use of data transformations", Practical Assessment, Research \& Evaluation, 8(6) 
Osmanagić, Nidžara, Jasna Prester, and Najla Podrug (2005), "Manufacturing Strategies and Structures in Croatia", Conference Proceedings: International Conference Enterprise in Transition, 841-853.

Padma, P., L.S. Ganesh and Chandrasekharan Rajendran (2008), "A study on the ISO 14000 certification and organizational performance of Indian manufacturing firms", Benchmarking: an International Journal, 15 (1), 73-100.

Paiva, Ely Laureano, Aleda V.Roth and Jaime Evaldo Fensterseifer (2008), "Organizational knowledge and the manufacturing strategy process: A resourcebased view analysis", Journal of Operations Management, 26 (1), 115-132.

Paladino, Angela (2007), "Investigating the Drivers of Innovation and New Product Success: A Comparison of Strategic Orientations", Journal of Product Innovation Management, 24 (6), 534-553.

Palmatier, G.E. and J.S. Shull (1989), "The Marketing Edge”, Oliver Wright Limited Publications, Essex Junction, VT.

Parker, Richard and Lindsey Churchill (1986), "Positioning by Opening the Consumer's Mind", International Journal of Advertising, 5 (1), 1-14.

Percy, Larry, John R. Rossiter and Richard Elliott (2001), "Positioning Strategy", Strategic Advertising Management, Oxford University Press, Great Clarendon St, Oxford, 107-127.

Peteraf, Margaret (1993), "The Cornerstones of Competitive Advantage: A Resource Based View", Strategic Management Journal, 14(3), 179-92.

Pike, Stevens and Chris Ryan (2004), "Destination Positioning Analysis through a Comparison of Cognitive, Affective and Conative Perceptions", Journal of Travel Research, 42 (4), 333-342.

Platts, K.W. and M.J. Gregory (1990), "Manufacturing audit in the process of strategy formulation", International Journal of Operations \& Production Management, $10(9), 5-26$.

Platts, K.W., J.F. Mills, M.C. Bourne, A.D. Neely, A.H. Richards, and M.J. Gregory, (1998), "Testing manufacturing strategy formulation processes", International Journal of Production Economics, 56, 517-523.

Porter, M.E. (1980), Competitive strategy: techniques for analyzing industries and competitors, New York: Free Press.

Porter, M.E. (1985), Competitive Advantage: Creating and Sustaining Superior Performance, New York: Free Press. 
Porter, M.E. (1990), “The Competitive Advantage of Nations", Harvard Business Review, 68 (2), 73-93.

Porter, M.E. (1991), “Towards a Dynamic Theory of Strategy", Strategic Management Journal, 12(8), 95-117.

Porter, M.E. (1996), “What is Strategy?" Harvard Business Review, 74(6), 61-78.

Powell, Thomas C. (1992), "Organizational Alignment as Competitive Advantage," Strategic Management Journal, 13 (September), 119-34.

Powers, T.L., J.U. Sterling, and J.F. Wolter (1988), "Marketing and manufacturing conflict: sources and resolution", Production and Inventory Management Journal, 29, 56-60.

Prabhaker, Paul (2001), "Integrated marketing-manufacturing strategies", Journal of Business \& Industrial Marketing, 16(2), 113.

Prajogo, Daniel I., Tritos Laosirihongthong, Amrik Sohal, and Sakun Boon-itt (2007), "Manufacturing strategies and innovation performance in newly industrialized countries", Industrial Management \& Data Systems, 107 (1), 52-68.

Pun, Kit Fai (2005), "An empirical investigation of strategy determinants and choices in manufacturing enterprises", Journal of Manufacturing Technology Management, $16(3), 282-301$.

Pun, Kit Fai. (2004), “A conceptual synergy model of strategy formation for manufacturing”, International Journal of Operations \& Production Management, 24 (9), 903-928.

Qian, Li, Liu Qi, and Cao Yu-cheng (2008), "Analysis on enterprise strategy thought based on the valuation innovation", China-USA Business Review, 7 (2), 62-65.

Rajotte, James (2007), "Manufacturing: Moving forward - Rising to the challenge." Ottawa: House of Commons.

Ray, Saibal (2005), "An integrated operations-marketing model for innovative products and services", International Journal of Production Economics, 95 (3), 327-345.

Reddy, Allan C. and David P. Campbell (1993), "Positioning Hospital: A model for regional hospitals", Journal of Health Care Marketing, 13 (1), 40-44.

Reitsperger, W. D. and S. J. Daniel (1990), "Dynamic Manufacturing: A Comparison of Attitude in the USA and Japan", Management International Review, 30 (3), 203-216.

Richardson, P., A. Taylor, and J. Gordon (1985), "A strategic approach to evaluating manufacturing performance", Interfaces, 15 (6), 15-27. 
Ries, Al and Jack Trout (1981), Positioning: The Battle for Your Mind, New York: McGraw Hill

Ries, Al and Jack Trout (1986), Marketing Warfare, Plume Books.

Rigger (1995), Positioning in theory and practice: towards a research agenda, as quoted in Blankson, Charles and Stavros P. Kalafatis (1999a), "Issues and challenges in the positioning of service brands: a review", Journal of Product and Brand Management, 8 (2), 106-118.

Robert J. Beaver (1993), Statistics for Management and Economics (7th Ed.), Prentice Hall, Upper Saddle, NJ 07458

Romaniuk, Jenni (2001), "Brand positioning in financial services: A longitudinal test to find the best brand position", Journal of Financial Services Marketing, 6 (2), 111-121.

Rosenberg, N. (1982), "Inside the Black Box: Technology and Economics", Cambridge University Press, Cambridge, MA.

Rummel, R.J. (1970), Applied factor analysis, Evanston: Northwestern University Press.

Russo, M. and P. Fouts (1997), “A resource-based perspective on corporate environmental performance \& profitability”, Academy of Management Journal, $40,534-559$.

Sabherwal, Rajiv and Yolande E. Chan (2001), "Alignment between Business and IS Strategies: A Study of Prospectors, Analyzers, and Defenders", Information Systems Research, 12 (1), 11-33.

Samiee, Saeed and Patrik Anckar (1998), "Currency Choice in Industrial Pricing: A Cross-National Evaluation", Journal of Marketing, 62 (3), 112-127.

Samuel, H.N. Leung, W.K. Chan Joseph, and W.B. Lee (2003), "Team leaders, manufacturing strategies and competitive performances", Team Performance Management, 9 (7), 190-198.

Santos, Fernando C. A. (2000), "Integration of human resource management and competitive priorities of manufacturing strategy", International Journal of Operations \& Production Management, 20 (5), 610-628.

Sarmiento, Roberto, Mike Byrne, Luis Rene Contreras, and Nick Rich (2007), "Delivery reliability, manufacturing capabilities and new models of manufacturing efficiency", Journal of Manufacturing Technology Management, 18 (4), 367386.

Sayman, Serdar, Stephen J. Hoch, and Jagmohan S. Raju (2002), "Positioning of Store Brands", Marketing Science, 21 (4), 378-397. 
Schendel, D. (1994), "Introduction to competitive organizational behavior: Toward an organizationally based theory of competitive advantage", Strategic Management Journal, 15 (8), 1-4.

Schendel, D. and C. Hofer (1979), "Strategic Management: A New View of Business Policy and Planning", Little, Brown \& Co. Boston, MA.

Schewe, Charles D. (1991), "Strategically positioning your way into the aging marketplace", Business Horizons, 34 (3), 59-66.

Schouten, John W. and James H. McAlexander (1989), "Positioning Services for Competitive Advantage: The Case of Duds and Suds", Journal of Services Marketing, 13 (Spring), 67-76.

Schroeder, R. G., G. D. Scudder and D. R. Elm (1989), "Innovation in Manufacturing", Journal of Operations Management, 8(1), 1-15.

Schroeder, R., J. Anderson, and G. Cleveland (1986), "The content of manufacturing strategy: an empirical study", Journal of Operations Management, 6 (4), 405415.

Schroeder, Roger G., Kimberly A. Bates, and Mikko A. Junttila (2002), “A ResourceBased View of Manufacturing Strategy and the Relationship to Manufacturing Performance", Strategic Management Journal, 23 (2), 105, 13.

Schwab, D.P. (1999), Research Methods for Organizational Studies, Mahwah: NJ, Lawrence Erlbaum Associates.

Scully, J. and S.E. Fawcett (1993), "Comparative logistics and production costs for global manufacturing strategy", International Journal of Operations \& Production Management, 13 (12), 62-78.

Sebastiao, Helder J. (2005), "Market Driving Relationship Marketing For Radical Innovations", AMA Winter Educators' Conference Proceedings, 16, 114-116.

Shapiro, B.P., V.K. Rangan, and J.J. Sviokla (1992), "Staple yourself to an order", Harvard Business Review, 70, 113-122.

Shapiro, Benson P. (1977), "Can marketing and manufacturing coexist?" Harvard Business Review, 55 (5), 104-114.

Shiffler, R. (1988), “Maximum z scores and outliers”, American Statistican, 42, 79-80.

Shostack, G. Lynn (1987), "Service positioning through structural change", Journal of Marketing, 51 (January), 34-43. 
Skaggs, Bruce C. and Mark Youndt (2004), "Strategic positioning, human capital and performance in service organizations: a customer interaction approach", Strategic Management Journal, 25 (1), 85-99.

Skinner, W. (1969), "Manufacturing-missing link in corporate strategy", Harvard Business Review, 47 (3), 136-145.

Skinner, W. (1974), "The focused factory”, Harvard Business Review, May/June, 113121.

Skinner, W. (1978), "Manufacturing in Corporate Strategy", Wiley, New York, NY.

Slack, N. and M. Lewis (2002), “Operations Strategy”, Harlow.

Spencer, M. and J.F. Cox III (1994), "Sales and manufacturing coordination in repetitive manufacturing: characteristics and problems", International Journal of Production Economics, 37 (1), $73-81$.

Spring, Martin and John F. Dalrymple (2000), Product customisation and manufacturing strategy", International Journal of Operations \& Production Management, 20 (4), 441-467.

Stalk Jr., G. and T.M. Hout (1990), Competing Against Time, Free Press, New York, NY.

Stempel, G.H. and Westley, B.H. (1981), Research Methods in Mass Communication, Englewood Cliffs, NJ: Prentice-Hall.

Stevens, J. (1992), Applied Multivariate Statistics for the Social Sciences (Second Edition ed.). Hillsdale, NJ: Lawrence Erlbaum Associates Inc.

Stevens, J. (1996), Applied multivariate statistics for the social sciences $\left(3^{\text {rd }}\right.$ ed.), Hillsdale: Lawrence Erlbaum Associates.

Stiff, Ronald and Inder Khera (1977), "Industrial Product Positioning: Pragmatic Uses", Industrial Marketing Management, 6 (2), 119-123.

Stobaugh, R. and P. Telesio (1983), "Match manufacturing policies and product strategy", Harvard Business Review, 61 (2), 113-20.

Swamidass, P.M. (1986), "Manufacturing strategy: its assessment and practice”, Journal of Operation Management, 6 (4), 471-84.

Swamidass, P.M., and W.T. Newell (1987), "Manufacturing strategy, environmental uncertainty and performance: a path analytic model", Management Science, 33(4), 509-524.

Sweeney, M. T. (1994), "Benchmarking for Strategic Manufacturing Management", International Journal of Operations \& Product Management, 14 (9), 4-15. 
Swink, M. and M.H. Way (1995), "Manufacturing strategy: propositions, current research, renewed directions", International Journal of Operations and Production Management, 15 (7).

Swink, Morgan and W. Harvey Hegarty (1998), "Core manufacturing capabilities and their links to product differentiation", International Journal of Operations \& Production Management, 18 (4), 374-396.

Swink, Morgan, Ram Narasimhan and Soo Wook Kim (2005), "Manufacturing Practices and Strategy Integration: Effects on Cost Efficiency, Flexibility, and MarketBased Performance”, Decision Sciences, 36 (3), 427-457.

Tabachnick, B.G. and L.S. Fidell (1989), Using multivariate statistics $\left(2^{\text {nd }}\right.$ ed.), New York: Harper \& Row.

Takala, Josu, Jarkko Hirvelä, Yang Liu, Dušan Malindžák (2007), "Global manufacturing strategies require "dynamic engineers"?, Industrial Management \& Data Systems, 107 (3), 326-344.

Takala, Josu, Juha Leskinen, Henry Sivusuo, Jarkko Hirvelä, Tauno Kekäle (2006), "The sand cone model: illustrating multi-focused strategies", Management Decision, 44 (3), 335-345.

Taps, S. B. and K. Steger-Jensen (2007), "Aligning supply chain design with manufacturing strategies in developing regions", Production Planning \& Control, 18 (6), 475-486.

Teece, D.J., G. Pisano, and A. Shuen (1997), "Dynamic capabilities and strategic management", Strategic Management Journal, 18 (7), 509-533.

Theodorou, Petros and Giannoula Florou (2008), "Manufacturing strategies and financial performance-The effect of advanced information technology: CAD/CAM systems", Omega, 36 (1), 107-121.

Theoharakis, Vasilis and Graham Hooley (2008), "Customer orientation and innovativeness: Differing roles in New and Old Europe", International Journal of Research in Marketing, 25 (1), 69-79.

Thun, Jörn-Henrik (2008), "Empirical analysis of manufacturing strategy implementation", International Journal of Production Economics, 113 (1), 370382.

Timmila, M. and A.P.J. Vepsalainen (1995), "A model for strategic repositioning of service processes", International Journal of Service Industry Management, 6 (4), $57-80$. 
Tractinsky, Noam and Oded Lowengart (2003), "E-retailers' competitive intensity: A positioning mapping analysis", Journal of Targeting, Measurement and Analysis for Marketing, 12 (2), 114-136.

Trochim, W.M.K (2002), Research methods knowledge base, Retrieved on June 15, 2009 from http://www.socialresearchmethods.net/kb/convdisc.php

Tull, Donald S. and Lynn Kahle (1989), Marketing Management, as quoted in Augustine, A.J., W.J. Long, and J. Pantzallis (1992), "Hospital positioning a strategic tool of the 1990s", Journal of Health Care Marketing, 12 (1), 15-23.

Tunalv, C. (1990), "Manufacturing Strategies and Decentralization", International Journal of Production Management, 10(2), 107-119.

Tunalv, C. (1992), "Manufacturing Strategy-Plans and Business Performance", International Journal of Operations and Production Management, 12 (3).

Turias, Ignacio J., José M. Gutiérrez and Pedro L. Galindo (2005), "Modelling the effective thermal conductivity of an unidirectional composite by the use of artificial neural networks", Composites Science and Technology, 65 (3-4), 609619.

Tyler, B.B. (2001), "The complementarity of cooperative and technological competencies: a resource-based perspective", Journal of Engineering \& Technology Management, 18 (1), 1-27.

University of Northern Iowa (2009), SPSS - Statistics on Likert Scale Surveys [online], Available: http://www.uni.edu/its/us/document/stats/spss2.html\#lik [accessed 20 February 2009]

United States Department of Labor (2009), Computer and Electronic Product Manufacturing [online], Available: http://www.bls.gov/oco/cg/cgs010.htm [accessed 10 January 2009]

Ussahawanitchakit, Phapruke (2007), "Effects of Marketing Capability on Export Performance of Gift Businesses in Thailand", International Journal of Business Research, 7 (3), 53-62.

Utterback, J.M. and W.J. Abernathy (1975), "A dynamic model of process and product innovation", Omega, 3, 639-656.

Van Dierdonck, R. and J.G. Miller (1980), "Designing production planning and control systems", Journal of Operations Management, 1 (1), 37-46.

Van Doren, Doris S. and Alan P. Spielman (1989), "Hospital Marketing: Strategy Reassessment in a Declining Market," Journal of Health Care Marketing, 9 (March), 15-24. 
Varadarajan, P. Rajan and Terry Clark (1994), "Delineating the Scope of Corporate, Business, and Marketing Strategy", Journal of Business Research, 31, 93-105.

Vardis, Harry and S. Vasa-Sideris (2000), "The PISCES Process: guiding clients to creative positioning strategies", Journal of Business and Industrial Marketing, $15(2 / 3), 163-169$.

Venkatraman, N. (1989), "The Concept of Fit in Strategy Research: Toward Verbal and Statistical Correspondence", Academy of Management Review, 14 (3), 423-444.

Venkatraman, N. (1990), "Performance Implications of Strategic Coalignment: A Methodological Perspective”, Journal of Management Studies, 27 (1), 19-41.

Venkatraman, N. and John E. Prescott (1990), "Environment-Strategy Coalignment: An empirical test of its performance implications", Strategic Management Journal, $11,1-23$.

Verhoef, Peter C. and Peter S.H. Leeflang (2009), "Understanding the Marketing Department's Influence within the Firm", Journal of Marketing, 73, 14-37.

Vokurka, R. J. and S. W. O'Leary-Kelly (2000), "A Review of Empirical Research on Manufacturing Flexibility", Journal of Operations Management, 18 (4), 485501.

Volckner, F. and H. Sattler (2006), "Drivers of Brand Extension Success", Journal of Marketing, 70, 18-34.

Vollmann, T.E., W.L. Berry, and D.C. Whybark (1997), "Manufacturing Planning and Control Systems”, McGraw-Hill, New York, NY.

Vorhies, D.W. and N.A. Morgan (2005), "Benchmarking Marketing Capabilities for Sustainable Competitive Advantage", Journal of Marketing, 69 (1), 80-94.

Vorhies, D.W., M. Harker and C.P. Rao (1999), "The capabilities and performance advantages of market-driven firms", European Journal of Marketing, 33 (11/12), 1171-1202.

Vorhies, Douglas W. and Neil A. Morgan (2003), “A Configuration Theory Assessment of Marketing Organization Fit with Business Strategy and Its Relationship with Marketing Performance," Journal of Marketing, 67, 100-115.

Ward, P.T., R. Duray, G.K. Leong, Chee-Chuong Sum (1995), "Business environment, operations strategy, and performance: An empirical study of Singapore manufacturers", Journal of Operations Management, 13, 99-115

Ward, P.T., D. Bickford and K. Leong (1996), "Configurations of manufacturing strategy, business strategy, environment, and structure", Journal of Management, 22 (4), 597-626. 
Ward, P.T., and R. Duray (2000), "Manufacturing strategy in context: environment, competitive strategy and manufacturing strategy", Journal of Operations Management, 18(2), 123-38.

Ward, P.T., G.K. Leong, and D.L. Snyder (1990), "Manufacturing strategy: an overview of current process and content models", in Ettlie, J.E., Burstein, M.C. and Felgenbaum, A. (Eds), Manufacturing Strategy, Kluwer Academic Publishers, Boston, MA.

Ward, Peter T., John K. McCreery, Gopesh Anand (2007), "Business strategies and manufacturing decisions: An empirical examination of linkages", International Journal of Operations \& Production Management, 27 (9), 951-973.

Weir, K. A., A. K. Kochhar, S. A. LeBeau and D. G. Edgeley (2000), "An Empirical Study of the Alignment Between Manufacturing and Marketing Strategies", Long Range Planning, 33 (6), 831-848.

Wernerfelt, B. (1984), "A Resource-based view of the firm", Strategic Management Journal, 5, 171-180.

Wheelwright, S. C. (1981), "Japan - Where Operations are really Strategic", Harvard Business Review, July-Aug., 67-74.

Wheelwright, S.C. (1978), "Reflecting corporate strategy in manufacturing decisions", Business Horizons, 21 (1), 57-65.

Wheelwright, S.C. (1984), "Manufacturing strategy: defining the missing link", Strategic Management Journal, 5 (1), 77-91.

Wheelwright, S.C. and R.H. Hayes (1985), "Competing through manufacturing", Harvard Business Review, 63 (1), 99-108.

Wheelwright, S.C., K.B. Clark (1992), “Revolutionizing Product Development”, Free Press, New York, NY.

White, G. P. (1996), "A meta-analytic model of manufacturing capabilities", Journal of Operations Management, 14, 315-331.

Williams, Fredrik P., Derrick E. D'Souza, Martin E.Rosenfeldt, and Massoud Kassaee (1995), "Manufacturing strategy, business strategy and firm performance in a mature industry", Journal of Operations Management, 13 (1), 19-33.

Wind, Yoram and Thomas S. Robertson (1983), "Marketing Strategy: New Directions for Theory and Research", Journal of Marketing, 47 (2), 12.

Wong, Hiu-Kan and Paul D. Ellis (2007), "Is market orientation affected by the product life cycle?" Journal of World Business, 42, 145-156. 
Wyner, Gordon and Hilary Owen (1994), "What's your position?" Marketing Research, 6 (1), 54-56.

Yamina, Shahid, Felix Mavondo, A. Gunasekaran, and James C. Sarros (1997), “A study of competitive strategy, organisational innovation and organisational performance among Australian manufacturing companies", International Journal of Production Economics, 52 (1), 161-172.

Zahra, S. A. and A. P. Nielsen (2002), "Sources of Capabilities, Integration and technology commercialization", Strategic Management Journal, 23 (5), 377-98.

Zhao, Xiande, Chee-Chuong Sum, Yinan Qi, Huiying Zhang, and Tien-Sheng Lee (2006), "A taxonomy of manufacturing strategies in China", Journal of Operations Management, 24, 621-636.

Zhu, Zhen and Cheryl Nakata (2007), "Reexamining the Link between Customer Orientation and Business Performance: The Role of Information Systems", Journal of Marketing Theory \& Practice, 15 (3), 187-203.

Zineldin, Mosad (1996), "Bank strategic positioning and some determinants of bank selection", International Journal of Bank Marketing, 14(6), 12-22.

Zwol, Roelof van (2006), "Multimedia Strategies for $B^{3}$-SDR, Based on Principal Component Analysis" In Advances in XML Information Retrieval and Evaluation, Springer Berlin / Heidelberg, 540-553 


\section{Appendix 1: Definitions of Positioning Strategies}

\section{In chronological order by year}

\begin{tabular}{|c|c|c|}
\hline Author & Year & Positioning Definition \\
\hline $\begin{array}{l}\text { Alpert and } \\
\text { Gatty }\end{array}$ & 1969 & $\begin{array}{l}\text { The differentiation of brands by studying the ways in which their } \\
\text { consumer differ as well as how consumer perceptions of various } \\
\text { brand differ is termed product positioning. (pg. } 65 \text { ) }\end{array}$ \\
\hline Doyle & 1975 & $\begin{array}{l}\text { Brand positioning is concerned with planning successful new } \\
\text { product. 1) The brand must effectively meet some consumer need. } \\
\text { 2) The successful brand must be a coherent totality and 3) it must } \\
\text { be a unique blend of attributes. }\end{array}$ \\
\hline Bates & 1976 & $\begin{array}{l}\text { The precise identification of a target market segment and the } \\
\text { development of a unique market offer designed to exactly meet the } \\
\text { market segment's buying requirement (27). }\end{array}$ \\
\hline $\begin{array}{l}\text { Houston and } \\
\text { Hanieski }\end{array}$ & 1976 & $\begin{array}{l}\text { Positioning can be most easily described as a promotional strategy } \\
\text { which attempts to place a brand along one or a number of } \\
\text { dimensions relative to other brands in the same generic class. }\end{array}$ \\
\hline $\begin{array}{l}\text { Stiff and } \\
\text { Khera }\end{array}$ & 1977 & $\begin{array}{l}\text { Product positioning is the marketing analyst's equivalent of the } \\
\text { purchasing agent's vendor analysis. Vendor analysis is "concerned } \\
\text { with the identification, definition, and measurement of vendor } \\
\text { capacity to satisfy the buyer's particular requirements" }\end{array}$ \\
\hline Albers & 1979 & $\begin{array}{l}\text { Optimal product positioning means to determine the levels of the } \\
\text { attributes of a new product to be introduced into a market such as } \\
\text { to meet best certain objectives as specified by a firm. (pg.222) }\end{array}$ \\
\hline $\begin{array}{l}\text { Aaker and } \\
\text { Shansby }\end{array}$ & 1982 & $\begin{array}{l}\text { The positioning decision often means selecting those associations } \\
\text { which are to be built upon and emphasized and those associations } \\
\text { which are to be removed or de-emphasized. }\end{array}$ \\
\hline Arora & 1982 & $\begin{array}{l}\text { To establish a market position, the retailer strives to develop a } \\
\text { store image which is analytically determined and designed to } \\
\text { appeal to the store's target customers. }\end{array}$ \\
\hline Berry & 1982 & $\begin{array}{l}\text { Positioning is identifying - and then occupying - an available } \\
\text { position in the market. Identifying a position involves examining } \\
\text { competitive presence within various market segments and then } \\
\text { addressing the question: Which segment is more available? }\end{array}$ \\
\hline Crawford & 1985 & $\begin{array}{l}\text { Product positioning addresses the question, how is one product } \\
\text { different from others? }\end{array}$ \\
\hline $\begin{array}{l}\text { Hendon and } \\
\text { Williams }\end{array}$ & 1985 & $\begin{array}{l}\text { A marketing strategy aimed at a particular market segment and } \\
\text { designed to achieve a desired position in the minds of the } \\
\text { customers (pg. } 70 \text { ). }\end{array}$ \\
\hline $\begin{array}{l}\text { Johansson and } \\
\text { Thorelli }\end{array}$ & 1985 & $\begin{array}{l}\text { Product positioning is the activity by which a desirable "position in } \\
\text { the mind of the customer" is created for the product. (pg.58) }\end{array}$ \\
\hline Dillon et al. & 1986 & $\begin{array}{l}\text { Positioning (repositioning) strategies can be characterized as } \\
\text { attempts to move a brand to a particular location within a }\end{array}$ \\
\hline
\end{tabular}




\begin{tabular}{|c|c|c|}
\hline & & $\begin{array}{l}\text { perceptual space. The location (actual or desired) of a brand in the } \\
\text { perceptual space (i.e., the brand's position) portrays the image }\end{array}$ \\
\hline $\begin{array}{l}\text { Parker and } \\
\text { Churchill }\end{array}$ & 1986 & $\begin{array}{l}\text { A position involves market's perception that a given product, brand } \\
\text { or company differs significantly form its competitors by offering a } \\
\text { particular class of benefits to a particular class of buyers. The } \\
\text { benefits associated with a position can be objective }\end{array}$ \\
\hline Bennion Jr & 1987 & $\begin{array}{l}\text { The company's product positioning decision defines its target } \\
\text { market and competitors }\end{array}$ \\
\hline $\begin{array}{l}\text { Friedmann } \\
\text { and Lessing }\end{array}$ & 1987 & $\begin{array}{l}\text { Product positioning is the position or image or the firm's product } \\
\text { in the consumer's mind. (pg.266) }\end{array}$ \\
\hline Shostack & 1987 & $\begin{array}{l}\text { When a firm or provider establishes and maintains a distinct place } \\
\text { for itself and its offering in the market, it is said to be successfully } \\
\text { positioned.(pg.34) }\end{array}$ \\
\hline DiMingo & 1988 & $\begin{array}{l}\text { Market positioning is the process of identifying and selecting a } \\
\text { market or segment that represents business potential, targeting } \\
\text { vulnerable competitors, and devising a strategy to compete. } \\
\text { Essentially, the process involves determining the criteria for com }\end{array}$ \\
\hline DiMingo & 1988 & $\begin{array}{l}\text { Psychological positioning, the second side of the positioning coin, } \\
\text { involves forging a distinctive corporate or product identity closely } \\
\text { based on market positioning factors and then using the tools of } \\
\text { communication }\end{array}$ \\
\hline DiMingo & 1988 & $\begin{array}{l}\text { True positioning is the process of distinguishing a company or } \\
\text { product from competitors along real dimensions-products or } \\
\text { corporate values that are meaningful to customers-to become the } \\
\text { preferred company or product in a market. (p.34) }\end{array}$ \\
\hline $\begin{array}{l}\text { Narus and } \\
\text { Anderson }\end{array}$ & 1988 & $\begin{array}{l}\text { A channel position is the reputation a manufacturer acquires } \\
\text { among distributors for furnishing products, services, financial } \\
\text { returns, program, and systems that are in some way superior to } \\
\text { those offered by competing manufacturers. (pg.33) }\end{array}$ \\
\hline $\begin{array}{l}\text { Corstjens and } \\
\text { Doyle }\end{array}$ & 1989 & $\begin{array}{l}\text { Positioning refers to the target market segments served by retailer } \\
\text { and differential advantage it is perceived to offer (pg. 171). }\end{array}$ \\
\hline $\begin{array}{l}\text { Schouten and } \\
\text { McAlexander }\end{array}$ & 1989 & $\begin{array}{l}\text { The success of a positioning strategy lies in the firm's ability to } \\
\text { differentiate itself in a positive way along one or more important } \\
\text { dimensions from its competitors in the mind of customer. (Pg.69) }\end{array}$ \\
\hline Schewe & 1991 & $\begin{array}{l}\text { Positioning involves placing a product or brand in a particular } \\
\text { location in the consumer's mind; it is slotted in relation to some } \\
\text { point of reference--often a competitive brand or product, some } \\
\text { product attribute, price/quality, usage application, some pro }\end{array}$ \\
\hline $\begin{array}{l}\text { Augustine } e t \\
\text { al. }\end{array}$ & 1992 & $\begin{array}{l}\text { "Positioning is the act of designing the company's image and value } \\
\text { offer so that the segment's customers understand and appreciate } \\
\text { what the company stands for in relation to its competitors." (pg.15) }\end{array}$ \\
\hline Davies & 1992 & $\begin{array}{l}\text { Positioning is linked to identifying the dimensions along with } \\
\text { consumer distinguish between offers (pg.15) }\end{array}$ \\
\hline
\end{tabular}




\begin{tabular}{|c|c|c|}
\hline Davies & 1992 & $\begin{array}{l}\text { Positioning in the marketing literature is linked to using image in } \\
\text { general and advertising in particular to locate products in market } \\
\text { gaps. (pg.15) }\end{array}$ \\
\hline Denton & 1992 & $\begin{array}{l}\text { Position occupied by a product or idea (or institution or country) in } \\
\text { the mind of the consumer by which it is judged to be similar to or } \\
\text { different from other products, ideas, institutions, or countries } \\
\text { offered as competition. (pg.69) }\end{array}$ \\
\hline $\begin{array}{l}\text { Dibb and } \\
\text { Simkin }\end{array}$ & 1993 & $\begin{array}{l}\text { Positioning is not what is done to the product or brand, it is what is } \\
\text { created in the minds of target customers; the product is positioned } \\
\text { in the minds of these customers and is given an image (pg.31) }\end{array}$ \\
\hline $\begin{array}{l}\text { Dibb and } \\
\text { Simkin }\end{array}$ & 1993 & $\begin{array}{l}\text { Positioning is the place which a product occupies in a given } \\
\text { market as perceived by the product's targeted customers (pg.31) }\end{array}$ \\
\hline Lautman & 1993 & $\begin{array}{l}\text { An effective position can be defined as one that enables a brand or } \\
\text { service to occupy a preferred and unique niche in a customer's } \\
\text { mind that is also consistent with the overall marketing strategy. } \\
\text { (pg.12) }\end{array}$ \\
\hline $\begin{array}{l}\text { Reddy and } \\
\text { Campbell }\end{array}$ & 1993 & $\begin{array}{l}\text { Positioning is the act of designing a company's marketing mix and } \\
\text { image so that the target market understands and appreciates what } \\
\text { the firm stands for in relation to its competitors. (p.40) }\end{array}$ \\
\hline Brooksbank & 1994 & $\begin{array}{l}\text { "Positioning strategy refers to the choice of target market segment } \\
\text { which describes the customers a business will seek to serve and the } \\
\text { choice of differential advantage which defines how it will compete } \\
\text { with rivals in the segment." (pg.10) }\end{array}$ \\
\hline $\begin{array}{l}\text { Mühlbacher } e t \\
\text { al. }\end{array}$ & 1994 & $\begin{array}{l}\text { Positioning is generally referred to as a process of finding and } \\
\text { establishing a distinct place in the market that is determined by the } \\
\text { customer's view of one's own offering in comparison to competing } \\
\text { alternatives. (pg.288) }\end{array}$ \\
\hline $\begin{array}{l}\text { Wyner and } \\
\text { Owen }\end{array}$ & 1994 & $\begin{array}{l}\text { The location imagery reflects the practice of describing a brand's } \\
\text { status with consumers as a "position" in their minds. This position } \\
\text { can be thought of as a place on a map that is described by the } \\
\text { dimensions consumers use when thinking about a category. }\end{array}$ \\
\hline $\begin{array}{l}\text { Crama and } \\
\text { Hansen }\end{array}$ & 1995 & $\begin{array}{l}\text { Product positioning problem consists in choosing the } \\
\text { characteristics in attribute space of a new product in such a way as } \\
\text { to maximize this product's market share, i.e., to attract maximum } \\
\text { number of customers among a given population of consumers }\end{array}$ \\
\hline Devlin et al. & 1995 & $\begin{array}{l}\text { The process of positioning is essentially concerned with the } \\
\text { identification of an appropriate competitive advantage for products } \\
\text { or services in relations to a particular set of target markets (pg.120) }\end{array}$ \\
\hline $\begin{array}{l}\text { Henthorne } \\
\text { and } \\
\text { Williams }\end{array}$ & 1995 & $\begin{array}{l}\text { Market positioning is management's concept of where the product } \\
\text { should stand in the marketplace and how the product should be } \\
\text { viewed in relation to competing products. (p.20) }\end{array}$ \\
\hline Hibbert & 1995 & $\begin{array}{l}\text { "the act of designing the organization's image and value offer so } \\
\text { that the organization's customers understand and appreciate what } \\
\text { the organization stands for in relation to its competitors" (pg.12) }\end{array}$ \\
\hline Hibbert & 1995 & $\begin{array}{l}\text { Positioning is essentially what you do to the mind of the prospect } \\
\text { (pg.12) }\end{array}$ \\
\hline
\end{tabular}




\begin{tabular}{|c|c|c|}
\hline Javalgi et al. & 1995 & $\begin{array}{l}\text { Positioning is the process of building and maintaining a distinctive } \\
\text { image, relative to other competing brands, in the mind of the } \\
\text { buying decision maker. }\end{array}$ \\
\hline $\begin{array}{l}\text { Kaul and } \\
\text { Rao }\end{array}$ & 1995 & $\begin{array}{l}\text { The product positioning and design problem is part of a broader } \\
\text { "product policy" decision that examines what products a firm } \\
\text { should offer for sale and what physical characteristics and } \\
\text { perceptual attributes these products should have. }\end{array}$ \\
\hline Zineldin & 1996 & $\begin{array}{l}\text { a "position" reflects how consumers perceive the product's/ } \\
\text { service's or organization's performance on specific attributes } \\
\text { relative to that of the competitors (pg.12) }\end{array}$ \\
\hline $\begin{array}{l}\text { Higgins and } \\
\text { Weinstein }\end{array}$ & 1997 & $\begin{array}{l}\text { We define service positioning as the "image of the service in the } \\
\text { minds of target customers." (pg. } 41 \text { ) }\end{array}$ \\
\hline $\begin{array}{l}\text { Kauer and } \\
\text { Berkowitz }\end{array}$ & 1997 & $\begin{array}{l}\text { In marketing strategy, positioning has been defined as the "act of } \\
\text { designing the company's offerings and image, so that they occupy } \\
\text { a meaningful and distinct competitive position in the target } \\
\text { customer's minds." }\end{array}$ \\
\hline Marken & 1997 & $\begin{array}{l}\text { In fact, the biggest differences you see in advertising are the } \\
\text { "against" or comparison campaigns. In short, market positioning. }\end{array}$ \\
\hline Hooley et al. & 1998 & $\begin{array}{l}\text { Competitive positioning decisions embrace identification of a } \\
\text { target market or markets - where the firm will compete - and the } \\
\text { competitive advantage that will be pursued in serving those targets } \\
\text { - how the firm will compete. (pg.98) }\end{array}$ \\
\hline \begin{tabular}{|l|} 
Sheinin \\
\end{tabular} & 1998 & $\begin{array}{l}\text { Positioning is the process of influencing perceptions by specifying } \\
\text { the attributes, benefits or images which represent differentiation } \\
\text { (pg.137). }\end{array}$ \\
\hline $\begin{array}{l}\text { Blankson and } \\
\text { Kalafatis }\end{array}$ & $1999 b$ & $\begin{array}{l}\text { "...positioning is the deliberate, proactive, iterative process of } \\
\text { defining, modifying and monitoring consumer perceptions of a } \\
\text { marketable object...." (pg.55) }\end{array}$ \\
\hline Botha et al. & 1999 & $\begin{array}{l}\text { Positioning may be defined as the process of defining and } \\
\text { reinforcing a distinctive place for a destination in the minds of } \\
\text { potential visitors within target markets. (pg.341-42) }\end{array}$ \\
\hline Botha et al. & 1999 & $\begin{array}{l}\text { The image consumers held of a brand relative to competing brands } \\
\text { in the same product category. (pg. } 341 \text { ) }\end{array}$ \\
\hline $\begin{array}{l}\text { Ganesh and } \\
\text { Oakenfull }\end{array}$ & 1999 & $\begin{array}{l}\text { Positioning decision determines the place that a firm's products } \\
\text { occupy in the minds of consumers in a given market, what benefits } \\
\text { it will stress, and what customers it will target. (pg.86) }\end{array}$ \\
\hline $\begin{array}{l}\text { Ganesh and } \\
\text { Oakenfull }\end{array}$ & 1999 & $\begin{array}{l}\text { Product positioning is the process by which a desirable "position in } \\
\text { the mid of the consumer" is created for the product. (pg. } 86 \text { ) }\end{array}$ \\
\hline John et al. & 1999 & $\begin{array}{l}\text { We can define a firm's position in a value chain as its set of } \\
\text { internalized activities within the overall set of activities undertaken } \\
\text { by all the relevant firms (p. 84). }\end{array}$ \\
\hline Keller & 1999 & $\begin{array}{l}\text { It is all about creating the optimal location in the minds of existing } \\
\text { and potential customers so that they think of the brand in the right } \\
\text { way. }\end{array}$ \\
\hline
\end{tabular}




\begin{tabular}{|c|c|c|}
\hline Lawton & 1999 & $\begin{array}{l}\text { Positioning is a means of locating an organization in its } \\
\text { environment. }\end{array}$ \\
\hline Kalafatis et al. & 2000 & $\begin{array}{l}\text { "...positioning is the deliberate, proactive, iterative process of } \\
\text { defining, modifying and monitoring consumer perceptions of a } \\
\text { marketable object...." (pg.417) }\end{array}$ \\
\hline $\begin{array}{l}\text { Berthon and } \\
\text { Pitt }\end{array}$ & 2001 & $\begin{array}{l}\text { Positioning is something that occurs in the minds of a customer, } \\
\text { and which marketers actively seek to influence by framing (direct } \\
\text { and indirect) objective knowledge in new ways. (pg.14) }\end{array}$ \\
\hline $\begin{array}{l}\text { Blankson and } \\
\text { Kalafatis }\end{array}$ & 2001 & $\begin{array}{l}\text { Positioning is concerned with the attempt to modify tangible } \\
\text { characteristics and intangible perceptions of a marketable object in } \\
\text { relation to competition (pg. } 36 \text { ) }\end{array}$ \\
\hline Hooley et al. & 2001 & $\begin{array}{l}\text { Competitive positioning is the combination of choice of target } \\
\text { market (where the firm will compete) and competitive advantage } \\
\text { (how the firm will compete). (pg.503) }\end{array}$ \\
\hline $\begin{array}{l}\text { Lowengart } \\
\text { and } \\
\text { Menipaz }\end{array}$ & 2001 & $\begin{array}{l}\text { The positioning of a nation is a result of an explicit or implicit } \\
\text { effort by a country to create and present an image to MNCs. This } \\
\text { positioning reveals to a targeted population of MNCs what the } \\
\text { country offers in terms of important business criteria }\end{array}$ \\
\hline $\begin{array}{l}\text { Lowry and } \\
\text { Owens }\end{array}$ & 2001 & $\begin{array}{l}\text { Positioning is the act of designing an organization's offering and } \\
\text { image to occupy a distinctive place in the target market's mind. } \\
\text { (p.28) }\end{array}$ \\
\hline Percy et al. & 2001 & $\begin{array}{l}\text { "the choice of: target market, where we want to compete; [and] } \\
\text { differential advantage, how we wish to compete" (pg.107) }\end{array}$ \\
\hline Percy et al. & 2001 & $\begin{array}{l}\text { "The identification of target market or markets, the customers that } \\
\text { the organization will seek to serve', and 'The creation of a } \\
\text { differential advantage, or competitive edge, that will enable the } \\
\text { organization to serve the target market more effectively than } \\
\text { competitors }\end{array}$ \\
\hline Percy et al. & 2001 & $\begin{array}{l}\text { "Positioning strategy is the choice of target market segments, } \\
\text { which determine where the business competes, and the choice of } \\
\text { differential advantage, which dictates how it competes" (pg.107) }\end{array}$ \\
\hline Romaniuk & 2001 & $\begin{array}{l}\text { A brand's position is how it is perceived in the minds of } \\
\text { consumers, relative to competitor's brands. (pg.112) }\end{array}$ \\
\hline $\begin{array}{l}\text { Bigné } \\
\text { López }\end{array}$ & 2002 & $\begin{array}{l}\text { Deciding on a specific positioning is just a matter of choosing } \\
\text { where to place a company/product in the mind of } \\
\text { managers/consumers (pg. 23). }\end{array}$ \\
\hline Lury & 2002 & $\begin{array}{l}\text { The definition of positioning comprises of four key elements: the } \\
\text { target consumer, the market in which the brand competes, the offer } \\
\text { it makes, and the elements which make that offer unique. (pg. } 8 \text { ) }\end{array}$ \\
\hline $\begin{array}{l}\text { Orth and } \\
\text { Tureckova }\end{array}$ & 2002 & $\begin{array}{l}\text { Positioning refers to the process of establishing and maintaining a } \\
\text { distinctive place in the market for an organization and/or its } \\
\text { individual offers. (pg.249) }\end{array}$ \\
\hline Sayman et al. & 2002 & $\begin{array}{l}\text { Positioning is operationalized as the perceptual distance between } \\
\text { two brands, where brands position Ned closer to each other exhibit } \\
\text { higher cross-price sensitivity. (pg.378-79) }\end{array}$ \\
\hline
\end{tabular}




\begin{tabular}{|c|c|c|}
\hline Gershon & 2003 & $\begin{array}{l}\text { An organization's strategic position is its perceptual location } \\
\text { relative to other. (pg.12) }\end{array}$ \\
\hline $\begin{array}{l}\text { Gwin and } \\
\text { Gwin }\end{array}$ & 2003 & $\begin{array}{l}\text { Through a brand's positioning, a company tries to build a } \\
\text { sustainable competitive advantage on product attribute(s) - } \\
\text { tangible or intangible - in the mind of the consumer. (pg. } 30)\end{array}$ \\
\hline $\begin{array}{l}\text { Gwin and } \\
\text { Gwin }\end{array}$ & 2003 & $\begin{array}{l}\text { Positioning "refers to how customers think about proposed and/or } \\
\text { present brands in a market." (pg.30) }\end{array}$ \\
\hline Morgan et al. & 2003 & $\begin{array}{l}\text { Product-market positions are defined here as the ways in which } \\
\text { firm-specific resources and assets are deployed to build positional } \\
\text { advantages in a firm's product markets. (pg.1416) }\end{array}$ \\
\hline $\begin{array}{l}\text { Tractinsky } \\
\text { and } \\
\text { Lowengart }\end{array}$ & 2003 & $\begin{array}{l}\text { Positioning is the way a firm designs and presents its image to } \\
\text { potential customers such that the target audiences understand what } \\
\text { the firm offers relative to other firms in the same marketplace. }\end{array}$ \\
\hline $\begin{array}{l}\text { Tractinsky } \\
\text { and } \\
\text { Lowengart }\end{array}$ & 2003 & $\begin{array}{l}\text { "Competitive positioning is the totality of offer and image of the } \\
\text { company relative to competing companies." (pg.116) }\end{array}$ \\
\hline $\begin{array}{l}\text { Blankson and } \\
\text { Kalafatis }\end{array}$ & 2004 & $\begin{array}{l}\text { Positioning is concerned with attempt to modify the tangible } \\
\text { characteristics and intangible perceptions of a marketable object in } \\
\text { relation to competition (pg.7) }\end{array}$ \\
\hline $\begin{array}{l}\text { Blankson and } \\
\text { Kalafatis }\end{array}$ & 2004 & $\begin{array}{l}\text { "...positioning is the deliberate, proactive, iterative process of } \\
\text { defining, measuring, modifying, and monitoring consumer } \\
\text { perceptions of a marketable object. ." (pg.315) Positioning is } \\
\text { concerned with the attempt to modify the tangible characteristics }\end{array}$ \\
\hline $\begin{array}{l}\text { Skaggs and } \\
\text { Youndt }\end{array}$ & 2004 & $\begin{array}{l}\text { According to the positioning view of strategy, firms undertake } \\
\text { strategic positions in order to differentiate themselves from } \\
\text { existing and potential competitors along dimensions that are of } \\
\text { importance to customers (pg.87) }\end{array}$ \\
\hline Baines et al. & 2005 & $\begin{array}{l}\text { Strategic positioning is concerned with choosing those production } \\
\text { related activities that an organizations should carry out internally, } \\
\text { and those that should be external and under the ownership and } \\
\text { control of suppliers, partners, distributors and customer }\end{array}$ \\
\hline $\begin{array}{l}\text { Hassan and } \\
\text { Craft }\end{array}$ & 2005 & $\begin{array}{l}\text { The term positioning often is used to refer to the firm's decision to } \\
\text { determine the place that its brand and corporate image occupy in a } \\
\text { given market including the type of benefits to be stressed and the } \\
\text { type of segments to be targeted (p.83). }\end{array}$ \\
\hline $\begin{array}{l}\text { Hooley and } \\
\text { Greenley }\end{array}$ & 2005 & $\begin{array}{l}\text { Competitive positioning is central to market-focused management, } \\
\text { comprising the choice of target market the firm will operate in, and } \\
\text { how it will compete in that market. }\end{array}$ \\
\hline Kim et al. & 2005 & $\begin{array}{l}\text { positioning is defined as the process of locating a destination or } \\
\text { the attractions of a destination in the minds of potential customers } \\
\text { within its target markets }\end{array}$ \\
\hline
\end{tabular}




\section{Appendix 2: Positioning Development Process}

\begin{tabular}{|c|c|c|c|c|c|c|c|c|c|c|c|}
\hline Study's Reference \# & 1 & 2 & 3 & 4 & 5 & 6 & 7 & 8 & 9 & 10 & 11 \\
\hline Year & 82 & 85 & 88 & 93 & 90 & 90 & 94 & 94 & 00 & $\mathbf{0 0}$ & 04 \\
\hline Steps/Study Type & C & $\mathrm{E}$ & C & $\mathrm{C}$ & $\mathrm{C}$ & $\mathrm{C}$ & C & $\mathrm{E}$ & C & E & C \\
\hline Define objectives/business & & 1 & & & & & & 1 & & & \\
\hline Generate/screen product/positioning concept & & & & & 1 & & & & & 1,3 & \\
\hline Identify/analyze the competitors & 1 & & & & & & & 3 & & & 1 \\
\hline Analyze market opportunities/prepare & & & 1 & & & 1 & & & 1 & & \\
\hline Compare product strategy with business strategy & & & & & & 2 & & & & & \\
\hline Determine/construct market segments & & 2 & & 1 & & & & 2 & & & \\
\hline Evaluate segment attractiveness & & 3 & & & & & & 4 & & & \\
\hline Select a segment/targeting & & 4 & 2 & 2 & & & 1 & 9 & 2 & & \\
\hline Determine competitor's positions & 2 & & & & & & 2 & 6 & & & 2 \\
\hline Analyze/understand customers & 3 & & & 3 & & 3 & & & & & 2 \\
\hline Determine/select the competitive dimensions & & & & & & & & 5,8 & & & 2 \\
\hline Internal analysis-skills/resources & & & & & & & & 7 & & & \\
\hline Develop product/services to meet their needs & & & & 4 & & & & & & & \\
\hline Evaluate consumer perception of competing offering & & & & 5 & & 4 & & & & & \\
\hline Develop and test best ideas as full concept & & & & & 2 & & & & & 4 & \\
\hline Test finished/positioning concept & & & & & 3 & & & & & 5 & \\
\hline Select/develop positioning strategy & 4 & 5 & 3 & 6 & & 5 & 3 & 9 & 3 & & 3 \\
\hline Develop a marketing mix & & 6 & & & & & & 10 & 4 & 6 & \\
\hline Communicate the positioning to the customers & & & & 7 & & 6 & & & & 6 & \\
\hline Monitor/validate position & 5 & 7 & & & & 7 & & & & 7 & 4 \\
\hline
\end{tabular}

C: Conceptual; E: Empirical

\section{Reference for Positioning Development Process Studies}

\begin{tabular}{|l|l|l|l|}
\hline Ref \# & Study & Ref \# & Study \\
\hline 1 & Aaker and Shansby, 1982 & 7 & Brooksbank, 1994 \\
\hline 2 & Doyle and Saunders, 1985 & 8 & Mühlbacher, Dreher, and Gabriel-Ritter, 1994 \\
\hline 3 & DiMingo, 1988 & 9 & Easingwood and Koustelos, 2000 \\
\hline 4 & Clement and Grotemeyer, 1990 & 10 & Vardis and Vasa-Sideris, 2000 \\
\hline 5 & Dovel, 1990 & 11 & Hooley, Saunders, and Piercy, 2004 \\
\hline 6 & Dibb and Simkin, 1993 & & \\
\hline
\end{tabular}




\section{Appendix 3: Cover Letter and Questionnaire \\ An Empirical Study to Determine the Co-alignment of Firm's Manufacturing and Positioning Strategies}

[date]

[name], [title], [organization],

Dear Mr. [last name],

I am a doctoral student at Sprott School of Business at Carleton University in Ottawa, Canada. I am currently working towards completing my Ph.D. thesis on "Co-alignment of Manufacturing and Positioning Strategies".

This research will offer practical contributions to the area of marketing strategy and operations management. The findings of the study would provide insights to the companies on development of effective positioning and manufacturing strategy leading to improved organizational performance.

This letter is to kindly request you to participate in my study by completing the enclosed questionnaire and returning it in the envelope provided. Your responses will be kept confidential and will not be disclosed to any outside parties. Anonymity will be ensured by aggregating the results of individual questionnaires when reporting the research findings. The questionnaire should take approximately 15 minutes to complete. When completing the questionnaire, you can leave blank any questions that you do not wish to answer. Your response will contribute to the success of this study and will be greatly appreciated.

There are no foreseen risks to the participants of this study. The research findings from this study will be presented in the final Ph.D. thesis report and in a series of papers to be submitted to conferences and academic journals. The findings will also be posted on Irfanbutt.com in the summer of 2009. The data will be stored both in hard copy (filled out questionnaires) and electronic copy (file with all the responses) with only the researcher having access to it. It is not going to be destroyed and might be used for future analysis related to the topic of the present study.

Your participation is essential to ensure a representative sample and enable us to produce useful results for businesses and for me to complete my doctoral thesis. Therefore, I will very much appreciate your help in completing this questionnaire, which is brief and will only take a few minutes of your time.

Thank you very much for your help.

Irfan Butt

Ph.D. Candidate

Sprott School of Business 


\section{Ethics considerations related to participation in the empirical study on Co-alignment of Positioning and Manufacturing Strategies}

(As required by the Carleton University Research Ethics Committee and the Social Sciences and Humanities Research Council of Canada)

- As noted in the letter on the previous page, your replies will be kept strictly confidential and analyzed without identification. In the event that you would like to receive an executive summary of the results, please put a check-mark in the appropriate box at the back of the questionnaire, next to the serial number. The person who will receive the questionnaires will detach the back page from the main part, make note of the respondents who wish to receive the executive summary, and forward to me the questionnaires separately. This will preserve your anonymity since it prevents any possibility of "matching" survey responses with those requesting the executive summary.

- The data obtained from the study participants will be kept on file indefinitely, anonymously since the participants are not identified, for possible future analyses.

- You may decline answering any specific questions, and/or withdraw your agreement to participate at any time during the study and have your responses, if any to your time of withdrawal, deleted from the database without reprisal.

- This project was reviewed and received ethics clearance by the Carleton University Research Ethics Committee.

- Should you have any questions or concerns about the study, please contact:

- The project supervisor:

Dr. Uma Kumar

Professor of Management Science and Technology

Sprott School of Business, Carleton University

1125 Colonel By Drive, Ottawa, Ontario K1S 5B6

Tel: + (1) (613) 520-2600 ext. 6601

E-mail: uma_kumar@carleton.ca

- and/or, the Ph.D. student who is working on this project for his thesis:

Mr. Irfan Butt, Doctoral Candidate

Sprott School of Business, Carleton University

1125 Colonel By Drive, Ottawa, Ontario K1S 5B6

Tel: + (1) (613) 520-2600 ext 6327

E-mail: ibutt@connect.carleton.ca

- and/or, Professor Antonio Gualtieri

Chair, Carleton University Research Ethics Committee

Carleton University

Office of Research Services, 401 Tory

1125 Colonel By Drive, Ottawa, Ontario K1S 5B6

Tel: + (1) (613) 520-2517

E-mail: ethics@carleton.ca 


\section{An Empirical Study to Determine the Co-alignment of Firm's Manufacturing and Positioning Strategies}

\section{Survey Questionnaire}

This questionnaire should be completed by a senior executive familiar with the functional capabilities and strategy of the company. If you do not want to answer any question then please proceed to the next question. We would be grateful if you try to answer all the questions.

(All information will be held in strict confidence and only summary statistics will be reported.)

1. What is your position within the company?

2. What products do you produce?

3. Who do you sell your products to? (Please check all that applies)

Consumers $\quad \square$ Business firms $\quad \square$ Other (please specify)

4. How many employees do you have in your company?
$<100$
$100-199$
$200-499$
$>500$

5. What is the ownership of the company?

Canadian $\square$ Foreign (please specify)

\section{A. YOUR FIRM'S ORIENTATION}

To what extent do you agree with the following statements? (please encircle the number)

\section{a) Customer \& Competitor's Orientation}

1 Our commitment to serving the customer needs is closely monitored

2 Our objectives and strategies are driven by the creation of customer satisfaction

3 Our competitive strategies are based on understanding customer needs

4 Our salespeople regularly share information within our business concerning competitors' strategies

5 Top management regularly discusses competitors' strengths and strategies

6 We respond rapidly to competitive actions that threaten us

\section{STRONGLY \\ Disagree}

12

12

$\begin{array}{lllll}1 & 2 & 3 & 4 & 5\end{array}$

$\begin{array}{lllll}1 & 2 & 3 & 4 & 5\end{array}$

$\begin{array}{lllll}1 & 2 & 3 & 4 & 5\end{array}$

$\begin{array}{llll}2 & 3 & 4 & 5\end{array}$


b) Innovation Orientation

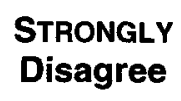

1 We introduce radical product innovations into the market more frequently than our competitors

2 Our percentage of radical product innovations in the product range in the last 3 years is significantly higher compared to the competition

3 We often use innovative technologies in the new product development

4 We are very proactive in the development and deployment of new technologies

5 We always rank among the first to use a new technology for new product development

6 Our products always reflect state-of-the-art technology

c) Resource and Market Orientation

1 We gain a competitive advantage from our unique practices

2 We believe that organizations should build and maintain core competencies and skills

3 Our practices are unique and cannot be easily copied by others

4 Our business strategy is translated into manufacturing terms

5 Potential manufacturing investments are screened for consistency with our business strategy

6 At our plant, manufacturing is kept in step with our business strategy

7 Manufacturing management is not aware of our business strategy

8 Corporate decisions are often made without consideration of the manufacturing strategy

$\begin{array}{llllllll}9 & \text { Our components/materials make-versus-buy decisions are } & 1 & 2 & 3 & 4 & 5\end{array}$ made to sustain or strengthen our manufacturing competence $\begin{array}{lllll}1 & 2 & 3 & 4 & 5\end{array}$

$\begin{array}{lllll}1 & 2 & 3 & 4 & 5\end{array}$

$\begin{array}{lllll}1 & 2 & 3 & 4 & 5\end{array}$

$\begin{array}{lllll}1 & 2 & 3 & 4 & 5\end{array}$

$\begin{array}{lllll}1 & 2 & 3 & 4 & 5\end{array}$

$\begin{array}{lllll}1 & 2 & 3 & 4 & 5\end{array}$

\begin{tabular}{cccccc}
$\begin{array}{c}\text { STRONGLY } \\
\text { Disagree }\end{array}$ & \multicolumn{3}{c}{$\begin{array}{c}\text { STRONGLY } \\
\text { Agree }\end{array}$} & $\begin{array}{c}\text { NOT } \\
\text { APPLCALLE }\end{array}$ \\
1 & 2 & 3 & 4 & 5 & $\square$
\end{tabular}

\begin{tabular}{cccccc}
$\begin{array}{c}\text { STRONGLY } \\
\text { Disagree }\end{array}$ & \multicolumn{3}{c}{$\begin{array}{c}\text { STRONGLY } \\
\text { Agree }\end{array}$} & $\begin{array}{c}\text { NOT } \\
\text { APPLCALLE }\end{array}$ \\
1 & 2 & 3 & 4 & 5 & $\square$
\end{tabular}

StRONGLY
Agree $\begin{gathered}\text { NOT } \\ \text { APPLICABLE }\end{gathered}$

\begin{tabular}{ccccrc}
$\begin{array}{c}\text { STRONGLY } \\
\text { Disagree }\end{array}$ & & \multicolumn{2}{c}{$\begin{array}{c}\text { STRONGLY } \\
\text { Agree }\end{array}$} & $\begin{array}{c}\text { NOT } \\
\text { APPLCABLE }\end{array}$ \\
1 & 2 & 3 & 4 & 5 & $\square$
\end{tabular}

$\begin{array}{lllll}1 & 2 & 3 & 4 & 5\end{array}$

$\begin{array}{lllll}1 & 2 & 3 & 4 & 5\end{array}$

$\begin{array}{lllll}1 & 2 & 3 & 4 & 5\end{array}$

$\begin{array}{lllll}1 & 2 & 3 & 4 & 5\end{array}$

$\begin{array}{lllll}1 & 2 & 3 & 4 & 5\end{array}$

$\begin{array}{llll}2 & 3 & 4 & 5\end{array}$

$\begin{array}{lllll}1 & 2 & 3 & 4 & 5\end{array}$ 


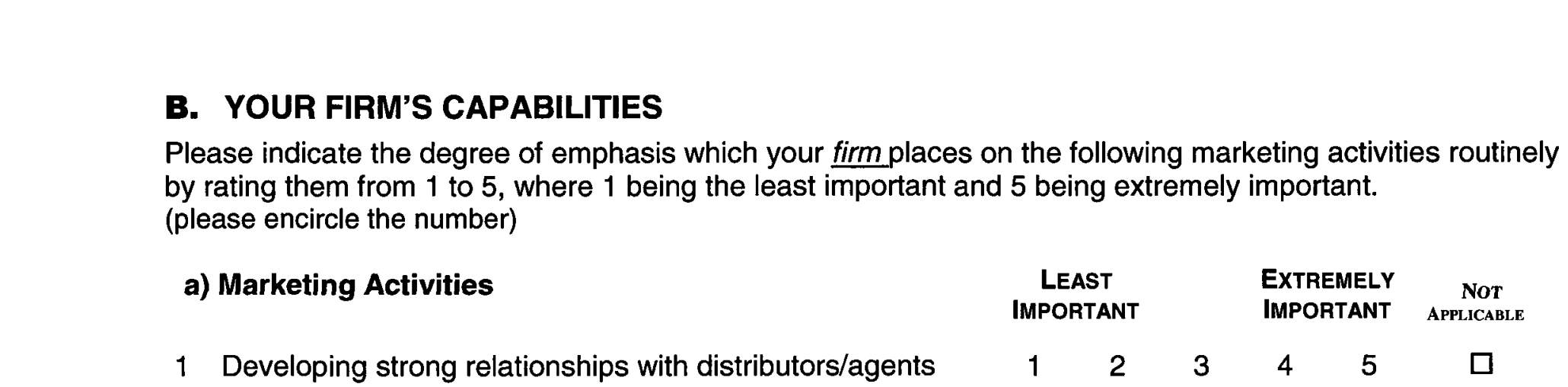

B. YOUR FIRM'S CAPABILITIES
Please indicate the degree of emphasis which your firm places on the following marketing activ
by rating them from 1 to 5 , where 1 being the least important and 5 being extremely important.
(please encircle the number)
$\begin{aligned} & \text { a) Marketing Activities } \\ & \text { LEAST }\end{aligned}$
EXTREMEL
IMPORTAN
IMPORTANT

2 Attracting and retaining the best distributors/agents

3 Developing and executing advertising programs

4 Managing brand image

5 Managing corporate image and reputation

6 Gathering information about customers

7 Gathering information about competitors

8 Using market research skills to develop effective marketing programs

9 Tracking customer wants and needs

10 Making full use of marketing research information

11 Developing marketing planning skills

12 Recognizing the requirements of the customers

13 Understanding the factors influencing customers choice

14 Providing high levels of service support to distributors/agents

Please indicate the degree of emphasis which your firm places on the following manufacturing activities routinely by rating them from 1 to 5 , where 1 being the least important and 5 being extremely important. (please encircle the number)

b) Manufacturing Activities

1 Reducing production costs

2 Reducing overall costs

3 Reducing inventory levels

4 Improving product support services

5 Improving product performance

6 Improving product reliability

7 Meeting product specification

8 Improving product features
B. YOUR FIRM'S CAPABILITIES
Please indicate the degree of emphasis which your firm places on
by rating them from 1 to 5 , where 1 being the least important and 5
(please encircle the number)
a) Marketing Activities
1 Developing strong relationships with distributors/agents

B. YOUR FIRM'S CAPABILITIES
Please indicate the degree of emphasis which your firm places on
by rating them from 1 to 5 , where 1 being the least important and 5
(please encircle the number)
a) Marketing Activities
1 Developing strong relationships with distributors/agents

B. YOUR FIRM'S CAPABILITIES
Please indicate the degree of emphasis which your firm places on
by rating them from 1 to 5 , where 1 being the least important and 5
(please encircle the number)
a) Marketing Activities
1 Developing strong relationships with distributors/agents

B. YOUR FIRM'S CAPABILITIES
Please indicate the degree of emphasis which your firm places on
by rating them from 1 to 5 , where 1 being the least important and 5
(please encircle the number)
a) Marketing Activities
1 Developing strong relationships with distributors/agents

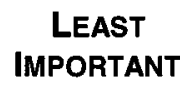

$\begin{array}{lllll}1 & 2 & 3 & 4 & 5\end{array}$

$\begin{array}{lllll}1 & 2 & 3 & 4 & 5\end{array}$

$\begin{array}{lllll}1 & 2 & 3 & 4 & 5\end{array}$

$\begin{array}{lllll}1 & 2 & 3 & 4 & 5\end{array}$

$\begin{array}{lllll}1 & 2 & 3 & 4 & 5\end{array}$

$\begin{array}{lllll}1 & 2 & 3 & 4 & 5\end{array}$

$\begin{array}{lllll}1 & 2 & 3 & 4 & 5\end{array}$

$\begin{array}{lllll}1 & 2 & 3 & 4 & 5\end{array}$

$\begin{array}{lllll}1 & 2 & 3 & 4 & 5\end{array}$

$\begin{array}{lllll}1 & 2 & 3 & 4 & 5\end{array}$

$\begin{array}{lllll}1 & 2 & 3 & 4 & 5\end{array}$

$\begin{array}{lllll}1 & 2 & 3 & 4 & 5\end{array}$

$\begin{array}{lllll}1 & 2 & 3 & 4 & 5\end{array}$

\begin{tabular}{ccccc}
\multicolumn{2}{c}{$\begin{array}{c}\text { LEAST } \\
\text { IMPORTANT }\end{array}$} & \multicolumn{3}{c}{$\begin{array}{c}\text { EXTREMEL } \\
\text { IMPORTANT }\end{array}$} \\
1 & 2 & 3 & 4 & 5 \\
1 & 2 & 3 & 4 & 5 \\
1 & 2 & 3 & 4 & 5 \\
1 & 2 & 3 & 4 & 5 \\
1 & 2 & 3 & 4 & 5 \\
1 & 2 & 3 & 4 & 5 \\
1 & 2 & 3 & 4 & 5 \\
1 & 2 & 3 & 4 & 5
\end{tabular}

NoT
APPLICABLE

$\square$
5
5
5
5
$\square$
$\square$
$\square$
$\square$
$\square$
$\square$
$\square$
$\square$
$\square$
$\square$
$\square$
$\square$

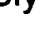


9 Increasing variety of sizes

10 Increasing variety of products

11 Increasing delivery speed

12 Maintaining delivery due date

13 Increasing design innovation

14 Increasing production innovation

$\begin{array}{lllll}1 & 2 & 3 & 4 & 5\end{array}$

$\begin{array}{lllll}1 & 2 & 3 & 4 & 5\end{array}$

$\begin{array}{lllll}1 & 2 & 3 & 4 & 5\end{array}$

$\begin{array}{lllll}1 & 2 & 3 & 4 & 5\end{array}$

$\begin{array}{lllll}1 & 2 & 3 & 4 & 5\end{array}$

$\begin{array}{lllll}1 & 2 & 3 & 4 & 5\end{array}$

\section{c. YOUR FIRM'S POSITIONING STRATEGY}

a) Please indicate the degree of emphasis which your marketing department/firm places on the following aspects of your most important product category while communicating with customers (Please encircle the number).

\section{Least \\ Emphasis}

Most

a. High quality

123

b. Impressive service

c. Low price

123

4

5

d. Price relative to competitors

e. Value to customer

f. Friendliness of staff

g. High durability

h. Product features

i. Product benefits

j. Brand image

k. High reliability

I. Company image

$\mathrm{m}$. Product uniqueness

n. New technology

o. Extra effort to meet customer's requirements

p. Customizing product to meet customer's needs

123

45

45

123

123

45




\section{YOUR FIRM'S MANUFACTURING STRATEGY}

a) Please indicate the degree of emphasis which your manufacturing plant places on the following competitive priorities for your most important product category (please encircle the number).

$$
\text { Least }
$$
a. Product quality
b. Product cost
c. Plant flexibility
d. Product delivery time
e. Product innovation

$\begin{array}{lllll}1 & 2 & 3 & 4 & 5 \\ 1 & 2 & 3 & 4 & 5 \\ 1 & 2 & 3 & 4 & 5 \\ 1 & 2 & 3 & 4 & 5 \\ 1 & 2 & 3 & 4 & 5\end{array}$

b) Now please identify the FOUR MOST IMPORTANT aspects from the ones (above) you have just rated

\section{Rankin}

g Manufacturing Aspect (a. Product Quality, b. Product Cost, c. Plant Flexibility, etc.)

1

2

3

4

\section{E. YOUR INDUSTRY'S ENVIRONMENT}

To what extent do you agree with the following statements? (Please encircle the number)

\section{Strongly Disagree}

1 Competition in our industry is cut-throat.

2 There are many "promotion wars" in our industry

3 Price competition is a hallmark of our industry

4 Our major customers are in a strong bargaining position with us

5 Our products are not much different from those of our competitors

6 We comply with our customers' demands, even if they are unreasonable

7 It is easy for new players to enter our industry

8 New entrants into our industry can expect retaliation from existing firms

9 Competitors outside our industry offer viable substitutes for our products
Strongly

Agree

$\begin{array}{lllll}1 & 2 & 3 & 4 & 5 \\ 1 & 2 & 3 & 4 & 5 \\ 1 & 2 & 3 & 4 & 5 \\ 1 & 2 & 3 & 4 & 5 \\ 1 & 2 & 3 & 4 & 5 \\ 1 & 2 & 3 & 4 & 5 \\ 1 & 2 & 3 & 4 & 5 \\ 1 & 2 & 3 & 4 & 5\end{array}$

$\begin{array}{lllll}1 & 2 & 3 & 4 & 5\end{array}$ 
10 The prices of our products are always under pressure from substitute $\quad \begin{array}{lllll}1 & 2 & 3 & 4 & 5\end{array}$ products

11 We have a large number of suppliers to choose from for our inputs $\quad \begin{array}{lllll}1 & 2 & 3 & 4 & 5\end{array}$ (e.g., raw materials)

12 Our major suppliers have the strength to bargain with us effectively $\quad \begin{array}{lllll}1 & 2 & 3 & 4 & 5\end{array}$

13 Our major suppliers or vendors have the power to dictate prices to us $\quad \begin{array}{lllll}1 & 2 & 3 & 4 & 5\end{array}$

Indicate the change in the following factors over the last 2 years

Slow

Rapid

14 The rate at which products and services become outdated

15 The rate of innovation of new products or service

16 The rate of innovation of new operating processes

17 The rate of change in taste and preferences of customers in your industry

F. YOUR PRODUCT LIFE CYCLE

Which of the following statements best describes the stage of your most important product category? (please encircle the appropriate alphabet)

A INTRODUCTORY - PRIMARY DEMAND FOR THE PRODUCT IS BEGINNING TO GROW. THE MARKET IS NEW, THE TECHNOLOGY AND COMPETITION ARE JUST BEGINNING TO EMERGE.

B GROWTH - PrimARY DEMAND FOR THE PRODUCT IS BEGINNING TO GROW. THE TECHNOLOGY AND COMPETITIVE STRUCTURE OF THE MARKET ARE CHANGING RAPIDLY.

C MATURE - THE PRODUCTS IN THE MARKET ARE FAMILIAR TO A MAJORITY OF PERSPECTIVE CUSTOMERS. THE TECHNOLOGY AND COMPETITIVE STRUCTURE OF THE MARKET ARE FAIRLY STABLE.

D DECLINE - PRODUCTS ARE VIEWED AS COMMODITIES BY A VAST MAJORITY OF CUSTOMERS. WEAKER COMPETITORS ARE BEGINNING TO LEAVE THE MARKET, AND THE STABLE TECHNOLOGY IS ABOUT TO BE SUPERSEDED.

\section{G. YOUR FIRM'S PERFORMANCE}

Compared to your competitors, indicate your performance on the following dimensions in the last two years. (Please encircle the number)

\begin{tabular}{|c|c|c|c|c|c|c|}
\hline & & $\begin{array}{r}\text { SIGNIFICANTLY } \\
\text { LOWER }\end{array}$ & $\begin{array}{l}\text { Lower than our } \\
\text { competitors }\end{array}$ & $\begin{array}{l}\text { Same as our } \\
\text { competitors }\end{array}$ & $\begin{array}{l}\text { Higher than our } \\
\text { competitors }\end{array}$ & $\begin{array}{c}\text { Significantly } \\
\text { Higher }\end{array}$ \\
\hline 1 & Market Share & 1 & 2 & 3 & 4 & 5 \\
\hline 2 & Sales Growth & 1 & 2 & 3 & 4 & 5 \\
\hline 3 & Return on investment & 1 & 2 & 3 & 4 & 5 \\
\hline 4 & Overall Profitability & 1 & 2 & 3 & 4 & 5 \\
\hline 5 & Profit Growth & 1 & 2 & 3 & 4 & 5 \\
\hline 6 & Customer's satisfaction & 1 & 2 & 3 & 4 & 5 \\
\hline 7 & Customer's loyalty & 1 & 2 & 3 & 4 & 5 \\
\hline
\end{tabular}


Other Comments: (your comments will remain confidential and anonymous)

Thank you very much for completing the questionnaire Your contribution is invaluable and we truly appreciate it 


\section{Appendix 4: Convergent Validity-Correlation Matrix of Constructs}

Customer Orientation
\begin{tabular}{|l|c|c|c|}
\hline Item & Cust-Orient-1 & Cust-Orient-2 & Cust-Orient-3 \\
\hline Cust-Orient-1 & 1 & & \\
Cust-Orient-2 & 0.605 & 1 & \\
Cust-Orient-3 & 0.475 & 0.580 & 1 \\
\hline
\end{tabular}

\section{Competitor Orientation}

\begin{tabular}{|l|c|c|c|}
\hline Item & Compt-Orient-1 & Compt-Orient-2 & Mkt-Info-2 \\
\hline Compt-Orient-1 & 1.000 & & \\
Compt-Orient-2 & 0.577 & 1.000 & \\
Mkt-Info-2 & 0.460 & 0.565 & 1.000 \\
\hline
\end{tabular}

Marketing Capability - Customer Requirement
\begin{tabular}{|l|c|c|c|c|}
\hline Item & Mkt-Cust-1 & Mkt-Cust-2 & Mkt-Cust-3 & Mkt-Info-1 \\
\hline Mkt-Cust-1 & 1.000 & & & \\
Mkt-Cust-2 & 0.626 & 1.000 & & \\
Mkt-Cust-3 & 0.511 & 0.741 & 1.000 & \\
Mkt-Info-1 & 0.472 & 0.341 & 0.377 & 1.000 \\
\hline
\end{tabular}

Marketing Capability - Distribution

\begin{tabular}{|l|c|c|c|}
\hline Item & Mkt-Dist-1 & Mkt-Dist-2 & Mkt-Dist-3 \\
\hline Mkt-Dist-1 & 1 & & \\
Mkt-Dist-2 & 0.906 & 1 & \\
Mkt-Dist-3 & 0.759 & 0.785 & 1 \\
\hline
\end{tabular}

Marketing Capability - Communication

\begin{tabular}{|l|c|c|c|}
\hline Item & Mkt-Com-1 & Mkt-Com-2 & Mkt-Com-3 \\
\hline Mkt-Com-1 & 1 & & \\
Mkt-Com-2 & 0.468 & 1 & \\
Mkt-Com-3 & 0.289 & 0.505 & 1 \\
\hline
\end{tabular}

Marketing Capability - Planning

\begin{tabular}{|l|r|r|r|}
\hline Item & Mkt-Plan-1 & Mkt-Plan-2 & \multicolumn{1}{|c|}{ Mkt-Info-3 } \\
\hline Mkt-Plan-1 & 1.000 & & \\
Mkt-Plan-2 & 0.721 & 1.000 & \\
Mkt-Info-3 & 0.667 & 0.685 & 1.000 \\
\hline
\end{tabular}

Resource Orientation

\begin{tabular}{|l|c|c|c|}
\hline Item & Res-Orient-1 & Res-Orient-2 & Res-Orient-3 \\
\hline Res-Orient-1 & 1 & & \\
Res-Orient-2 & 0.475 & 1 & \\
Res-Orient-3 & 0.408 & 0.308 & 1 \\
\hline
\end{tabular}


Market Orientation

\begin{tabular}{|l|c|c|}
\hline Item & Mkt-Orient-4 & Mkt-Orient-5 \\
\hline Mkt-Orient-4 & 1 & \\
Mkt-Orient-5 & 0.690 & 1 \\
\hline
\end{tabular}

Manufacturing Capability - Cost

\begin{tabular}{|l|c|c|c|}
\hline Item & Man-Cost-1 & Man-Cost-2 & Man-Cost-3 \\
\hline Man-Cost-1 & 1 & & \\
Man-Cost-2 & 0.813 & 1 & \\
Man-Cost-3 & 0.382 & 0.330 & 1 \\
\hline
\end{tabular}

Manufacturing Capability - Quality
\begin{tabular}{|l|c|c|c|c|c|}
\hline Item & Man-Quality-1 & Man-Quality-2 & Man-Quality-3 & Man-Quality-5 & Man-Innov-1 \\
\hline Man-Quality-1 & 1.000 & & & & \\
Man-Quality-2 & 0.527 & 1.000 & & & \\
Man-Quality-3 & 0.445 & 0.751 & 1.000 & & \\
Man-Quality-5 & 0.345 & 0.547 & 0.479 & 1.000 & 1.000 \\
Man-Innov-1 & 0.265 & 0.528 & 0.420 & 0.611 & \\
\hline
\end{tabular}

Manufacturing Capability - Delivery

\begin{tabular}{|l|c|c|}
\hline Item & Man-Del-1 & Man-Del-2 \\
\hline Man-Del-1 & 1.000 & \\
Man-Del-2 & 0.481 & 1.000 \\
\hline
\end{tabular}

Manufacturing Capability - Flexibility

\begin{tabular}{|l|c|c|}
\hline Item & Man-Flex-1 & Man-Fex-2 \\
\hline Man-Flex-1 & 1 & \\
Man-Fex-2 & 0.614 & 1 \\
\hline
\end{tabular}

\section{Environmental Dynamism}

\begin{tabular}{|l|c|c|c|c|}
\hline Item & Env-Dynamism-1 & Env-Dynamism-2 & Env-Dynamism-3 & Env-Dynamism-4 \\
\hline Env-Dynamism-1 & 1 & & & \\
Env-Dynamism-2 & 0.656 & 1 & & \\
Env-Dynamism-3 & 0.311 & 0.477 & 0.439 & 1 \\
Env-Dynamism-4 & 0.383 & 0.470 & \\
\hline
\end{tabular}

Innovation Orientation

\begin{tabular}{|l|c|c|c|c|c|c|}
\hline Item & $\begin{array}{c}\text { Innov-Type- } \\
1\end{array}$ & $\begin{array}{c}\text { Innov- } \\
\text { Type-2 }\end{array}$ & $\begin{array}{c}\text { Innov- } \\
\text { Orient-1 }\end{array}$ & $\begin{array}{c}\text { Innov- } \\
\text { Orient-2 }\end{array}$ & $\begin{array}{c}\text { Innov- } \\
\text { Orient-3 }\end{array}$ & $\begin{array}{c}\text { Innov- } \\
\text { Orient-4 }\end{array}$ \\
\hline Innov-Type-1 & 1 & & & & & \\
Innov-Type-2 & 0.854 & 1 & & & \\
Innov-Orient-1 & 0.568 & 0.611 & 1 & & \\
Innov-Orient-2 & 0.642 & 0.676 & 0.783 & 1 & & \\
Innov-Orient-3 & 0.661 & 0.687 & 0.692 & 0.793 & 1 \\
Innov-Orient-4 & 0.467 & 0.488 & 0.575 & 0.657 & 0.616 & 1 \\
\hline
\end{tabular}


PS - Customization

\begin{tabular}{|l|c|c|}
\hline Item & PS-Customization-1 & $\begin{array}{c}\text { PS-Customization- } \\
2\end{array}$ \\
\hline $\begin{array}{l}\text { PS-Customization-1 } \\
\text { PS-Customization-2 }\end{array}$ & 1 & 1 \\
\hline
\end{tabular}

PS - Customer Focus

\begin{tabular}{|l|c|c|}
\hline Item & PS-Differentiation-1 & $\begin{array}{c}\text { PS-Differentiation- } \\
2\end{array}$ \\
\hline PS-Differentiation-1 & 1 & \\
PS-Differentiation-2 & 0.790 & 1 \\
\hline
\end{tabular}

\section{PS - Product Focus}

\begin{tabular}{|l|c|c|}
\hline PS-Differentiation-3 & 1 & \\
PS-Differentiation-4 & 0.520 & 1 \\
\hline
\end{tabular}

PS - Innovation
\begin{tabular}{|l|c|c|}
\hline Item & PS-Innovation-1 & PS-Innovation-2 \\
\hline PS-Innovation-1 & 1 & \\
PS-Innovation-2 & 0.606 & 1 \\
\hline
\end{tabular}

PS - Quality
\begin{tabular}{|l|r|r|r|}
\hline Item & PS-Quality & PS-Reliability-1 & PS-Reliability-2 \\
\hline PS-Quality & 1 & & \\
PS-Reliability-1 & 0.437 & 1 & \\
PS-Reliability-2 & 0.437 & 0.604 & 1 \\
\hline
\end{tabular}

PS - Price
\begin{tabular}{|l|c|c|}
\hline Item & PS-Value-1 & PS-Value-2 \\
\hline PS-Value-1 & 1 & \\
PS-Value-2 & 0.631 & 1 \\
\hline
\end{tabular}

Performance - Financial
\begin{tabular}{|l|c|c|c|c|c|}
\hline Item & $\begin{array}{c}\text { OP-Market } \\
\text { Share }\end{array}$ & $\begin{array}{c}\text { OP-Sales } \\
\text { Growth }\end{array}$ & OP-ROI & $\begin{array}{c}\text { OP-Overall } \\
\text { Profit }\end{array}$ & $\begin{array}{c}\text { OP-Profit } \\
\text { Growth }\end{array}$ \\
\hline OP-Market Share & 1 & & & & \\
OP-Sales Growth & 0.534 & 1 & & & \\
OP-ROI & 0.439 & 0.483 & 1 & 1 & \\
OP-Overall Profit & 0.397 & 0.432 & 0.805 & 0.792 & 1 \\
OP-Profit Growth & 0.397 & 0.514 & 0.740 & & 1 \\
\hline
\end{tabular}

Performance - Non Financial

\begin{tabular}{|l|c|c|}
\hline Item & OP-Cust-Satisfaction & OP-Cust-Loyalty \\
\hline $\begin{array}{l}\text { OP-Cust-Satisfaction } \\
\text { OP-Cust-Loyalty }\end{array}$ & 1 & \\
\hline
\end{tabular}


Competitive Rivalry

\begin{tabular}{|l|c|c|c|}
\hline Item & Indus-Rival-1 & Indus-Rival-2 & Indus-Rival-3 \\
\hline Indus-Rival-1 & 1 & & \\
Indus-Rival-2 & 0.396 & 1 & \\
Indus-Rival-3 & 0.573 & 0.461 & 1 \\
\hline
\end{tabular}

Threat of Substitutes

\begin{tabular}{|l|c|c|}
\hline Item & Indus-Substitu-1 & Indus-Substitu-2 \\
\hline Indus-Substitu-1 & 1 & \\
Indus-Substitu-2 & 0.479 & 1 \\
\hline
\end{tabular}

Supplier Power
\begin{tabular}{|l|c|c|}
\hline Item & Indus-S.Power-2 & Indus-S.Power-3 \\
\hline Indus-S.Power-2 & 1 & \\
Indus-S.Power-3 & 0.601 & 1 \\
\hline
\end{tabular}




\section{Appendix 5: Significant differences between small and large \& medium firms}

\begin{tabular}{|c|c|c|c|c|c|c|c|c|c|}
\hline \multicolumn{10}{|c|}{ Independent Samples Test } \\
\hline & \multicolumn{2}{|c|}{$\begin{array}{c}\text { Levene's Test } \\
\text { for Equality of } \\
\text { Variances } \\
\end{array}$} & \multicolumn{7}{|c|}{ t-test for Equality of Means } \\
\hline & \multirow[b]{2}{*}{$\mathrm{F}$} & \multirow[b]{2}{*}{ Sig. } & \multirow[b]{2}{*}{$t$} & \multirow[b]{2}{*}{ df } & \multirow{2}{*}{$\begin{array}{l}\text { Sig. } \\
(2- \\
\text { tailed) }\end{array}$} & \multirow{2}{*}{$\begin{array}{c}\text { Mean } \\
\text { Difference }\end{array}$} & \multirow{2}{*}{$\begin{array}{l}\text { Std. Error } \\
\text { Difference }\end{array}$} & \multicolumn{2}{|c|}{$\begin{array}{l}95 \% \text { Confidence } \\
\text { Interval of the } \\
\text { Difference }\end{array}$} \\
\hline & & & & & & & & Lower & Upper \\
\hline $\begin{array}{l}\text { customer } \\
\text { orientation }\end{array}$ & 0.468 & 0.495 & 1.609 & 192 & 0.109 & 0.1783 & 0.11080 & 0.04022 & 0.39684 \\
\hline & & & 1.494 & 59.550 & 0.141 & 0.1783 & 0.11937 & $0.06050^{-}$ & 0.41712 \\
\hline \multirow[t]{2}{*}{$\begin{array}{l}\text { competitor } \\
\text { orientation }\end{array}$} & 0.945 & 0.332 & $0.350^{-}$ & 187 & 0.726 & -0.0516 & 0.14719 & 0.34195 & 0.23877 \\
\hline & & & $0.382^{-}$ & 75.905 & 0.704 & -0.0516 & 0.13507 & 0.32062 & 0.21744 \\
\hline \multirow[t]{2}{*}{$\begin{array}{l}\text { mkt cpblty - } \\
\text { distribution }\end{array}$} & 7.685 & 0.006 & 2.542 & 175 & 0.012 & 0.5252 & 0.20663 & 0.11744 & 0.93304 \\
\hline & & & 2.178 & 49.305 & 0.034 & 0.5252 & 0.24114 & 0.04074 & 1.00975 \\
\hline \multirow[t]{2}{*}{$\begin{array}{l}\text { mkt cpblty - } \\
\text { communication }\end{array}$} & 0.095 & 0.758 & 1.253 & 188 & 0.212 & 0.1848 & 0.14752 & $0.10622^{-}$ & 0.47578 \\
\hline & & & 1.301 & 67.259 & 0.198 & 0.1848 & 0.14208 & 0.09879 & 0.46836 \\
\hline \multirow[t]{2}{*}{$\begin{array}{l}\text { mkt cpblty - } \\
\text { information }\end{array}$} & 2.442 & 0.120 & 0.684 & 192 & 0.495 & -0.0920 & 0.13449 & 0.35726 & 0.17326 \\
\hline & & & 0.765 & 77.951 & 0.447 & -0.0920 & 0.12031 & 0.33152 & 0.14752 \\
\hline \multirow{2}{*}{$\begin{array}{l}\text { mkt cpblty - } \\
\text { customer } \\
\text { requirement }\end{array}$} & 0.000 & 0.998 & 0.663 & 192 & 0.508 & 0.0782 & 0.11793 & 0.15439 & 0.31082 \\
\hline & & & 0.703 & 71.279 & 0.484 & 0.0782 & 0.11128 & 0.14365 & 0.30009 \\
\hline \multirow[t]{2}{*}{$\begin{array}{l}\text { environmental } \\
\text { dynamism }\end{array}$} & 3.861 & 0.051 & 0.766 & 191 & 0.445 & -0.1077 & 0.14062 & 0.38503 & 0.16972 \\
\hline & & & 0.875 & 81.442 & 0.384 & -0.1077 & 0.12309 & $0.35255^{-}$ & 0.13724 \\
\hline \multirow{2}{*}{$\begin{array}{l}\text { innovation } \\
\text { orientation \& } \\
\text { type }\end{array}$} & 2.213 & 0.138 & 0.817 & 188 & 0.415 & 0.1337 & 0.16362 & 0.18904 & 0.45648 \\
\hline & & & 0.888 & 69.389 & 0.377 & 0.1337 & 0.15051 & 0.16651 & 0.43395 \\
\hline \multirow[t]{2}{*}{$\begin{array}{l}\text { performance } \\
\text { financial }\end{array}$} & 3.484 & 0.063 & $4.363^{-}$ & 192 & 0.000 & -0.5821 & 0.13343 & 0.84532 & 0.31896 \\
\hline & & & 5.057 & 83.392 & 0.000 & -0.5821 & 0.11511 & $0.81107^{-}$ & 0.35321 \\
\hline \multirow[t]{2}{*}{$\begin{array}{l}\text { performance } \\
\text { nonfinancial }\end{array}$} & 0.537 & 0.465 & 0.378 & 192 & 0.706 & -0.0428 & 0.11321 & 0.26605 & 0.18052 \\
\hline & & & $0.397^{-}$ & 70.440 & 0.692 & -0.0428 & 0.10763 & 0.25741 & 0.17188 \\
\hline
\end{tabular}




\begin{tabular}{|c|c|c|c|c|c|c|c|c|c|}
\hline \multirow[t]{2}{*}{$\begin{array}{l}\text { ps - customer } \\
\text { focus }\end{array}$} & \multirow[t]{2}{*}{5.275} & \multirow[t]{2}{*}{0.023} & \multirow{2}{*}{$\begin{array}{r}0.180 \\
- \\
0.218\end{array}$} & 192 & 0.857 & -0.0246 & 0.13663 & 0.29408 & \multirow{2}{*}{$\begin{array}{l}0.24490 \\
0.19902\end{array}$} \\
\hline & & & & 91.554 & 0.828 & -0.0246 & 0.11258 & 0.24821 & \\
\hline $\begin{array}{l}\text { ps - product } \\
\text { focus }\end{array}$ & 5.723 & 0.018 & 3.446 & 192 & 0.001 & 0.5211 & 0.15124 & 0.22284 & 0.81945 \\
\hline & & & 2.940 & 54.503 & 0.005 & 0.5211 & 0.17725 & 0.16586 & 0.87644 \\
\hline \multirow[t]{2}{*}{ ps - brand focus } & 0.081 & 0.776 & 0.193 & 192 & 0.848 & 0.0302 & 0.15705 & 0.27953 & 0.33999 \\
\hline & & & 0.200 & 68.973 & 0.842 & 0.0302 & 0.15139 & $0.27179^{-}$ & 0.33226 \\
\hline \multirow[t]{2}{*}{ ps - innovation } & 0.073 & 0.788 & 2.631 & 192 & 0.009 & 0.4513 & 0.17152 & 0.11298 & 0.78959 \\
\hline & & & 2.535 & 62.311 & 0.014 & 0.4513 & 0.17799 & 0.09551 & 0.80705 \\
\hline \multirow[t]{2}{*}{ ps - quality } & 0.007 & 0.933 & 0.858 & 192 & 0.392 & 0.0962 & 0.11210 & 0.12494 & 0.31729 \\
\hline & & & 0.892 & 69.220 & 0.375 & 0.0962 & 0.10781 & 0.11889 & 0.31124 \\
\hline \multirow[t]{2}{*}{ ps - service } & 0.137 & 0.712 & 1.558 & 192 & 0.121 & 0.2823 & 0.18119 & 0.07511 & 0.63965 \\
\hline & & & 1.617 & 69.034 & 0.110 & 0.2823 & 0.17456 & 0.06597 & 0.63051 \\
\hline \multirow[t]{2}{*}{ ps - price } & 2.247 & 0.136 & 0.977 & 192 & 0.330 & 0.1764 & 0.18057 & 0.17978 & 0.53253 \\
\hline & & & 1.052 & 73.152 & 0.296 & 0.1764 & 0.16766 & $0.15775^{\circ}$ & 0.51050 \\
\hline \multirow[t]{2}{*}{ ps - value } & 1.858 & 0.174 & $1.147^{-}$ & 192 & 0.253 & -0.1413 & 0.12313 & 0.38416 & 0.10158 \\
\hline & & & 1.303 & 80.210 & 0.196 & -0.1413 & 0.10843 & 0.35707 & 0.07449 \\
\hline \multirow[t]{2}{*}{$\begin{array}{l}\text { man cpblty - } \\
\text { cost }\end{array}$} & 3.898 & 0.050 & 3.370 & 190 & 0.001 & -0.4599 & 0.13647 & 0.72904 & 0.19068 \\
\hline & & & $4.050^{-}$ & 86.428 & 0.000 & -0.4599 & 0.11354 & 0.68555 & 0.23417 \\
\hline \multirow[t]{2}{*}{$\begin{array}{l}\text { man cpblty - } \\
\text { quality }\end{array}$} & 0.826 & 0.365 & 0.139 & 191 & 0.890 & 0.0175 & 0.12645 & 0.23189 & 0.26693 \\
\hline & & & 0.156 & 76.041 & 0.876 & 0.0175 & 0.11225 & 0.20604 & 0.24108 \\
\hline \multirow[t]{2}{*}{$\begin{array}{l}\text { man cpblty - } \\
\text { flexibility }\end{array}$} & 0.590 & 0.443 & 2.495 & 172 & 0.014 & 0.5082 & 0.20373 & 0.10608 & 0.91036 \\
\hline & & & 2.669 & 57.443 & 0.010 & 0.5082 & 0.19039 & 0.12704 & 0.88941 \\
\hline \multirow[t]{2}{*}{$\begin{array}{l}\text { man cpblty - } \\
\text { delivery }\end{array}$} & 1.105 & 0.294 & 0.018 & 188 & 0.986 & -0.0031 & 0.17687 & 0.35202 & 0.34580 \\
\hline & & & 0.019 & 70.020 & 0.985 & -0.0031 & 0.16597 & 0.33412 & 0.32790 \\
\hline \multirow[t]{2}{*}{$\begin{array}{l}\text { man cpblty - } \\
\text { innovation }\end{array}$} & 0.007 & 0.934 & 0.545 & 185 & 0.586 & 0.0832 & 0.15250 & 0.21770 & 0.38403 \\
\hline & & & 0.558 & 63.880 & 0.579 & 0.0832 & 0.14906 & 0.21463 & 0.38096 \\
\hline $\begin{array}{l}\text { resource } \\
\text { orientation }\end{array}$ & 0.917 & 0.339 & 0.623 & 192 & 0.534 & 0.0771 & 0.12369 & 0.16685 & 0.32109 \\
\hline
\end{tabular}




\begin{tabular}{|c|c|c|c|c|c|c|c|c|c|}
\hline \multirow[b]{2}{*}{ mkt orientation } & \multirow[b]{2}{*}{0.316} & \multirow[b]{2}{*}{0.575} & 0.658 & 70.876 & 0.512 & 0.0771 & 0.11714 & & 0.31069 \\
\hline & & & 1.681 & 186 & 0.094 & -0.2546 & 0.15146 & 0.55337 & 0.04424 \\
\hline & & & $1.631^{\circ}$ & 63.713 & 0.108 & -0.2546 & 0.15607 & 0.56637 & 0.05724 \\
\hline $\begin{array}{l}\text { industry } \\
\text { competitiveness }\end{array}$ & 5.806 & 0.017 & $0.254^{-}$ & 192 & 0.800 & -0.0393 & 0.15484 & 0.34468 & 0.26615 \\
\hline & & & 0.313 & 94.665 & 0.755 & -0.0393 & 0.12564 & 0.28871 & 0.21018 \\
\hline $\begin{array}{l}\text { industry } \\
\text { substitutability }\end{array}$ & 0.232 & 0.631 & 1.434 & 192 & 0.153 & 0.2433 & 0.16968 & 0.09142 & 0.57794 \\
\hline & & & 1.442 & 65.946 & 0.154 & 0.2433 & 0.16873 & 0.09361 & 0.58014 \\
\hline $\begin{array}{l}\text { industry supplier } \\
\text { power }\end{array}$ & 0.159 & 0.690 & 0.118 & 192 & 0.906 & -0.0188 & 0.15932 & 0.33303 & 0.29544 \\
\hline & & & 0.123 & 69.716 & 0.902 & -0.0188 & 0.15250 & 0.32296 & 0.28537 \\
\hline
\end{tabular}




\section{Appendix 6: Significant differences between Canadian and foreign firms}

\begin{tabular}{|c|c|c|c|c|c|c|c|c|c|}
\hline \multicolumn{10}{|c|}{ Independent Samples Test } \\
\hline & \multicolumn{2}{|c|}{$\begin{array}{l}\text { Levene's Test } \\
\text { for Equality of } \\
\text { Variances }\end{array}$} & \multicolumn{7}{|c|}{ t-test for Equality of Means } \\
\hline & \multirow[b]{2}{*}{$\mathrm{F}$} & \multirow[b]{2}{*}{ Sig. } & \multirow[b]{2}{*}{$t$} & \multirow[b]{2}{*}{ df } & \multirow{2}{*}{$\begin{array}{l}\text { Sig. } \\
(2- \\
\text { tailed) }\end{array}$} & \multirow{2}{*}{$\begin{array}{c}\text { Mean } \\
\text { Difference }\end{array}$} & \multirow{2}{*}{$\begin{array}{l}\text { Std. Error } \\
\text { Difference }\end{array}$} & \multicolumn{2}{|c|}{$\begin{array}{l}95 \% \text { Confidence } \\
\text { Interval of the } \\
\text { Difference }\end{array}$} \\
\hline & & & & & & & & Lower & Upper \\
\hline $\begin{array}{l}\text { customer } \\
\text { orientation }\end{array}$ & 3.728 & 0.055 & 1.514 & 192 & 0.132 & 0.1743 & 0.11507 & 0.05270 & 0.40121 \\
\hline & & & 1.796 & 72.416 & 0.077 & 0.1743 & 0.09704 & $0.01918^{-}$ & 0.36769 \\
\hline \multirow[t]{2}{*}{$\begin{array}{l}\text { competitor } \\
\text { orientation }\end{array}$} & 4.189 & 0.042 & 1.244 & 187 & 0.215 & 0.1892 & 0.15210 & $0.11081^{-}$ & 0.48928 \\
\hline & & & 1.420 & 69.134 & 0.160 & 0.1892 & 0.13326 & $0.07660^{-}$ & 0.45507 \\
\hline \multirow[t]{2}{*}{$\begin{array}{l}\text { mkt cpblty - } \\
\text { distribution }\end{array}$} & 2.427 & 0.121 & 1.881 & 175 & 0.062 & 0.3997 & 0.21250 & 0.01966 & 0.81911 \\
\hline & & & 1.718 & 48.989 & 0.092 & 0.3997 & 0.23260 & 0.06771 & 0.86716 \\
\hline \multirow[t]{2}{*}{$\begin{array}{l}\text { mkt cpblty - } \\
\text { communication }\end{array}$} & 0.855 & 0.356 & 0.494 & 188 & 0.622 & 0.0760 & 0.15378 & 0.22737 & 0.37935 \\
\hline & & & 0.560 & 64.935 & 0.578 & 0.0760 & 0.13581 & $0.19525^{-}$ & 0.34722 \\
\hline \multirow[t]{2}{*}{$\begin{array}{l}\text { mkt cpblty - } \\
\text { information }\end{array}$} & 5.849 & 0.017 & 0.311 & 192 & 0.756 & -0.0434 & 0.13970 & 0.31895 & 0.23213 \\
\hline & & & 0.375 & 74.884 & 0.709 & -0.0434 & 0.11567 & 0.27384 & 0.18702 \\
\hline \multirow{2}{*}{$\begin{array}{l}\text { mkt cpblty - } \\
\text { customer } \\
\text { requirement }\end{array}$} & 1.353 & 0.246 & 0.831 & 192 & 0.407 & 0.1017 & 0.12230 & 0.13957 & 0.34290 \\
\hline & & & 0.956 & 68.757 & 0.342 & 0.1017 & 0.10631 & 0.11043 & 0.31376 \\
\hline \multirow[t]{2}{*}{$\begin{array}{l}\text { environmental } \\
\text { dynamism }\end{array}$} & 1.929 & 0.167 & 0.411 & 191 & 0.682 & -0.0600 & 0.14608 & 0.34815 & 0.22812 \\
\hline & & & 0.452 & 64.237 & 0.653 & -0.0600 & 0.13286 & 0.32541 & 0.20538 \\
\hline \multirow[t]{2}{*}{$\begin{array}{l}\text { innovation } \\
\text { orientation \& } \\
\text { type }\end{array}$} & 8.758 & 0.003 & 0.437 & 188 & 0.662 & 0.0730 & 0.16697 & 0.25635 & 0.40240 \\
\hline & & & 0.552 & 83.108 & 0.583 & 0.0730 & 0.13241 & 0.19033 & 0.33638 \\
\hline \multirow[t]{2}{*}{$\begin{array}{l}\text { performance } \\
\text { financial }\end{array}$} & 7.085 & 0.008 & 3.379 & 192 & 0.001 & -0.4765 & 0.14104 & 0.75470 & 0.19834 \\
\hline & & & $4.270^{\circ}$ & 81.830 & 0.000 & -0.4765 & 0.11161 & 0.69855 & 0.25448 \\
\hline \multirow[t]{2}{*}{$\begin{array}{l}\text { performance } \\
\text { nonfinancial }\end{array}$} & 1.235 & 0.268 & 0.760 & 192 & 0.448 & 0.0892 & 0.11735 & 0.14222 & 0.32069 \\
\hline & & & 0.860 & 66.890 & 0.393 & 0.0892 & 0.10374 & 0.11784 & 0.29632 \\
\hline
\end{tabular}




\begin{tabular}{|c|c|c|c|c|c|c|c|c|c|}
\hline \multirow[t]{2}{*}{$\begin{array}{l}\text { ps - customer } \\
\text { focus }\end{array}$} & \multirow[t]{2}{*}{7.447} & \multirow[t]{2}{*}{0.007} & \multirow{2}{*}{$\begin{array}{r}0.675 \\
0 \\
0.904\end{array}$} & \multirow{2}{*}{$\begin{array}{r}192 \\
92.839\end{array}$} & \multirow{2}{*}{$\begin{array}{l}0.500 \\
0.368\end{array}$} & \multirow{2}{*}{$\begin{array}{l}-0.0956 \\
-0.0956\end{array}$} & \multirow{2}{*}{$\begin{array}{l}0.14163 \\
0.10583\end{array}$} & \multirow{2}{*}{$\begin{array}{r}0.37500 \\
- \\
0.30581\end{array}$} & 0.18371 \\
\hline & & & & & & & & & 0.11452 \\
\hline $\begin{array}{l}\text { ps - product } \\
\text { focus }\end{array}$ & 0.598 & 0.440 & 0.727 & 192 & 0.468 & 0.1174 & 0.16151 & $0.2011 \overline{-}$ & 0.43596 \\
\hline & & & 0.825 & 67.284 & 0.412 & 0.1174 & 0.14226 & 0.16652 & 0.40134 \\
\hline \multirow[t]{2}{*}{ ps - brand focus } & 1.998 & 0.159 & 0.628 & 192 & 0.531 & -0.1022 & 0.16282 & 0.42338 & 0.21893 \\
\hline & & & 0.704 & 65.986 & 0.484 & -0.1022 & 0.14520 & 0.39212 & 0.18767 \\
\hline \multirow[t]{2}{*}{ ps - innovation } & 0.851 & 0.357 & 1.254 & 192 & 0.211 & 0.2262 & 0.18044 & $0.12968^{-}$ & 0.58211 \\
\hline & & & 1.307 & 59.465 & 0.196 & 0.2262 & 0.17302 & 0.11994 & 0.57237 \\
\hline \multirow{2}{*}{ ps - quality } & 3.807 & 0.052 & 0.550 & 192 & 0.583 & 0.0641 & 0.11647 & 0.16562 & 0.29382 \\
\hline & & & 0.672 & 76.453 & 0.504 & 0.0641 & 0.09538 & 0.12584 & 0.25404 \\
\hline \multirow[t]{2}{*}{ ps - service } & 0.005 & 0.943 & 2.266 & 192 & 0.025 & 0.4231 & 0.18673 & 0.05476 & 0.79139 \\
\hline & & & 2.309 & 57.729 & 0.025 & 0.4231 & 0.18325 & 0.05622 & 0.78993 \\
\hline \multirow[t]{2}{*}{ ps - price } & 3.783 & 0.053 & 1.365 & 192 & 0.174 & 0.2552 & 0.18695 & $0.11350^{-}$ & 0.62396 \\
\hline & & & 1.593 & 70.451 & 0.116 & 0.2552 & 0.16017 & $0.0641 \overline{8}^{-}$ & 0.57464 \\
\hline \multirow{2}{*}{ ps - value } & 0.086 & 0.770 & 0.150 & 192 & 0.881 & -0.0192 & 0.12821 & $0.27212^{-}$ & 0.23365 \\
\hline & & & $0.160^{\circ}$ & 61.527 & 0.873 & -0.0192 & 0.11988 & 0.25891 & 0.22045 \\
\hline \multirow[t]{2}{*}{$\begin{array}{l}\operatorname{man} \text { cpbity - } \\
\text { cost }\end{array}$} & 2.893 & 0.091 & 3.223 & 190 & 0.001 & -0.4581 & 0.14213 & 0.73842 & $0.17771^{-}$ \\
\hline & & & $3.858^{-}$ & 70.748 & 0.000 & -0.4581 & 0.11873 & 0.69482 & 0.22131 \\
\hline \multirow[t]{2}{*}{$\begin{array}{l}\text { man cpblty - } \\
\text { quality }\end{array}$} & 0.000 & 0.988 & 0.110 & 191 & 0.912 & -0.0145 & 0.13139 & 0.27363 & 0.24470 \\
\hline & & & $0.107^{-}$ & 52.856 & 0.915 & -0.0145 & 0.13479 & 0.28484 & 0.25591 \\
\hline \multirow[t]{2}{*}{$\begin{array}{l}\text { man cpblty - } \\
\text { flexibility }\end{array}$} & 2.156 & 0.144 & 2.677 & 172 & 0.008 & 0.5440 & 0.20320 & 0.14291 & 0.94507 \\
\hline & & & 2.984 & 61.107 & 0.004 & 0.5440 & 0.18233 & 0.17942 & 0.90856 \\
\hline \multirow[t]{2}{*}{$\begin{array}{l}\text { man cpblty - } \\
\text { delivery }\end{array}$} & 2.057 & 0.153 & 0.494 & 188 & 0.622 & -0.0906 & 0.18362 & 0.45284 & 0.27160 \\
\hline & & & $0.53 \overline{6}^{-}$ & 60.912 & 0.594 & -0.0906 & 0.16919 & $0.42895^{\circ}$ & 0.24771 \\
\hline \multirow[t]{2}{*}{$\begin{array}{l}\text { man cpblty - } \\
\text { innovation }\end{array}$} & 0.378 & 0.540 & 0.337 & 185 & 0.737 & 0.0534 & 0.15869 & 0.25962 & 0.36651 \\
\hline & & & 0.357 & 56.977 & 0.722 & 0.0534 & 0.14967 & 0.24627 & 0.35315 \\
\hline $\begin{array}{l}\text { resource } \\
\text { orientation }\end{array}$ & 3.927 & 0.049 & 0.491 & 192 & 0.624 & -0.0630 & 0.12841 & 0.31631 & 0.19024 \\
\hline
\end{tabular}




\begin{tabular}{|c|c|c|c|c|c|c|c|c|c|}
\hline \multirow[b]{2}{*}{ mkt orientation } & \multirow[b]{2}{*}{3.502} & \multirow[b]{2}{*}{0.063} & 0561 & 67.967 & 0.577 & -0.0630 & 0.11241 & 201 & 0.16127 \\
\hline & & & $1.540^{-}$ & 186 & 0.125 & -0.2423 & 0.15729 & $0.55257^{-}$ & 0.06801 \\
\hline & & & $1.840^{\circ}$ & 75.327 & 0.070 & -0.2423 & 0.13165 & 0.50452 & 0.01996 \\
\hline $\begin{array}{l}\text { industry } \\
\text { competitiveness }\end{array}$ & 0.648 & 0.422 & 0.746 & 192 & 0.457 & 0.1197 & 0.16048 & 0.19688 & 0.43619 \\
\hline & & & 0.793 & 61.047 & 0.431 & 0.1197 & 0.15091 & 0.18209 & 0.42141 \\
\hline $\begin{array}{l}\text { industry } \\
\text { substitutability }\end{array}$ & 0.071 & 0.790 & 0.023 & 192 & 0.982 & 0.0040 & 0.17703 & $0.34512^{-}$ & 0.35322 \\
\hline & & & 0.023 & 57.849 & 0.981 & 0.0040 & 0.17344 & 0.34314 & 0.35124 \\
\hline $\begin{array}{l}\text { industry supplier } \\
\text { power }\end{array}$ & 0.543 & 0.462 & 0.526 & 192 & 0.600 & 0.0869 & 0.16522 & 0.23900 & 0.41275 \\
\hline & & & 0.489 & 52.104 & 0.627 & 0.0869 & 0.17768 & 0.26966 & 0.44341 \\
\hline
\end{tabular}




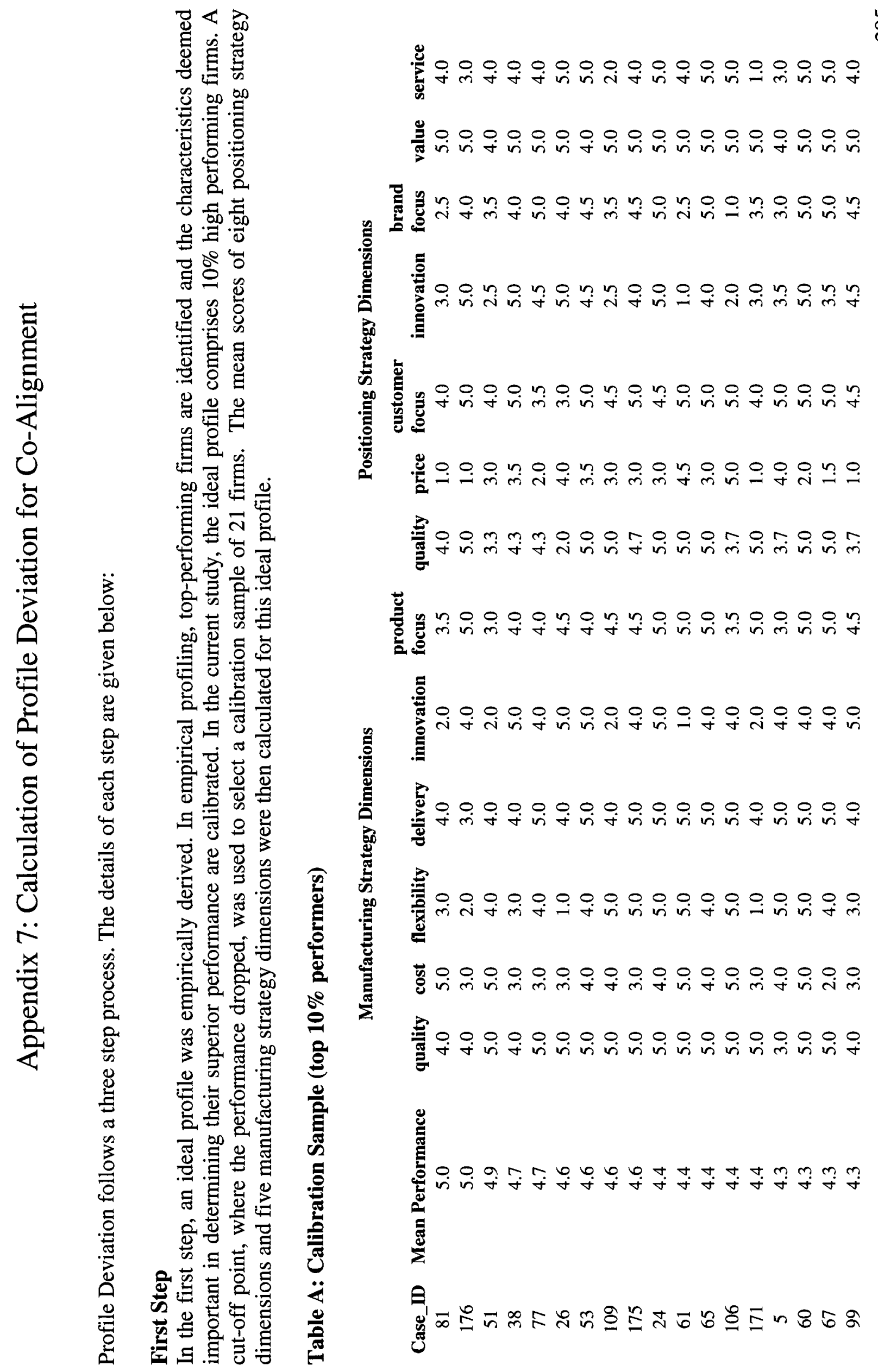




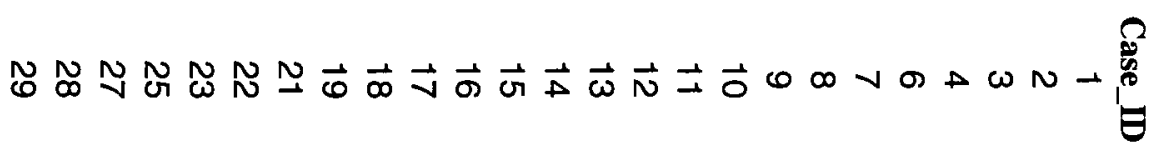

$\sqcap \omega \omega N \omega \omega \omega \omega \omega \omega \omega N \omega \omega \omega \omega \omega \omega \omega \sqcap \omega \omega N \omega \uparrow$

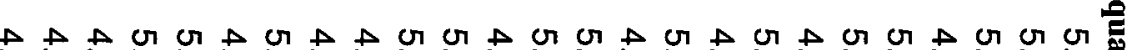

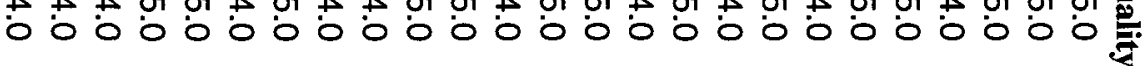

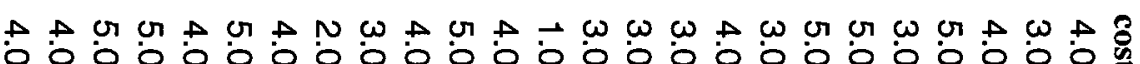

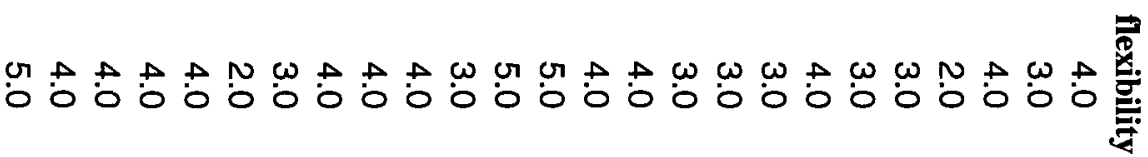

io

$\underset{\omega}{\omega} \stackrel{\oplus}{\oplus} \stackrel{+}{0}$

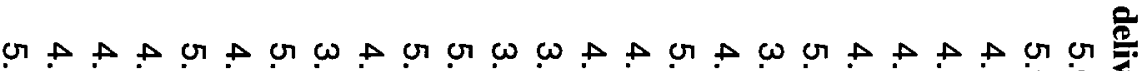

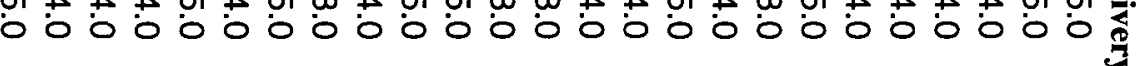

$\omega \neq+\omega \neq \omega \omega \omega \omega+\omega N$ or $\omega \omega \neq+\neq \omega \omega \omega \neq+N \omega$

ir ur ir

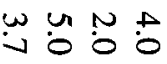

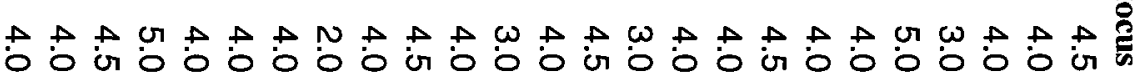

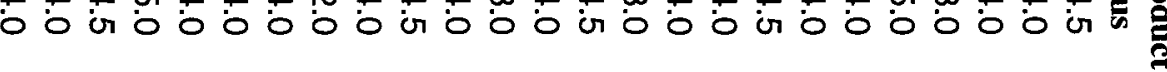

$\stackrel{\leftrightarrow}{\omega} \stackrel{N}{0} \ddot{0}$

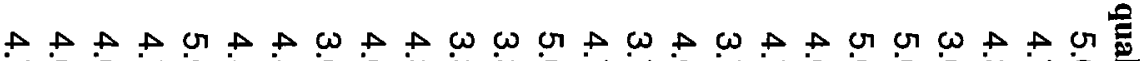

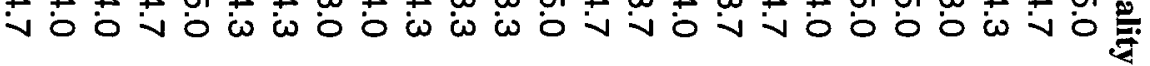

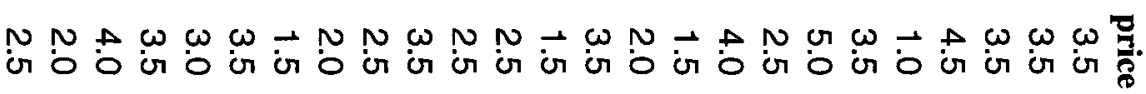

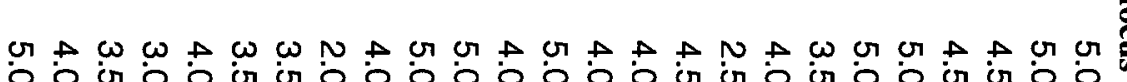

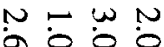

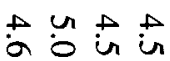

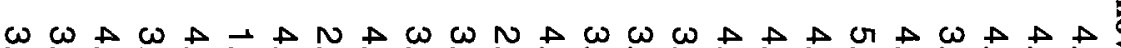

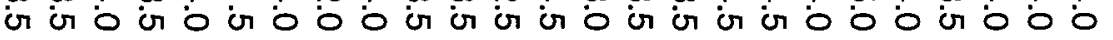

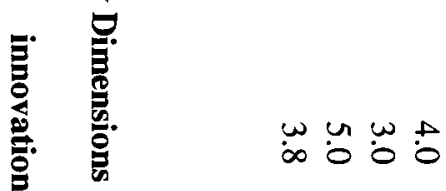

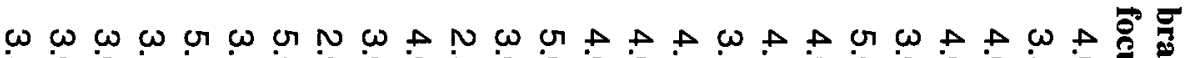

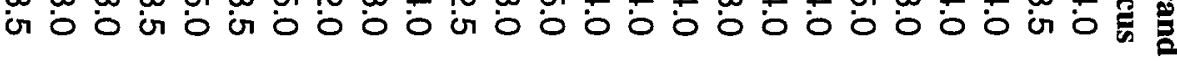

ib $\underset{i r}{\omega} \stackrel{\omega}{i}$

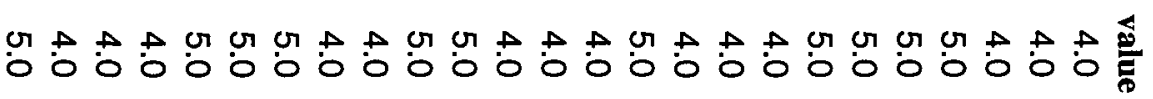

$+\underset{\infty}{\infty} \dot{0} \dot{0}$

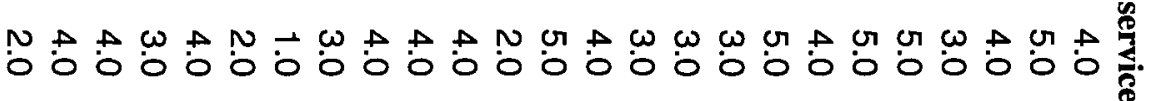

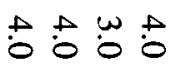


ํำ

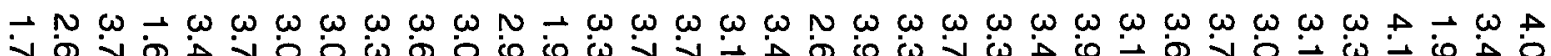

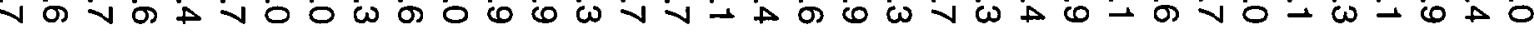

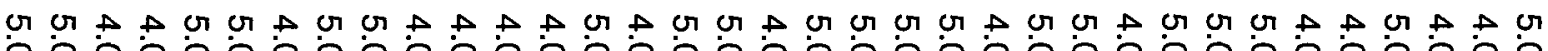

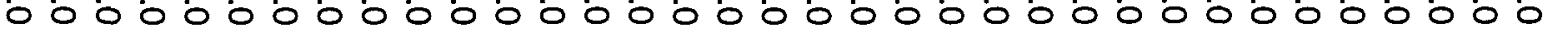

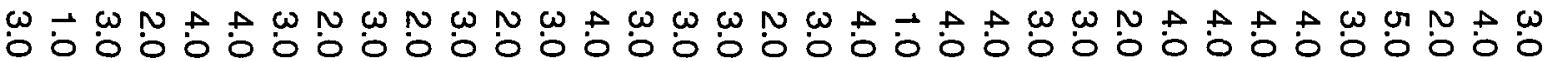

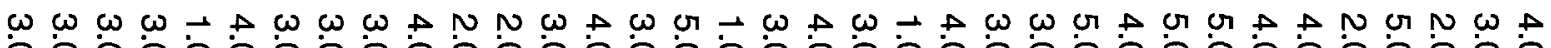

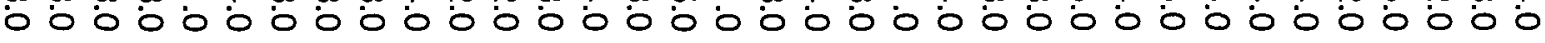

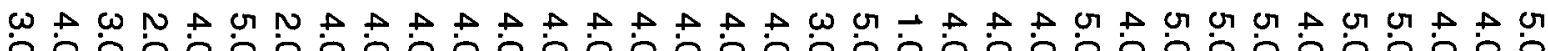

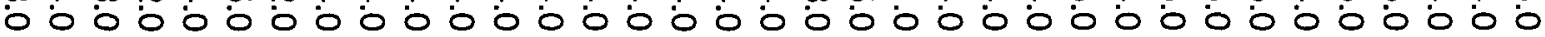

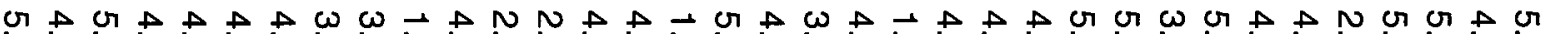

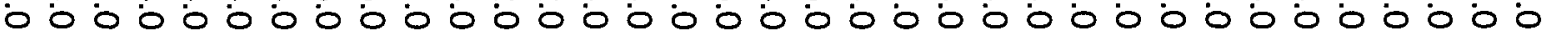

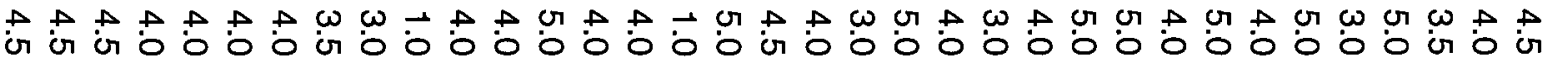

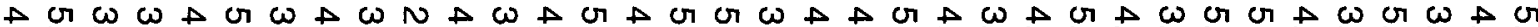
范

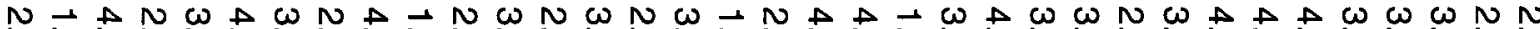

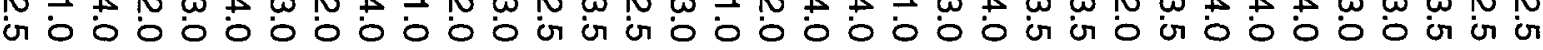

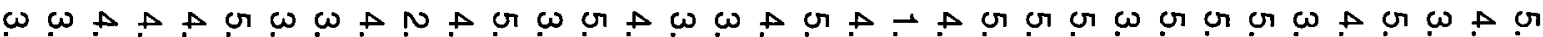

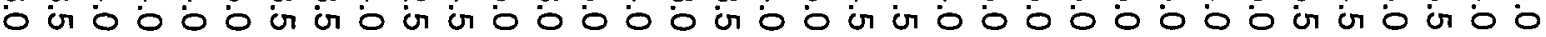

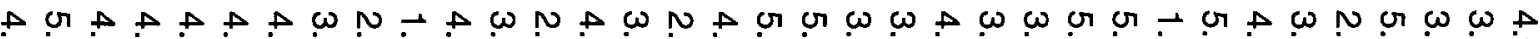

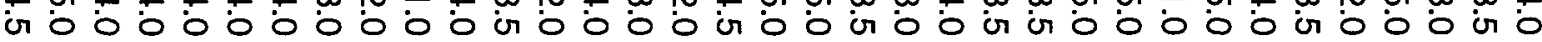

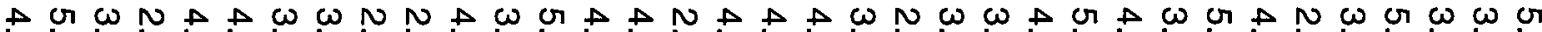

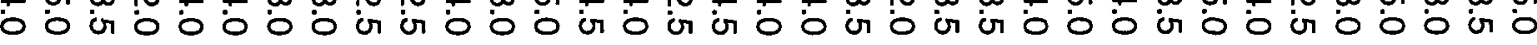

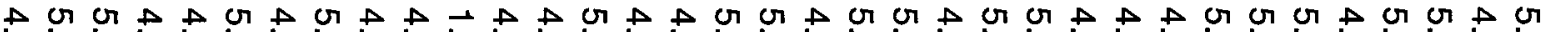

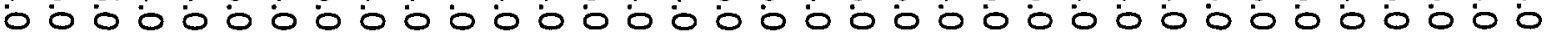

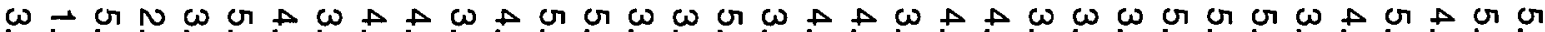

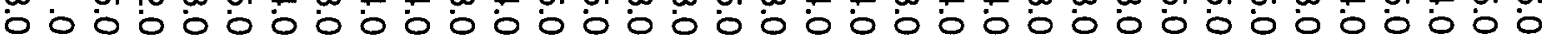




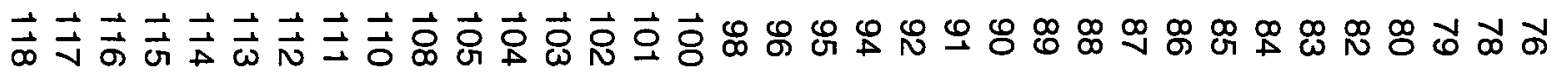

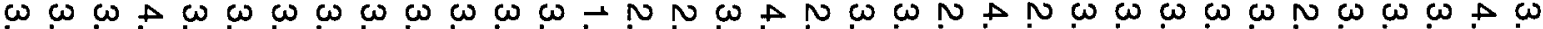

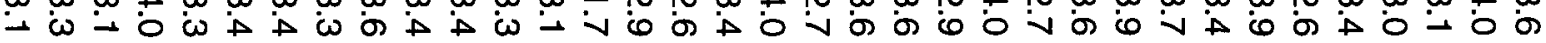

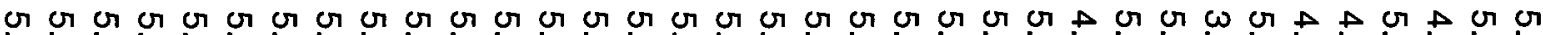

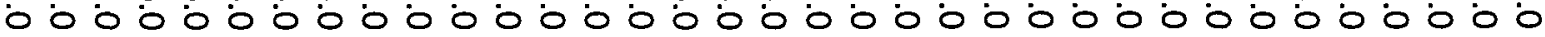

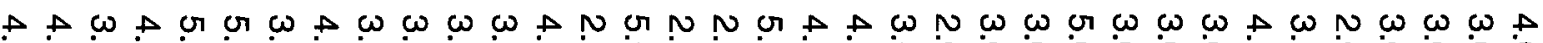

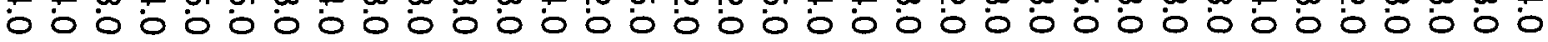

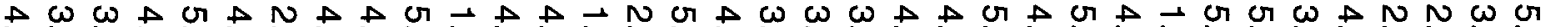

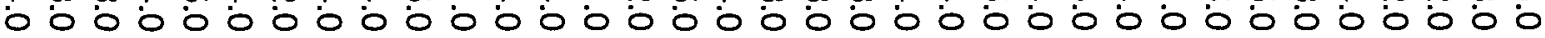

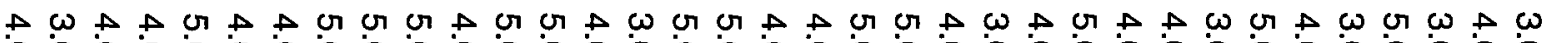

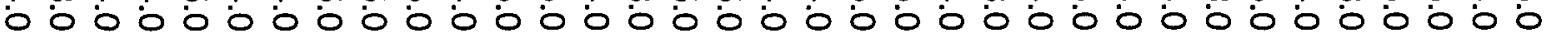

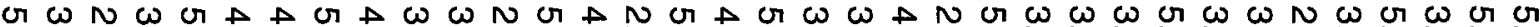
O

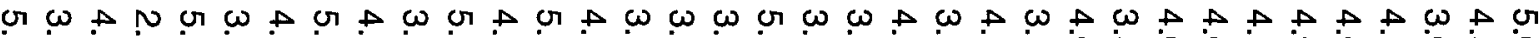

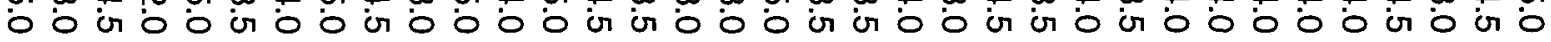

G

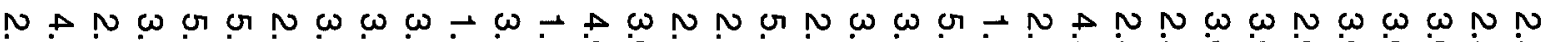

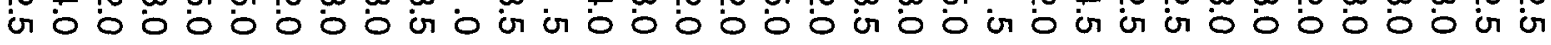

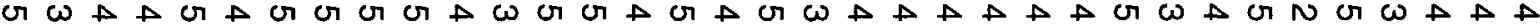

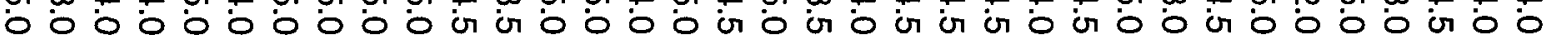

G $\omega N \omega$ N

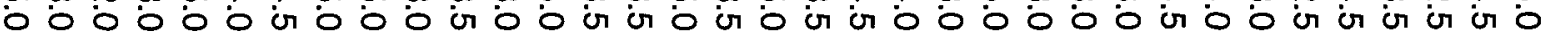

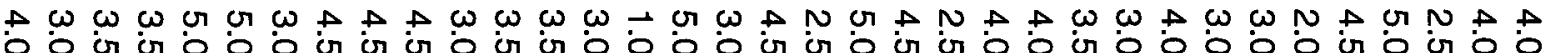

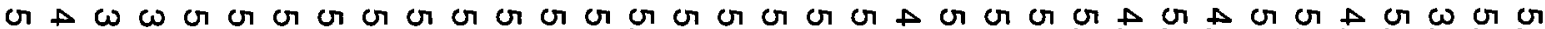
泪

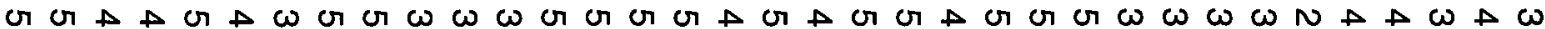
向 


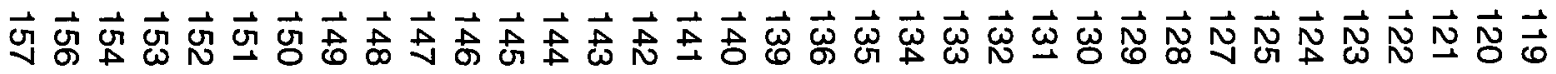

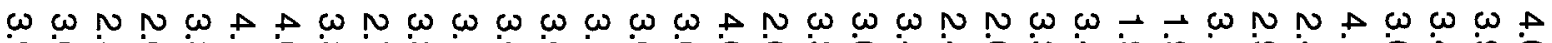
ठ ठ ठ

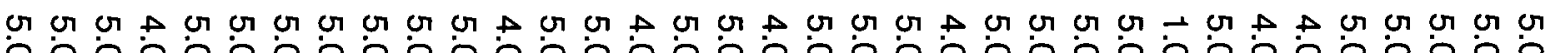

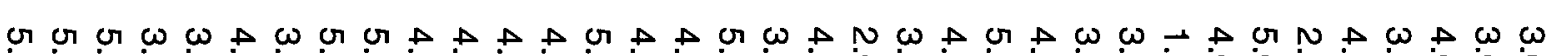
○ 0 O

M $N \mu$ U O $\pi$ 局

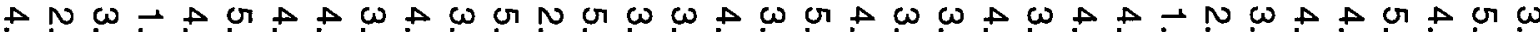

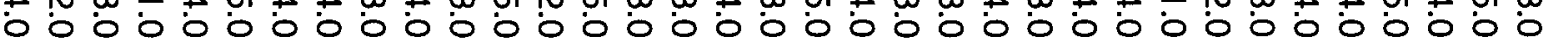

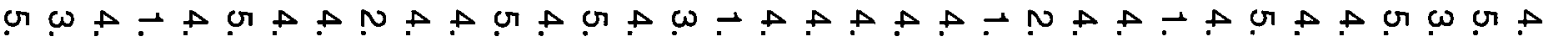

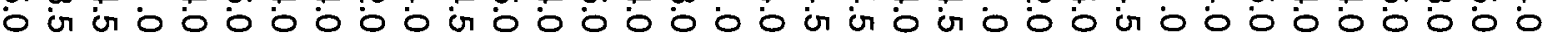

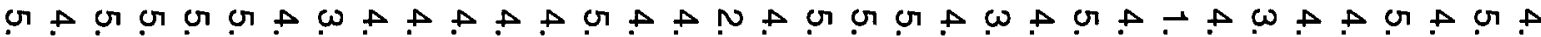

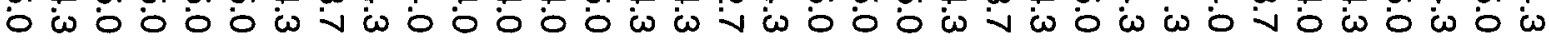

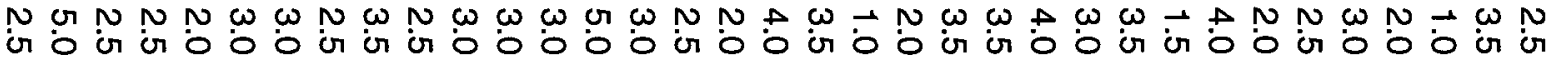

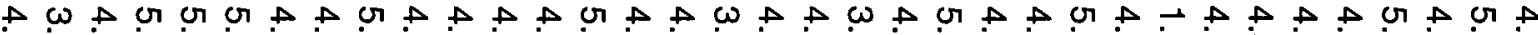

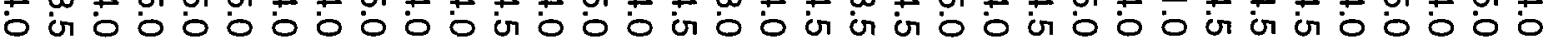

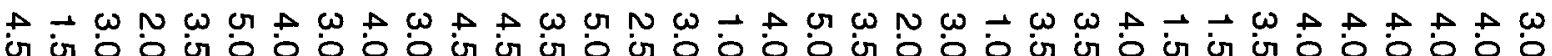

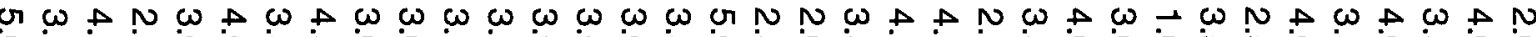

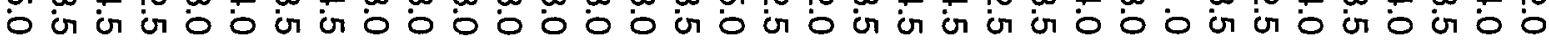

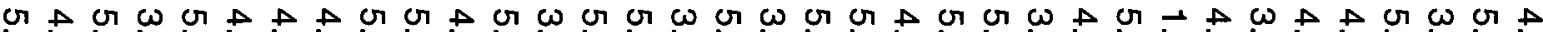
菏

G $\omega$ G $\rightarrow$ G $\rightarrow A \omega N \omega N$ G $N$ G $\rightarrow \perp A N N N \omega$ G $A N$ G O 


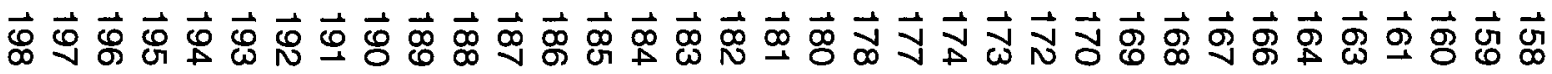

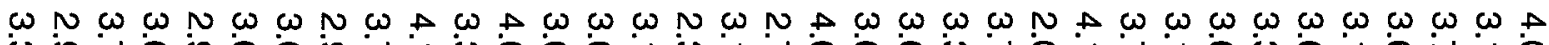
$\omega$ ம

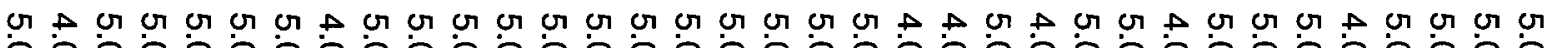

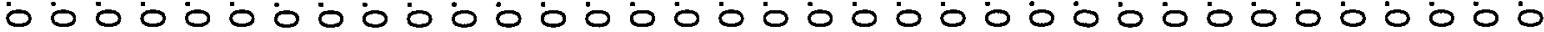

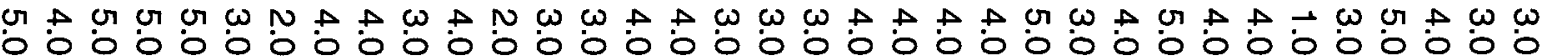

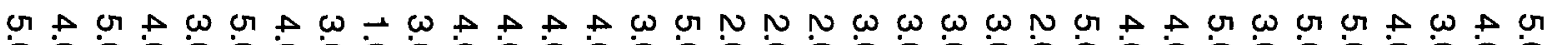

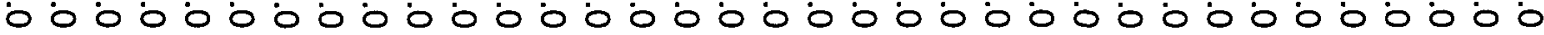

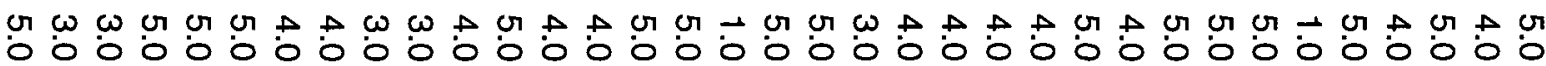

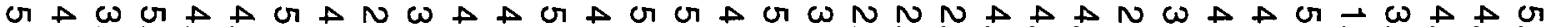

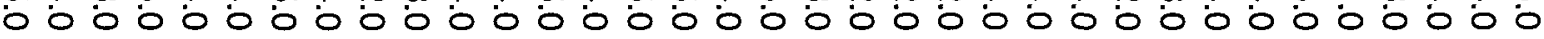

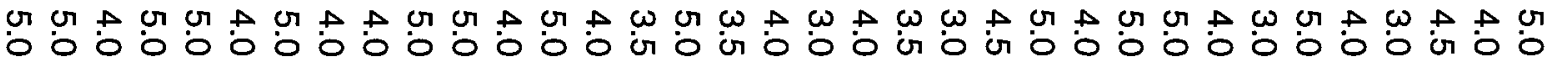

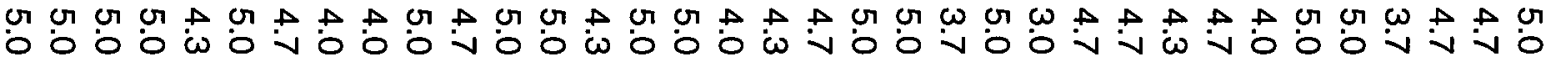

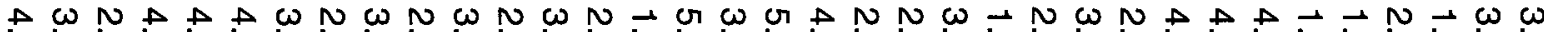

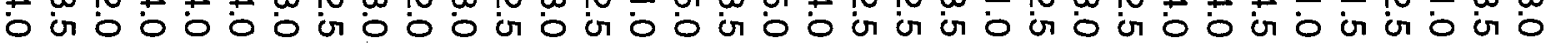

G $A$ G G G $A$ G $A+N$ G $A A+$ G G $A$ G $A$ G $A+A \omega$ G G G $A+$ G G $A N A$ G

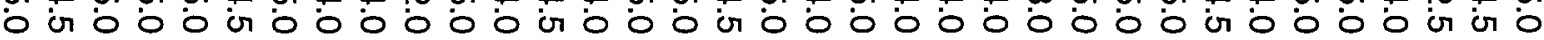

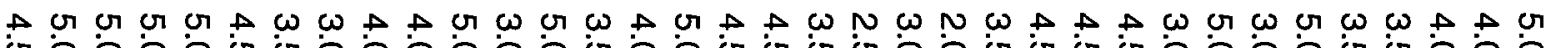

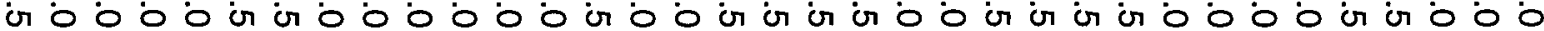

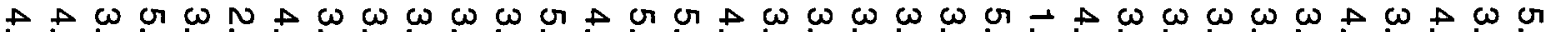

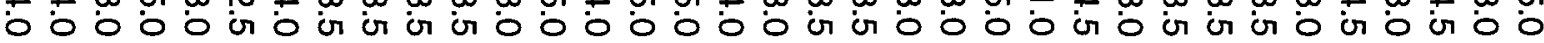

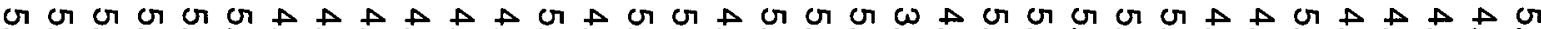

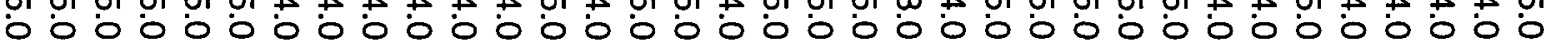

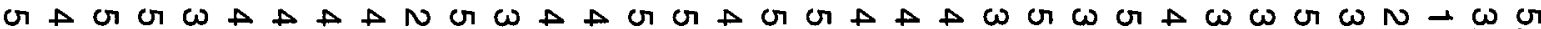

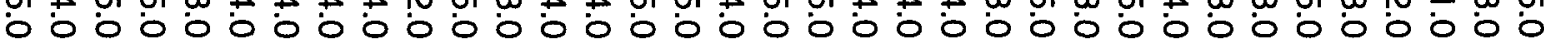




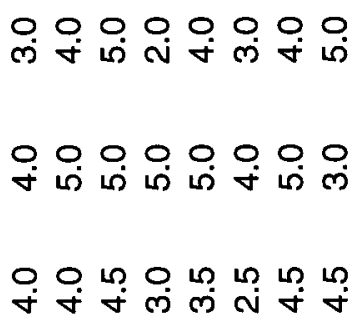

L

लं $\dot{\forall} \dot{\forall} \dot{\forall} \dot{\forall} \dot{\nabla}$

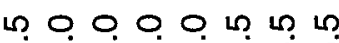

ن

นกำ

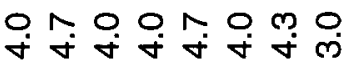

웁

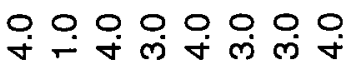

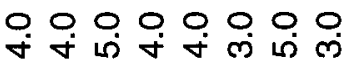

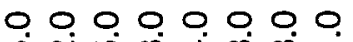

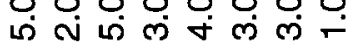

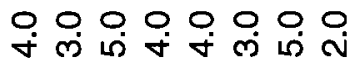

욱 운 운 우

ก

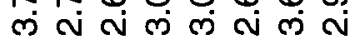

융

氖:

ڤ્ป

है

금

马्ष

产

ํㅗำ

$\stackrel{8}{ \pm}$

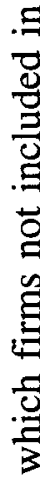

$\$$

8

过

ป

$\stackrel{2}{ \pm}$

告

里

궁

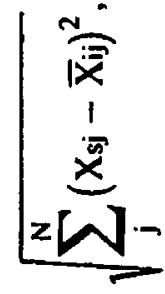

II

.ั.

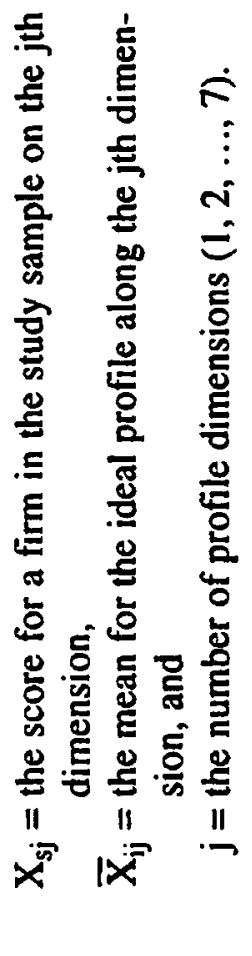

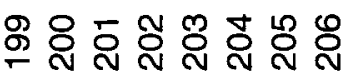




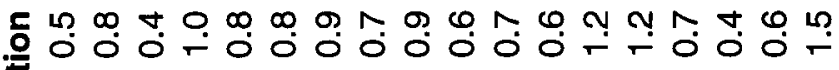
要

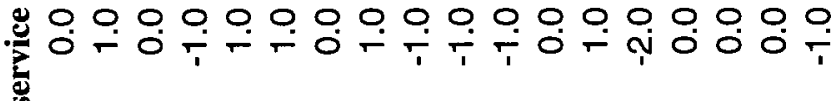

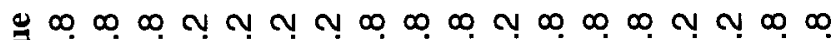

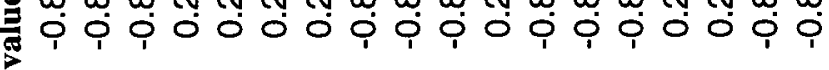

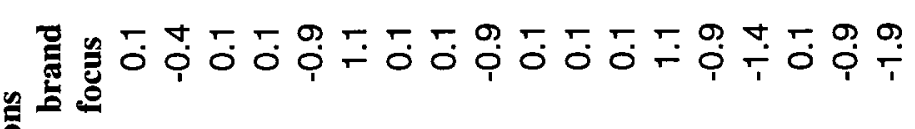

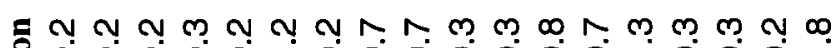

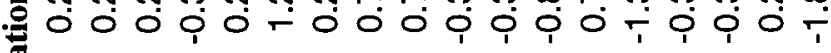
을

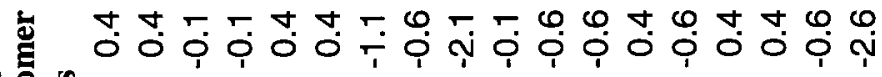
这

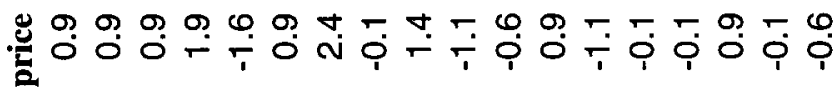

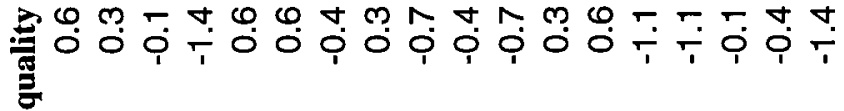

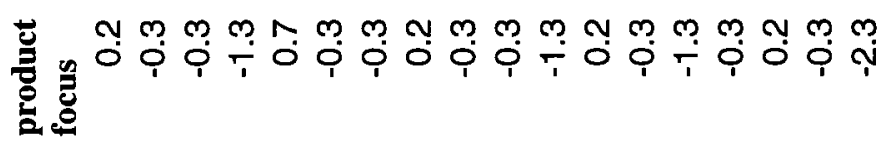

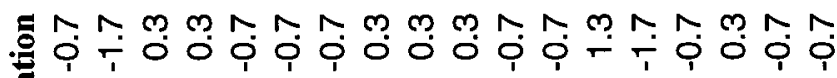
.

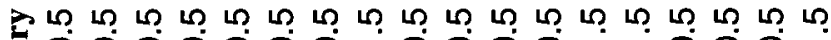

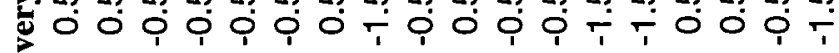
क्ष

룰 空 要

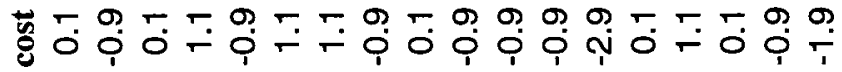

चm m 严 


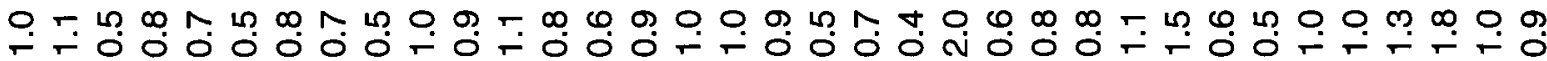

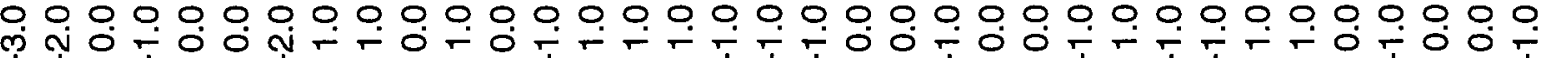

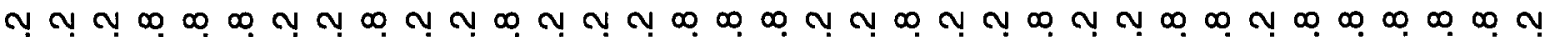
○

F

ก ○ ஸ

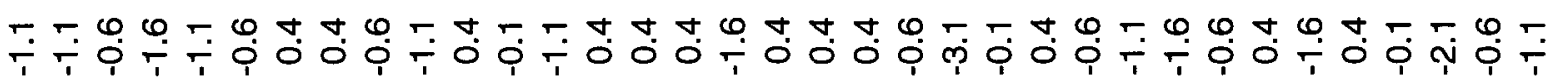

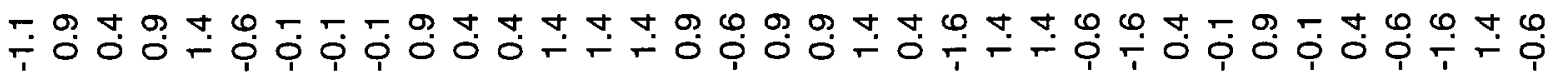

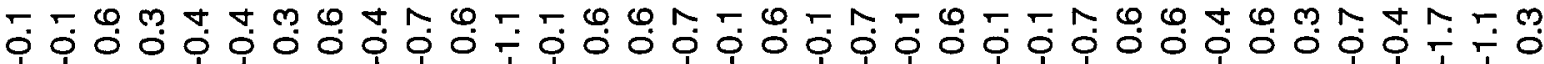

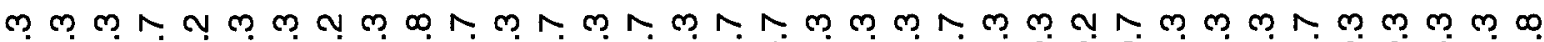

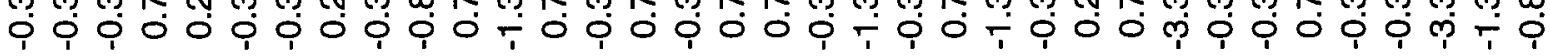

NNmNm

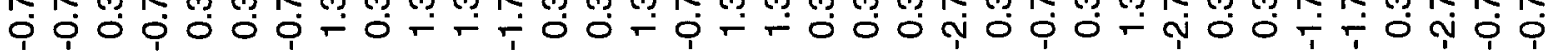

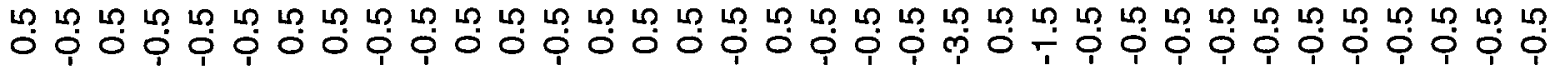

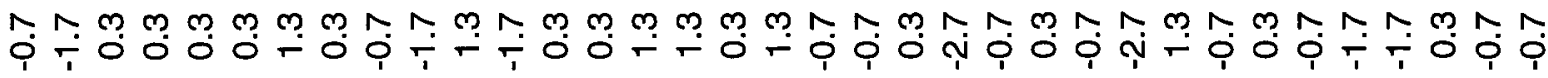

ந் ๓ o 


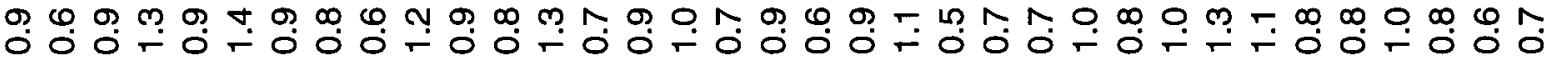

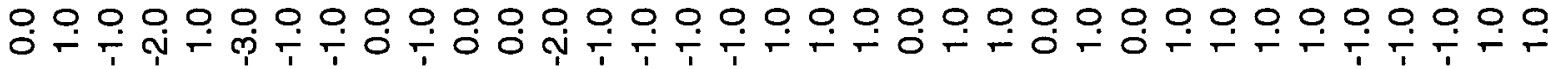

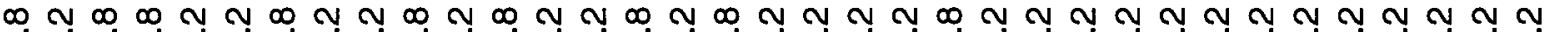
○َ

の

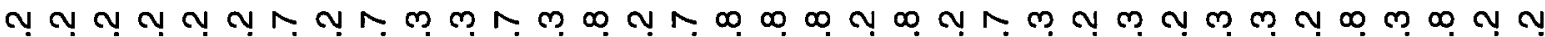
○ 0000

†

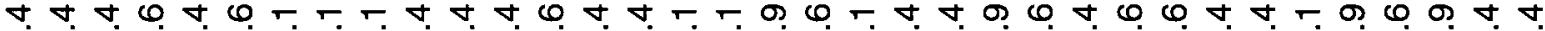

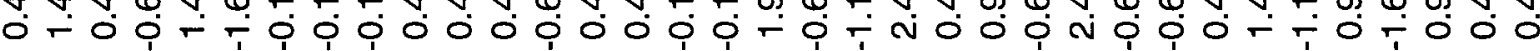
웅 mmmm N ب

mmmmmmmmmNmNNRNmNNRmNmNNmmmNmmNRNmm

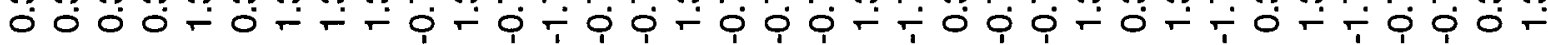

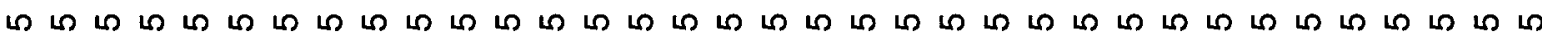
لَّ

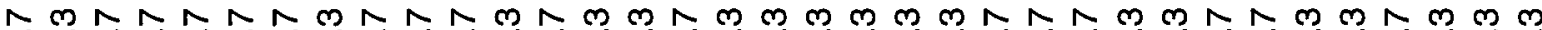

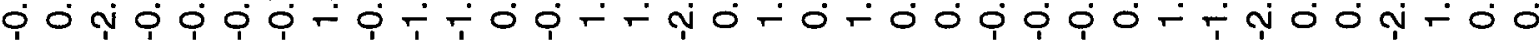

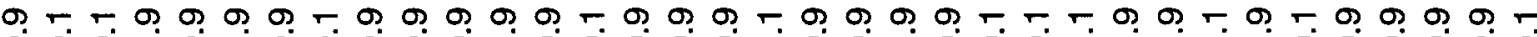

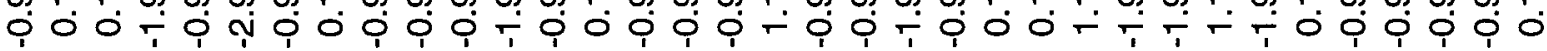
NMMNNMMMMNMN ○. 0 o 
品 0 ○

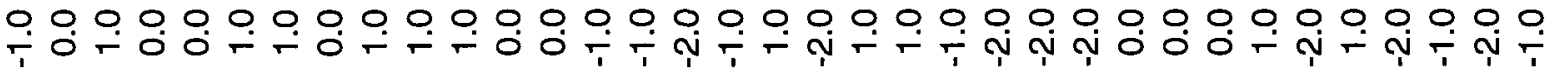

พ

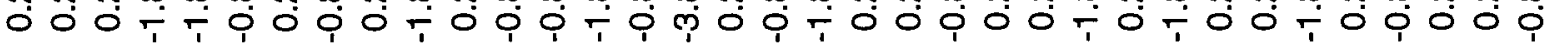
官

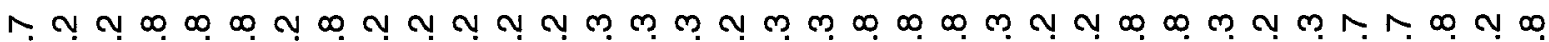
إب

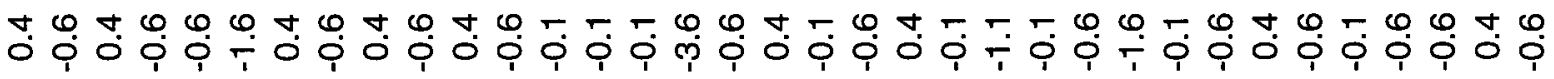

穴

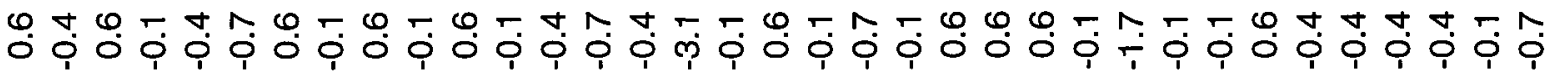

m

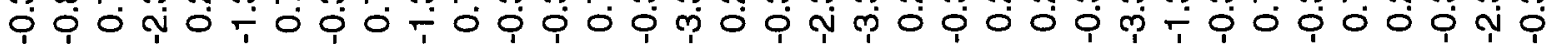

$m$ m m 递官

苗 풍 m

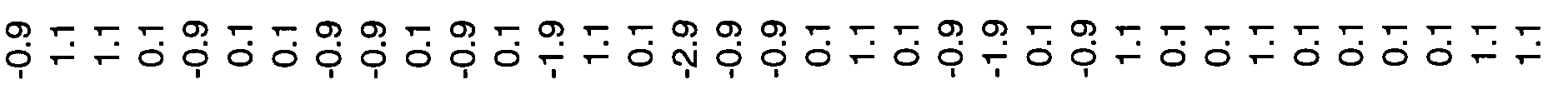
m

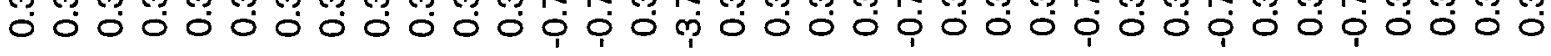


Lீ

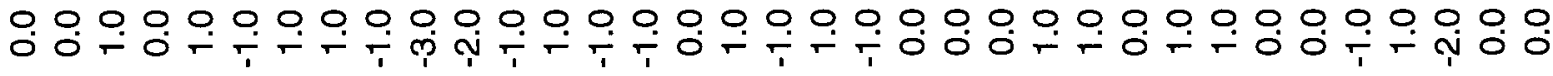

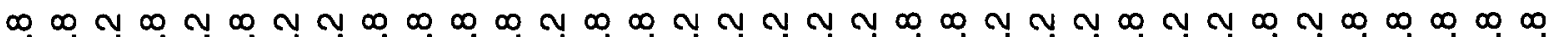
送

苗

ஸุ 血



オ サ ரழ

m m m ó

m

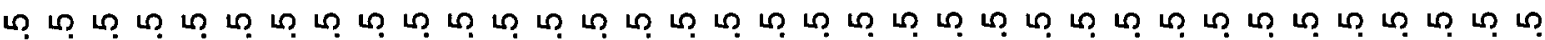
茴

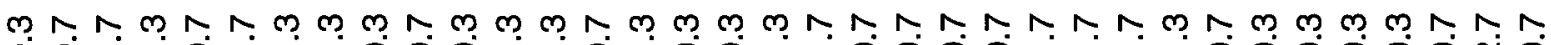
0̆

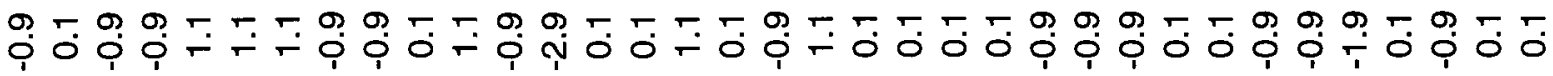
m m

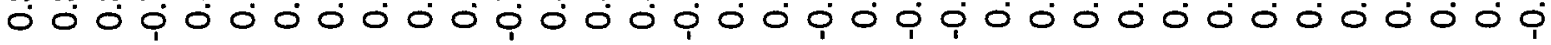


品 品

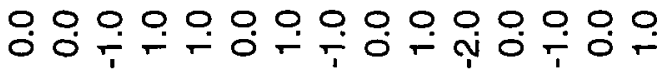

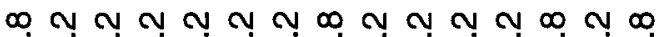

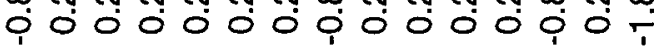

б苍苗

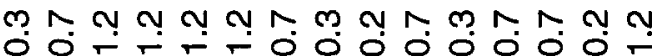

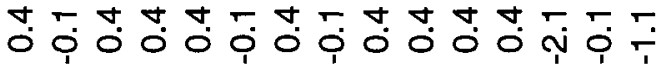

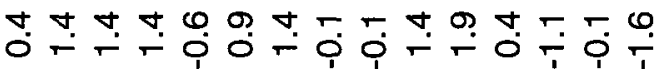

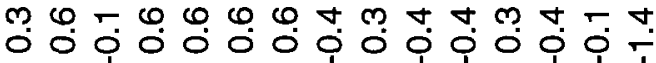

กติน

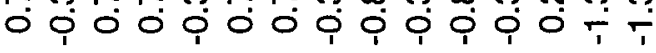

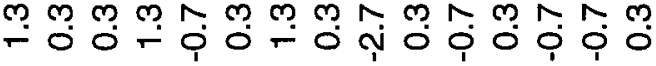

若

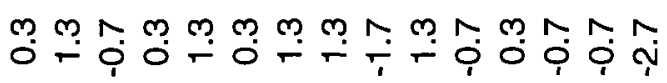

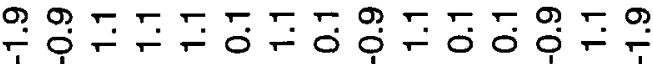

Mํ

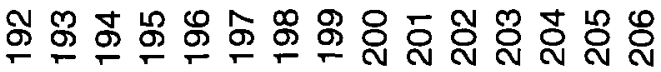

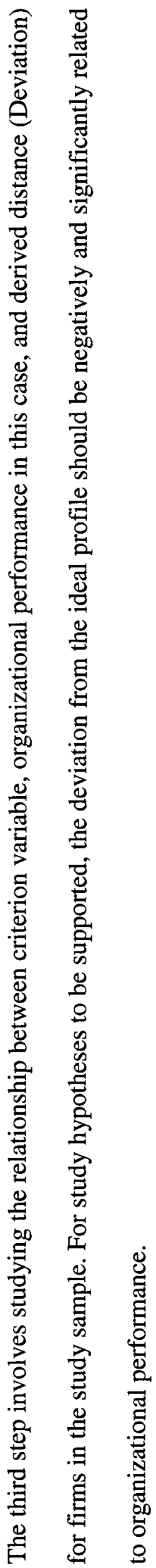

